\title{
INVESTIGATION OF THE LATERAL- TORSIONAL BUCKLING BEHAVIOUR OF ENGINEERED WOOD I-JOISTS WITH VARYING END CONDITIONS
}

BY

\section{Benoît Pelletier}

\author{
A THESIS SUBMITTED TO THE \\ FACULTY OF GRAdUATE AND POSTDOCTORAL STUdIES \\ IN PARTIAL FULFILLMENT OF THE REQUIREMENTS FOR THE \\ MASTER OF APPLIED SCIENCE IN CIVIL ENGINEERING
}

OTTAWA-CARLETON INSTITUTE FOR CIVIL ENGINEERING

FACULTY OF CIVIL ENGINEERING

UNIVERSITY OF OTTAWA

(C) Benoît Pelletier, Ottawa, Canada, 2017 


\begin{abstract}
The need to include economical and yet environmentally friendly products in modern day structural systems has pushed the development of engineered wood products such as engineering wooden I-joists. These products are engineered to resist high transverse loads and use the wood material more efficiently. Beam members, especially those that are deep and have long spans, are prone to lateral-torsional buckling as a possible mode of failure. Laboratory testing rarely take into account actual end conditions and initial imperfection which might have a significant impact on the buckling behavior of beams. The current research project aims to investigate the lateraltorsional buckling of wooden I-joists. A total of 41 joists were tested using various commercial joists hangers and enhanced connections to represent different support conditions. A numerical 3D model was also developed using commercially available finite element program ABAQUS to determine the buckling loads and associated mode shapes of joists similar to those tested. It was demonstrated that the lateral stiffness of the joists' top flange support has a significant influence on the buckling load and that a stiffness variation of the bottom flange lateral support shows no significant impact on the buckling load. The results also suggest that an enhanced rotational connection can significantly increase the buckling load of a member. The verified FE model was capable of predicting the buckling load of wood I-joists with various end conditions and initial imperfections with reasonable accuracy.
\end{abstract}




\section{Acknowledgements}

I would like to express my deepest gratitude to my supervisor, Dr. Ghasan Doudak, to have given me the opportunity to work on this project. With his time and guidance, I have been able to accomplished this challenge and expand my engineering expertise.

A special thanks goes to Dr. Magdi Mohareb for his support, his time in the examination of my work and the advice he has given me throughout the years.

I must express my deepest gratitude to Simpson Strong-Tie to have provide the joists hangers tested with these experiments and Boise Cascasde for the I-joists specimens.

I would also like to thank my student colleagues, Mr. Daniel Lacroix for the guidance and help, and Mr. Rémi St-Amour for helping me conduct the experimental work. I would like to also thank Ms. Ghazanfarah Hafeez, Ms. Sarah De Carufel, Mr. Corey Guertin Normoyle and Mr. Christian Viau for making these university years a great experience.

J'aimerais remercier tout spécialement ma partenaire Clotilde Maurice, qui a toujours cru en mes capacités, qui m'a écouté et guidé dans mon cheminement et qui m’a fourni un soutien financier lors des dernières années. Sans elle à mes côtés, je n'aurais jamais pu entreprendre et relevé un tel défi professionnel. Je remercie également mes parents qui m’ont supportés dans nos décisions et m'ont permis de poursuivre ce rêve académique. Un merci tout particulier à mon ami de longue date, Bruno St-Aubin, avec qui j'ai passé plusieurs soirées à échanger des idées et discuter de nos expériences ou simplement pour me changer les esprits lors des périodes plus difficiles et qui était toujours là pour me donner le goût de me surpasser dans cette grande aventure. 


\section{Table of Content}

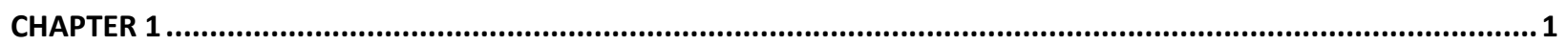

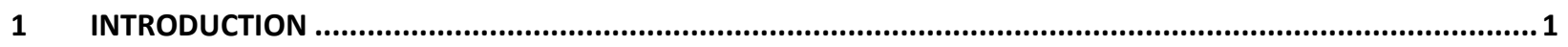

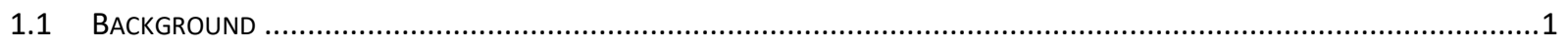

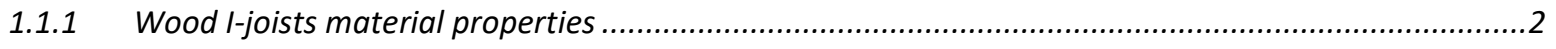

1.1.2 Lateral Torsional Buckling behaviour of I-shaped beams ..........................................................

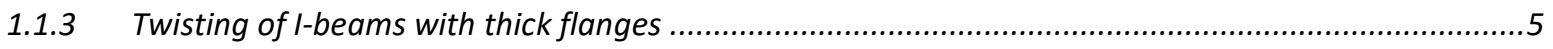

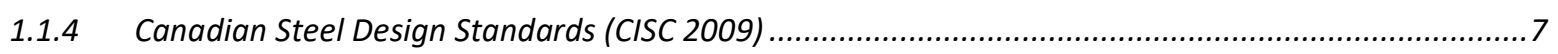

1.1.5 North American design standard for wood construction ..............................................................

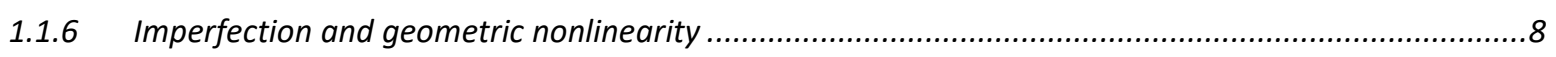

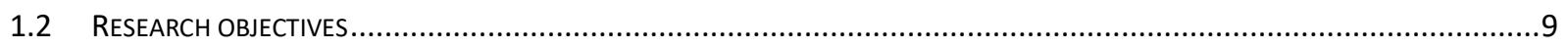

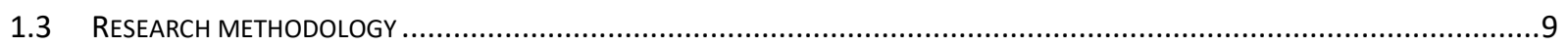

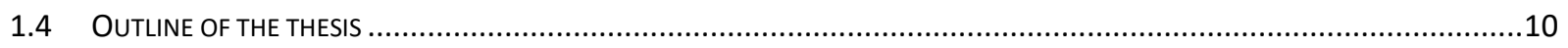

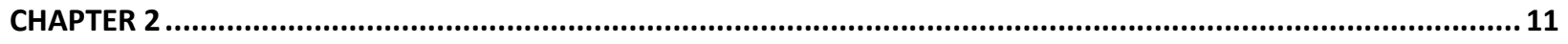

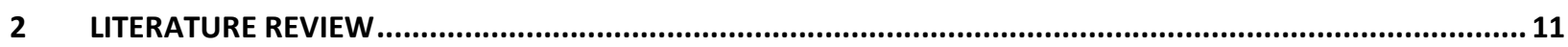

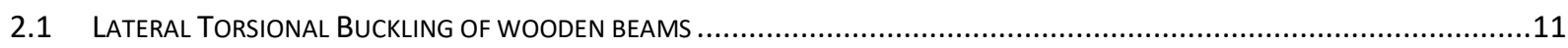

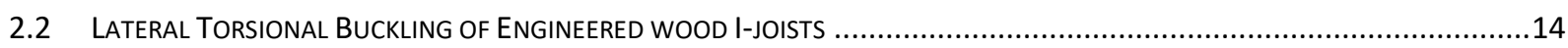

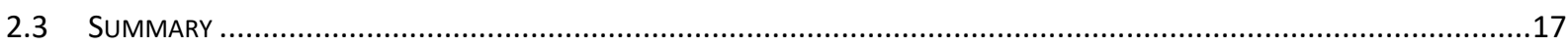

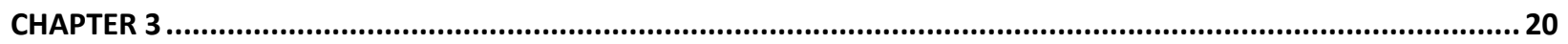

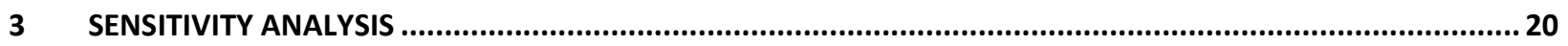

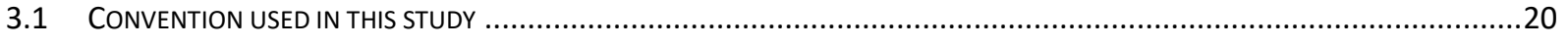

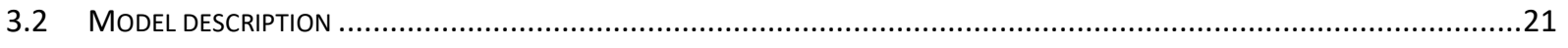

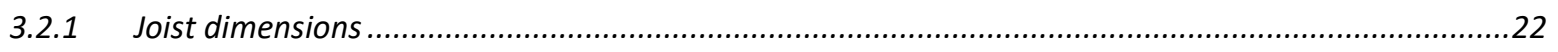

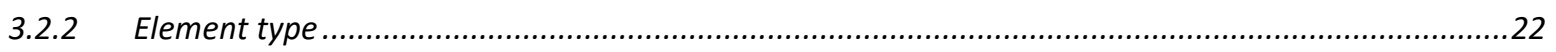

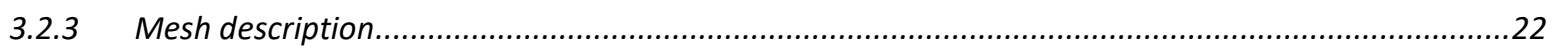

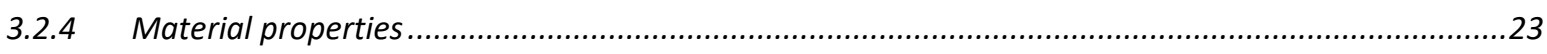

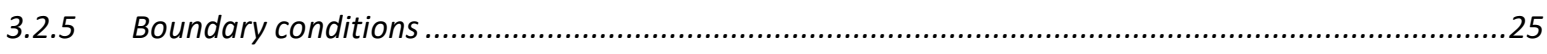

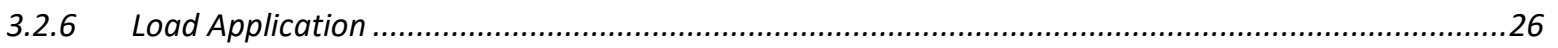

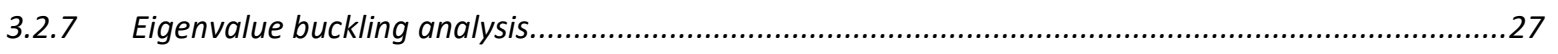

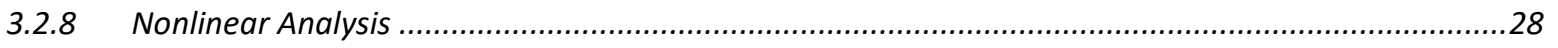

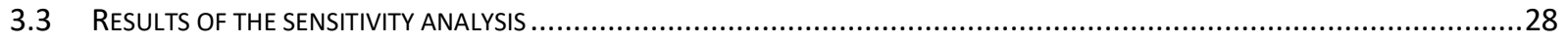

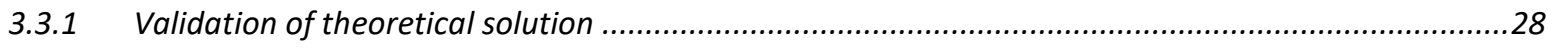


3.3.2 Results of the varying lateral stiffness .......................................................................................28

3.3.3 Results of nonlinear analysis for joists with initial imperfections .....................................................31

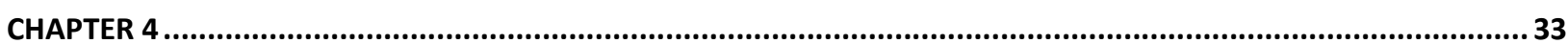

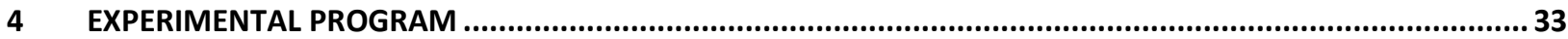

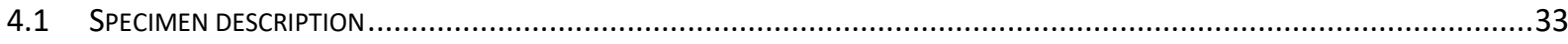

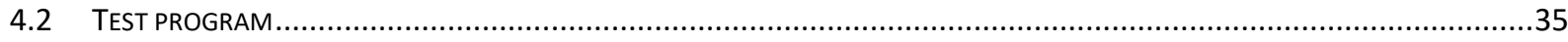

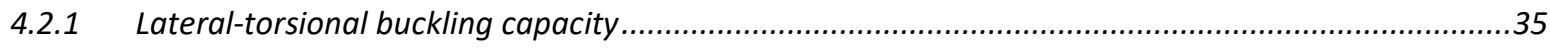

4.2.2 Web Transverse Modulus of Elasticity .......................................................................................... 47

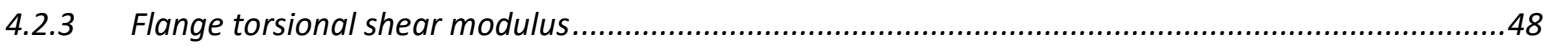

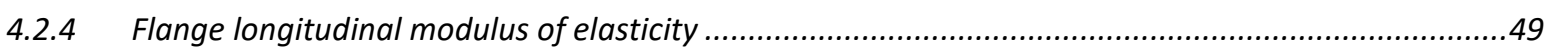

4.2.5 Top-Mounted hangers lateral displacement rigidity ..................................................................... 49

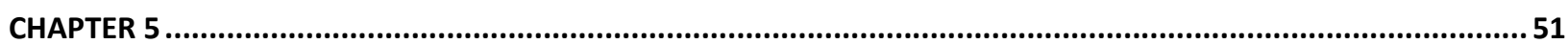

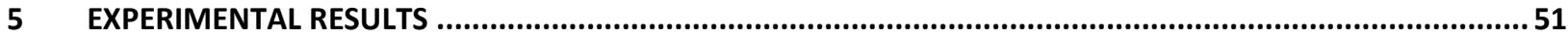

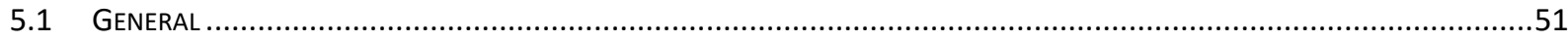

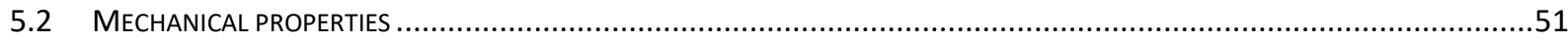

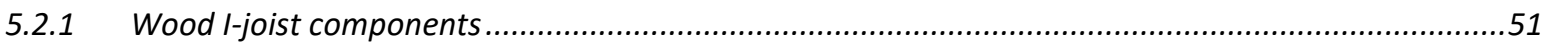

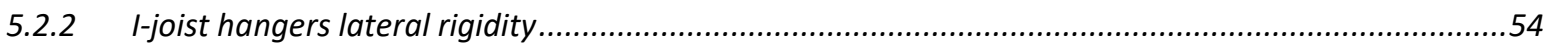

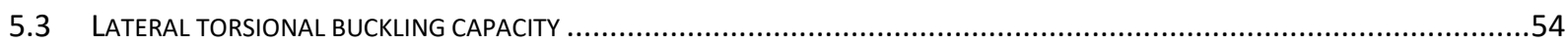

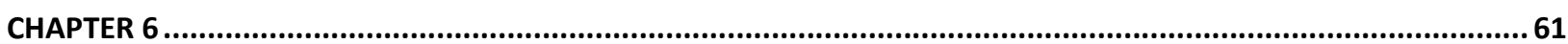

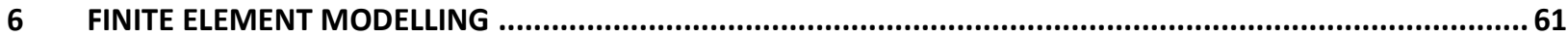

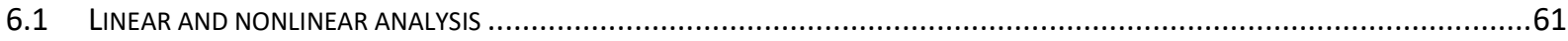

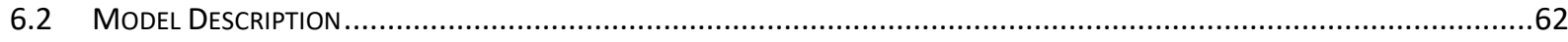

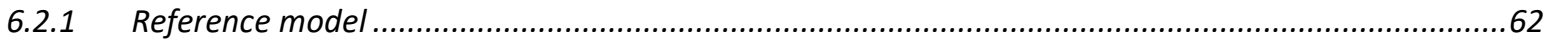

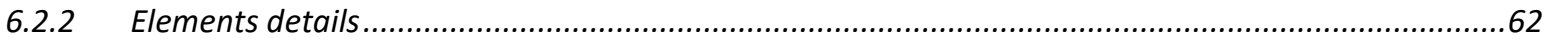

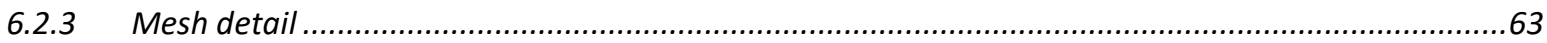

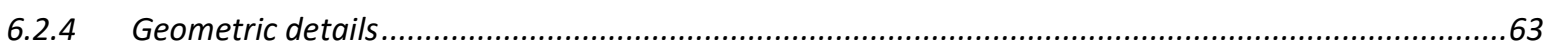

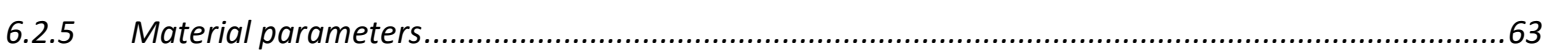

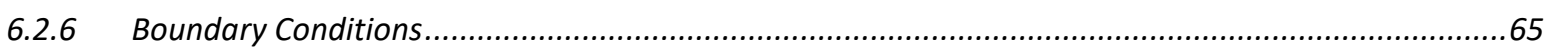

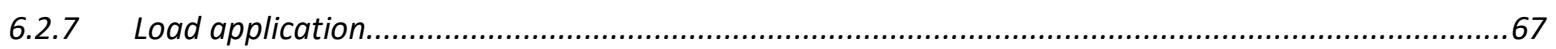

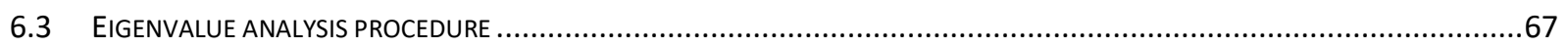

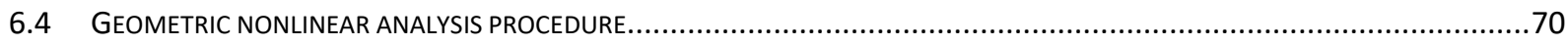

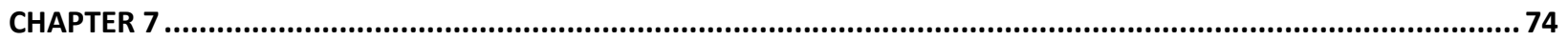




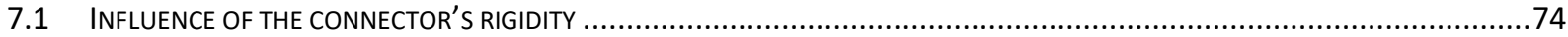

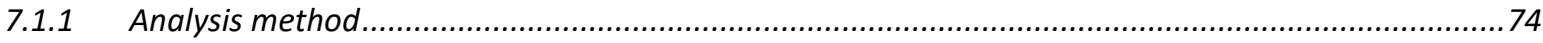

7.1.2 Influence of commercial hangers stiffness based on experimental investigation ............................75

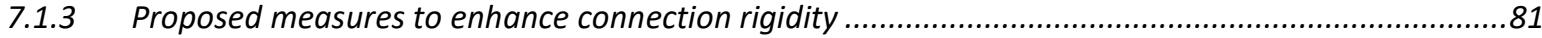

7.2 EXPERIMENTAL VS NUMERICAL PREDICTIONS OF LATERAL TORSIONAL BUCKLING LOADS........................................85

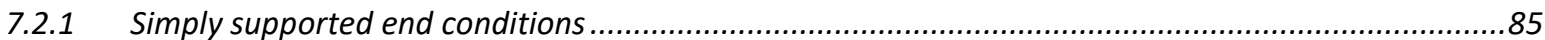

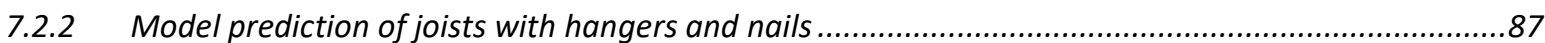

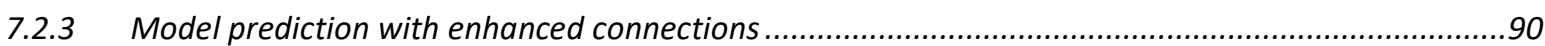

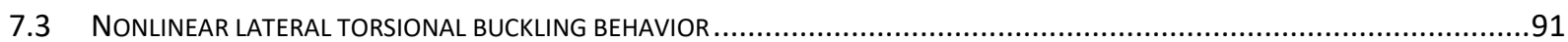

7.3.1 Geometric nonlinear analysis with Simply Supported end conditions. ..........................................91

7.3.2 Commercial hangers and enhanced connection influence on LTB behavior of joists..........................94

7.3.3 Experimental buckling displacements and nonlinear FEA comparison ...........................................96

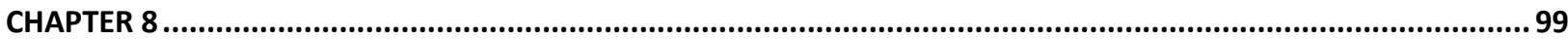

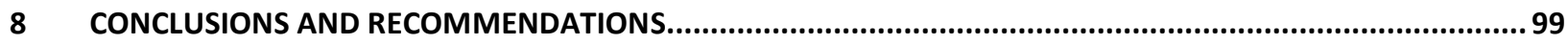

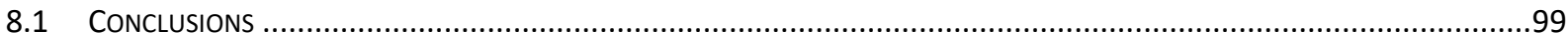

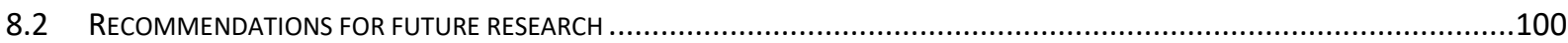

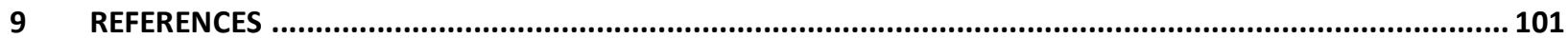

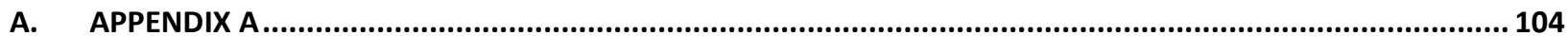

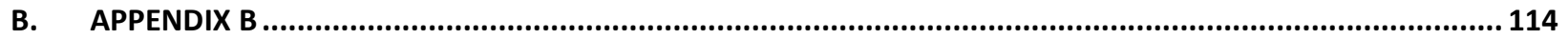




\section{List of Table}

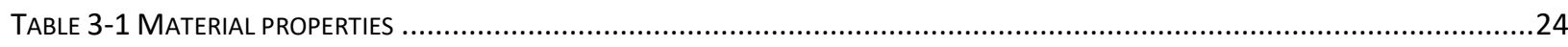

TABLE 3-2 FINITE ELEMENT MODEL RESPONSE TO SUPPORT LATERAL STIFFNESS VARIATIONS .......................................................29

TABLE 3-3 FINITE ELEMENT MODEL RESPONSE TO ROTATION FIXITY OF THE FLANGES ...................................................................31

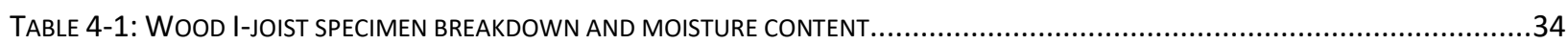

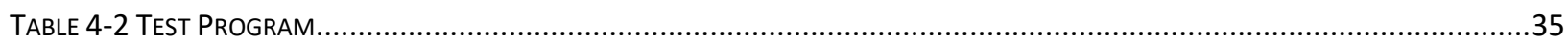

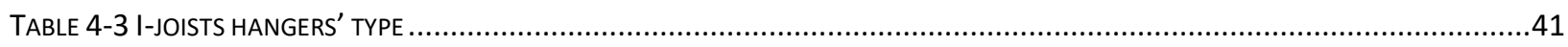

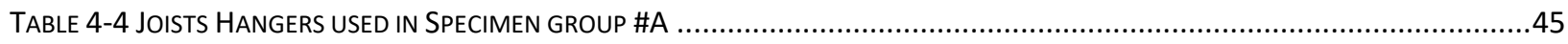

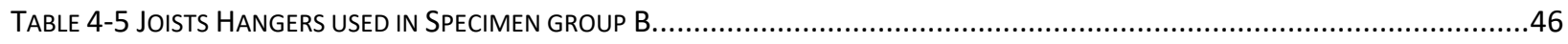

TABLE 4-6 I-JOIST WEB THICKNESS, SPAN AND APPLICATION RATE FOR TRANSVERSE MOE TEST ...............................................47

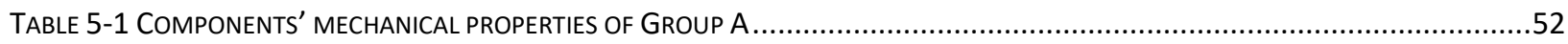

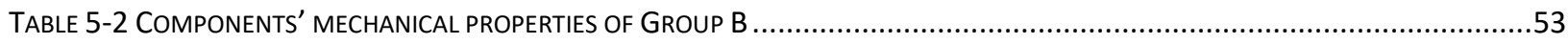

TABLE 5-3 LATERAL STIFFNESS AT BOTTOM OF TOP MOUNTED HANGERS ..............................................................................54

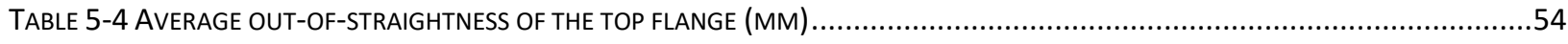

TABle 5-5 LATERAL Torsional BuCKLING CAPACITY - Simply SuPPorted Boundary Conditions (KN*M) ...............................55

Table 5-6 Lateral Torsional Buckling CAPACItY - Top Mounted Hangers (KN*M) ....................................................56

TABLE 5-7 LATERAL TORSIONAL BuCKLING CAPACITY - Front Mounted HANGERS (KN*M) ....................................................56

TABLE 5-8 LATERAL TORSIONAL BuCKLING CAPACITY - RotATIONAL FIXITY (KN*M) ............................................................57

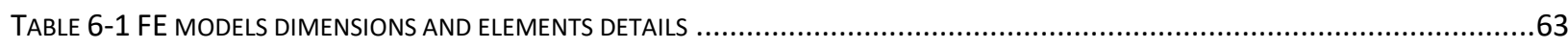

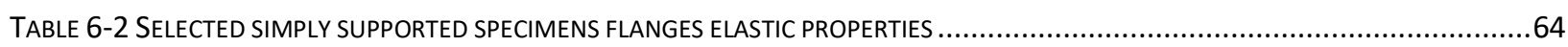

TABLE 6-3 AVERAGE MODULUS OF ELASTICITY INPUT PARAMETERS OF JOIST COMPONENTS ......................................................64

TABLE 6-4 CRITICAL EIGENVALUE BUCKLING LOADS FOR SELECTED SPECIMENS WITH VARYING FLANGES PROPERTIES............................68

TABLE 6-5 CRITICAL EIGENVALUE BUCKLING LOADS WITH AVERAGE MATERIAL INPUT FOR EACH BOUNDARY CONDITION........................68

TABLE 6-6 INITIAL OUT-OF-STRAIGHTNESS OF SELECTED SPECIMENS WITH VARYING FLANGES PROPERTIES. ....................................71

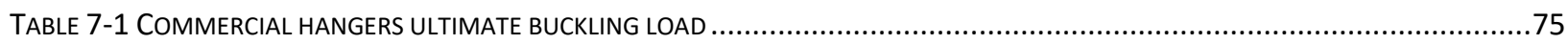

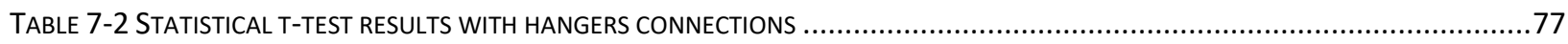

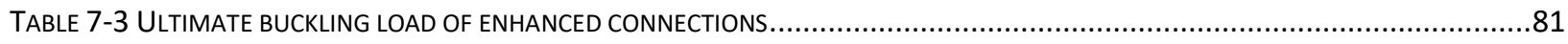

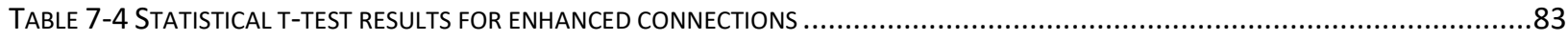

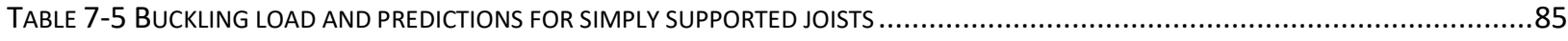

TABLE 7-6 BUCKLING LOAD AND AVERAGE PREDICTION FOR SIMPLY SUPPORTED JOISTS ........................................................87

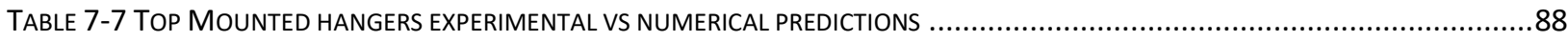

TABLE 7-8 TOP MOUNTED HANGERS WITH RESPECTIVE MATERIAL PROPERTIES VALUES ...........................................................8 


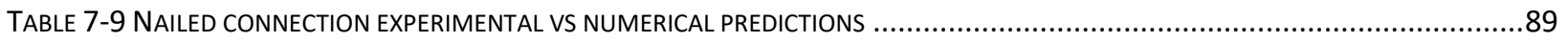

TABLE 7-10 ENHANCED ROTATIONAL CONNECTIONS EXPERIMENTAL VS NUMERICAL PREDICTIONS ...............................................90

TABLE 7-11 ANGLE BRACKET CONNECTIONS COMPARISON WITH RESPECTIVE MATERIAL PROPERTIES...........................................91

TABLE 7-12 AVERAGE MOMENT COMPARED TO NUMERICAL PREDICTIONS AT VARIOUS SPAN RATIO ...............................................92

TABLE 7-13 RESISTING MOMENT OF JOISTS TESTED WITH SIMPLY SUPPORT CONDITION AND HANGERS AT VARIOUS SPAN RATIO DISPLACEMENTS.......

TABLE 7-14 RESISTING MOMENT OF JOISTS TESTED WITH SIMPLY SUPPORT CONDITION AND ENHANCED CONNECTIONS AT VARIOUS SPAN

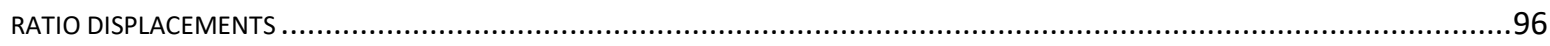




\section{List of Figures}

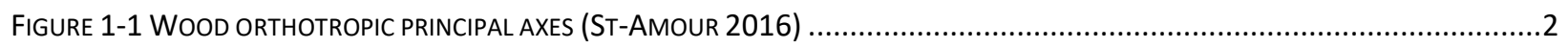

FIGURE 1-2 I-SECTION UNDERGOING LATERAL TORSIONAL BUCKLING (KALA 2013) ................................................................

FigURE 1-3 LATERAL BUCKLING OF THEORETICAL AND REALISTIC I-BEAMS (St-AMOUR 2016) ..................................................

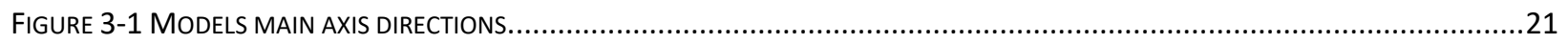

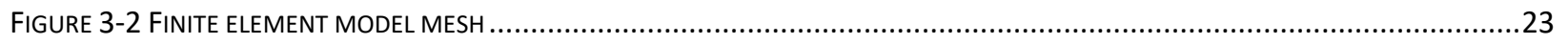

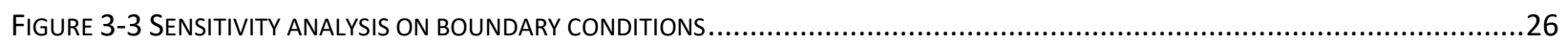

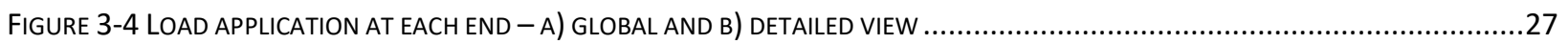

FIGURE 3-5 RESPONSE OF THE CRITICAL MOMENT TO TOP FLANGE SUPPORT LATERAL STIFFNESS ................................................30

FIGURE 3-6 LATERAL DISPLACEMENT OF THE SHEAR CENTER WITH TOP FLANGE IMPERFECTION ...................................................32

FIGURE 3-7 ROTATION OF SECTION ABOUT THE SHEAR CENTER WITH TOP FLANGE IMPERFECTION .................................................32

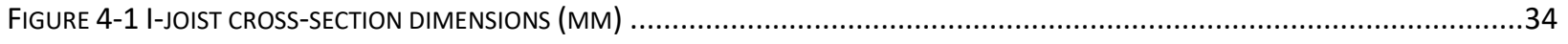

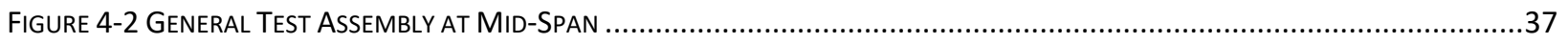

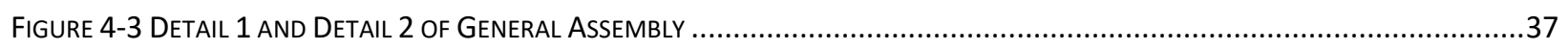

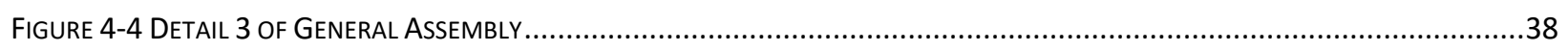

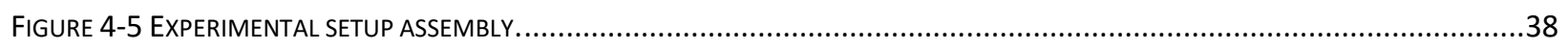

Figure 4-6 Elevation And Side VIeW of Joists Length With A) Joists Hangers panels B) Simply SUPPorted Condition ..........40

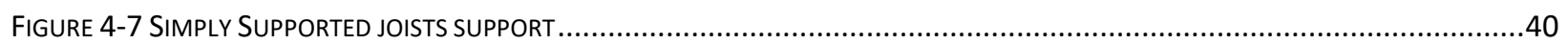

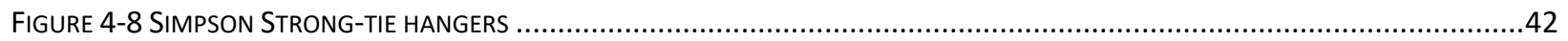

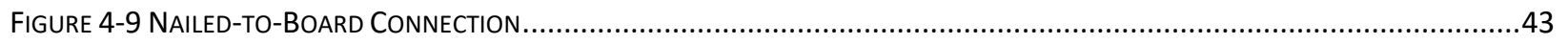

FIGURE 4-10 HWR WITH SCREWED FLANGES CONNECTION (LEFT) AND ANGLES CONTAINED FLANGES CONNECTION (RIGHT) .................44

FIGURE 4-11 WEB TRANSVERSE MODULUS OF ELASTICITY TEST CONFIGURATION .....................................................................

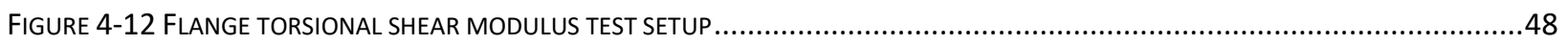

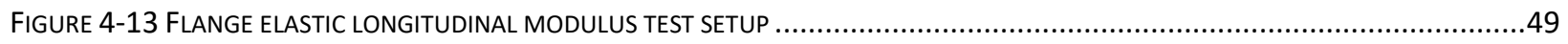

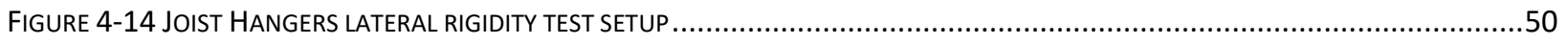

FIGURE 5-1 TYPICAL DEFORMATION OF LATERAL-TORSIONAL BUCKLING EXPERIMENT ..........................................................57

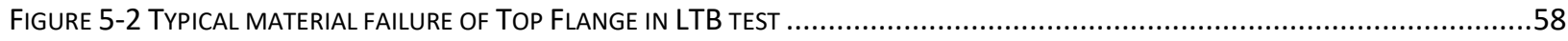

FiguRE 5-3 Moment-Lateral DISPLACEMENT Of Top FLANGe - SPECIMENS B-3 TO B-7 …................................................58

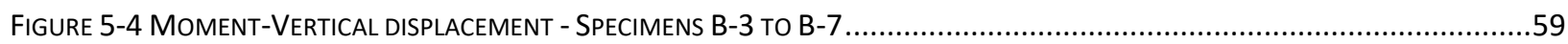

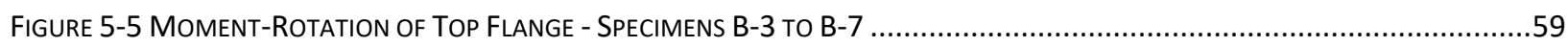

FIGURE 5-6 MOMENT- RotATION OF BOtTOM FLANGE - SPECIMENS B-3 TO B-7 …..............................................................60

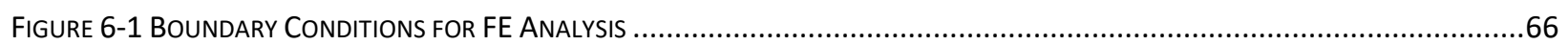

FIGURE 6-2 LONGITUDINAL SUPPORT AND LOAD APPLICATION AT MID-SPAN ON BOTTOM FLANGE OF JOISTS......................................67 
FIGURE 6-3 MAIN BUCKLING MODE FOR EACH BOUNDARY TYPE.

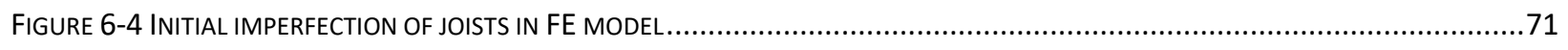

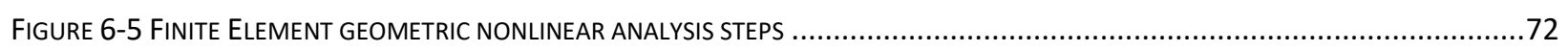

FIGURE 6-6 SPECIMEN B-4 LATERAL DISPLACEMENT OF TOP FLANGE - BUCKLING LOAD AND GEOMETRIC NONLINEAR BEHAVIOR ............73

FIGURE 6-7 SPECIMEN B-4 - SECTION ROTATION - BUCKLING LOAD AND GEOMETRIC NONLINEAR BEHAVIOR ..................................73

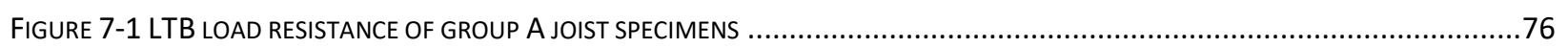

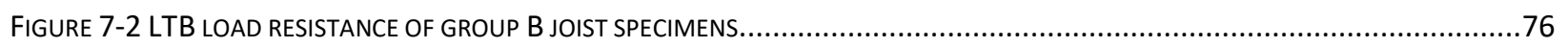

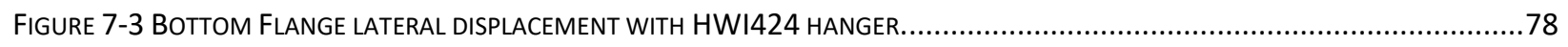

FIGURE 7-4 TOP VIEW OF DISPLACEMENT OF JOIST TOP FLANGE WITH HU316 HANGER ...............................................79

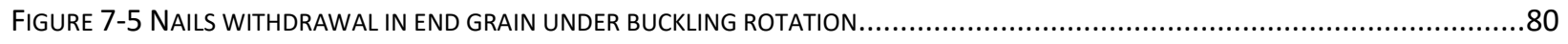

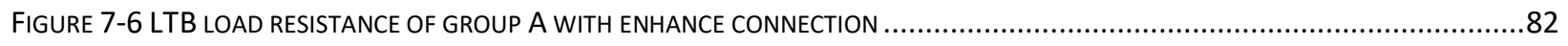

FIGURE 7-7 LTB LOAD RESISTANCE OF GROUP B WITH ENHANCED CONNECTION .......................................................

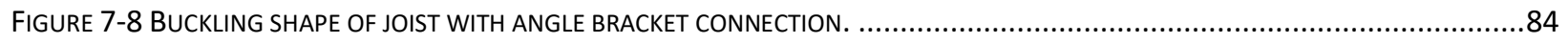

FIGURE 7-9 SIMPLY SUPPORTED SPECIMENS NUMERICAL PREDICTIONS VS EXPERIMENTAL OBSERVATIONS....................................86

FigURE 7-10 SPECIMEN GROUP A - TOP FLANGE DISPLACEMENT WITH SIMPLY SUPPORTED CONDITION......................................93

FiguRE 7-11 SPECIMEN GROUP B - TOP FLANGE DISPLACEMENT WITH SIMPLY SUPPORTED CONDITION.....................................93

FIGURE 7-12 NON-LINEAR LOAD-DISPLACEMENT RELATIONSHIP OF SPECIMEN 22, GROUP B .............................................97

FIGURE 7-13 NON-LINEAR LOAD-DISPLACEMENT RELATIONSHIP OF SPECIMEN 4, GROUP B ..................................................97

FIGURE 7-14 NON-LINEAR LOAD-DISPLACEMENT RELATIONSHIP OF SPECIMEN 5, GROUP B ...................................................98

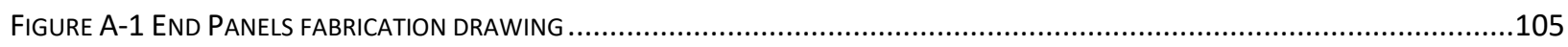

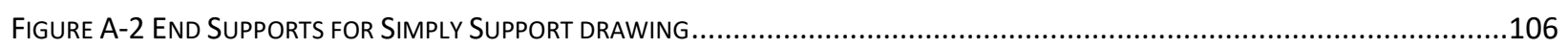

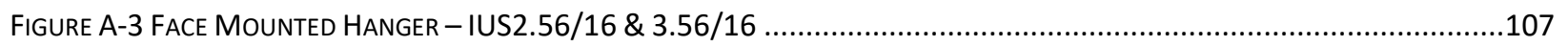

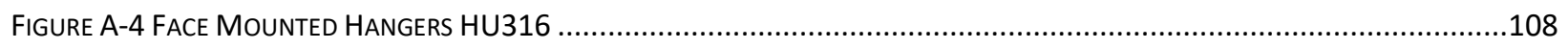

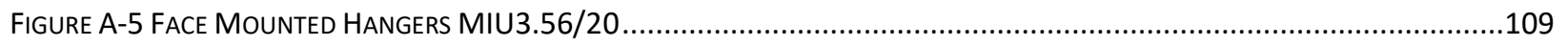

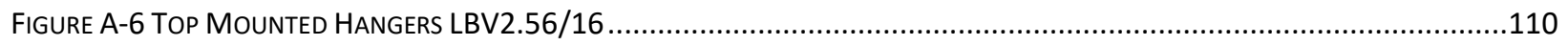

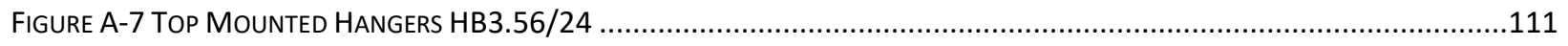

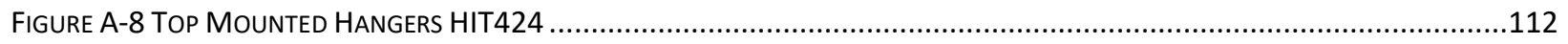

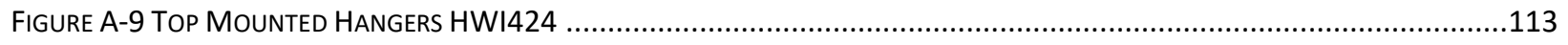

FIGURE B-1 BUCKLING DISPLACEMENT - SPECIMEN A-1 - SIMPLY SUPPORTED END CONDITIONS ......................................115

FIGURE B-2 BUCKLING DISPLACEMENT - SPECIMEN A-2 - SIMPLY SUPPORTED END CONDITIONS ...........................................116

FIGURE B-3 BUCKLING DISPLACEMENT - SPECIMEN A-3 - SIMPLY SUPPORTED END CONDITIONS ........................................117

FIGURE B-4 BUCKLING DISPLACEMENT - SPECIMEN A-4 - SIMPLY SUPPORTED END CONDITIONS ..........................................118

FIGURE B-5 BUCKLING DISPLACEMENT - SPECIMEN A-5 - SIMPLY SUPPORTED END CONDITIONS ...........................................119

FIGURE B-6 BUCKLING DISPLACEMENT - SPECIMEN A-6 - SIMPLY SUPPORTED END CONDITIONS .........................................120 
FIGURE B-7 BUCKLING DISPLACEMENT - SPECIMEN A-7 - SIMPLY SUPPORTED END CONDITIONS .............................................121

FIGURE B-8 BUCKLING DISPLACEMENT - SPECIMEN A-7 - LBV2.56/16 TOP MOUNTED HANGERS..........................................121

FIGURE B-9 BUCKLING DISPLACEMENT - SPECIMEN A-8 - SIMPLY SUPPORTED END CONDITIONS .............................................122

FIGURE B-10 BUCKLING DISPLACEMENT - SPECIMEN A-8 - LBV2.56/16 TOP MOUNTED HANGERS ........................................122

FIGURE B-11 BUCKLING DISPLACEMENT - SPECIMEN A-9 - SIMPLY SUPPORTED END CONDITIONS ........................................123

FIGURE B-12 BUCKLING DISPLACEMENT - SPECIMEN A-9 - LBV2.56/16 TOP MOUNTED HANGERS ......................................123

FIGURE B-13 BUCKLING DISPLACEMENT - SPECIMEN A-10 - SIMPLY SUPPORTED END CONDITIONS .......................................124

FIGURE B-14 BUCKLING DISPLACEMENT - SPECIMEN A-10 - LBV2.56/16 TOP MOUNTED HANGERS ...................................124

FIGURE B-15 BUCKLING DISPLACEMENT - SPECIMEN A-11 - SIMPLY SUPPORTED END CONDITIONS .......................................125

FIGURE B-16 BUCKLING DISPLACEMENT - SPECIMEN A-11 - IUS2.56/16 FACE MOUNTED HANGERS .....................................125

FIGURE B-17 BUCKLING DISPLACEMENT - SPECIMEN A-12 - SIMPLY SUPPORTED END CONDITIONS .......................................126

FIGURE B-18 BUCKLING DISPLACEMENT - SPECIMEN A-12 - IUS2.56/16 FACE MOUNTED HANGERS ....................................126

FIGURE B-19 BUCKLING DISPLACEMENT - SPECIMEN A-13 - SIMPLY SUPPORTED END CONDITIONS ........................................127

FIGURE B-20 BUCKLING DISPLACEMENT - SPECIMEN A-13 - HU316 FACE MOUNTED HANGERS ..........................................127

FIGURE B-21 BUCKLING DISPLACEMENT - SPECIMEN A-14 - SIMPLY SUPPORTED END CONDITIONS .......................................128

FiguRE B-22 BUCKLING DISPLACEMENT - SPECIMEN A-14 - HU316 FACE MOUNTED HANGERS ..........................................128

FIGURE B-23 BUCKLING DISPLACEMENT - SPECIMEN A-15 - SIMPLY SUPPORTED END CONDITIONS ........................................129

FIGURE B-24 BUCKLING DISPLACEMENT - SPECIMEN A-15 - NAILED THROUGH END GRAIN ................................................129

FIGURE B-25 BUCKLING DISPLACEMENT - SPECIMEN A-16 - SIMPLY SUPPORTED END CONDITIONS .........................................130

FIGURE B-26 BUCKLING DISPLACEMENT - SPECIMEN A-16 - NAILED THROUGH END GRAIN .............................................130

FIGURE B-27 BUCKLING DISPLACEMENT - SPECIMEN A-17 - ANGLE BRACKET ENHANCED CONNECTION ...................................131

FIGURE B-28 BUCKLING DISPLACEMENT - SPECIMEN A-18 - ANGLE BRACKET ENHANCED CONNECTION ....................................132

FIGURE B-29 BUCKLING DISPLACEMENT - SPECIMEN B-1 - SIMPLY SUPPORTED END CONDITIONS ........................................133

FIGURE B-30 BUCKLING DISPLACEMENT - SPECIMEN B-2 - SIMPLY SUPPORTED END CONDITIONS .......................................134

FIGURE B-31 BUCKLING DISPLACEMENT - SPECIMEN B-3 - SIMPLY SUPPORTED END CONDITIONS .......................................135

FIGURE B-32 BUCKLING DISPLACEMENT - SPECIMEN B-4 - SIMPLY SUPPORTED END CONDITIONS ........................................136

FIGURE B-33 BUCKLING DISPLACEMENT - SPECIMEN B-5 - SIMPLY SUPPORTED END CONDITIONS .......................................137

FIGURE B-34 BUCKLING DISPLACEMENT - SPECIMEN B-6 - SIMPLY SUPPORTED END CONDITIONS .........................................138

FIGURE B-35 BUCKLING DISPLACEMENT - SPECIMEN B-7 - SIMPLY SUPPORTED END CONDITIONS .......................................139

FIGURE B-36 BUCKLING DISPLACEMENT - SPECIMEN B-8 - SIMPLY SUPPORTED END CONDITIONS .........................................140

FiguRE B-37 BUCKLING DISPLACEMENT - SPECIMEN B-8 - HWI424 Top MounTEd HANGERS .............................................140

FIGURE B-38 BUCKLING DISPLACEMENT - SPECIMEN B-9 - SIMPLY SUPPORTED END CONDITIONS ..........................................141

FIgURE B-39 BUCKLING DISPLACEMENT - SPECIMEN B-9 - HWI424 TOP MOUNTED HANGERS.............................................141

FIGURE B-40 BUCKLING DISPLACEMENT - SPECIMEN B-10 - SIMPLY SUPPORTED END CONDITIONS .......................................142 
FIGURE B-41 BUCKLING DISPLACEMENT - SPECIMEN B-10 - HB3.56/24 TOP MOUNTED HANGERS .........................................142

FIGURE B-42 BUCKLING DISPLACEMENT - SPECIMEN B-11 - SIMPLY SUPPORTED END CONDITIONS .......................................143

FIGURE B-43 BUCKLING DISPLACEMENT - SPECIMEN B-11 - HB3.56/24 TOP MOUNTED HANGERS ........................................143

FIGURE B-44 BUCKLING DISPLACEMENT - SPECIMEN B-12 - HIT424 TOP MOUNTED HANGERS ..............................................144

FIGURE B-45 BUCKLING DISPLACEMENT - SPECIMEN B-13 - HIT424 TOP MOUNTED HANGERS ..............................................145

FIGURE B-46 BUCKLING DISPLACEMENT - SPECIMEN B-14 - SIMPLY SUPPORTED END CONDITIONS ......................................146

FIGURE B-47 BUCKLING DISPLACEMENT - SPECIMEN B-14 - IUS3.56/16 FACE MOUNTED HANGERS .....................................146

FIGURE B-48 BUCKLING DISPLACEMENT - SPECIMEN B-15 - SIMPLY SUPPORTED END CONDITIONS .....................................147

FIGURE B-49 BUCKLING DISPLACEMENT - SPECIMEN B-15 - IUS3.56/16 FACE MOUNTED HANGERS ....................................147

FIGURE B-50 BUCKLING DISPLACEMENT - SPECIMEN B-16 - MUI3.56/16 FACE MOUNTED HANGERS .....................................148

FIGURE B-51 BUCKLING DISPLACEMENT - SPECIMEN B-17 - MUI3.56/16 FACE MOUNTED HANGERS ....................................149

FIGURE B-52 BUCKLING DISPLACEMENT - SPECIMEN B-18 - SIMPLY SUPPORTED END CONDITIONS ......................................150

FIGURE B-53 BUCKLING DISPLACEMENT - SPECIMEN B-18 - NAILED IN END GRAIN CONNECTION ..........................................150

FIGURE B-54 BUCKLING DISPLACEMENT - SPECIMEN B-19 - SIMPLY SUPPORTED END CONDITIONS .......................................151

FIGURE B-55 BUCKLING DISPLACEMENT - SPECIMEN B-19 - NAILED IN END GRAIN CONNECTION .........................................151

FIGURE B-56 BUCKLING DISPLACEMENT - SPECIMEN B-20 - SIMPLY SUPPORTED END CONDITIONS ......................................152

FIGURE B-57 BUCKLING DISPLACEMENT - SPECIMEN B-20 - SIDE SCREWED FLANGES CONNECTION ......................................152

FIGURE B-58 BUCKLING DISPLACEMENT - SPECIMEN B-21 - SIMPLY SUPPORTED END CONDITIONS .......................................153

FIGURE B-59 BUCKLING DISPLACEMENT - SPECIMEN B-21 - SIDE SCREWED FLANGES CONNECTION ........................................153

FIGURE B-60 BUCKLING DISPLACEMENT - SPECIMEN B-22 - SIMPLY SUPPORTED END CONDITIONS .........................................154

FIGURE B-61 BUCKLING DISPLACEMENT - SPECIMEN B-22 - ANGLE BRACKET ENHANCED CONNECTION ....................................154

FIGURE B-62 BUCKLING DISPLACEMENT - SPECIMEN B-23 - SIMPLY SUPPORTED END CONDITIONS .........................................155

FIGURE B-63 BUCKLING DISPLACEMENT - SPECIMEN B-23 - ANGLE BRACKET ENHANCED CONNECTION ..................................155 


\section{Notation}

$C_{w} \quad=$ warping constant

$C_{w g}=$ global warping constant

$C_{w l} \quad=$ local warping constant

$C_{p} \quad=$ stability factor

$E_{\min }^{\prime}=$ adjusted modulus of elasticity

$E \quad=$ modulus of elasticity

$E_{1,2,3}=$ modulus of elasticity along axis 1,2 or 3 of the section

$E_{L} \quad=$ modulus of elasticity along the longitudinal direction

$E_{T} \quad=$ modulus of elasticity along the transversal direction

$E_{w t} \quad=$ transverse modulus of elasticity of the web

$E C_{w} \quad=$ warping stiffness

$E I_{y} \quad=$ weak axis bending stiffness

$F_{c E} \quad=$ critical buckling design value for compression member

$F_{c}^{*} \quad=$ reference compression design value parallel to grain multiplied by all applicable adjustment factor except $C_{p}$

$G \quad=$ shear modulus

$G_{i, j} \quad=$ shear modulus along the plane $\mathrm{i}, \mathrm{j}$

$G_{T} \quad=$ transverse shear modulus

GJ = torsional rigidity

$I_{y} \quad=$ weak axis inertia

$J \quad=$ St-Venant constant

$\left[\mathrm{K}^{*}\right] \quad=$ stiffness matrix

$\left[\mathrm{K}_{\mathrm{G}}\right]=$ geometric matrix

$\left[K_{S}\right] \quad=$ strong axis stiffness matrix

$\left[\mathrm{K}_{\mathrm{W}}\right]=$ weak axis stiffness matrix

$M \quad=$ uniform moment

$M_{C r} \quad=$ lateral torsional bending critical moment 


$$
\begin{array}{ll}
M_{\text {max }} & =\text { maximum bending moment in the beam segment } \\
M_{a}, M_{c} & =\text { bending moment at quarter span } \\
M_{b} & =\text { bending moment at mid-span } \\
{\left[P_{r e f}\right]} & =\text { reference load } \\
b & =\text { flange width } \\
b_{i} & =\text { component width } \\
c & =\text { reliability factor } \\
\mathrm{d} & =\text { section height } \\
h_{i} & =\text { component thickness } \\
i & =\text { number of components of a section } \\
l & =\text { beam unsupported length } \\
l_{e} & =\text { effective length } \\
{\left[u_{S}\right]} & =\text { strong axis nodal displacement } \\
t & =\text { flange thickness } \\
\left(v_{\mathrm{i}}\right) & =\text { nodal displacement vector of the mode shape } \mathrm{i} \\
w & =\text { web thickness } \\
w_{(x)} & =\text { lateral displacement of beam } \\
x, y, z & =\text { cartesian coordinates } \\
\epsilon & =\text { normal strain } \\
\gamma & =\text { shear strain } \\
\lambda & =\text { load multiplier } \\
\mu & =\text { poisson's ratio } \\
\omega_{2} & =\text { moment gradient factor } \\
\Pi & =\text { total potential energy } \\
\sigma & =\text { normal stress } \\
\theta_{(x)} & =\text { angle of twist of beam } \\
&
\end{array}
$$




\section{CHAPTER 1}

\section{INTRODUCTION}

Wood is an abundant, renewable and versatile material that has been a popular choice for architects and engineers especially for low- and medium-rise construction. The development of engineered wood products, such as wood I-joists, meant that structural bending members that are longer and deeper can be achieved without significantly increasing the overall building weight. The present chapter provides a description of the research motivation, general background on the lateral torsional buckling instability phenomenon, and the methodology used to achieve the research objectives.

\subsection{Background}

Engineered wood I-joists are proprietary structural elements that provide an alternative to traditional solid sawn lumber joists due to their favorable mechanical properties and enhanced efficiency. Wood I-joists typically comprise of a composite assembly of machine stress-rated lumber (MSR) or engineered laminated veneer lumber (LVL) used as flanges and oriented strand board (OSB) or plywood panel as web. The resulting product provides an increased ability to resist flexure forces, while spanning longer. Also, the application of finger joints along the flanges allows the use of relatively small lumber pieces and thus producing less material waste. The increase in span and depth, however, comes at the price of increased risk of instability and potential buckling failure. Similar to solid sawn joists, engineered I-joists are typically sheathed with wood panels bracing them at the top face and partially restraining lateral displacement of the top flange. However, during or after construction, several conditions might lead to the wood I-joists not being adequately braced. Such cases include: workers walking on floor or roof joists during installation, wind uplift governing the design of a roof, and continuous or cantilever beams with negative moments. Design against lateral torsional buckling failure of I-joists is only addressed by few design standards and is done in a cursory manner (e.g. AWC 2015), or as part of non-mandatory commentary material (e.g. CSA 2014). Established knowledge on the behavior of beams to lateral 
torsional buckling failure has addressed cases involving idealized boundary conditions. However, practical construction often involves non-ideal boundary conditions. For example, a variety of metallic hangers and connection details are used in construction, the effect of which has been very scarcely investigated. In this context, the current research aims at investigating the effect of such "realistic" boundary conditions on the lateral stability of the engineer wood I-joists and assessing the ability of using numerical models and current design requirements to predict the buckling behavior.

\subsubsection{Wood I-joists material properties}

Wood can be considered as an orthotropic material with properties in longitudinal, radial and tangential directions different and independent from each other (FPL 2010). The longitudinal axis is parallel to the grain, the radial axis is perpendicular to the grain and normal to the growth rings, and the tangential axis is perpendicular to the grain but tangent to the growth rings, as illustrated in Figure 1-1.

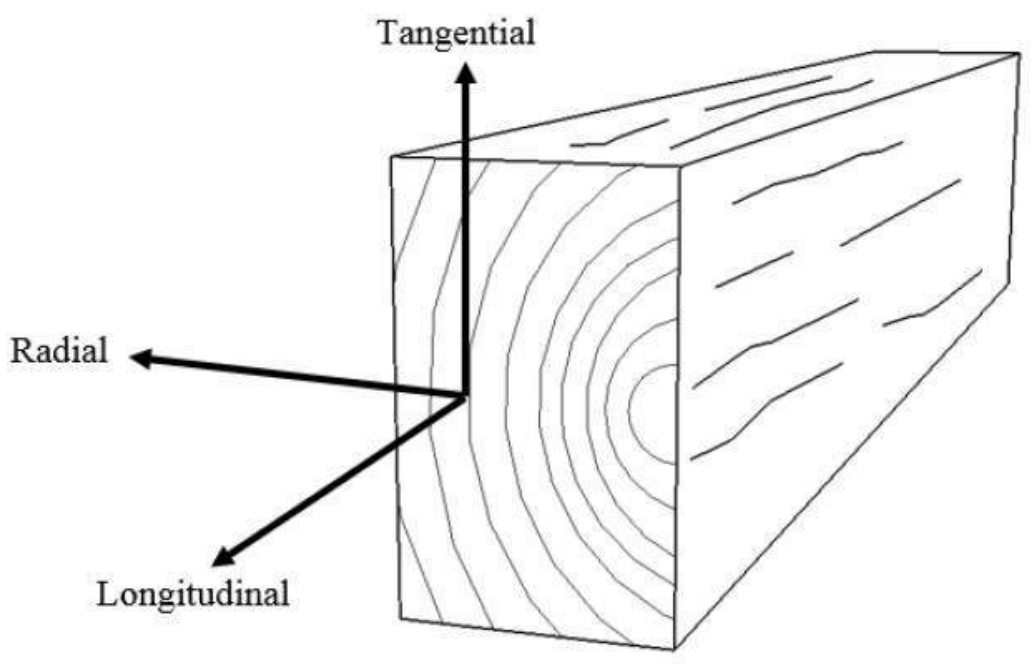

Figure 1-1 Wood orthotropic principal axes (St-Amour 2016)

The mechanical properties in the tangential and radial axis are very close for a large array of species and therefore, they are commonly assumed to be identical (FPL 2010). For this reason, the properties of wood are generally considered for the parallel and perpendicular to grain directions, which is also consistent with the design standards (e.g. CSA 2014). 
Although wood can be modelled as an orthotropic material, not all the material properties have an important role in the lateral torsional buckling resistance. Xiao (2014) conducted a sensitivity analysis on rectangular solid sawn lumber and concluded that the modulus of elasticity along the longitudinal direction $\left(E_{L}\right)$ and the transverse shear modulus $\left(G_{T}\right)$ are the two variables which have the strongest influence on the lateral torsional buckling capacity. St-Amour (2016) presented a sensitivity analysis on the mechanical properties of wood I-joist and it was revealed that the most influential mechanical properties are the longitudinal modulus of elasticity and the torsional shear modulus of the compression flange. The longitudinal modulus of elasticity and the torsional shear modulus of the tension flange, and the transverse modulus of elasticity of the web also impact the buckling response but to a lesser degree. Studies have also investigated the material properties of OSB (St-Amour 2016; Thomas 2001), and their effect on the lateral torsional buckling capacity of wood I-joists (Grandmont 2011).

\subsubsection{Lateral Torsional Buckling behaviour of I-shaped beams}

A beam member resisting flexural forces about its strong axis can develop a buckling instability if it is not laterally and/or torsionally restrained. As the beam deflects, axial stresses develop in the flanges and as a result, one flange experiences compressive stresses and the other tension stresses. The compression flange tends to buckle out of plane while the tension flange resists this tendency. When the tension flange's restoring force is not adequate to prevent buckling, the beam undergoes lateral torsional buckling manifested by lateral deflection and twist (Figure 1-2). 


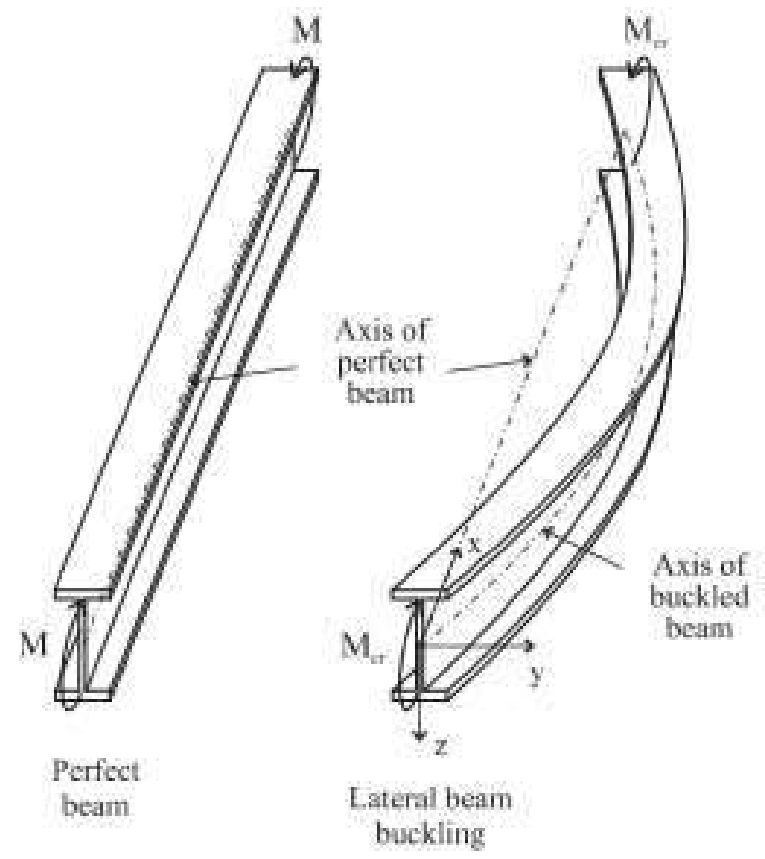

Figure 1-2 I-section undergoing lateral torsional buckling (Kala 2013)

The resistance of the beam to this lateral deflection and twist is influenced by several factors, including: geometric properties, section type (mono or doubly symmetric I-section, z section, etc.), moment distribution along the span, position of the applied loads relative to the shear center and boundary conditions (Timoshenko and Gere 1961). The load position has a great influence on the beam capacity, where a load applied above the shear center has a destabilizing effect that will decrease the lateral torsional buckling resistance and a load applied below the shear center would tend to have the opposite (stabilizing) effect.

A closed form solution for the lateral torsional buckling of a beam has been derived by formulation of the principle of stationary total potential energy. Timoshenko and Gere (1961) developed the basis for most design provisions for a beam with simply supported end conditions and uniform moment. The total potential energy of an I-beam with length $l$ having a weak-axis bending rigidity $E I_{y}$, a torsional rigidity $G J$ and a warping stiffness $E C_{w}$ and subjected to a uniform moment $M$ can be written as: 


$$
\Pi=\frac{1}{2} \int_{0}^{l} E I_{y} w^{\prime \prime 2} d x+\frac{1}{2} \int_{0}^{l} G J \theta^{\prime 2} d x+\frac{1}{2} \int_{0}^{l} E C_{w} \theta^{\prime 2} d x+\int_{0}^{l} M \theta w^{\prime \prime} d x
$$

where $w(x)$ and $\theta(x)$ denote the lateral displacement and angle of twist functions, respectively. For equation 1-1, the following assumptions are made (Vlasov 1961):

1. Material is linearly elastic

2. Section is doubly-symmetric

3. Section remains perpendicular to the neutral axis after deformation (shear deformation is neglected)

4. The loads are conservative (direction is constant)

5. Inertia effects are neglected

6. The equilibrium of the beam is taken in the deformed shaped, after buckling occurred.

By applying the stationary conditions at the deformed state and enforcing the boundary conditions, the resulting equilibrium equations are obtained. Using deformed configuration, which assume two sinusoidal functions for the lateral deformation and angle of twist along the length of the beam, the critical moment $M_{c r}$ for a simply supported I-beam of unsupported length $l$ subjected to a uniform moment $M$ is given as:

$$
M_{c r}=\frac{\pi}{l} \sqrt{E I_{y} G J+\left(\frac{\pi E}{l}\right)^{2} I_{y} C_{w}}
$$

Developing closed form solutions for a beam with other boundary conditions, moment distribution and/or load eccentricity other than those assumed in Equation 1-2 is not achievable. For this reason, design standards (e.g. CISC 2009, CSA 2014) use either moment gradient $\left(\omega_{2}\right)$ or effective length factors to account for various moment distributions and boundary conditions.

\subsubsection{Twisting of I-beams with thick flanges}

Twisting in a structural member can cause two kinds of stresses in the section components. The St-Venant torsional shear stress results from the rotation induced in the cross section. In the case of an open shaped I-section under twist, in addition of the section twist, the flanges will have a 
tendency to warp out of plane of the section. Restraining this warping deformation will result in axial stresses to develop in the flange and will combine with the St-Venant shear stresses (Kirby and Nethercot 1979). The warping of a section can occur both globally and locally (Gjelsvik 1981). For an I-section with thin flanges, the local warping can often be neglected however, when it comes to sections with thicker flanges, e.g. engineered wooden I-joists considered in this study, the local warping can be more considerable and therefore must be taken into account.

The warping constant $C_{W}$ for an I-section with thick flanges having a flange width $b$, a web height $d^{\prime}$ (taken between flange centroids), a flange thickness $t$, a web thickness $w$ and a moment of inertia about the weak axis $I_{y}$, can be computed as the summation of the global $\left(C_{W g}\right)$ and the local $\left(C_{W l}\right)$ warping components:

$$
C_{W}=C_{W g}+C_{W l}=\left(I_{y} d^{\prime 2} / 4\right)+\left(2 t^{3} b^{3}+w^{3} d^{\prime 3}\right) / 144
$$

Gjelsvik (1981) also proposed an approximate form for the St-Venant constant $J$ given by $\sum_{i=1,2,3 \ldots} \frac{b_{i} h_{i}^{3}}{3}$. where $i$ is the number of components of the section. A more precise value for the St-Venant constant $J_{e}$ is given by:

$$
J_{e}=\sum_{i=1,2,3 \ldots}\left(\frac{b_{i} h_{i}^{3}}{3}\right)\left[1-\frac{192 h_{i}}{\pi^{5} b_{i}} \sum_{n=1,3 \ldots}^{\infty} \frac{1}{n^{5}} \tanh \left(\frac{n \pi b_{i}}{2 h_{i}}\right)\right]
$$

where $b$ is the width and $h$ the thickness of the considered component. 


\subsubsection{Canadian Steel Design Standards (CISC 2009)}

The elastic critical moment of the unbraced segment in the steel design standard (CISC 2009) is given by equation 1-5:

$$
M_{C r}=\omega_{2} \frac{\pi}{l} \sqrt{E I_{y} G J+\left(\frac{\pi E}{l}\right)^{2} I_{y} C_{w}}
$$

where $\omega_{2}$ is the moment gradient factor, which can be computed by Equation 1-6:

$$
\omega_{2}=\frac{4 * M_{\max }}{\sqrt{M_{\max }^{2}+4 M_{a}^{2}+7 M_{b}^{2}+4 M_{c}^{2}}} \leq 2.5
$$

where $M_{\max }$ represents the maximum bending moment in the beam segment, $M_{b}$ denotes the bending moment at mid-span of the beam segment and $M_{a} \& M_{c}$ are the bending moment at quarter span of the beam segments.

\subsubsection{North American design standard for wood construction}

The American design standard for wood construction (AWC 2015) presents a method to compute the critical moment of a wood I-joist undergoing lateral torsional buckling. The calculation consists of considering the compressive flange of the wood I-joist as a column restrained in the plane of the web and undergoing lateral torsional buckling. Only the section properties of the flange are considered. The critical moment resistance is factored with the stability factor of a column $C_{p}$ shown in Equation 1-7:

$$
C_{p}=\frac{1+\left(F_{c E} / F_{c}^{*}\right)}{2 c}-\sqrt{\left[\frac{1+\left(F_{c E} / F_{c}^{*}\right)}{2 c}\right]^{2}-\frac{\left(F_{c E} / F_{c}^{*}\right)}{c}}
$$

where $F_{c E}=\frac{0.822 E_{\min }^{\prime}}{\left(l_{e} / d\right)^{2}}, F_{c}^{*}$ is the specified compression strength of the flange and $\mathrm{c}$ is a reliability factor.

The commentary to the Canadian wood design standard (CSA 2014) also includes a similar statement. 


\subsubsection{Imperfection and geometric nonlinearity}

In addition to the assumptions presented in section 1.1.2, the derivation of the lateral torsional buckling equation (Equation 1-2) assumes that the member has no initial imperfection. In reality, manufactured beams contain various extent of imperfections, depending on material used and manufacturing standards. These imperfections would induce lateral displacement and twist at the very early stages of the loading process, leading to a non-linear buckling behavior of the beam (Figure 1-3) (Kirby and Nethercot 1979).

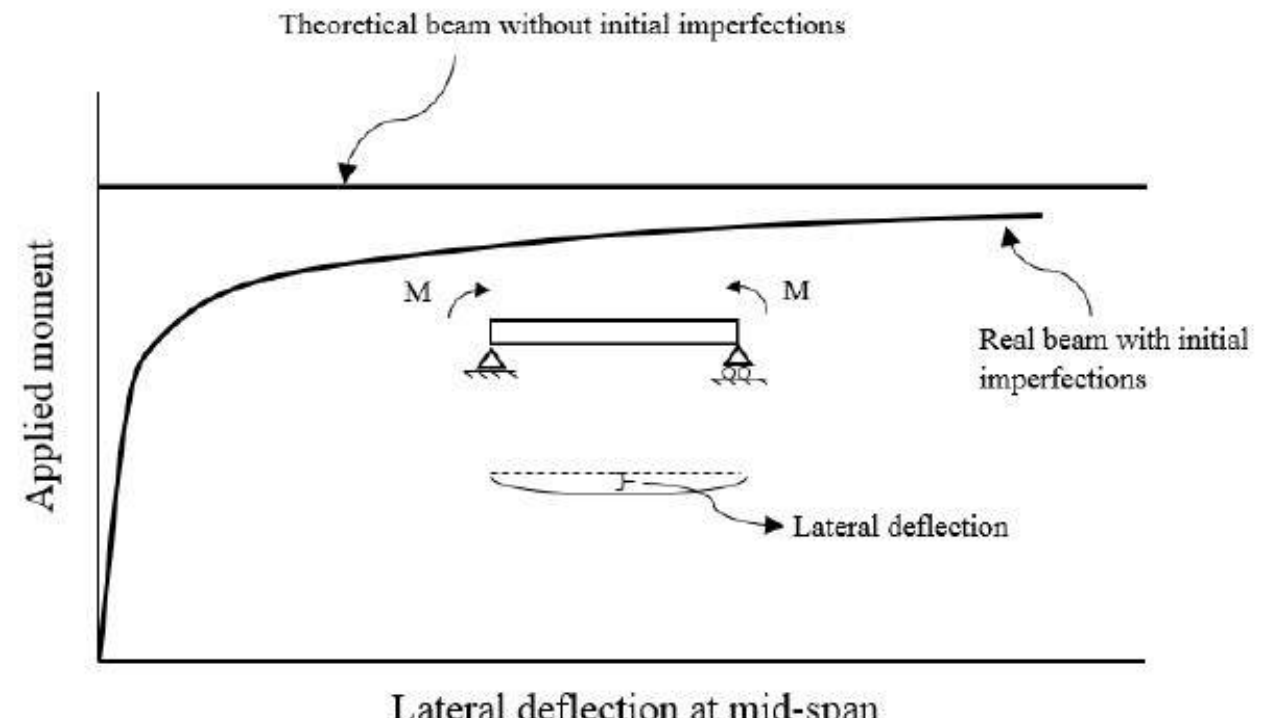

Figure 1-3 Lateral buckling of theoretical and realistic I-beams (St-Amour 2016)

Ascione (2014) investigated the influence of initial geometric imperfections on the lateral buckling of thin-walled pultruded GFRP I-profile beams. Two kinds of imperfections were analyzed: the out-of-straightness and the non-orthogonality of the flange and web assembly. A numerical analysis showed that these imperfections can affect the pre-buckling behavior as well as the resistance of the section and implied that out of straightness should be considered in design, especially for serviceability requirements. 


\subsection{Research objectives}

The current research aims at investigating the lateral torsional buckling behavior of engineered wood I-joists. Specific goals include:

- Experimentally investigating the lateral torsional buckling behaviour of wood I-joists based on idealized pinned ends as well as "realistic" boundary conditions using metallic joist hangers;

- Developing a finite element model using a commercially available software package to predict the lateral torsional buckling load of the wood I-joists and validating the model by comparisons against the full-scale test results;

- Conducting sensitivity analysis on the effect of lateral rigidity of wood I-joists flange support and torsional fixity of the flange on the resistance of the beams to lateral torsional buckling;

- Investigating the effect of initial imperfection on the buckling behavior of the wood I-joists during the entire loading history.

\subsection{Research methodology}

The approach taken to meet the objectives of the study relies on both experimental and numerical analysis as outlined in the following steps:

1. A sensitivity analysis of the flange support's lateral stiffness as well as rotational stiffness is first conducted to identify the most influential components.

2. An experimental investigation is undertaken to document the wood I-joists non-linear buckling behavior and investigate the buckling load under various end conditions, including: a) idealized simply supported condition, b) commercially available metallic joist hangers and c) custom designed connections.

3. A finite element model capable of predicting the buckling behavior of the wood I-joists using component material inputs determined in the experimental investigation is 
developed. Both linear and nonlinear buckling analysis is conducted and model results are validated using experimental observations.

\subsection{Outline of the thesis}

Chapter 1 introduces the engineered I-joists wood product under the scope of this study, and presents research needs, objectives and methodology.

Chapter 2 presents the available literature found on lateral buckling phenomenon in wooden beams and engineered wood I-joists.

Chapter 3 describes the sensitivity analysis performed on the lateral stiffness of the wood I-joists flange support.

Chapter 4 describes the experimental investigation, test setup and loading regimes.

Chapter 5 presents the results of the experimental investigation on various end support conditions, and describes the behavior of the test specimens.

Chapter 6 describes the finite element model and validates the numerical predictions using the experimental test results.

Chapter 7 discusses the results obtained from the experimental investigations and numerical predictions.

Chapter 8 presents a summary of the relevant observations and conclusions as well as recommendations for further research. 


\section{CHAPTER 2}

\section{LITERATURE REVIEW}

This chapter presents a review of the literature that investigated lateral and torsional instability of wooden beams with focus on experimental investigation methods consistent with the approach taken in the current study. The literature presented in Section 2.1 focuses on the lateral torsional buckling behavior of rectangular sections under various load distributions. Section 2.2 presents the literature on lateral torsional buckling of engineered wood I-joists. Finally, Section 2.3 summarizes the literature and provides links to the present study.

\subsection{Lateral Torsional Buckling of wooden beams}

Hooley and Madsen (1964) conducted an experimental study on glued-laminated beams without bracing along the span to investigate their lateral torsional buckling failure. The objective of the study was to present simple code provisions in a rational way by validating the existing theory of lateral torsional buckling with simply supported or cantilevered beams subjected to a concentrated load. The experimental results correlated well with the theory and the study concluded that the slenderness ratio $\mathrm{Ld} / \mathrm{b}^{2}$ governs the lateral stability of the beams. Based on this ratio, the concept of short, intermediate and long beams was introduced and defined for design purposes. The tests in this study showed that this approach yielded a safety factor ranging from 2.5 for short beams to 3 for long beam. To account for the flexibility of the support in realistic conditions, a $15 \%$ reduction of the LTB load was suggested.

Zahn (1973) formulated the governing equilibrium conditions for wooden rectangular beams with

continuous lateral bracing along the beam's main axis through energy-based solutions. The shear resistance provided by the deck system was incorporated along with the enforcement of the boundary conditions and a closed form solution was obtained to investigate various loading and support conditions. 
Bell and Eggen (2001) investigated the capacities of beam-columns subjected to lateral instability as evaluated by the Norwegian (NS3470-1 1999) and European timber codes (CEN 2004). Linear and non-linear buckling models were developed, using simply supported rectangular wood beams with one axial force and two equal and opposite moments at the member ends. The non-linear analysis included initial imperfections in the members. A reduction of $10 \%$ for the critical axial force and bending moment buckling loads was observed for the non-linear buckling analysis. The Norwegian code was found to be conservative since it assumed a linear relationship between the flexural and axial capacities. On the other hand, it was demonstrated that Eurocode 5 overestimates the capacity by as much as $30 \%$, for certain combination of axial force and bending moment.

AFPA (2003) released a technical report to address the design of timber members for stability, where slenderness, loading and support conditions were discussed. The effective length and equivalent moment factor approaches for adjusting the buckling capacity were outlined and compared. The report proposed conservative values to be used for support configurations other than cantilevered and continuous beams. Closed form solutions for lateral torsional buckling of beams were derived using differential equations, series approximation and energy methods which also enabled the formulation of a load eccentricity expression.

Hindman et al. (2005b) studied the lateral torsional buckling behavior of twelve rectangular cantilever beams composed of various structural composite lumber products. The elastic constant ratios and torsional rigidity of the structural composite lumber material resulted in a more constant buckling behavior than what was observed with solid sawn lumber wood members. The test configuration consisted of a cantilevered beam with a concentrated load positioned at the free end. The material was tested at three different lengths. Emphasis was put on modifying the LRFD equations provides by AFPA (2003) to incorporate the experimentally determined E:G ratio of the material and to produce more reliable predictions of the buckling load for structural composite lumber. It was observed that the LRFD equation (AFPA 2003) was non conservative for Laminated Veneer Lumber (LVL) but was deemed suitable for solid sawn and Parallel Strand Lumber (PSL). The buckling load was identified by a clear change of slope on the force-rotation plot. Experimental data showed that the beams capacity increased even after the point where a change in the slope was observed. 
Suryoatmono and Tjondro (2008) performed lateral torsional buckling tests on simply supported rectangular wooden beams with a concentrated force applied at mid-span. Finite element models were developed using isotropic and orthotropic material properties and the results were compared to those obtained from the experimental study and the classical lateral torsional buckling solution. The classical solution used was based on isotropic material and neglected warping. It was found to be reliable in predicting the capacity for isotropic material properties but overestimate the results obtained from the finite element models using orthotropic material properties. The authors proposed the use of a reduction factor for the isotropic formulation when dealing with orthotropic material with such factor depending on the beam dimensions, specific gravity and other factors.

Xiao (2014) and Xiao et al. (2014) conducted a sensitivity analysis on the effect of orthotropic material properties on the lateral torsional buckling behavior of a rectangular timber beam. A finite element model was developed to study the influence of the material properties on the buckling load by varying one property at a time and comparing it to a reference case. The study showed that the numerical model was mostly affected by variation in the longitudinal modulus of elasticity and the transverse shear modulus of the timber member. The remaining material properties were shown to have a negligible effect on the predicted critical moment. Full-scale lateral torsional buckling experiments were also conducted on lumber members. The members were tested with simply supported end conditions and were subjected to a concentrate load at mid-span. The experimental results obtained were compared to numerical buckling analysis, and the fit was deemed reasonable. Using the validated numerical model, a parametric study was conducted to study the effect of the load position relative to the shear center. The results were found to be consistent with the load eccentricity factor proposed by the AFPA (2003).

$\mathrm{Du}$ (2016) studied the behavior of wooden beam-deck systems subjected to buckling. Models for sway and non-sway systems were formulated with closed form, analytical and energy-based solutions. Various boundary conditions and moment distribution were taken into account in the models. The effects of beam and deck spans, load type and height, lateral and twisting restraints, lateral restraint height and stiffness on the buckling load of the system were assessed through a parametric study. The non-sway model was subject to lateral instability only with uplift forces while for the sway model, buckling was observed in cases with both uplift and downward forces. 
In general, the non-sway model consistently predicts critical moments higher than those based on the sway model. Large differences were observed for long beam span or short deck span. The effects of bracing action of the deck board, the deck span between beams and the span type (continuous or single span) of the system were documented and discussed.

Hu et al. (2017a, 2017b) investigated the effect of bracing height on wooden beams subjected to lateral-torsional buckling. Energy based solutions were formulated for a simply supported beam with rigid or flexible bracing, located at mid-span and subjected to uniformly distributed or midspan point load. The study indicated that beams are prone to two potential buckling patterns; a symmetric mode and an anti-symmetric mode. Whether the symmetric or the anti-symmetric mode governs the critical moment is shown to depend on the lateral brace height and stiffness threshold value. The bracing height as well as its stiffness influence on the buckling load were assessed through a parametric study.

\subsection{Lateral Torsional Buckling of Engineered wood I-joists}

Hindman et al. (2003) investigated the material properties of structural composite lumber products using an isotropic and orthotropic material properties inputs. The tests were executed on machine stress-rated lumber (MSR), laminated-veneer lumber (LVL), parallel strand lumber (PSL) and laminated strand lumber (LSL) which are materials frequently used for the flanges components of wood I-joist. The modulus of elasticity and the shear modulus were measured experimentally. It was determined that the modulus of elasticity to shear modulus ratio E:G was significantly lower than generally assumed in design code provisions. The torsional rigidity of the whole wood I-joists was also investigated. The torsional stiffness was also computed using mathematical models based on isotropic and orthotropic formulations. The MSR and LSL materials showed good agreement with the measured torsional stiffness while the LVL, PSL and I-joist materials were best predicted by the orthotropic model.

Hindman et al. (2005a) compared the buckling loads for two types of wood I-joists specimens of various lengths, with flanges constructed of structural composite lumber, either LVL or LSL. The I-joists' webs consisted of either plywood or oriented strand board (OSB). The specimens were set 
up as unbraced cantilever beams and the experimental buckling load was defined as the point where a significant increase appears on the force-angular displacement plot. The buckling load was compared with design equations (AFPA 2003) and the elastic beam buckling theory (Timoshenko and Gere 1961). It was found that both the design equation and the elastic beam buckling prediction provided conservative estimates when compared to the experimental wood Ijoist buckling loads.

Zhu et al. (2005) studied the buckling behavior of wood I-joists by comparing experimental tests to finite element simulations in ABAQUS. Both lateral buckling and local web buckling were observed in the experimental tests. The beams tested were simply supported and subjected to two concentrated loads applied at the top flange. The lateral movement of the top flange was restrained by five lateral bracing points along the span. Only the vertical deflection at mid-span was recorded. The buckling load was found to be related to the post-buckling load indicated by a "plateau" in the load-deflection curves and confirmed by visual observations during the experiments. Both lateral buckling and local web buckling of OSB webbed wood I-joists were observed in the tests and were verified with a finite element analysis. Geometric imperfections were introduced in the model to conduct non-linear buckling analysis of the test specimens. These analysis yielded load deformation response similar to that obtained in the test. An empirical formula based on postbuckling loads were derived for the stability capacity of the web. The authors' main conclusion was that the lateral buckling of wood I-joist was closely related to the span, flange size and the location of lateral restraints.

Burow et al. (2006) performed lateral torsional buckling tests on cantilevered and simply supported wood I-joist specimens. Three mathematical models were developed based on elastic stability solution (Timoshenko and Gere 1961) as well as the American code provisions (AFPA 2003; AWC 2015). Various loading and bracing configurations were incorporated. Torsional rigidity and bending stiffness of the wood I-joists were determined experimentally. From the non-linear forcerotation curve, the buckling load was defined as the point where the slope increment went beyond 0.2 degrees. It was shown that both the American timber design standard (AWC 2015) and the modified Euler model consistently underestimated the buckling load by an average of $78 \%$ and $44 \%$ respectively and the authors suggested modifications to provide more realistic predictions. 
Grandmont (2011) researched the effect of the material properties of the web on the lateral displacement of engineered wood I-joists. A finite element model was created to compare the influence of the material properties determined experimentally. It was observed that the material properties variation along the length of the OSB panel could significantly affect the prediction of the shear modulus of the specimens. The properties of the panels tends to differ significantly depending if they were determined on a global or local scale due to the heterogeneous properties of the wood composing the panels. The material properties of the web did not have a significant impact on the in-plane deflection of wood I-joist in the elastic range.

Aguilar (2013) investigated the lateral buckling behavior of wood I-joist joist subjected to human walking loads. The goal of this research was to derive mathematical models to predict the dynamic lateral-torsional buckling instability of the joists. The dynamic lateral-torsional buckling instability was analyzed by linearly combining the static lateral-torsional buckling instability with the dynamic lateral bending of the wood I-joists. Three different bracing configuration were investigated. The joists were tested with the simply supported condition and four commercial wood I-joist hangers: two top mounted and two face mounted. Various mathematical models based on Timoshenko and Gere (1961) were derived to predict the static LTB critical load of the simply supported beams, beams with hangers and various bracing configurations. The end condition with hanger support was modeled using a lateral spring analogy with the rotation of the section prevented. Numerical values for the spring analogy were obtained by testing the lateral stiffness of the wood I-joist hangers with a lever design set-up. The stiffness of the hangers was found to be smaller for the top mount hangers compared to the face mount hangers. A static and dynamic lateral-torsional buckling test was conducted with five different end conditions. The static test was done by applying a point load at mid-span on the top flange. Lateral-torsional buckling instability was assumed to occur when the wood I-joist deflected laterally and twisted. The author concluded that the buckling loads were influenced by the overall lateral stiffness of the end support conditions. The comparison between the theoretical model and the experimental test yields a $4 \%$ variation for the simply support condition and up to $10 \%$ with the hanger stiffness values obtained from individual testing. 
St-Amour (2016) investigated the effect of the material properties of wood I-joists on the lateral torsional buckling behavior. An experimental investigation was conducted to determine experimentally the lateral bending stiffness and rotational stiffness for entire joists as well as their various components. Full-scale LTB experiments were conducted by subjecting wood I-joist with various span length and simply supported end conditions to a concentrate point load located on the top flange at mid-span. A finite element model was created to predict the eigenvalue linear and non-linear buckling behavior of the joists. The model used material input determined experimentally. The buckling loads obtained with the numerical predictions and those obtained experimentally were compared to various design standards. The author concluded that the lateral bending and rotational stiffness observed from whole joists were adequate material input for the numerical model. The FE linear and nonlinear predictions were found to be in reasonable agreement with the experimental buckling loads and displacements. The FE geometric nonlinear analysis incorporated the initial imperfection that was measured during the LTB tests into the models and was able to replicate the experimental nonlinear behavior.

\subsection{Summary}

This chapter presented the studies that have been conducted on lateral torsional buckling instability in timber rectangular beams and engineered wood I-joists products. Many parameters were studied for the wooden members over the years. Studies by Bell and Eggen (2001), Hindman et al. (2005a), Hindman et al. (2005b), Burow et al. (2006) and Xiao (2014), Xiao et al. (2014), investigated the ability of various code design provisions to estimate the buckling load. Burow et al. (2006) and Hindman et al. (2005b) investigated the American design standards (AWC 2015) model for stability of wood I-joists and concluded that it underestimates the buckling load. Other studies, such as Zahn (1973), Aguilar (2013), Du (2016) and Hu (2016) focused their studies on the bracing action in order to prevent buckling failures. The importance of understanding the material properties of wood as an orthotropic material has been the focus of some studies (Hindman et al. 2003; Burow et al. 2006; Suryoatmono and Tjondro 2008; Grandmont 2011; Xiao 2014; St-Amour 2016). 
The topic of loading height has been investigated numerically in a number of lateral torsional bucking studies (e.g. Prescott and Carrington (1920), Ings and Trahair (1987), Pi et al. (1992)).Since this topic is not directly related to the present study, it was not covered in details, however, a fuller review of the associated literature is found in $\mathrm{Hu}$ (2016).

The existing literature on LTB of wood elements is found to be limited and understanding such instability phenomenon could still benefit from additional experimental and analytical investigations. So far, loading on structural members to induce material failure experimentally has been done using a simple platform with loads manually added. This mechanism prevents adding any restraints to the tested specimen since the load application point is free to move with the specimen (e.g. Xiao (2014) and St-Amour (2016)). This method greatly limits the magnitude of load that can be applied. This is why an aim of the current study was to develop a load application mechanism that would provide more flexibility on the magnitude of load application while maintaining the basic concept of not letting the load mechanism interfere with the specimen buckling mode.

There was no consensus in the literature on how to determine the point that constitutes buckling failure. Some studies identified the buckling load as the approximate bifurcation point where a significant lateral displacement was observed in the elastic range (Aguilar 2013; Hindman et al. 2005b; Burow et al. 2006), while other considered the ultimate capacity until inelastic deformations occurred or failure of the I-joists components happened (Xiao 2014; St-Amour 2016).

Very few studies considered the impact of realistic boundary conditions on the LTB capacity of the beams. Hooley and Madsen (1964) recognized that full fixity could be difficult to achieve for beams with realistic connections and therefore proposed a $15 \%$ reduction on the buckling capacity to account for this increase in flexibility. Aguilar (2013) studied the effect of various commercial I-joists hangers on the LTB capacity of the tested I-joists. The developed mathematical models predicted the LTB load of the joists by considering only a lateral translation of the section as a whole at their support without the possibility of being subjected to rotation. The current study aims 
to investigate the influence of joist hangers' lateral stiffness on the buckling load as they compare to idealized end conditions.

The initial geometric imperfection and nonlinear displacement of I-joists has not been adequately investigated in the literature. Zhu et al. (2005) and St-Amour (2016) have observed the displacement behavior associate with the initial imperfection on the buckling failure of wooden beams. The present study aims to investigate the nonlinear behavior influence on the resistance of the beam during the entire displacement history of the joists. 


\section{CHAPTER 3}

\section{SENSITIVITY ANALYSIS}

This chapter evaluates the effect of varying joist hanger stiffness on the critical lateral torsional buckling capacity of engineered wood I-joists. The results obtained from the sensitivity analysis are expected to assist in determining which boundary conditions variables has the most influence on the buckling load of the system.

An analysis to evaluate the impact of the initial imperfection on the buckling behaviour has also been conducted. This analysis will determine how the buckling load can be related to the nonlinear response of the joist.

Section 3.1 presents the sign convention and the terminology used in this study. Section 3.2 describes the finite element model used in the sensitivity analysis. Section 3.3 presents the results of the sensitivity analysis with boundary conditions stiffness variation and various initial imperfection.

\subsection{Convention used in this study}

The orientation of the principal axes of the wood I-joist used for this study is illustrated in Figure 3-1. The lateral axis (axis 3 ) represents the strong bending axis of the joist and the lateral direction vector. Axis 2 represents the height of the section, weak bending axis of the section and also strong bending axis of each flange taken individually. The longitudinal axis (axis 1) represents the length of the joists and the torsional direction of each flange. 


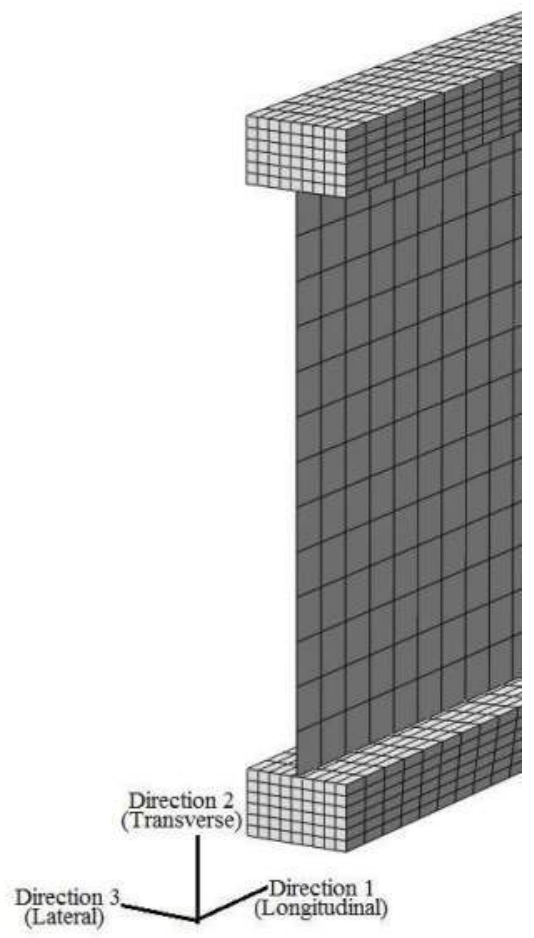

Figure 3-1 Models main axis directions

\subsection{Model description}

A commercial finite element software ABAQUS (Simulia 2014), which is capable of conducting eigenvalue and nonlinear analysis, has been used to develop the numerical model. The following assumptions are made when creating a model capable of processing these two analysis:

1. The I-joist acts as a composite beam consisting of two linear elastic materials;

2. The flanges are fully connected to the web, i.e. no slippage occurs at the flange to web connection;

3. Loads are conservative;

4. The support springs are linked to the ground with constant lateral rigidity.

For the Eigenvalue analysis, the following additional assumptions are also made:

5. The I-joist does not have initial imperfections; 
6. Pre-buckling deformations are neglected

\subsubsection{Joist dimensions}

The joist geometry for the sensitivity analysis was selected to be the larger of the two wood I-joist types investigated in this study. The cross section was $610 \mathrm{~mm}$ high with a top and bottom flange that measures $38 \mathrm{~mm}$ in thickness and $89 \mathrm{~mm}$ in width. The web consists of $11 \mathrm{~mm}$ thick plate. The joists length is $6096 \mathrm{~mm}$.

\subsubsection{Element type}

The OSB web linking the two flanges was modeled with shell type element S4R. This element has the ability to handle both thick and thin shells (Simulia 2014). It is a conventional stressdisplacement element with 4 nodes that uses reduced integration with hourglass control. It has 6 degrees of freedom per node (3 displacement and 3 rotation) for a total of 24 DOFs per element. The lumber flanges were modeled with 3D Stress solid element type C3D8R, which consists of an 8 node linear brick with reduced integration and hourglass control. Each node consists of 3 translational DOFs for a total of 24 DOFs per element.

\subsubsection{Mesh description}

The model was constructed using 240 elements along the lengths of the joist, 6 elements for the flanges thickness, 13 elements for the flange width and 21 for the web height. This element setup was sufficient to provide accurate estimate of the buckling load. This yields a 1:1 aspect ratio for the web elements, 1:1 for the flange cross-section aspect ratio and 4:1 for the flange's length elements.

At the nodes joining the web and flange elements, the degrees of freedom of the shell and solid elements are coupled using the ABAQUS feature "SHELL TO SOLID COUPLING". This feature enables the transfer of the translational degrees of freedom of the web shell elements to the solid elements located in the flanges. 


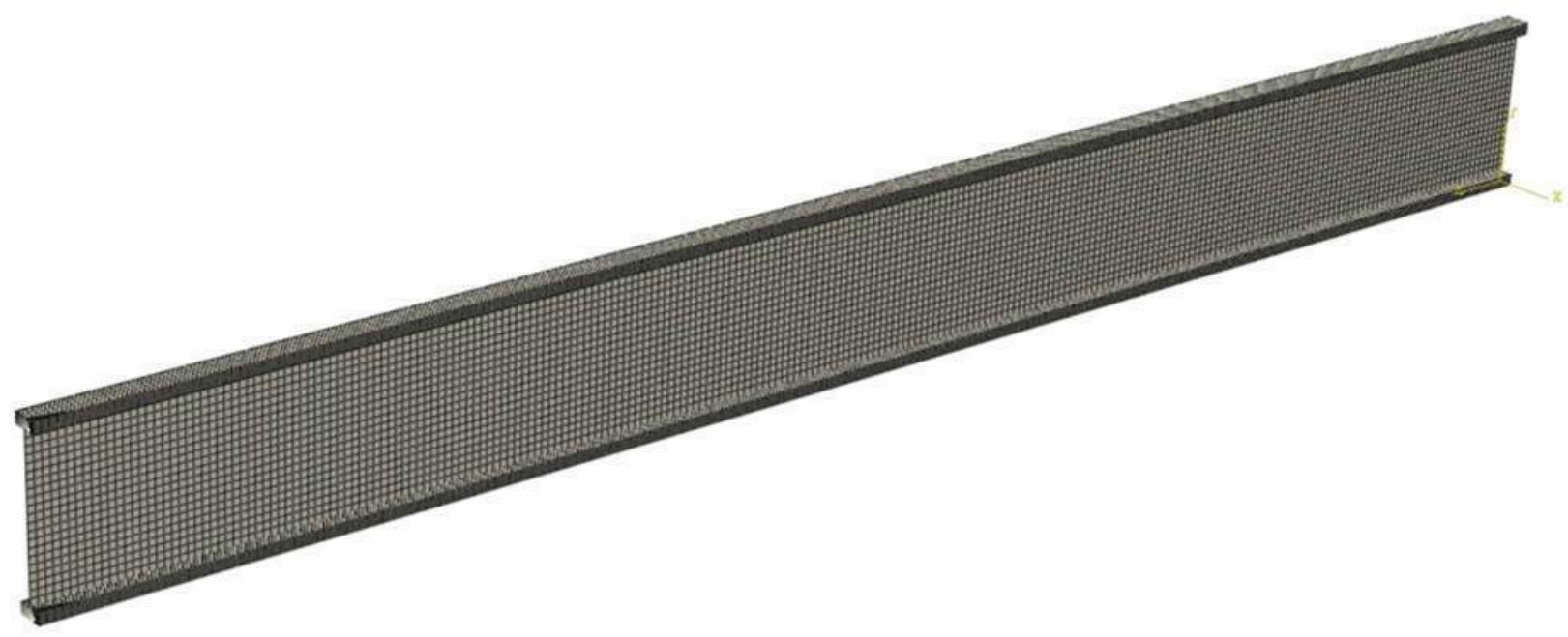

Figure 3-2 Finite element model mesh

\subsubsection{Material properties}

The I-joists considered in this study are composed of solid-sawn lumber for the flanges and oriented strand board (OSB) for the web. Both can be described as rectangular orthotropic materials, with unique and independent mechanical properties. The Engineering Constants feature in ABAQUS elastic properties is chosen since it can best describe the input values that are used in the model and can be formulated as:

$$
\left\{\begin{array}{l}
\varepsilon_{11} \\
\varepsilon_{22} \\
\varepsilon_{33} \\
\gamma_{12} \\
\gamma_{13} \\
\gamma_{23}
\end{array}\right\}=\left[\begin{array}{cccccc}
1 / E_{1} & v_{21} / E_{2} & v_{31} / E_{3} & 0 & 0 & 0 \\
v_{12} / E_{1} & 1 / E_{2} & v_{32} / E_{3} & 0 & 0 & 0 \\
v_{13} / E_{1} & v_{23} / E_{2} & 1 / E_{3} & 0 & 0 & 0 \\
0 & 0 & 0 & 1 / G_{12} & 0 & 0 \\
0 & 0 & 0 & 0 & 1 / G_{13} & 0 \\
0 & 0 & 0 & 0 & 0 & 1 / G_{23}
\end{array}\right]\left\{\begin{array}{c}
\sigma_{11} \\
\sigma_{22} \\
\sigma_{33} \\
\tau_{12} \\
\tau_{13} \\
\tau_{23}
\end{array}\right\}
$$

Where $\varepsilon$ is the normal strain, $\gamma$ is the shear strain, $E$ is the elastic modulus, $G$ is the shear modulus, $\sigma$ is the normal stress and $\tau$ is the shear stress about the principal axes 1,2 and 3 as illustrated in Figure 3-1.

The flanges consist of machine-stress rated (MSR) lumber with 2100Fb-1.8E grade. The modulus of elasticity in the longitudinal direction is $E_{1}=E=12,400 \mathrm{MPa}$ as given by the CSA-O86 (CSA 
2014). The lumber is longitudinally connected with finger joints however this detail is not included in the FE model since they are assumed to have no effect on the stiffness. It is well-established that the mechanical properties in the radial and tangential direction can be assumed to be identical (FPL 2010), thus $E_{2}=E_{3}=E_{T}, G_{12}=G_{13}, v_{12}=v_{13}$ and $v_{21}=v_{31}$. As a result, the wood flanges can be modelled as a transversely orthotropic material having a plane of isotropy about axes 2-3. Table 3-1 presents the material properties used in the sensitivity analysis. To obtain values of $E_{T}$, the shear modulus $G$ and the poisson's ratio $\mu$ for modeling purpose, the material properties were taken from the literature (FPL 2010) based on the Sitka Spruce species properties. The properties of the web are based on values found in literature (SBA 2004; Thomas 2001) as a Class O1 OSB panel.

Table 3-1 Material properties

\begin{tabular}{|c|c|c|c|c|c|c|c|c|c|}
\hline Parts & $\begin{array}{c}E_{1} \\
(\mathrm{MPa})\end{array}$ & $\begin{array}{c}E_{2} \\
(\mathrm{MPa})\end{array}$ & $\begin{array}{c}E_{3} \\
(\mathrm{MPa})\end{array}$ & $\mu_{12}$ & $\mu_{13}$ & $\mu_{23}$ & $\begin{array}{c}G_{12} \\
(\mathrm{MPa})\end{array}$ & $\begin{array}{c}G_{13} \\
(\mathrm{MPa})\end{array}$ & $\begin{array}{c}G_{23} \\
(\mathrm{MPa})\end{array}$ \\
\hline Flanges & 12400 & 750 & 750 & 0.37 & 0.45 & 0.45 & 775 & 775 & 37 \\
\hline Web & 1300 & 4500 & 1300 & 0.20 & 0.20 & 0.20 & 100 & 100 & 100 \\
\hline
\end{tabular}

Related to the current study, it is important to mention that St-Amour (2016) has conducted a sensitivity analysis on the influence of the material properties of engineered wooden I-joist on the buckling load. The analysis was conducted using a beam with simply supported end condition subjected to an uniform moment about its strong axis. The FE model response was analyzed as its material properties were changed from $50 \%$ to $150 \%$ for each parameter, while all other parameters were kept constant. The procedure was repeated with parameters $(E, G$ and $\mu)$ for the top and bottom flanges as well as the web. It was found that the elastic modulus along the longitudinal direction of the top flange has the most influence on the buckling load followed by the elastic modulus along the longitudinal direction of the bottom flange and by the shear moduli $G_{13}$ and $G_{12}$ for both flanges. Material properties for the web did not have a significant impact on the buckling load. 


\subsubsection{Boundary conditions}

The boundary conditions for the reference configuration is simply supported at both ends. The lateral movement of the top and bottom flanges are restraint by a support node on the top and bottom face respectively. The flanges are free to rotate about axis 2 as well as twist about their own longitudinal axis (axis 1).

The lateral rigidity of the spring acting as support for each flange can be investigated by replacing the node acting as lateral support by a spring using the "connect point to the ground" feature in ABAQUS in the lateral direction. Four lateral spring stiffnesses were investigated for each flange, namely 10, 35, 75 and $150 \mathrm{~N} / \mathrm{mm}$. Those stiffness values were taken from the lateral displacement stiffness tests on the joists hangers done by Aguilar (2013) for both the top- and face-mounted hangers.

The rotational restraint of each flanges was verified for two rotational degrees of freedom (DOF): the rotation along the section's weak axis and the torsion of the flanges along their own longitudinal axis. Each rotational DOF fixity was analyzed independently and simultaneously for the top and bottom flanges to investigate their effect on the buckling load of the beam. The rotational fixity can be tested by adding a longitudinal support or a vertical support on each side of the flanges at their ends to study the effect of weak axis rotation and torsion respectively. Figure 3-3 shows the location of the flange rotational fixity support as modeled in ABAQUS. 


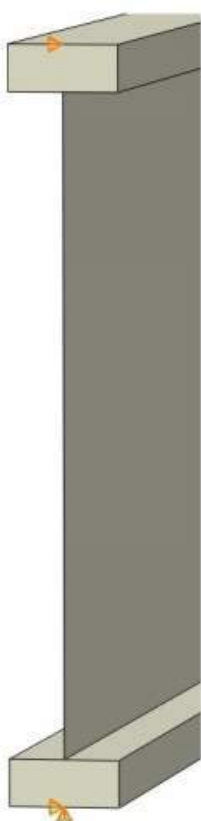

a)

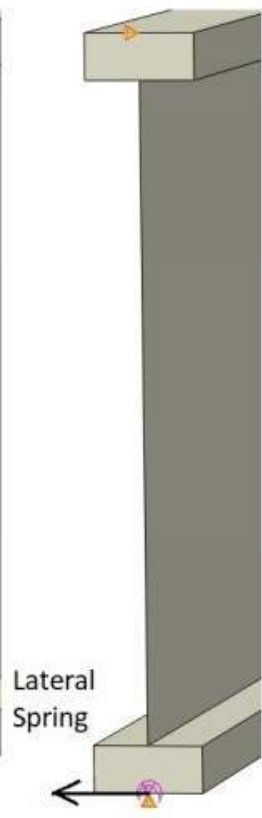

b)

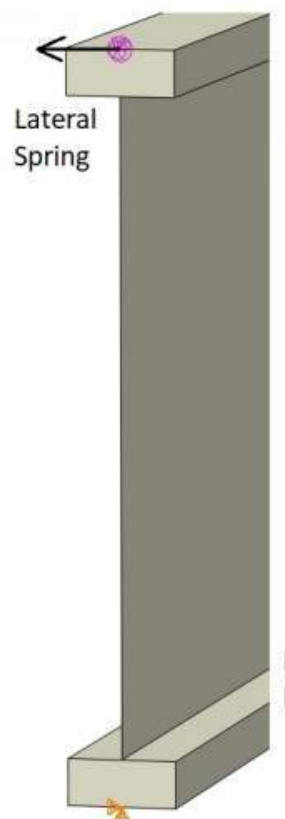

c)

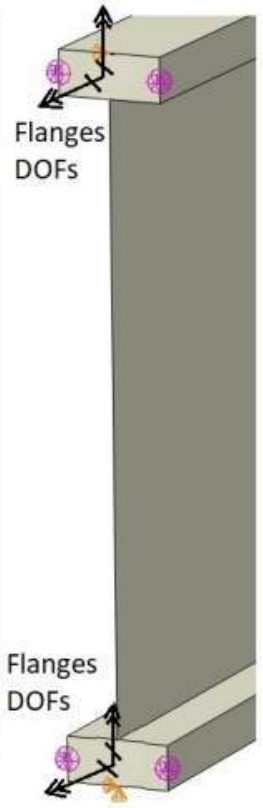

d)

Figure 3-3 Sensitivity analysis on boundary conditions

a) Simply supported conditions, b) Lateral spring on bottom flange,

c) Lateral spring on top flange, d) Rotational fixity on top and bottom flange.

\subsubsection{Load Application}

The load applied on the section was uniform moment about the strong axis. To apply a uniform moment about the strong axis, axial loads were applied at both flanges (Figure 3-4). The wood Ijoist self-weight is assumed to be negligible compared to the buckling load, and was therefore neglected in the FE buckling analysis. 


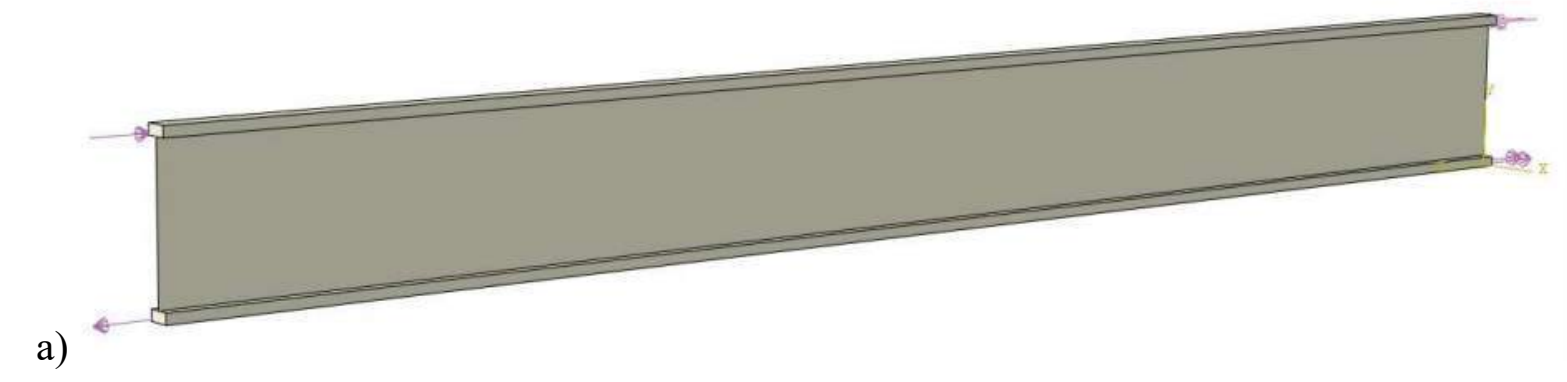

b)

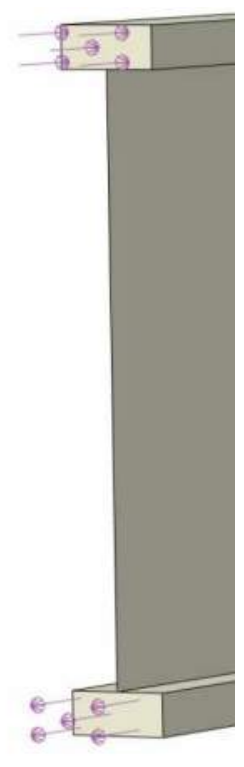

Figure 3-4 Load application at each end - a) global and b) detailed view

\subsubsection{Eigenvalue buckling analysis}

An eigenvalue buckling analysis is used to conduct the sensitivity study on the material properties. It evaluates the critical load at which the wood I-joist undergoes lateral-torsional buckling. To determine the critical load, the smallest eigenvalue $\lambda_{i}$ is sought for which Equation 3-2 has nontrivial solutions:

$$
\left(\left[K^{*}\right]+\lambda_{i}\left[K_{G}\right]\right)\left(v_{i}\right)=0
$$

Where $\left[\mathrm{K}^{*}\right]$ denotes the stiffness matrix, $\left[\mathrm{K}_{\mathrm{G}}\right]$ is the geometric matrix and $\left(v_{\mathrm{i}}\right)$ is the nodal displacement vector of mode shape $i$. 


\subsubsection{Nonlinear Analysis}

The ABAQUS software uses the RIKS increment methods derived from the Newton-Raphson method to compute the nonlinear response of a system (Simulia 2014). Nonlinear analysis is characterized by a nonlinear response of a given system where the structure's stiffness varies with respect to the displacement. To obtain such nonlinear response, a geometric imperfection must be induce in the system. The amount of initial imperfections has an impact on the nonlinear response. To assess this effect, a sensitivity analysis was conducted using various out-of-straightness magnitudes of the top flange. Analyses for 2, 8, 15 and $25 \mathrm{~mm}$ initial imperfection were undertaken and the lateral displacement of the section and the overall rotation were computed.

\subsection{Results of the sensitivity analysis}

\subsubsection{Validation of theoretical solution}

The critical buckling moment for an I-section can be determined using the closed form solution presented in Equation 3-2 and the classical solution presented in Equation 1-2. Assuming the

reference case to have $E_{\text {flange }}=12400 \mathrm{MPa}, G_{\text {flange }}=775 \mathrm{MPa}, E_{w e b}=4500 \mathrm{MPa}, G_{w e b}=100$ $M P a$, and using the transformed section properties ( $\mathrm{Du} 2016$ ) to obtained a similar homogeneous section properties, the resulting critical moment computed by the classical solution was found to be $6.75 \mathrm{kNm}$. The resulting critical moment for the reference case predicted by the FE model is $6.13 \mathrm{kNm}$. The critical moment computed with the theoretical solution is $10 \%$ higher than the one predicted by the finite element model. This variation can be attributed to the fact that the finite element model includes shear deformations and distortion of the web.

\subsubsection{Results of the varying lateral stiffness}

This section presents the results of the sensitivity analysis where varying rigidity in the boundary connections was investigated. As a reference case, a wood I-joist with simply supported boundary conditions, cross section dimensions outline in section 3.2.1, material properties defined in Table 3-1 and a length of $6096 \mathrm{~mm}$ was considered. The joist was assumed to be subjected to a uniform 
moment about the strong axis. The resulting critical moment for the reference case predicted by the FE model was $6.13 \mathrm{kNm}$. The FE model response is analyzed as the lateral support for each flange is modified with specified spring stiffness while all other parameters were kept constant. This procedure is repeated with all spring stiffness evaluated in section 3.2.5 for both the top and bottom flange. The results of the sensitivity analysis are presented in Table 3-2. From the results the following conclusions can be drawn:

- The lateral support stiffness of the top flange has the most influence on the LTB critical load. Up to $14 \%$ reduction in the LTB load can be observed in the range of stiffness values tested.

- The lateral support stiffness of the bottom flange has little to no influence on the LTB critical load.

Table 3-2 Finite element model response to support lateral stiffness variations

\begin{tabular}{|c|c|c|c|}
\cline { 2 - 4 } \multicolumn{1}{c|}{} & Top Flange & Bottom Flange & Mcr / Mcr-Ref \\
\hline $\begin{array}{c}\text { Simply Supported } \\
\text { (Reference case) }\end{array}$ & FS & FS & 1.000 \\
\hline \multirow{3}{*}{$\begin{array}{c}\text { Top Flange } \\
\text { Lateral Spring }\end{array}$} & 10 & FS & 0.86 \\
\cline { 2 - 4 } & 35 & FS & 0.95 \\
\cline { 2 - 4 } & 75 & FS & 0.98 \\
\hline \multirow{3}{*}{$\begin{array}{c}\text { Bottom Flange } \\
\text { Lateral Spring }\end{array}$} & FS & 10 & 0.99 \\
\cline { 2 - 4 } & FS & 35 & 1.00 \\
\cline { 2 - 4 } & FS & 75 & 1.00 \\
\cline { 2 - 4 } & 150 & 1.00 \\
\hline
\end{tabular}

*FS = Fully Supported

The lateral support stiffness of the top flange is further investigated by expanding the stiffness range from 0.1 to $1000 \mathrm{~N} / \mathrm{mm}$ as shown in Figure 3-5. It can be observed that if lateral stiffnesses of top flange support lower than those tested are considered, they can have a significant impact on the buckling load of a section. 


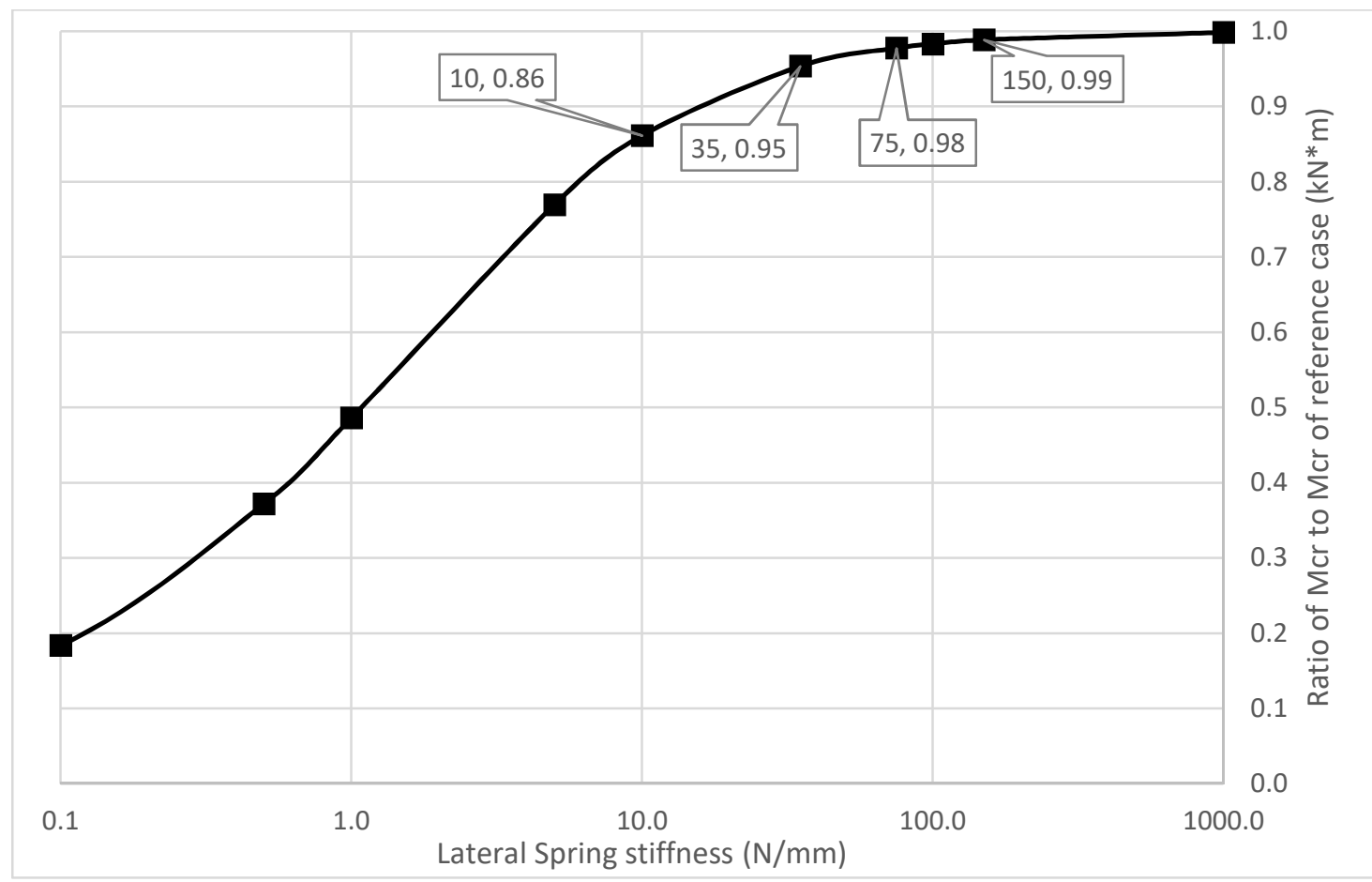

Figure 3-5 Response of the critical moment to top flange support lateral stiffness

The results of the sensitivity analysis investigating the effect of the rotational fixity of the flanges are presented in Table 3-3. It is observed that the critical moment is:

- Highly sensitive to the top flange rotational stiffness about the section weak axis;

- Slightly sensitive to the top flange torsional stiffness about its longitudinal axis;

- Not sensitive to the bottom flange rotational stiffness about the section weak axis;

- Slightly sensitive to the bottom flange torsional stiffness about its longitudinal axis; 
Table 3-3 Finite element model response to rotation fixity of the flanges

\begin{tabular}{|c|c|c|}
\hline & & Mcr / Mcr-Ref \\
\hline $\begin{array}{c}\text { Simply Supported } \\
\text { (Reference case) }\end{array}$ & All DOF Free & 1.00 \\
\hline \multirow{3}{*}{ Top Flange Fixity } & Section Weak Axis & 1.28 \\
\hline & Torsion & 1.02 \\
\hline & Both & 1.3 \\
\hline \multirow{3}{*}{$\begin{array}{l}\text { Bottom Flange } \\
\text { Fixity }\end{array}$} & Section Weak Axis & 1.00 \\
\hline & Torsion & 1.03 \\
\hline & Both & 1.03 \\
\hline \multirow{3}{*}{$\begin{array}{l}\text { Top And Bottom } \\
\text { Flanges Fixity }\end{array}$} & Section Weak Axis & 1.28 \\
\hline & Torsion & 1.06 \\
\hline & Both & 1.35 \\
\hline
\end{tabular}

\subsubsection{Results of nonlinear analysis for joists with initial imperfections}

The results of the sensitivity analysis on the wood I-joists with varying levels of initial lateral imperfection are shown in Figure 3-6 and Figure 3-7. The top flange imperfection of the joists has a significant influence on the applied moment, lateral deflection and rotation of the joist. A greater out-of-straightness yielded reduced initial geometric stiffness and tends to show higher lateral displacement and twist at lower bending capacity. This decrease in the member resistance can affect the serviceability limits of a beam during loading. 


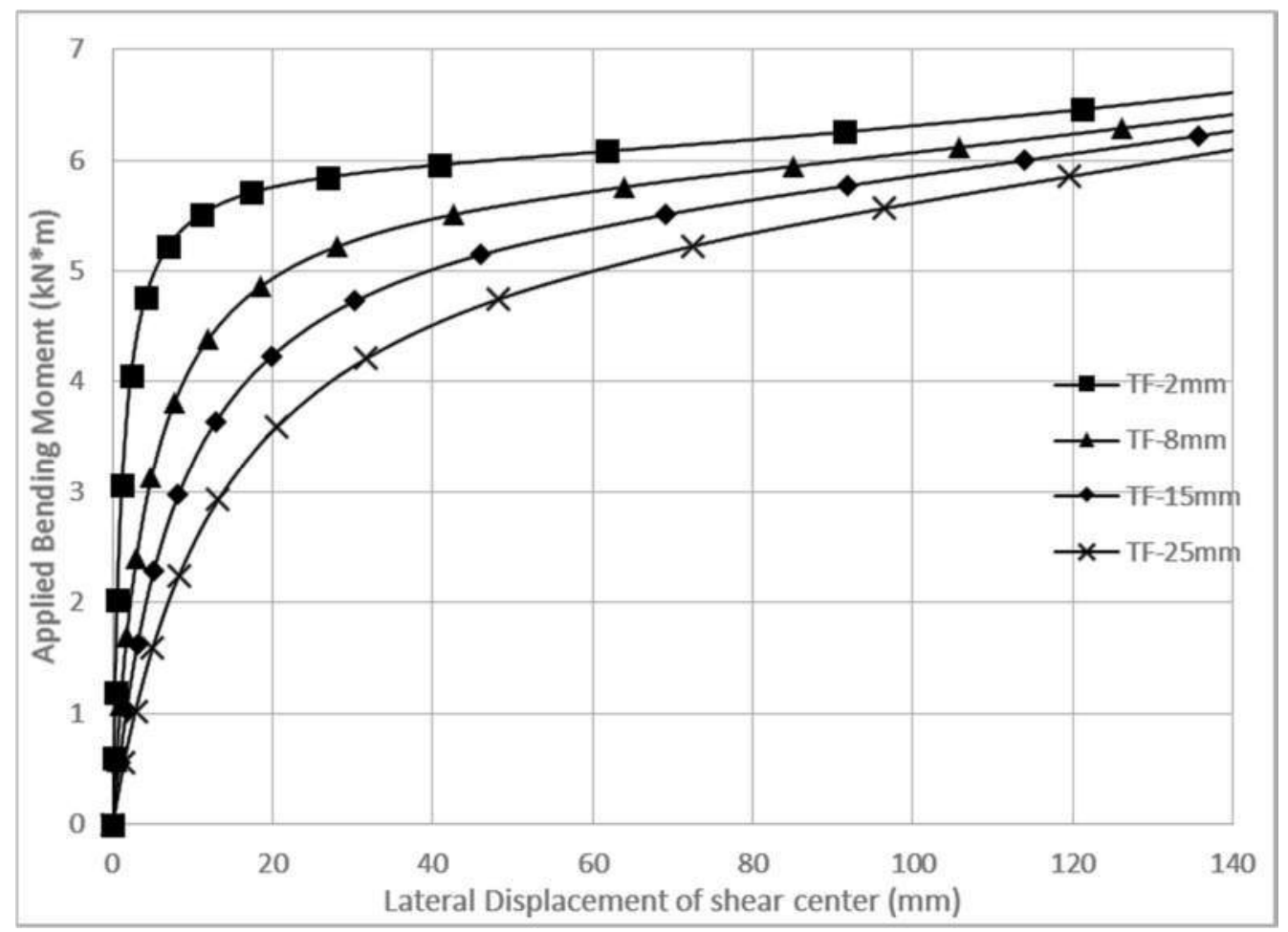

Figure 3-6 Lateral displacement of the shear center with top flange imperfection

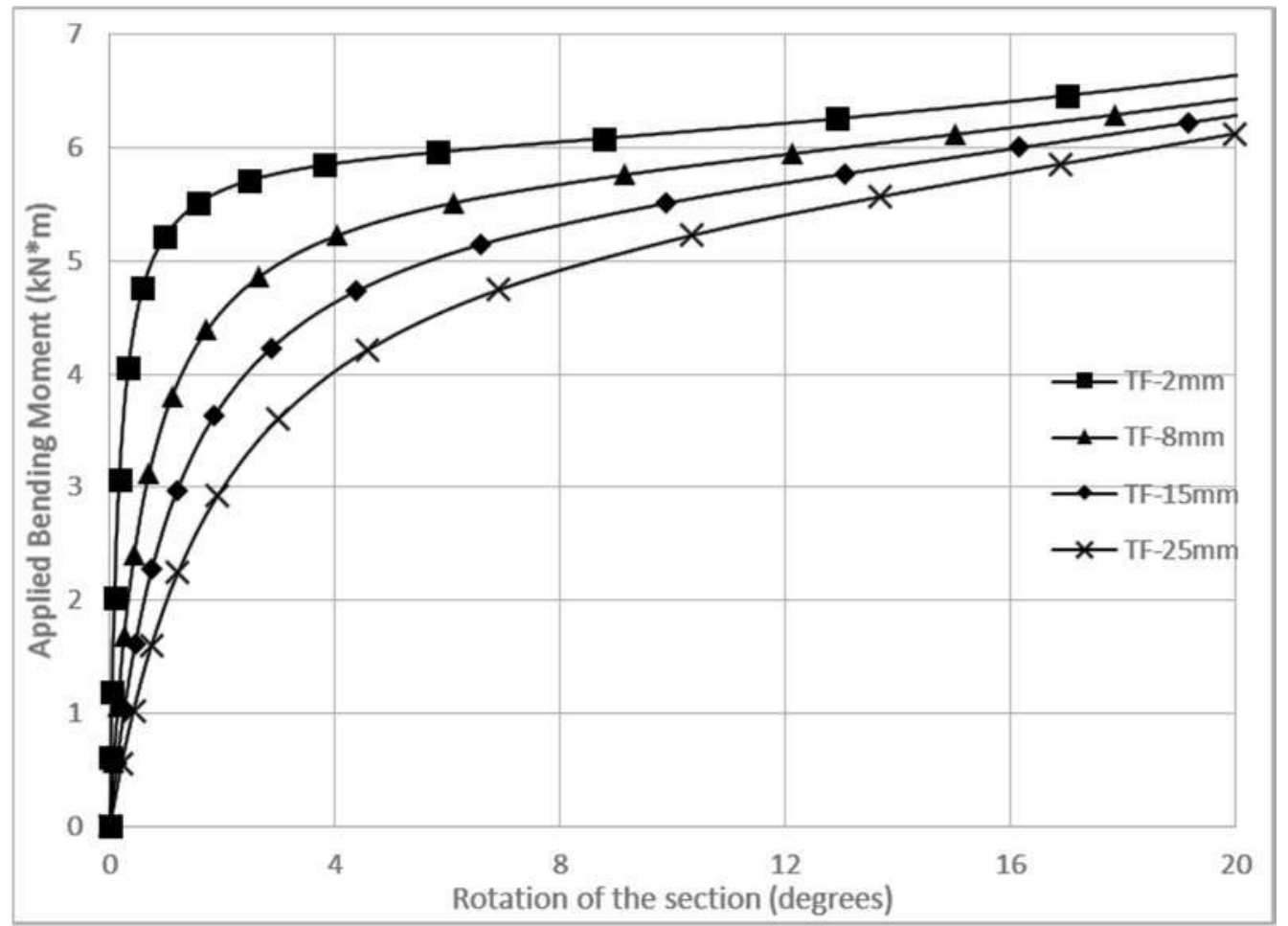

Figure 3-7 Rotation of section about the shear center with top flange imperfection 


\section{CHAPTER 4}

\section{Experimental Program}

As discussed in Chapter 3, the I-joist's lateral torsional buckling capacity is mostly dependant on the flanges' longitudinal modulus of elasticity $\left(E_{L}\right)$ and shear modulus in the transversal direction $\left(G_{t}\right)$, the web elastic modulus in the parallel and transverse to grain directions and the longitudinal and lateral stiffness of the end conditions.

This chapter presents the I-joist test specimen descriptions and provides details on the experimental program adopted in this study. An explanation of the test methods used to quantify the mechanical properties of the joists components, the lateral-torsional buckling critical loads and behavior of the I-joists associated with various end conditions are also provided.

\subsection{Specimen description}

Two different engineered wood I-joist cross-sections were used in this study. They were manufactured with machine stress rated (MSR) lumber flanges and oriented strand board (OSB) webs connected together with a waterproof structural adhesive (Cascade 2014). Glued finger joints and tongue-and-groove joints ensured continuity in the I-joist' flanges and between web and flanges, respectively. Figure 4-1 illustrates the two I-joist cross sectional dimensions investigated. The engineered I-joists were received at a length of $6.1 \mathrm{~m}$. Some of the $0.4 \mathrm{~m}$ deep I-joists were cut at $4.88 \mathrm{~m}$ in length to keep a smaller span-to-depth ratio. Table 4-1 presents the number of I-joists tested for each section along with span length. I-joist specimens' moisture content was measured and is also presented along with the coefficient of variation in the Table 4-1. The specimens were stored in the laboratory so their temperature and relative humidity were acclimatized to the lab environment. 
Table 4-1: Wood I-joist specimen breakdown and moisture content

\begin{tabular}{|c|c|c|c|c|c|}
\hline $\begin{array}{c}\text { Sample } \\
\text { Group \# }\end{array}$ & $\begin{array}{c}\text { Span } \\
\text { Length } \\
\text { (m) }\end{array}$ & $\begin{array}{c}\text { I-Joist } \\
\text { Section }\end{array}$ & $\begin{array}{c}\text { Number } \\
\text { of } \\
\text { specimens }\end{array}$ & $\begin{array}{c}\text { Average } \\
\text { Moisture } \\
\text { Content }\end{array}$ & $\begin{array}{c}\text { CoV } \\
\text { (\%) }\end{array}$ \\
\hline A & 4.6 & $0.4 \mathrm{~m}$ & 18 & 12.7 & 7.1 \\
\hline B & 5.8 & $0.6 \mathrm{~m}$ & 23 & 15.3 & 4.1 \\
\hline
\end{tabular}

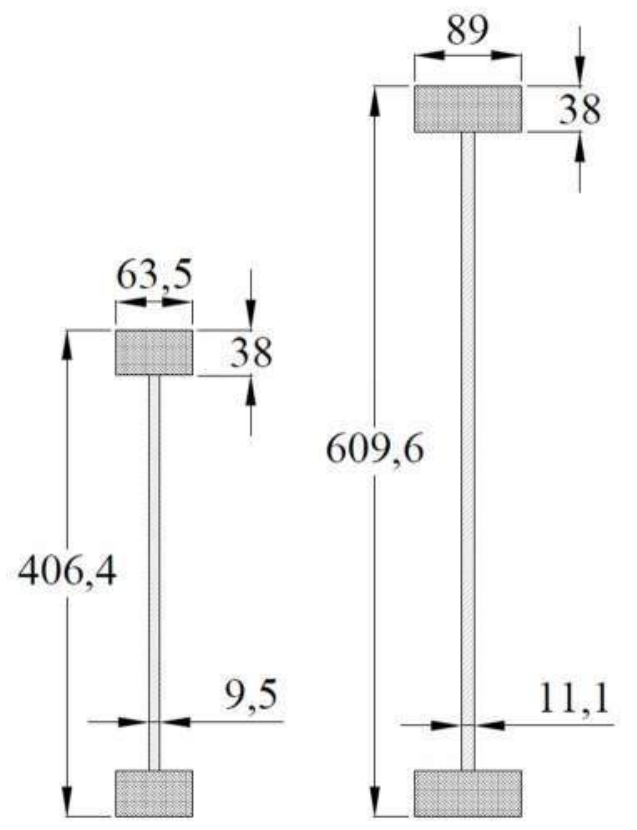

Figure 4-1 I-joist cross-section dimensions (mm) 


\subsection{Test program}

The test program consisted of two phases. The first phase included an experimental investigation of the critical lateral-torsional buckling loads and behavior of the engineered wood specimens associated with different boundary conditions. The second phase included component testing to determine the mechanical properties to be used in the finite element model. The test program is summarized in Table 4-2 and includes full scale testing of I-joists with various lengths and boundary conditions, determination of the longitudinal modulus of elasticity of the flange $\left(E_{f l}\right)$, the torsional shear modulus of the flange $\left(G_{t}\right)$, the transverse modulus of elasticity of the web $\left(E_{w t}\right)$, and the lateral rigidity of selected joists hangers.

\subsubsection{Lateral-torsional buckling capacity}

The lateral-torsional buckling capacity was evaluated by applying a concentrate load at mid span on the specimen's bottom flange as illustrated in Figure 4-2 to Figure 4-5. The load is applied by a cable and pulley system developed by the author specifically for this project. One end of the cable is attached to an HSS frame anchored to the lab's floor while the other is attached to a hydraulic jack via a load cell to record the applied tension in the cable. The pulley was attached to the underside of the flange by a series of shackles acting as hinges. This setup also enables continuous application of the vertical load while also allowing the bottom flange to displace laterally with minimal lateral restraint. As the joist displaces laterally and twists, the angle of the cable will vary and adjustment to the vertical load must be included in the analysis. This is possible because the geometry of the test setup is fully known as any time during the test.

Table 4-2 Test Program

1. Non-destructive lateral-torsional buckling test with Simply Supported End Conditions 10 specimens of the sample group $A$

12 specimens of the sample group $B$

44 tests

2 repeats per specimen 


\begin{tabular}{|c|c|}
\hline \multicolumn{2}{|c|}{ 2. Destructive lateral-torsional buckling test with Simply Supported End Conditions } \\
\hline 6 specimens of the sample group $A$ & \multirow{3}{*}{26 tests } \\
\hline 7 specimens of the sample group B & \\
\hline 1 non-destructive test and 1 destructive test per specimen & \\
\hline \multicolumn{2}{|l|}{ 3. Destructive lateral-torsional buckling test with Top Mounted Hangers } \\
\hline 4 specimens of the sample group $A$ & \multirow{3}{*}{20 tests } \\
\hline 6 specimens of the sample group B & \\
\hline 1 non-destructive test and 1 destructive test per specimen & \\
\hline \multicolumn{2}{|l|}{ 4. Destructive lateral-torsional buckling test with Face Mounted Hangers } \\
\hline 4 specimens of the sample group $A$ & \multirow{3}{*}{16 tests } \\
\hline 4 specimens of the sample group B & \\
\hline 1 non-destructive test and 1 destructive test per specimen & \\
\hline \multicolumn{2}{|l|}{ 5. Destructive lateral-torsional buckling test with increased fixity connectors } \\
\hline 4 specimens of the sample group $A$ & \multirow{3}{*}{20 tests } \\
\hline 6 specimens of the sample group B & \\
\hline 1 non-destructive test and 1 destructive test per specimen & \\
\hline \multicolumn{2}{|l|}{ 6. Non-destructive flange torsional shear modulus test } \\
\hline Include the flanges of 15 specimens of the sample group $A$ & \multirow{3}{*}{62 tests } \\
\hline Include the flanges of 16 specimens of the sample group B & \\
\hline 1 repeat per specimen & \\
\hline \multicolumn{2}{|l|}{ 7. Destructive flange modulus of elasticity tests } \\
\hline Same flanges of group A and B used for the hear modulus test & \multirow{2}{*}{124 tests } \\
\hline 2 repeats per specimen ( 1 on each side) & \\
\hline \multicolumn{2}{|l|}{ 8. Destructive web transverse modulus of elasticity test } \\
\hline Webs of same joists of group A and B as flanges tests & 31 tests \\
\hline \multicolumn{2}{|l|}{ 9. Non-Destructive lateral bending stiffness of Top Mounted hanger tests } \\
\hline 1 specimens of for all Top Mounted hangers & \multirow{2}{*}{8 tests } \\
\hline 2 repeats per specimen ( 1 on each side) & \\
\hline
\end{tabular}

The vertical displacement at mid-span and the lateral displacement of the top and bottom flanges at mid-span were recorded using wire sensors at each location. The angles of rotation of the top and bottom flanges were recorded with inclinometers placed at mid-span on the top and bottom of each respective flange. 


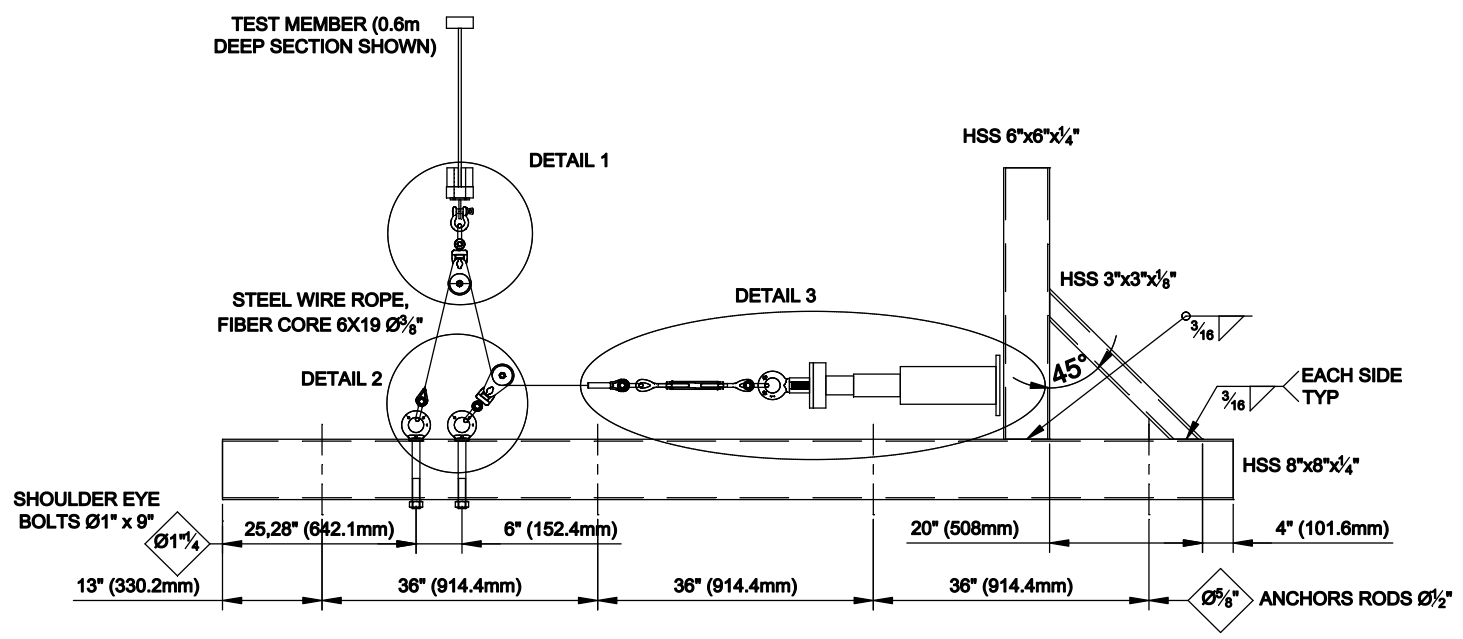

Figure 4-2 General Test Assembly at Mid-Span

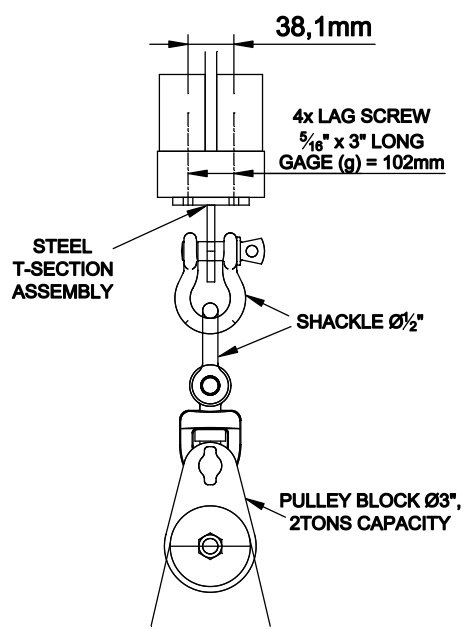

DETAIL 1

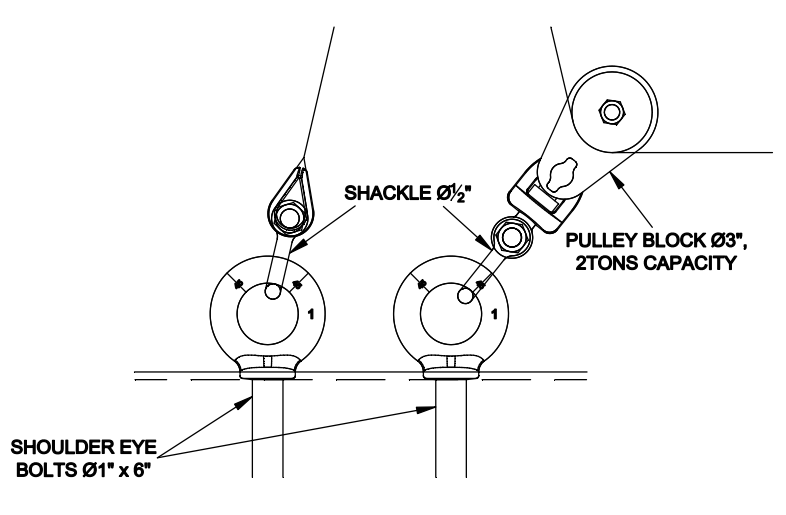

DETAIL 2

Figure 4-3 Detail 1 and Detail 2 of General Assembly 


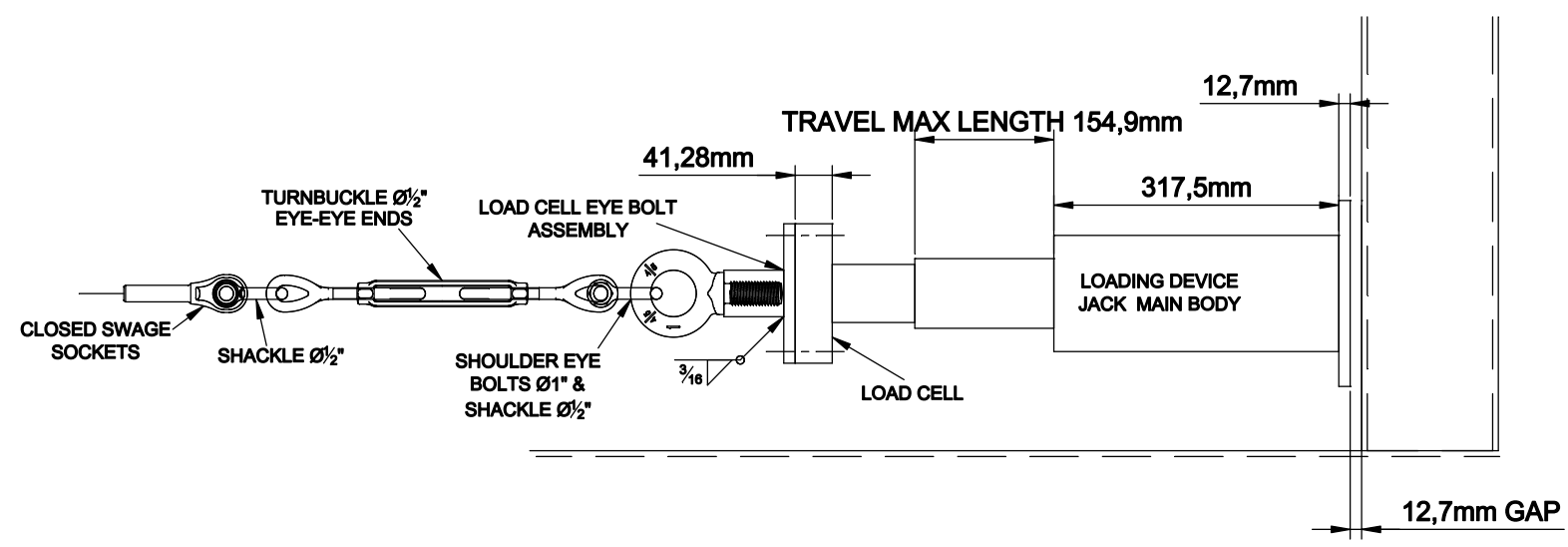

DETAIL 3

Figure 4-4 Detail 3 of General Assembly

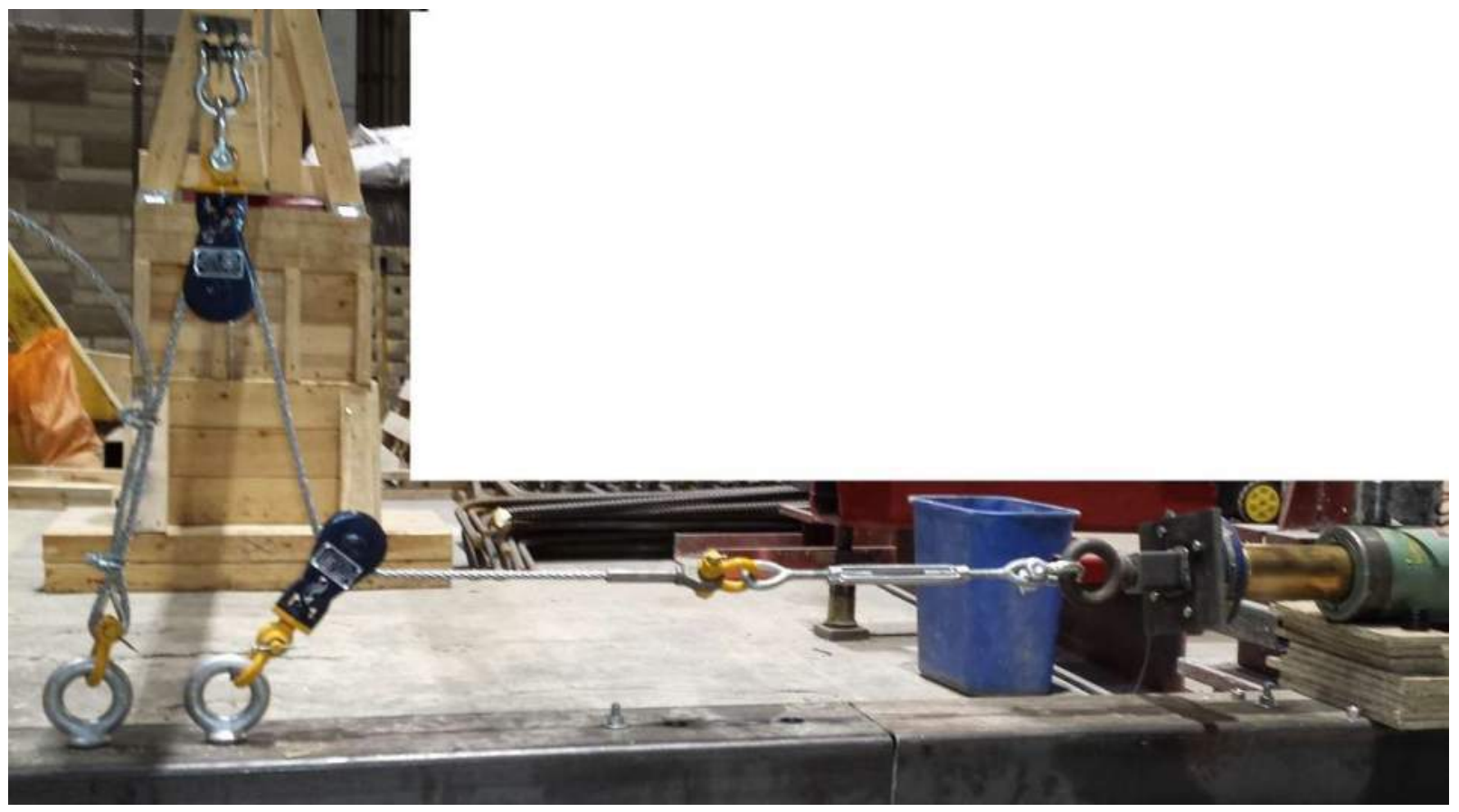

Figure 4-5 Experimental setup assembly.

Figure 4-5 was intentionally cut and cropped to emphasize the equipment assembly. 
Each joist end was supported by an elevated wood support, on which the chosen boundary conditions were enforced (Figure 4-6). Once set in the desired boundary condition setup, the initial out-of-straightness of the joists was documented using a self-leveling laser. Each specimen was subjected to two loading cycles. For the first cycle, the load was applied to the beam until the buckling of the section occurs and then the load is released when the measured lateral displacement of the top flange reached $120 \mathrm{~mm}$ in order to remain within the elastic deformation range. For the second loading cycle, the load was applied to the joists until buckling was attained.

The end supports were divided in 3 categories depending on the boundary conditions to be tested: simply supported, commercials available joists hangers and enhanced fixity connections. A complete set of drawing for each boundary condition categories can be found in Appendix A.

The first category of support used was designed to simulate simply supported reference case, where it is assumed that the vertical displacement, lateral displacement and rotation about the longitudinal axis are restrained. The longitudinal displacement of the joists, rotation about the strong and weak axis and distortion of the section are assumed to be free. The supports were designed so that they are easily built and replaced when needed as illustrated in Figure 4-7. The wooden frame consisted of $19 \mathrm{~mm} \times 89 \mathrm{~mm}$ lumber pieces with a 90mm opening reinforced with 2 diagonals $38 \mathrm{~mm} \times 89 \mathrm{~mm}$ elements on each side to prevent the distortion due to the rotation of the section. The joists were seated on top of a $102 \mathrm{~mm} \times 90 \mathrm{~mm} \times 6 \mathrm{~mm}$ aluminium plate to meet the requirements for bearing length set by the manufacturer. 

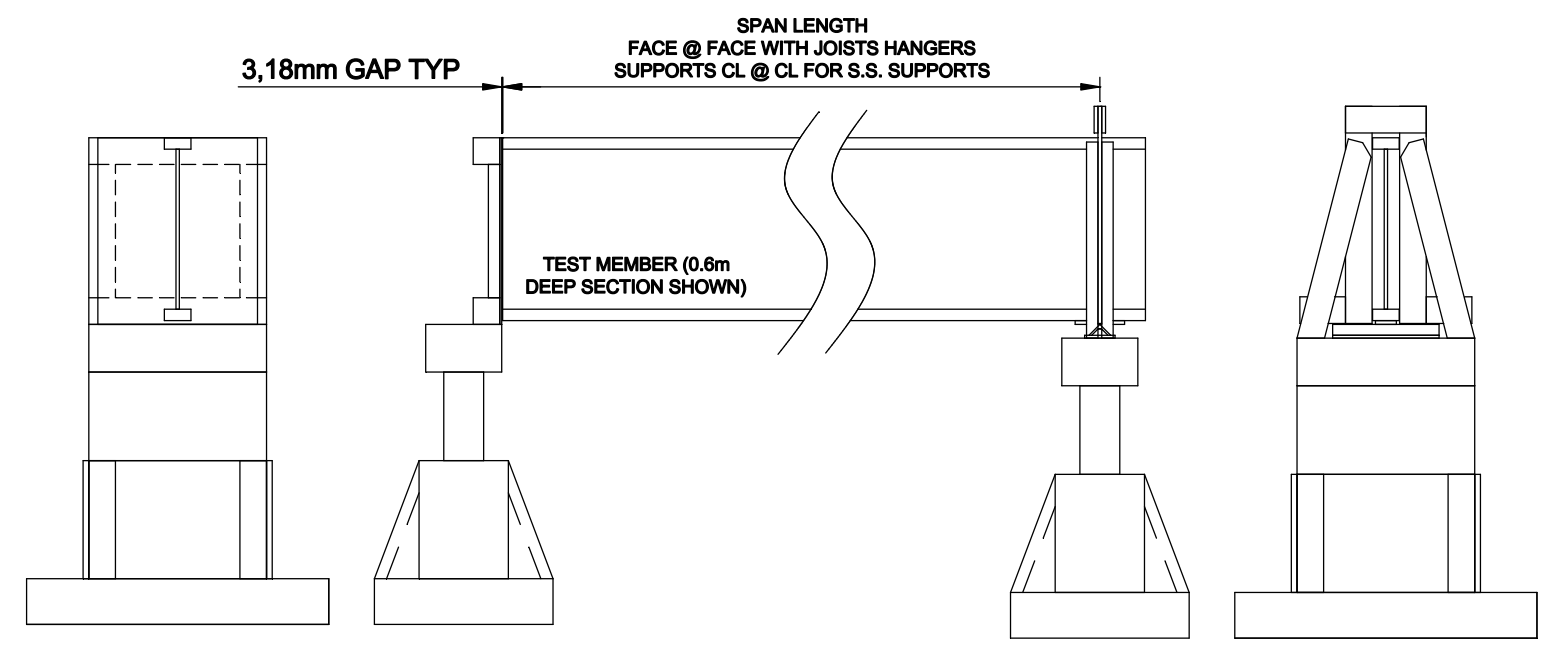

a)

b)

Figure 4-6 Elevation and Side View of Joists Length with a) Joists Hangers panels b) Simply Supported Condition

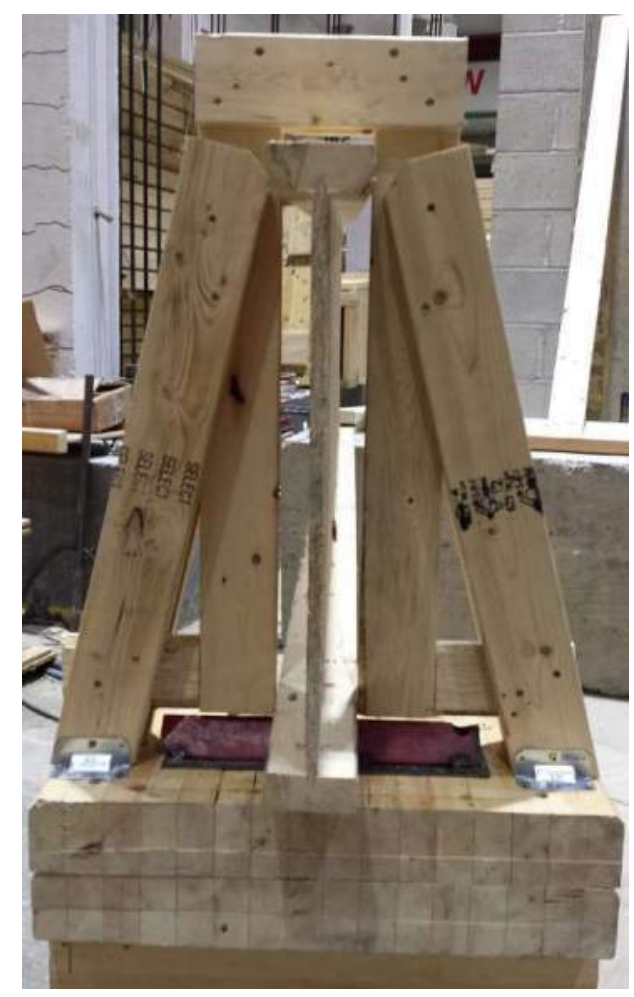

Figure 4-7 Simply Supported joists support 
Simpsons Strong-Tie products were selected (Figure 4-8) due to their wide availability in the market. The hangers were classified into 2 categories; namely face mounted and top mounted hangers. Table 4-3 describe the hangers' types used for each joist section. To simulate the support conditions for the hangers, small wood panels were constructed to fit the hangers' type. Both panel types consisted of $11 \mathrm{~mm}$ OSB as the face panel and $38 \mathrm{~mm} \times 89 \mathrm{~mm}$ lumber as side frame. $89 \mathrm{~mm}$ $\mathrm{x} 89 \mathrm{~mm}$ lumber pieces were used at the top to ensure enough nailing material on both the top and front face of the top mounted hangers. For the face mounted hangers, $38 \mathrm{~mm}$ x $89 \mathrm{~mm}$ lumber pieces were used to act as studs for nailing material. The wall panels were fixed to the elevated supports on each side. The hangers were fixed to the support with $16 \mathrm{~d}, 89 \mathrm{~mm}$ long nails as specified by the manufacturer. For stability purpose, some joists hangers required the joists to be nailed with 10d, $38 \mathrm{~mm}$ long joist nails on the bottom flange via lateral holes provided.

Table 4-3 I-joists hangers' type

\begin{tabular}{|c|c|c|}
\cline { 2 - 3 } \multicolumn{1}{c|}{} & \multicolumn{2}{c|}{ Section depth } \\
\cline { 2 - 3 } Face & $\mathbf{0 . 4} \mathbf{~ m}$ & $\mathbf{0 . 6} \mathbf{~ m}$ \\
\cline { 2 - 3 } Mounted & $\mathrm{IUS} 2.56 / 16$ & $\mathrm{MIU} 3.56 / 20$ \\
\cline { 2 - 3 } $\begin{array}{c}\text { Top } \\
\text { Mounted }\end{array}$ & HU316 & $\mathrm{IUS} 3.56 / 16$ \\
\cline { 3 - 3 } & & HIT424 \\
\cline { 3 - 3 } & & HWI424 \\
\cline { 2 - 3 } & & HB3.56/24 \\
\hline
\end{tabular}




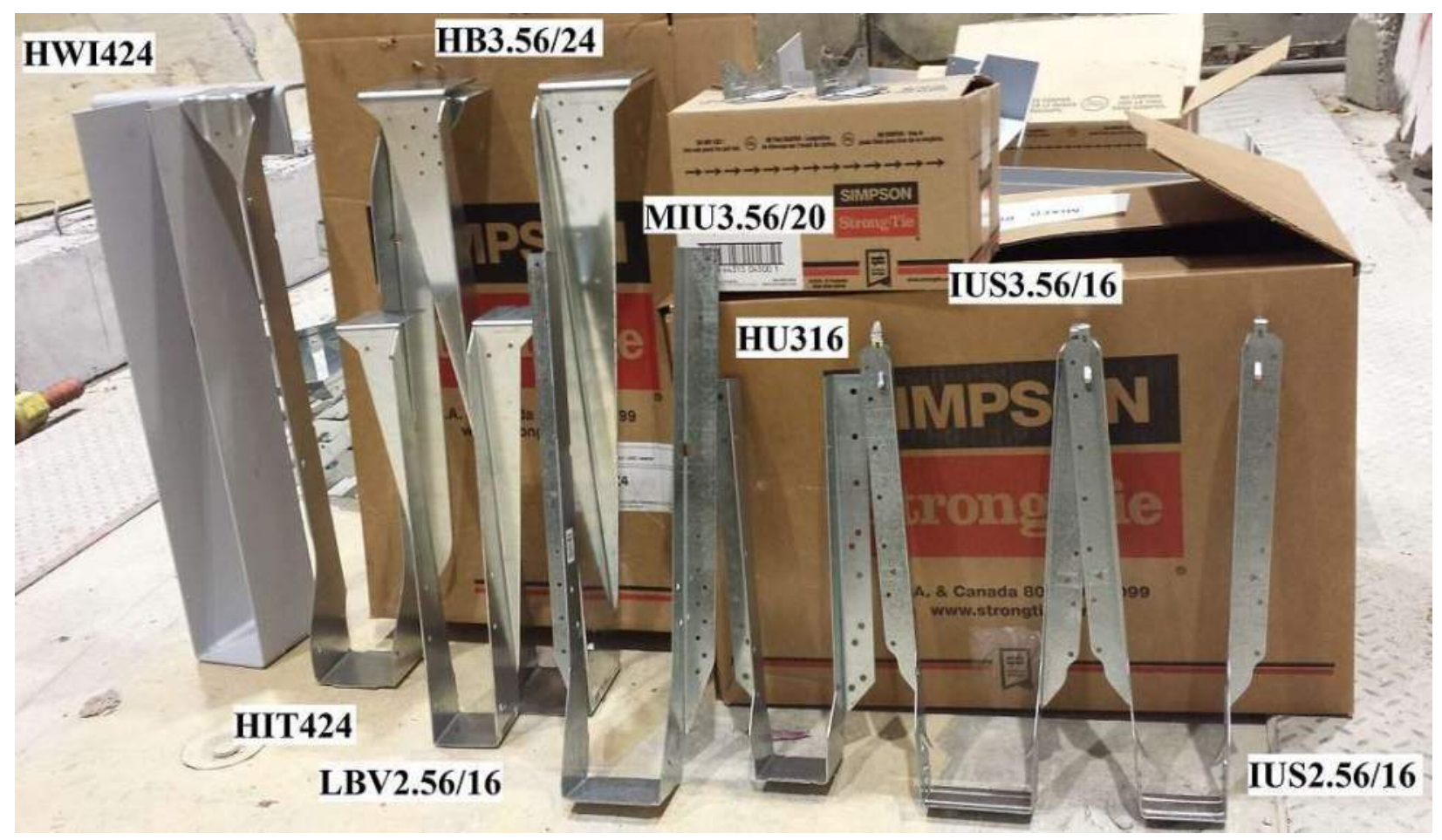

Figure 4-8 Simpson Strong-tie hangers

The third category of supports were the rotationally enhanced connections. Three connector designs were evaluated to investigate the effect of the joists enhanced fixity of their flanges at each end on the buckling behavior and critical load. The first design was taken from the joists manufacturer guide (Cascade 2014) where it is suggested to nail the joists directly to the wooden rim-board or wall. The bottom flange was fixed to the supports by two $12 \mathrm{~d}$ common nails driven through its top face to attain rotational and lateral retrain. The top flange was nailed through the wall and parallel to the grain in the flange with two $89 \mathrm{~mm}$ long $16 \mathrm{~d}$ common nails (Figure 4-9). The wall panel used in this connection was similar to the one used in the face mounted hangers without the vertical stud. The second design could only be tested on the $0.6 \mathrm{~m}$ deep joists since it resulted in a modification to the HWI424 top mounted hangers. To prevent any lateral displacements, a steel plate was welded on each side of the hanger, aligned with the bottom flange. Holes were drilled in the plate to allow nailing to the wall. To prevent the rotation relative to the weak axis of the section, six holes (three on each sides) were installed in the hanger and aligned with each flange. $38 \mathrm{~mm}$ long screws were used to connect the hanger to the joists (Figure 4-10). The same wall panels as that used for the top mounted hangers were used in this test setup. 
The third connection was intended to create high level of fixity on the rotational degree of freedom of the top flange. The bottom flange was therefore attached to the support by two $50 \mathrm{~mm} \times 50 \mathrm{~mm}$ x $6 \mathrm{~mm}$ angles at each end. Six $38 \mathrm{~mm}$ screws (three per flange side) were used to limit the rotation and translation. The top flange was secured in place using two $76 \mathrm{~mm} \times 76 \mathrm{~mm} \times 6 \mathrm{~mm}$ angles on each panel and by gripping the flange between the angles using two steel threaded rods. Figure 4-10 illustrates the connection details.

Table 4-4 and Table 4-5 list the combination of joists and connectors / hangers that were tested for all sample groups.

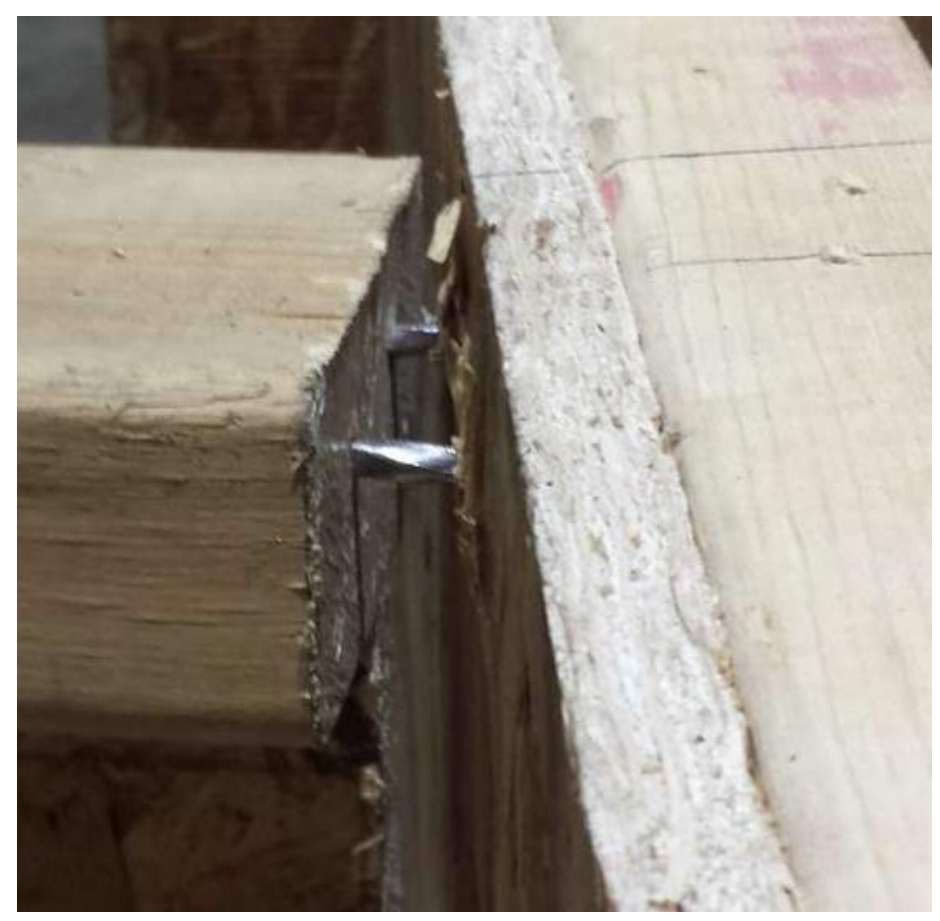

Figure 4-9 Nailed-to-Board Connection 

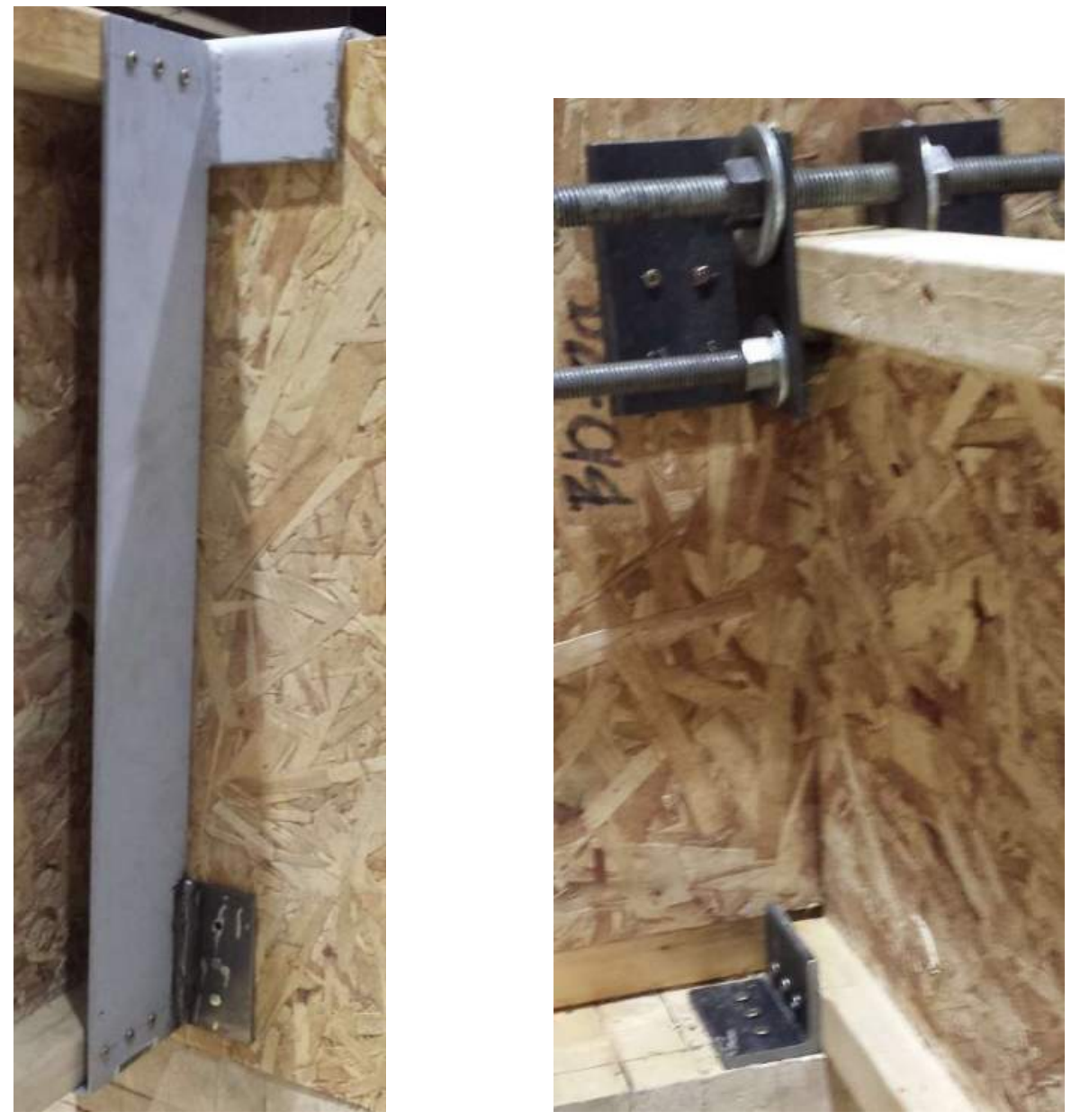

Figure 4-10 HWR with screwed flanges connection (left) and Angles contained Flanges Connection (right) 
Table 4-4 Joists Hangers used in Specimen group \#A

\begin{tabular}{|c|c|c|c|}
\hline $\begin{array}{l}\text { Sample } \\
\text { Group }\end{array}$ & $\begin{array}{c}\text { Specimen } \\
\#\end{array}$ & $\begin{array}{l}\text { LTB Boundary } \\
\text { Condition }\end{array}$ & $\begin{array}{l}\text { Hangers / } \\
\text { Connection }\end{array}$ \\
\hline \multirow{18}{*}{$A$} & 1 & Simply Supported & \\
\hline & 2 & Simply Supported & \\
\hline & 3 & Simply Supported & \\
\hline & 4 & Simply Supported & \\
\hline & 5 & Simply Supported & \\
\hline & 6 & Simply Supported & \\
\hline & 7 & Top Mounted & LBV2.56/16 \\
\hline & 8 & Top Mounted & LBV2.56/16 \\
\hline & 9 & Top Mounted & LBV2.56/16 \\
\hline & 10 & Top Mounted & LBV2.56/16 \\
\hline & 11 & Face Mounted & IUS2.56/16 \\
\hline & 12 & Face Mounted & IUS2.56/16 \\
\hline & 13 & Face Mounted & HU316 \\
\hline & 14 & Face Mounted & HU316 \\
\hline & 15 & Enhanced Connection & Nails in End grain \\
\hline & 16 & Enhanced Connection & Nails in End grain \\
\hline & 17 & Enhanced Connection & Angle Contained \\
\hline & 18 & Enhanced Connection & Angle Contained \\
\hline
\end{tabular}


Table 4-5 Joists Hangers used in Specimen group B

\begin{tabular}{|c|c|c|c|}
\hline $\begin{array}{l}\text { Sample } \\
\text { Group }\end{array}$ & $\begin{array}{c}\text { Specimen } \\
\#\end{array}$ & $\begin{array}{l}\text { LTB Boundary } \\
\text { Condition }\end{array}$ & $\begin{array}{l}\text { Hangers / } \\
\text { Connection }\end{array}$ \\
\hline \multirow{23}{*}{ B } & 1 & Simply Supported & \\
\hline & 2 & Simply Supported & \\
\hline & 3 & Simply Supported & \\
\hline & 4 & Simply Supported & \\
\hline & 5 & Simply Supported & \\
\hline & 6 & Simply Supported & \\
\hline & 7 & Simply Supported & \\
\hline & 8 & Top Mounted & HWI424 \\
\hline & 9 & Top Mounted & HWI424 \\
\hline & 10 & Top Mounted & HB3.56/24 \\
\hline & 11 & Top Mounted & HB3.56/24 \\
\hline & 12 & Top Mounted & HIT424 \\
\hline & 13 & Top Mounted & HIT424 \\
\hline & 14 & Face Mounted & IUS3.56/16 \\
\hline & 15 & Face Mounted & IUS3.56/16 \\
\hline & 16 & Face Mounted & MIU3.56/16 \\
\hline & 17 & Face Mounted & MIU3.56/16 \\
\hline & 18 & Enhanced Connection & Nails in End grain \\
\hline & 19 & Enhanced Connection & Nails in End grain \\
\hline & 20 & Enhanced Connection & Side Screwed \\
\hline & 21 & Enhanced Connection & Side Screwed \\
\hline & 22 & Enhanced Connection & Angle Contained \\
\hline & 23 & Enhanced Connection & Angle Contained \\
\hline
\end{tabular}




\subsubsection{Web Transverse Modulus of Elasticity}

The web transverse modulus of elasticity was determined using a conventional universal testing machine as shown in Figure 4-11. The tests were based on the Standard Test Method for Structural Panels in Flexure (ASTM 2011). Specimen were cut to $51 \mathrm{~mm}$ wide strips, perpendicular to the orientation of the strands of the board and they were tested as simply supported with a single point load at mid span. The span and load application rate were consistent with those required by the standard (Table 4-6). The specimens were tested up to failure.

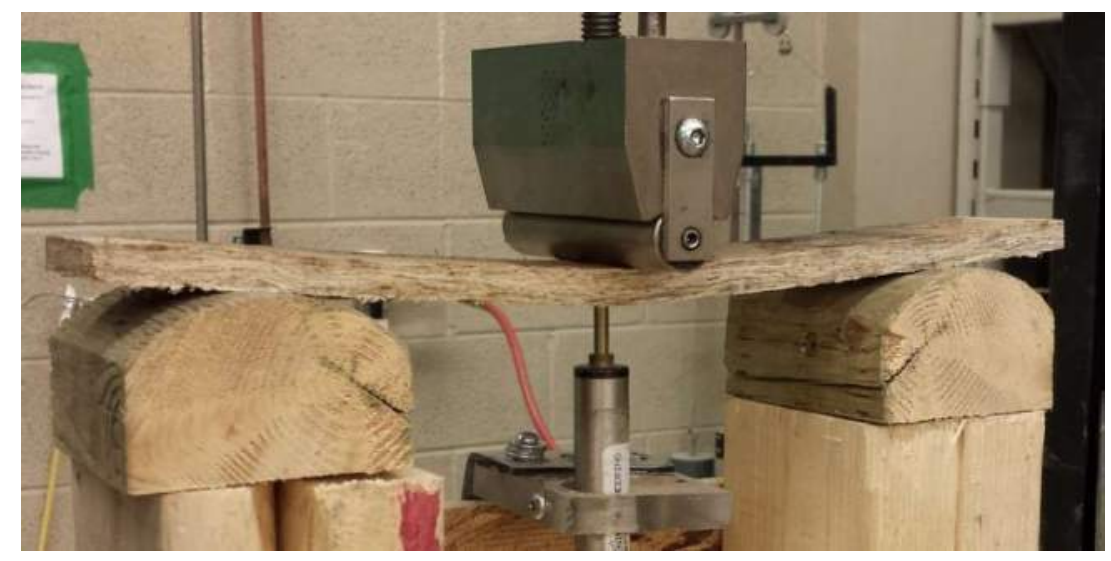

Figure 4-11 Web transverse modulus of elasticity test configuration

Table 4-6 I-Joist web thickness, span and application rate for transverse MOE test

\begin{tabular}{|c|c|c|c|}
\cline { 3 - 3 } \multicolumn{2}{c|}{} & \multicolumn{2}{c|}{ Section Depth } \\
\cline { 3 - 4 } \multicolumn{2}{c|}{} & $0.4 \mathrm{~m}$ & $0.6 \mathrm{~m}$ \\
\hline \multirow{4}{*}{$\begin{array}{c}\text { Web } \\
\text { Data }\end{array}$} & $\begin{array}{c}\text { Nominal Thickness } \\
(\mathrm{mm})\end{array}$ & 9.5 & 11.1 \\
\cline { 2 - 4 } & Span length (mm) & 229 & 267 \\
\cline { 2 - 4 } & $\begin{array}{c}\text { Load application rate } \\
(\mathrm{mm} / \mathrm{min})\end{array}$ & 1.4 & 1.6 \\
\hline
\end{tabular}




\subsubsection{Flange torsional shear modulus}

The flanges torsional modulus was determined as defined by the Standard Test Method of Static Tests of Lumber in Structural Sizes (ASTM 2015). Two equals and opposite loads were applied to the specimens as seen in Figure 4-12. The clamping devices were positioned to have the lower arm resting on a ground support while the higher arm supporting the load transfer device. Two inclinometers were installed on each specimen to record the angle of twist of the section. The inclinometers were installed at $305 \mathrm{~mm}$ from each clamp and were spaced $711 \mathrm{~mm}$ apart (8 times the nominal depth of the specimen). The flange specimen was loaded at a constant rate until it reached approximately $6^{\circ}$.

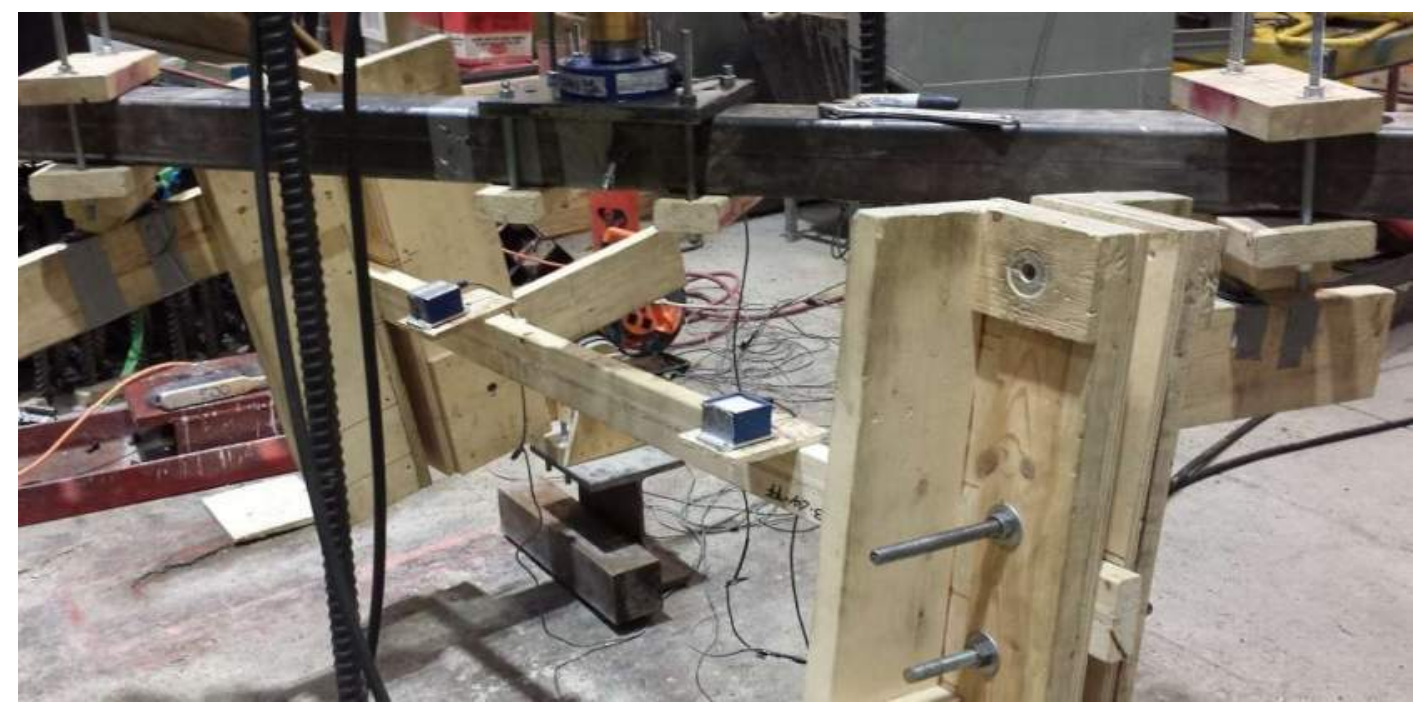

Figure 4-12 Flange torsional shear modulus test setup 


\subsubsection{Flange longitudinal modulus of elasticity}

The flanges of selected specimens were tested to determine their longitudinal modulus of elasticity in accordance with the test method describe in the American Standard Test Methods of Static Tests of Lumber in Structural Sizes (ASTM 2015). This method consists of a four-point bending test (Figure 4-13). The flange specimen was bent about its strong axis in order to simulate the same bending action that occurs in lateral-torsional buckling. The test was conducted on both sides of each specimen since it is unknown what direction the joint would buckle in. The flange specimen was deflected at a constant rate while the total applied force and vertical displacement at mid span were recorded.

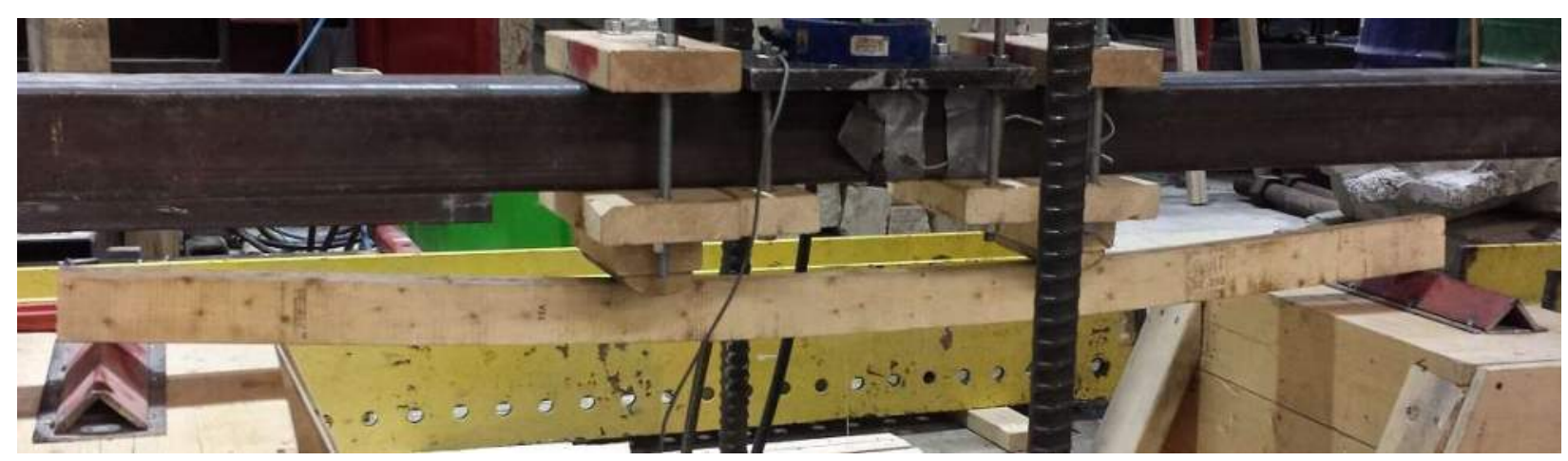

Figure 4-13 Flange elastic longitudinal modulus test setup

\subsubsection{Top-Mounted hangers lateral displacement rigidity}

Subsequent to conducting the full scale lateral-torsional buckling tests described in section 4.2.1, OSB and lumber panels used for nailing the hangers were dismantled to keep only the hangers and the top panel pieces nailed together. The lateral stiffness of the top mounted hangers was determined using a universal testing machine by applying a point load at the bottom of the hanger as shown in Figure 4-14. A wooden support frame was constructed to allow the assembly to be installed with sufficient torsional and vertical support to resist the applied load. The load application rate was set to a constant $0.2 \mathrm{~mm}$ per second. The universal testing machine recorded 
the load applied at the end of the hangers and a linear variable differential transformer (LVDT) recorded the deflection. The hangers were tested until $20 \mathrm{~mm}$ displacement was reached.

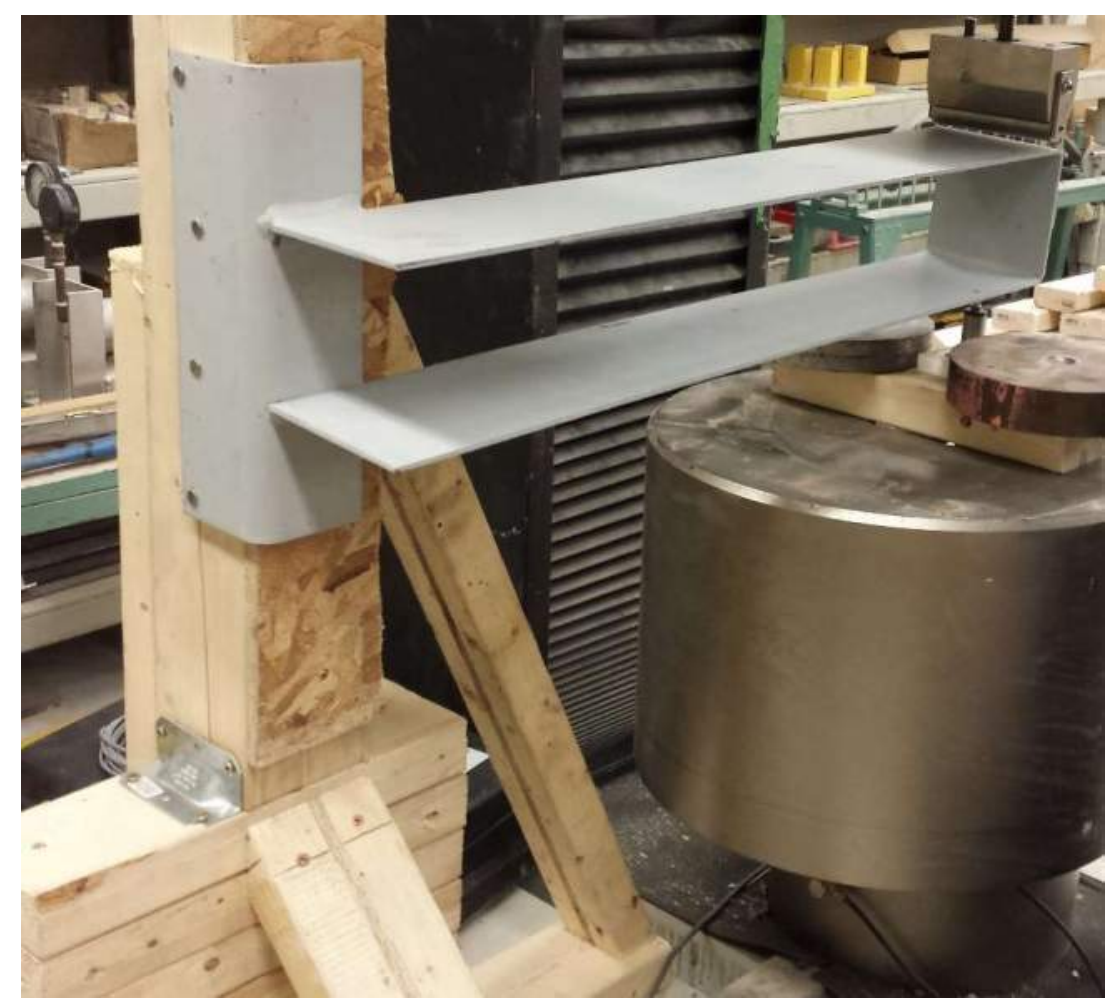

Figure 4-14 Joist Hangers lateral rigidity test setup 


\section{CHAPTER 5}

\section{EXPERIMENTAL RESULTS}

\subsection{General}

This chapter presents the experimental results obtained for the I-Joists wood components mechanical properties, hanger's lateral rigidity and I-joist lateral-torsional buckling capacity.

\subsection{Mechanical properties}

\subsubsection{Wood I-joist components}

After the lateral-torsional buckling tests were conducted, selected I-joist specimens were dismantled and the flange and web elements were cut for further testing. The data obtained from these specimens is then used as input in the numerical model. A total of 15 joists from the group A and 16 joists from the group B were selected for testing. In each group, the specimens were chosen such that a uniform distribution of the joist tested with the different boundary conditions were represented. Table 5-1 and Table 5-2 show the selected I-joists, boundary conditions and the resulting longitudinal MOE, torsional shear modulus and web transverse MOE. 
Table 5-1 Components' mechanical properties of Group A

\begin{tabular}{|c|c|c|c|c|c|c|}
\hline \multirow{2}{*}{$\begin{array}{c}\text { Specimen } \\
\#\end{array}$} & \multirow{2}{*}{$\begin{array}{c}\text { Hangers / } \\
\text { Connection }\end{array}$} & \multicolumn{2}{|c|}{$\begin{array}{c}\text { Flanges Longitudinal } \\
\text { Modulus of Elasticity } \\
\text { (MPa) }\end{array}$} & \multicolumn{2}{|c|}{$\begin{array}{c}\text { Flanges Torsional } \\
\text { Shear Modulus (MPa) }\end{array}$} & $\begin{array}{c}\text { Web } \\
\text { Transverse } \\
\text { Modulus of } \\
\text { Elasticity (MPa) }\end{array}$ \\
\cline { 3 - 6 } & & Top & Bottom & Top & Bottom & 2113 \\
\hline $\mathbf{1}$ & Simply Supported & 11257 & 10812 & 1018 & 945 & 2030 \\
\hline $\mathbf{2}$ & Simply Supported & 14174 & 13126 & 850 & 972 & 2117 \\
\hline $\mathbf{3}$ & Simply Supported & 13091 & 12713 & 1172 & 946 & 2625 \\
\hline $\mathbf{4}$ & Simply Supported & 14220 & 13138 & 1008 & 1060 & 2809 \\
\hline $\mathbf{5}$ & Simply Supported & 12486 & 12798 & 1131 & 1007 & 1955 \\
\hline $\mathbf{6}$ & Simply Supported & 13171 & 13003 & 955 & 1057 & 1897 \\
\hline $\mathbf{9}$ & LBV2.56/16 & 11938 & 12732 & 1056 & 1204 & 2018 \\
\hline $\mathbf{1 0}$ & LBV2.56/16 & 12530 & 13835 & 1021 & 1214 & 2017 \\
\hline $\mathbf{1 1}$ & IUS2.56/16 & 11469 & 12864 & 960 & 1023 & 1758 \\
\hline $\mathbf{1 2}$ & IUS2.56/16 & 10150 & 12667 & 991 & 1122 & 2154 \\
\hline $\mathbf{1 4}$ & HU316 & 13937 & 12196 & 1164 & 1048 & 1942 \\
\hline $\mathbf{1 5}$ & Nails in End grain & 12969 & 12203 & 1032 & 1057 & 1639 \\
\hline $\mathbf{1 6}$ & Nails in End grain & 12235 & 12860 & 1220 & 1038 & 2703 \\
\hline $\mathbf{1 7}$ & Angle Contained & 13325 & 12649 & 970 & 1235 & 2060 \\
\hline $\mathbf{1 8}$ & Angle Contained & 14282 & 13596 & 1114 & 1116 & $\mathbf{2 1 2 3}$ \\
\hline Average & & $\mathbf{1 2 7 4 9}$ & $\mathbf{1 2 7 4 6}$ & $\mathbf{1 0 4 4}$ & $\mathbf{1 0 7 0}$ & $\mathbf{1 5 . 8}$ \\
\hline COV \% & & $\mathbf{9 . 4}$ & $\mathbf{5 . 4}$ & $\mathbf{9 . 5}$ & $\mathbf{8 . 6}$ & \\
\hline & & & & & & \\
\hline
\end{tabular}


Table 5-2 Components' mechanical properties of Group B

\begin{tabular}{|c|c|c|c|c|c|c|}
\hline \multirow[t]{2}{*}{$\begin{array}{c}\text { Specimen } \\
\#\end{array}$} & \multirow[t]{2}{*}{$\begin{array}{l}\text { Hangers / } \\
\text { Connection }\end{array}$} & \multicolumn{2}{|c|}{$\begin{array}{l}\text { Flanges Longitudinal } \\
\text { Modulus of Elasticity } \\
\text { (MPa) }\end{array}$} & \multicolumn{2}{|c|}{$\begin{array}{c}\text { Flanges Torsional } \\
\text { Shear Modulus (MPa) }\end{array}$} & \multirow{2}{*}{$\begin{array}{c}\text { Web } \\
\text { Transverse } \\
\text { Modulus of } \\
\text { Elasticity (MPa) }\end{array}$} \\
\hline & & Top & Bottom & Top & Bottom & \\
\hline 2 & Simply Supported & 12407 & 10392 & 1297 & 1159 & 2048 \\
\hline 3 & Simply Supported & 8863 & 11022 & 1139 & 1122 & 1667 \\
\hline 4 & Simply Supported & 12249 & 10345 & 1301 & 1144 & 1702 \\
\hline 5 & Simply Supported & 9892 & 12010 & 1128 & 1053 & 2231 \\
\hline 6 & Simply Supported & 10144 & 10867 & 1306 & 1164 & 1801 \\
\hline 7 & Simply Supported & 10615 & 9528 & 1229 & 1053 & 1461 \\
\hline 8 & HWI424 & 14225 & 10549 & 1357 & 1024 & 1718 \\
\hline 9 & HWI424 & 12357 & 14058 & 1263 & 1431 & 1488 \\
\hline 13 & HIT424 & 12097 & 13260 & 1154 & 1175 & 985 \\
\hline 14 & IUS3.56/16 & 11789 & 15304 & 1133 & 1327 & 1165 \\
\hline 15 & IUS3.56/16 & 12414 & 9637 & 1277 & 1291 & 1489 \\
\hline 16 & MIU3.56/16 & 12074 & 9799 & 1166 & 1656 & 1728 \\
\hline 20 & Side Screwed & 14048 & 11648 & 1348 & 1116 & 1676 \\
\hline 21 & Side Screwed & 11996 & 12313 & 1426 & 1387 & 1611 \\
\hline 22 & Angle Contained & 9589 & 10927 & 1305 & 1168 & 1898 \\
\hline 23 & Angle Contained & 10034 & 11666 & 1062 & 1332 & 1683 \\
\hline Average & & 11550 & 11458 & 1243 & 1225 & 1647 \\
\hline Cov \% & & 13.4 & 14.2 & 8.2 & 13.7 & 18.3 \\
\hline
\end{tabular}




\subsubsection{I-joist hangers lateral rigidity}

The top-mount hanger supports also tested to evaluate their lateral stiffness. The resulting stiffness are reported in Table 5-3.

Table 5-3 Lateral Stiffness at bottom of top mounted hangers

\begin{tabular}{|c|c|c|}
\hline Group & Hangers & $\begin{array}{c}\text { Stiffness } \\
(\mathrm{N} / \mathrm{mm})\end{array}$ \\
\hline \multirow{2}{*}{$\mathrm{A}$} & LBV2.56/16 & 10.7 \\
\hline \multirow{3}{*}{$B$} & $\mathrm{HB} 3.56 / 24$ & 38.7 \\
\cline { 2 - 3 } & $\mathrm{HIT} 424$ & 13.7 \\
\cline { 2 - 3 } & $\mathrm{HWI} 424$ & 6.7 \\
\hline
\end{tabular}

\subsection{Lateral torsional buckling capacity}

The lateral-torsional buckling was evaluated for all the specimens in group A and B with different boundary conditions. Measurements taken during the test consisted of vertical displacement at mid-span as well as lateral deflection and angular displacement for both top and bottom flanges taken at mid-span. The out-of-straightness was measured at mid-span of the I-joist specimen. The average measured out-of-straightness is displayed in Table 5-4 for all specimen groups.

Table 5-4 Average out-of-straightness of the top flange ( $\mathrm{mm}$ )

\begin{tabular}{|c|c|c|c|}
\hline & Group A & Group B \\
\hline \multirow{4}{*}{ 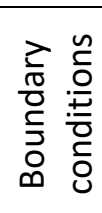 } & Simply Supported & 5.3 & 5.8 \\
\hline & Top Mounted & -- & 6.3 \\
\hline & Face Mounted & -- & 7.1 \\
\hline & Rotational Fixity & -- & 5.6 \\
\hline
\end{tabular}

All tested specimens showed lateral deflection as soon as the loading was applied. The main buckling mode shape of the I-joist specimens is shown in Figure 5-1. The specimens generally 
failed in the top flange along the flange strong axis (Figure 5-2). Figure 5-3 to Figure 5-6 display the moment-displacement curves that resulted from the test for the specimens \#3 to \#7 of the sample group B which were tested with simply supported ideal boundary conditions. Table 5-5 though Table 5-8 present the recorded critical moment capacity of the I-joists tested with different boundary conditions for all sample groups. The buckling load recorded has been taken as the maximum load resisted by the joists just before or at failure.

Table 5-5 Lateral Torsional Buckling Capacity - Simply Supported Boundary Conditions $(\mathrm{kN*})$

\begin{tabular}{|c|c|c|}
\hline $\begin{array}{c}\text { Specimen } \\
\#\end{array}$ & Group A & Group B \\
\hline 1 & 11.2 & 26.3 \\
\hline 2 & 11.4 & 23 \\
\hline 3 & 10.4 & 18.5 \\
\hline 4 & 10.1 & 18.8 \\
\hline 5 & 10.2 & 20.3 \\
\hline 6 & 10.1 & 19.7 \\
\hline 7 & --- & 18.8 \\
\hline Average & $\mathbf{1 0 . 6}$ & $\mathbf{2 0 . 8}$ \\
\hline COV \% & $\mathbf{5 . 4}$ & $\mathbf{1 3 . 8}$ \\
\hline
\end{tabular}


Table 5-6 Lateral Torsional Buckling Capacity - Top Mounted Hangers (kN*m)

\begin{tabular}{|c|c|c|}
\hline $\begin{array}{c}\text { Specimen } \\
\#\end{array}$ & Group A & Group B \\
\hline 7 & 8.5 & --- \\
\hline 8 & 9.2 & 18.9 \\
\hline 9 & 8.6 & 17.9 \\
\hline 10 & 9.5 & 20.2 \\
\hline 11 & --- & 19.7 \\
\hline 12 & --- & 18.4 \\
\hline 13 & --- & 21.9 \\
\hline Average & $\mathbf{8 . 9}$ & 19.5 \\
\hline COV \% & $\mathbf{5 . 1}$ & $\mathbf{7 . 4}$ \\
\hline
\end{tabular}

Table 5-7 Lateral Torsional Buckling Capacity - Front Mounted Hangers (kN*m)

\begin{tabular}{|c|c|c|}
\hline $\begin{array}{c}\text { Specimen } \\
\#\end{array}$ & Group A & Group B \\
\hline 11 & 9.0 & --- \\
\hline 12 & 9.0 & --- \\
\hline 13 & 9.3 & --- \\
\hline 14 & 9.1 & 17.0 \\
\hline 15 & --- & 15.8 \\
\hline 16 & --- & 17.8 \\
\hline 17 & --- & 18.5 \\
\hline Average & $\mathbf{9 . 1}$ & $\mathbf{1 7 . 3}$ \\
\hline COV \% & $\mathbf{1 . 5}$ & $\mathbf{6 . 7}$ \\
\hline
\end{tabular}


Table 5-8 Lateral Torsional Buckling Capacity - Rotational Fixity (kN*m)

\begin{tabular}{|c|c|c|}
\hline $\begin{array}{c}\text { Specimen } \\
\#\end{array}$ & Group A & Group B \\
\hline 15 & 9.8 & --- \\
\hline 16 & 9.6 & --- \\
\hline 17 & 15.0 & --- \\
\hline 18 & 15.1 & 22.9 \\
\hline 19 & --- & 23.4 \\
\hline 20 & --- & 24.8 \\
\hline 21 & --- & 21.6 \\
\hline 22 & --- & 21.3 \\
\hline 23 & --- & 23.4 \\
\hline Average & $\mathbf{1 2 . 4}$ & $\mathbf{2 2 . 9}$ \\
\hline COV \% & $\mathbf{2 4 . 9}$ & $\mathbf{5 . 6}$ \\
\hline
\end{tabular}

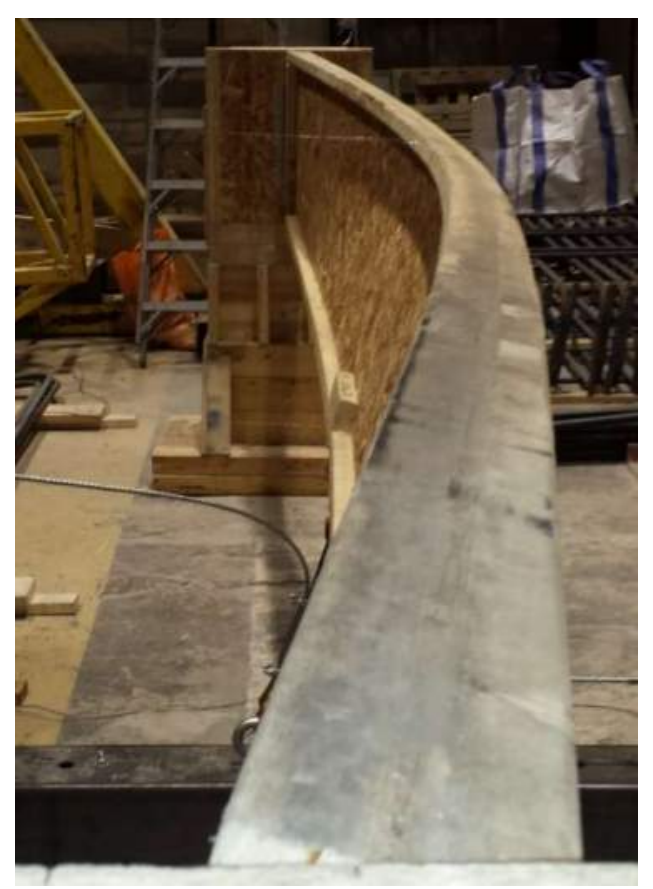

Figure 5-1 Typical deformation of lateral-torsional buckling experiment 


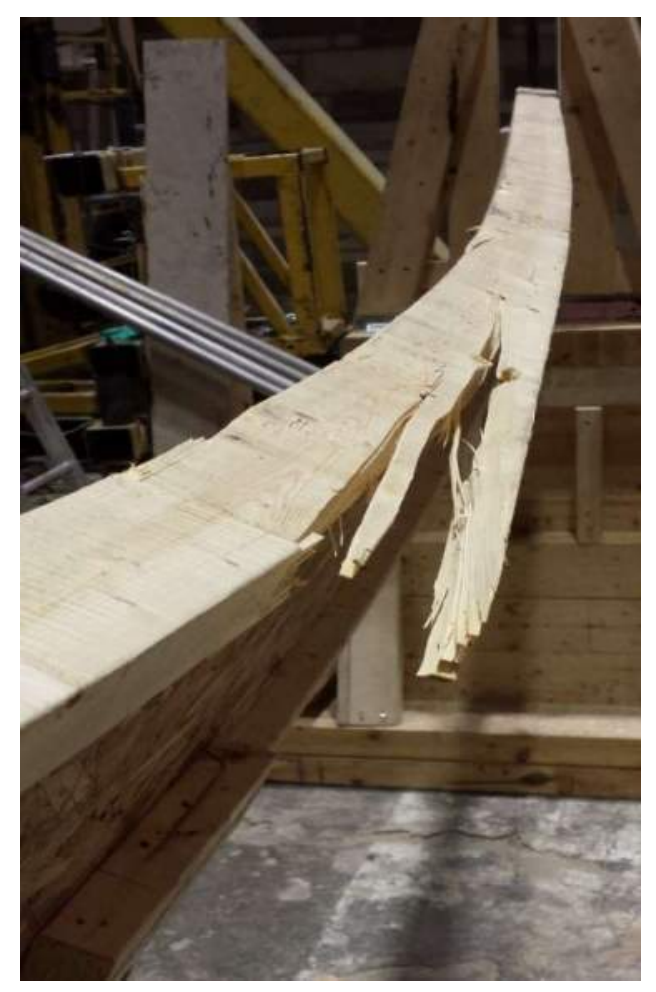

Figure 5-2 Typical material failure of Top Flange in LTB test

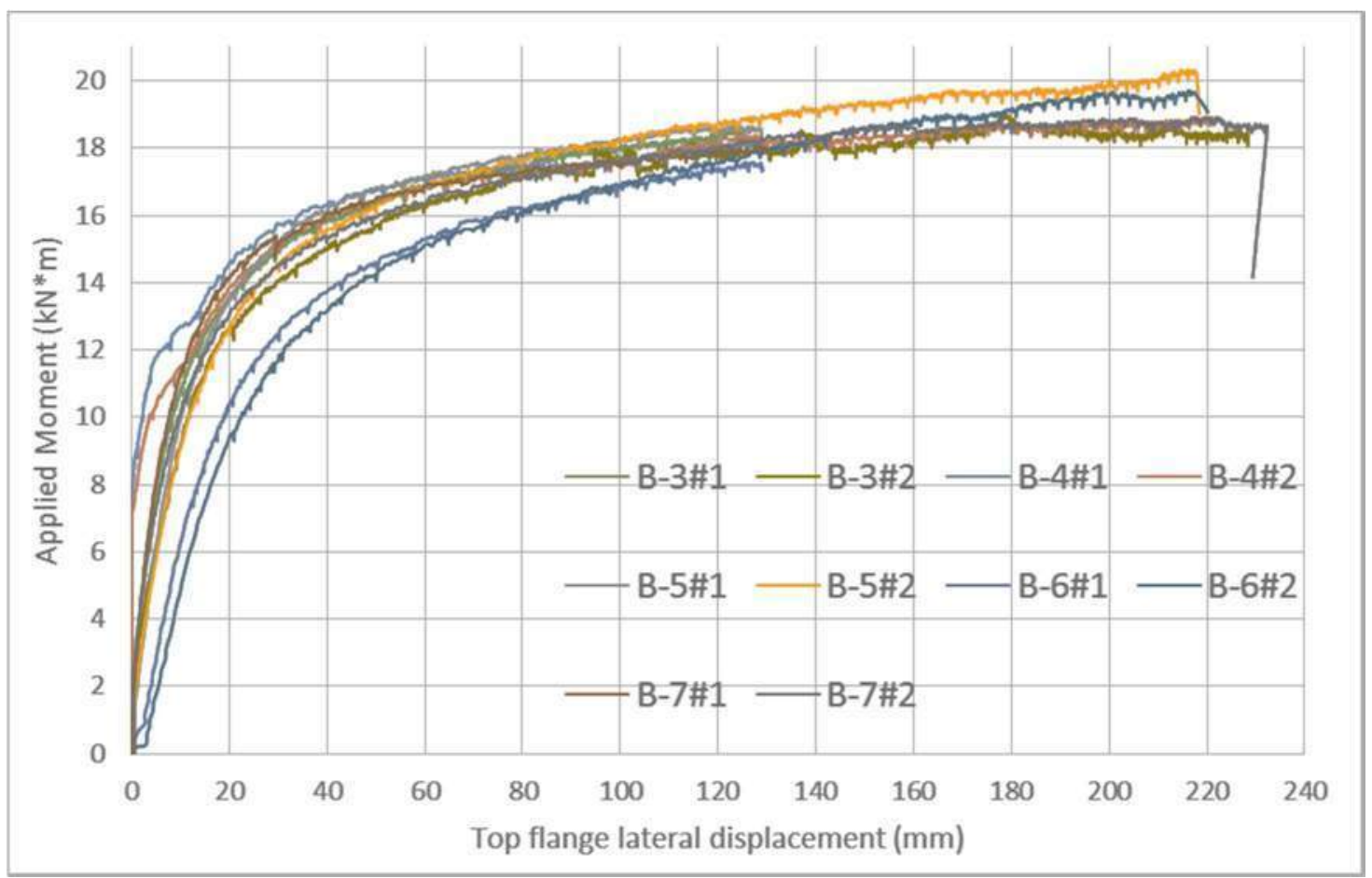

Figure 5-3 Moment-Lateral displacement of Top Flange - Specimens B-3 to B-7 


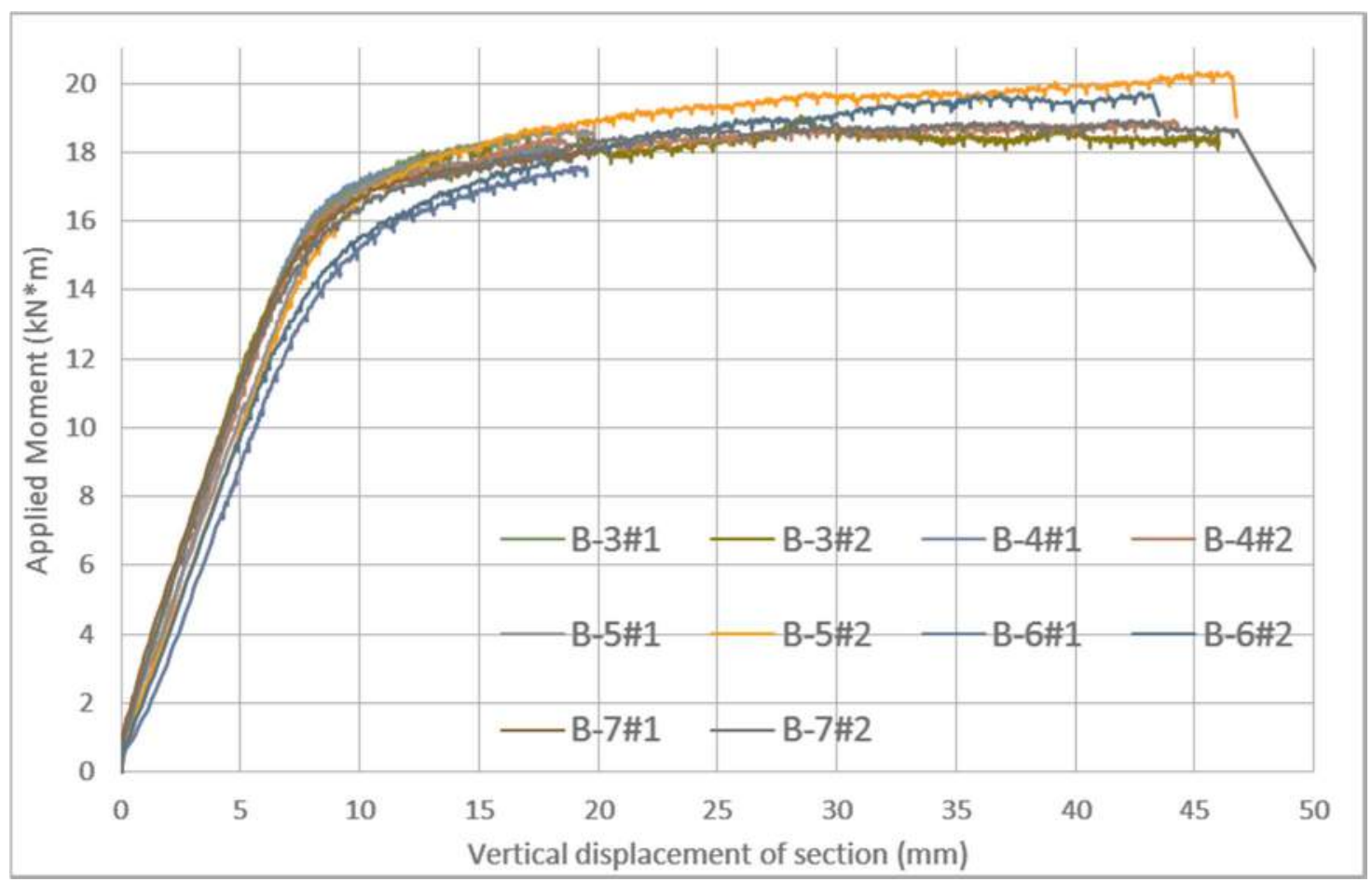

Figure 5-4 Moment-Vertical displacement - Specimens B-3 to B-7

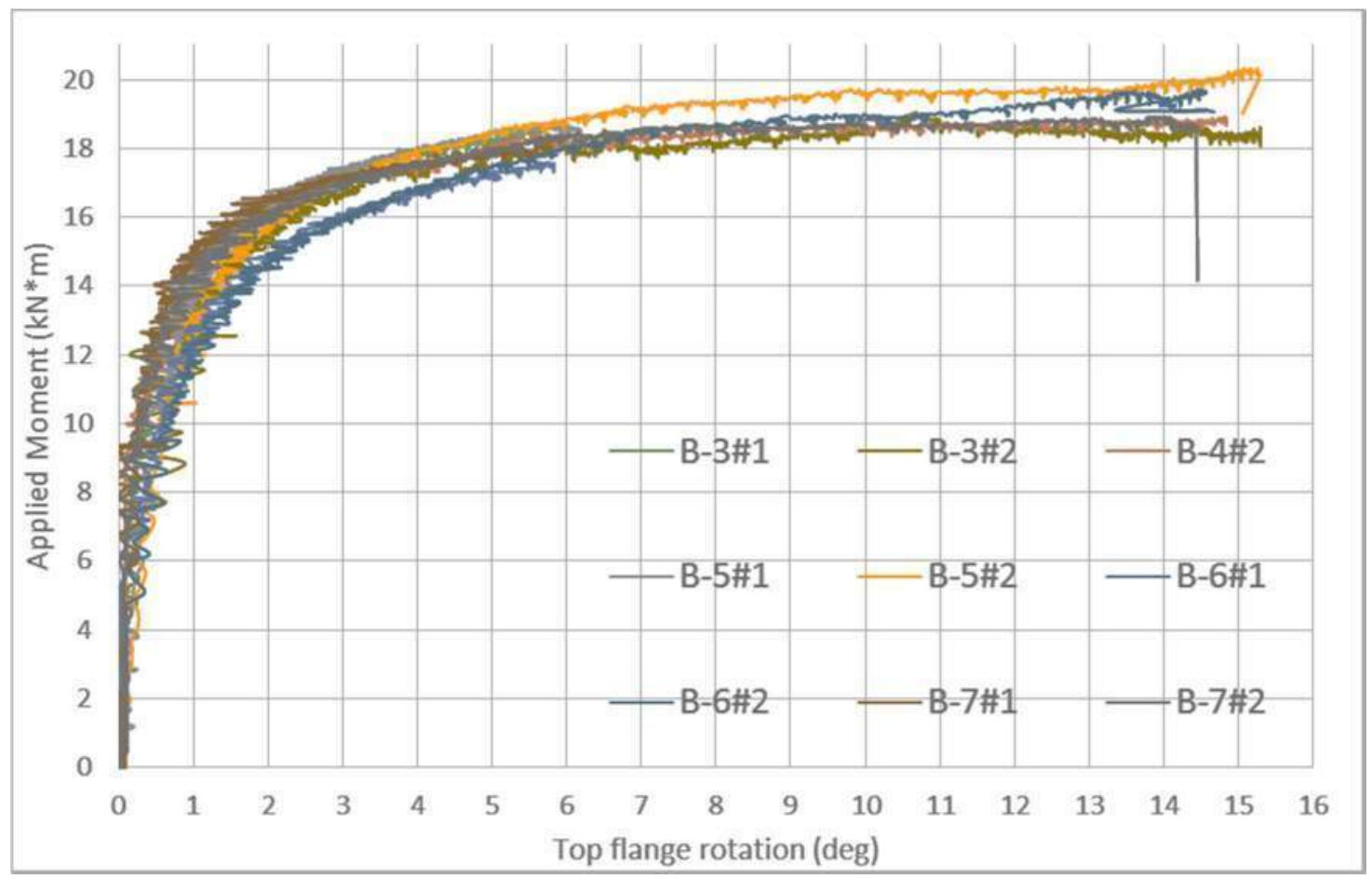

Figure 5-5 Moment-Rotation of Top Flange - Specimens B-3 to B-7 


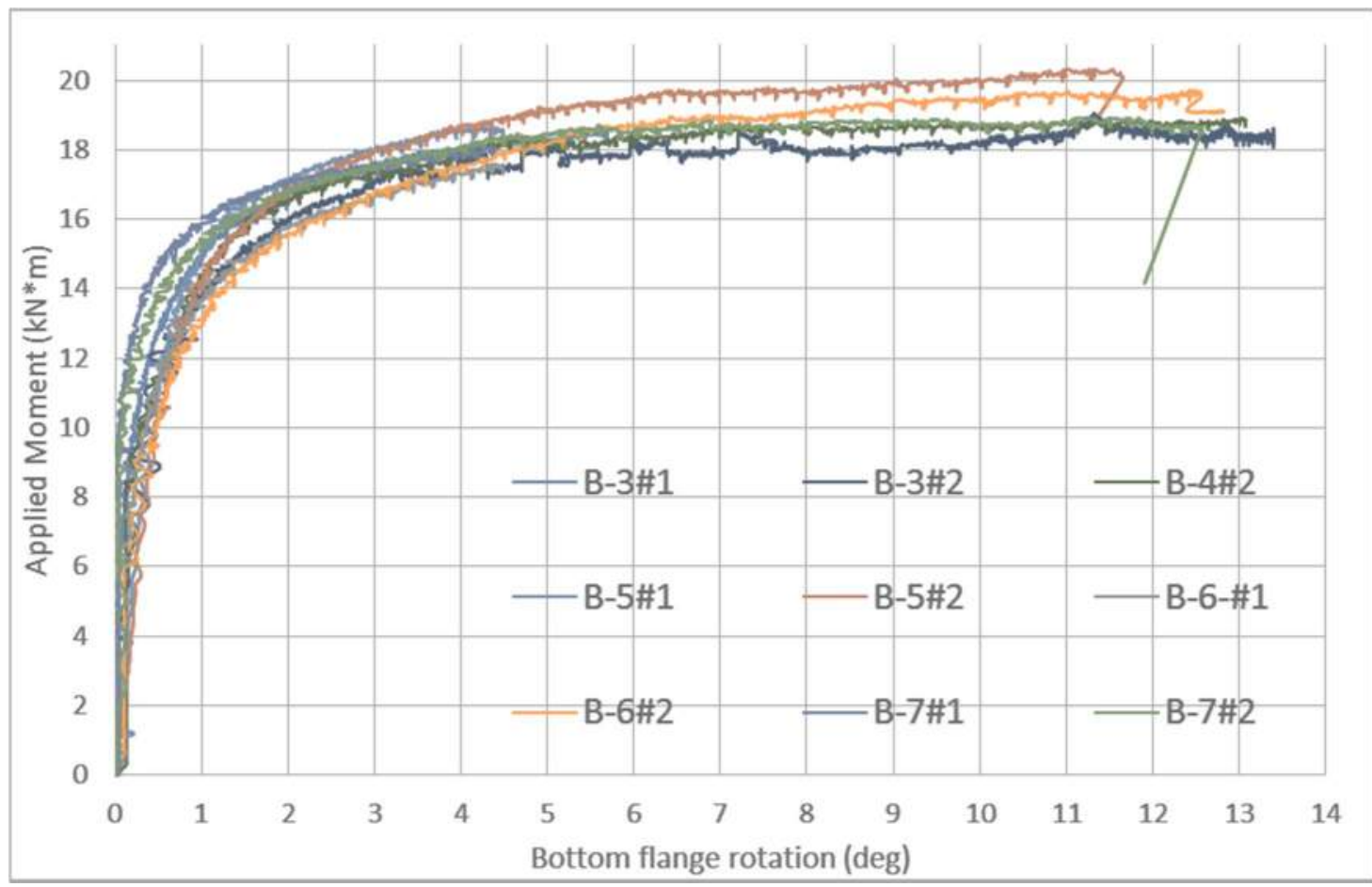

Figure 5-6 Moment- Rotation of Bottom Flange - Specimens B-3 to B-7 


\section{CHAPTER 6}

\section{Finite ELEMENT Modelling}

The objective of this chapter is to compare the FEA model results based on the measured mechanical properties to the experimental lateral-torsional buckling critical loads and behavior obtained in Chapter 5. The finite element analysis approach, model description and analysis procedures and results are presented from Sections 6.1 to 6.4 respectively.

\subsection{Linear and nonlinear analysis}

Due to its simplicity, linear analysis is the preferred approach in design. Geometric nonlinearity may need to be considered in the analysis in cases where, for example, the beam is not perfectly straight initially. In order to perform such nonlinear analyse, a series of steps must be followed. The first step to perform lateral-torsional buckling analysis on the perfectly straight beam. The pre-buckling analysis involves strong axis stiffness matrix $\left[K_{S}\right]$ subjected to a reference load $\left[P_{r e f}\right]$ acting in the same plane. The linear relationship between these two values is linked by the induced displacement and can be described with the following equation:

$$
\left[K_{S}\right] \lambda\left[u_{S}\right]=\lambda\left[P_{r e f}\right]
$$

Where $\left[u_{S}\right]$ is the nodal displacement as per the strong axis and $\lambda$ is the load multiplier.

The member deforms in the transverse direction during loading and the system is assumed to be linear until it undergoes lateral-torsional buckling.

The second step involves solving the following equation derived from the energy solution of the structure:

$$
\left(\left[K_{W}\right]+\lambda_{i}\left[K_{G}\right]\right)\left(v_{i}\right)=0
$$


where $K_{W}$ denotes the stiffness matrix, $K_{G}$ is the geometric matrix and $v_{i}$ is the nodal displacement vector of the main buckling mode shape $i$. Using an eigenvalue solver, the smallest value of $\lambda_{i}$ is seeked where Equation 6-2 has a non-trivial solution.

In ABAQUS Software, the nonlinear problem is solved using the Newton-Raphson iteration method (Simulia 2014). This method attempts to achieve convergence of the system of equation by means of iterations.

These imperfections naturally present in wood include initial out-of-straightness, which induce initial lateral displacement and rotation. By using commercial joist hangers, the stiffness at the boundary is affected by the variation in stiffness of the joist hangers, which in turns affects the overall stiffness of the joist system.

\subsection{Model Description}

\subsubsection{Reference model}

In order to compare the experimental results with those obtained from the FE analysis, the numerical model needs to be adapted for the variations encountered in the experimental process. A reference model was created using the joist basic geometry as describe in Figure 4-1 and span length described in Table 4-1 for each sample group. All sample group models were given the same mesh and element details.

The main axis directions used for modeling are the same as the axes used for the sensitivity analysis model described in Figure 3-1.

\subsubsection{Elements details}

The FE model used here is similar to that used in the sensitivity analysis (Chapter 3), where the web was modeled with S4R shell element and the flanges with C3D8R solid elements. These elements allow for effective representation of the structure of the joist's components while limiting the computational cost. 


\subsubsection{Mesh detail}

The meshing of the flanges and web was dependent on the size of the section. The ideal element aspect ratio would be as close as possible to unity. In the present models, the aspect ratio of the flanges elements width to height are 1.08 and 1.11 for the $0.6 \mathrm{~m}$ and $0.4 \mathrm{~m}$ joist section respectively. The longitudinal aspect ratio of the elements is 4.0 for both section's flanges. The aspect ratio of the shell elements used for the web was chosen as 1.0.

\subsubsection{Geometric details}

Table 6-1 presents the overall characteristics of the joist models for each specimen group tested. These characteristics include the number of elements, their dimensions and the aspect ratio for each section type.

Table 6-1 FE models dimensions and elements details

\begin{tabular}{|c|c|c|c|c|c|c|c|c|c|}
\hline \multirow{2}{*}{$\begin{array}{l}\text { Sample } \\
\text { Group \# }\end{array}$} & \multirow{2}{*}{$\begin{array}{l}\text { Span } \\
(\mathrm{mm})\end{array}$} & \multirow{2}{*}{$\begin{array}{c}\text { Member } \\
\text { length }(\mathrm{mm})\end{array}$} & \multicolumn{2}{|c|}{ \# Elements } & \multicolumn{2}{|c|}{ Element size $(\mathrm{mm})$} & \multicolumn{3}{|c|}{ Aspect Ratio } \\
\hline & & & Flange & Web & Flange & Web & $\begin{array}{c}\text { Flange } \\
\mathrm{W} / \mathrm{H}\end{array}$ & $\begin{array}{c}\text { Flange } \\
\mathrm{L} / \mathrm{H}\end{array}$ & $\begin{array}{c}\text { We } \\
\text { b }\end{array}$ \\
\hline \multirow{2}{*}{ A } & \multirow{2}{*}{4572} & 4877 & 10368 & $\begin{array}{c}249 \\
6\end{array}$ & \multirow{2}{*}{$\begin{array}{c}7.1 \times 6.4 \\
\times 25.4\end{array}$} & \multirow{2}{*}{$\begin{array}{c}25.4 x \\
25.4\end{array}$} & \multirow{2}{*}{1.11} & \multirow{2}{*}{4} & \multirow{2}{*}{1.0} \\
\hline & & 4572 & 9720 & $\begin{array}{c}234 \\
0\end{array}$ & & & & & \\
\hline \multirow{2}{*}{ B } & \multirow{2}{*}{5791} & 6096 & 18720 & $\begin{array}{c}504 \\
0\end{array}$ & \multirow{2}{*}{$\begin{array}{c}6.8 \times 6.4 \\
\times 25.4\end{array}$} & \multirow{2}{*}{$\begin{array}{c}25.4 x \\
25.4\end{array}$} & \multirow{2}{*}{1.08} & \multirow{2}{*}{4} & \multirow{2}{*}{1.0} \\
\hline & & 5791 & 17784 & $\begin{array}{c}478 \\
8\end{array}$ & & & & & \\
\hline
\end{tabular}

\subsubsection{Material parameters}

The material properties used in the FE model were determined from the experimental program describe in the Chapter 4. 
In order to validate the results of the FE model with the experimental load, six specimens tested with the simply supported boundary conditions of the sample groups A and B were analyzed and compared independently. These twelve specimens were modeled with varying longitudinal MOE and torsional shear modulus in the flange while all the other mechanical properties used average values. Table 6-2 presents the longitudinal elastic modulus and torsional shear modulus for each of the twelve selected specimens that were used in the numerical analysis.

For all other numerical models, Table 6-3 list the average mechanical values for each component used within each sample groups. The majority of these values were computed from the value presented in Table 5-1 and Table 5-2. The OSB web parallel MOE was assumed to be around 2.5 times the transversal MOE and the torsional shear modulus is assumed to be $100 \mathrm{MPa}$ based on average values in the literature (Grandmont 2011; Bohm et al. 2011).

Table 6-2 Selected simply supported specimens flanges elastic properties

\begin{tabular}{|c|c|c|c|c|c|}
\hline \multirow{4}{*}{ Group \# } & $\begin{array}{c}\text { Specimen } \\
\#\end{array}$ & \multicolumn{2}{|c|}{$\begin{array}{c}\text { Flanges Longitudinal } \\
\text { Modulus of Elasticity } \\
\text { (MPa) }\end{array}$} & $\begin{array}{c}\text { Flanges Torsional } \\
\text { Shear Modulus } \\
\text { (MPa) }\end{array}$ \\
\cline { 2 - 6 } & & Top & Bottom & Top & Bottom \\
\hline \multirow{4}{*}{ A } & 1 & 11257 & 10812 & 1018 & 945 \\
\cline { 2 - 6 } & 2 & 14174 & 13126 & 850 & 972 \\
\cline { 2 - 6 } & 3 & 13091 & 12713 & 1172 & 946 \\
\cline { 2 - 6 } & 4 & 14220 & 13138 & 1008 & 1060 \\
\hline \multirow{4}{*}{ B } & 5 & 12486 & 12798 & 1131 & 1007 \\
\cline { 2 - 6 } & 6 & 13171 & 13003 & 955 & 1057 \\
\cline { 2 - 6 } & 2 & 12407 & 10392 & 1297 & 1159 \\
\cline { 2 - 6 } & 3 & 8863 & 11022 & 1139 & 1122 \\
\cline { 2 - 6 } & 4 & 12249 & 10345 & 1301 & 1144 \\
\hline & 6 & 9892 & 12010 & 1128 & 1053 \\
\hline & 7 & 10144 & 10867 & 1306 & 1164 \\
\hline
\end{tabular}

Table 6-3 Average modulus of elasticity input parameters of joist components 


\begin{tabular}{|c|c|c|c|c|c|c|}
\hline \multirow{2}{*}{ Group \# } & \multicolumn{2}{|c|}{$\begin{array}{c}\text { Flanges } \\
\text { Longitudinal } \\
\text { Modulus of } \\
\text { Elasticity (MPa) }\end{array}$} & \multicolumn{2}{|c|}{$\begin{array}{c}\text { Flanges Torsional } \\
\text { Shear Modulus } \\
\text { (MPa) }\end{array}$} & $\begin{array}{c}\text { Web } \\
\text { Transverse } \\
\text { Modulus of } \\
\text { Elasticity (MPa) }\end{array}$ & $\begin{array}{c}\text { Web Parallel } \\
\text { Modulus of } \\
\text { Elasticity (MPa) }\end{array}$ \\
\cline { 2 - 5 } & Top & Bottom & Top & Bottom & 2123 & 5308 \\
\hline A & 12749 & 12746 & 1044 & 1070 & 1647 & 4118 \\
\hline B & 11550 & 11458 & 1243 & 1225 & & \\
\hline
\end{tabular}

\subsubsection{Boundary Conditions}

As described in Chapter 4, the joist specimens were tested experimentally with four distinct categories of boundary conditions: simply supported, top mounted and face mounted commercial joists hangers as well as hangers with enhanced rotational fixity. The degree of freedoms that best describe the first three experimental support configurations are the vertical displacement of the section and the lateral displacement of the top and bottom flange. The last configuration category also involves a rotational fixity at each extremity of the joists.

All boundary conditions are considered to be supported vertically at each joist extremity. The simply support condition can be described by having lateral supports on the side of the top and bottom flange without restraining the rotation of the flanges on themselves (Figure 6-1 A). To simulate the top mounted joist hangers, the top flange was considered to be restrained by a lateral support at mid-height and the bottom flange lateral support was represented by a lateral spring (Figure 6-1 B). The bottom flange spring stiffness was determined by experimental testing (Table 5-3). The enhanced connections with rotational fixity were designed to restrain rotation of the flanges about the joist's weak axis (axis 2) and twist about the longitudinal axis (axis 1). These rotational restraints for both flanges are modeled by adding a vertical and longitudinal support on each side of the flanges, at mid-height (Figure 6-1 D).

The modeling of the face-mounted hangers can be simulated by considering a bottom flange restrained from lateral movement by a support at mid-height. The top flange lateral support can be represent by a spring (Figure 6-1 C) to mimic the reduced stiffness of the top flange being 
supported along the web with stiffeners. In the present study, no tests have been made to determine the stiffness of such spring so no analysis could be done with this condition.

For the simply supported and hangers modeling, at least one longitudinal support needed to be introduced in the model to assure the stability of the joists. Since the experimental setup restrained the joists while letting the extremities free to translate longitudinally, the longitudinal support was placed at the same position of the load application (Figure 6-2).

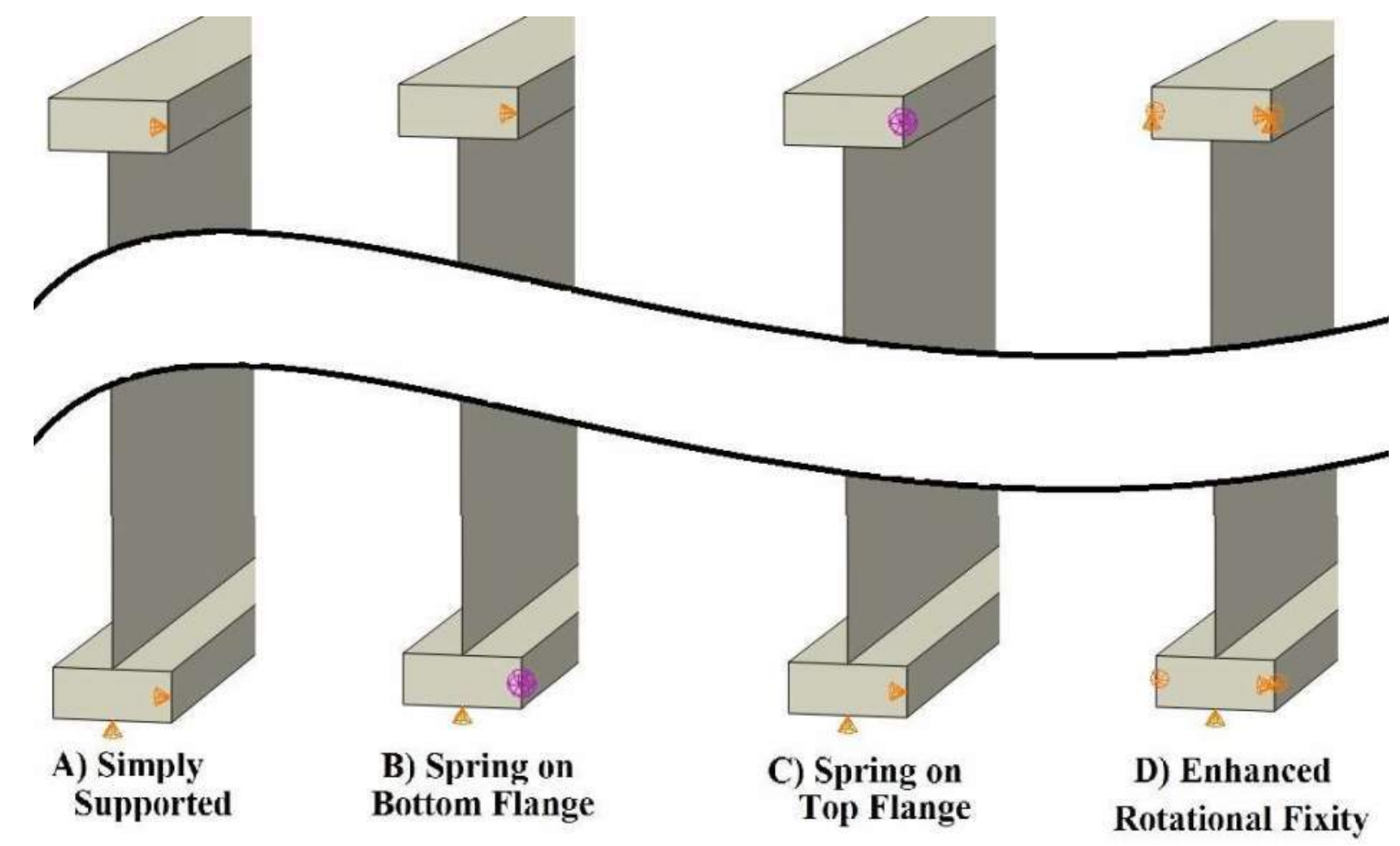

Figure 6-1 Boundary Conditions for FE Analysis 


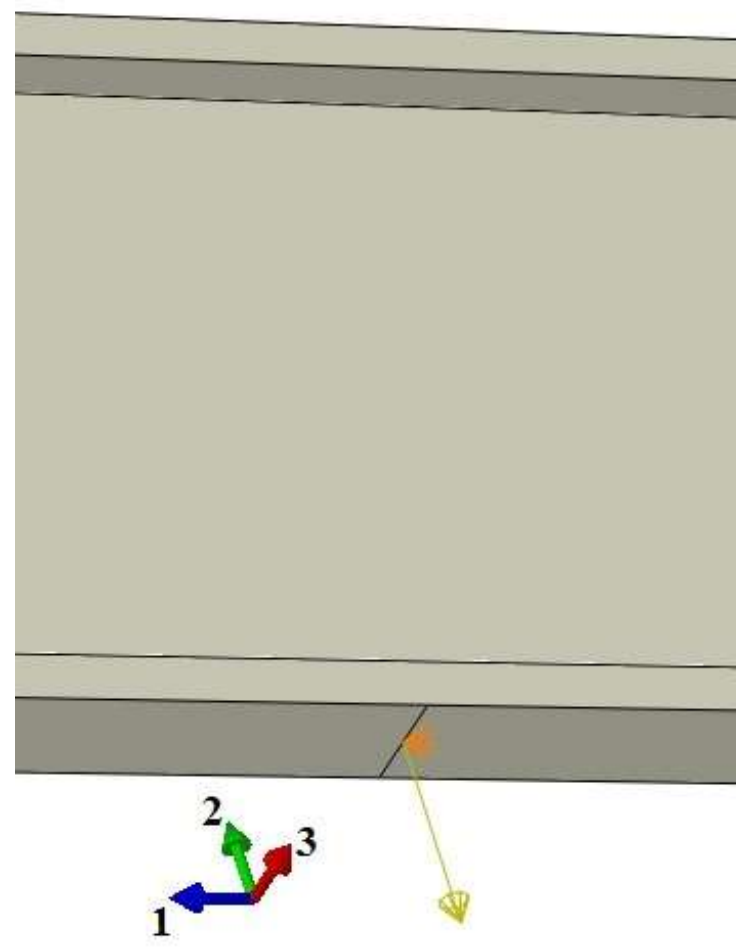

Figure 6-2 Longitudinal support and load application at mid-span on bottom flange of joists

\subsubsection{Load application}

To effectively model the load application from the load transfer device on the bottom flange, a concentrated load was positioned at mid-span as seen in Figure 6-2. The concentrated load may induce a stress concentration zone on the bottom flange. However, this does not affect the overall lateral stability behavior of the joists.

\subsection{Eigenvalue analysis procedure}

An eigenvalue analysis was conducted to determine the buckling capacity of the I-joist specimens and their buckling mode. Table 6-4 and Table 6-5 present the results for the linear buckling load for each model tested with the various I-joist specimens or end conditions. Table 6-4 lists the selected specimens that were tested with varying flange properties and simply supported end boundary conditions. Table 6-5 lists the results of varying boundary conditions of each sample 
group with average material properties input. Figure 6-3 shows an example of the main buckling mode for each category of end conditions tested.

Table 6-4 Critical Eigenvalue buckling loads for selected specimens with varying flanges properties.

\begin{tabular}{|c|c|c|}
\hline $\begin{array}{c}\text { Sample } \\
\text { Group }\end{array}$ & $\begin{array}{c}\text { Specimen } \\
\#\end{array}$ & $\begin{array}{c}\text { Buckling load } \\
\left(\mathrm{kN}^{*} \mathrm{~m}\right)\end{array}$ \\
\hline \multirow{4}{*}{$\mathrm{A}$} & 1 & 11.2 \\
\cline { 2 - 3 } & 2 & 11.4 \\
\cline { 2 - 3 } & 3 & 10.4 \\
\cline { 2 - 3 } & 4 & 10.1 \\
\cline { 2 - 3 } & 5 & 10.2 \\
\cline { 2 - 3 } & 6 & 10.1 \\
\hline \multirow{4}{*}{ B } & 2 & 23.0 \\
\cline { 2 - 3 } & 3 & 18.5 \\
\cline { 2 - 3 } & 4 & 18.9 \\
\cline { 2 - 3 } & 5 & 20.3 \\
\cline { 2 - 3 } & 6 & 19.7 \\
\cline { 2 - 3 } & 7 & 18.8 \\
\hline
\end{tabular}

Table 6-5 Critical Eigenvalue buckling loads with average material input for each boundary condition.

\begin{tabular}{|c|c|c|c|}
\hline $\begin{array}{l}\text { Sample } \\
\text { Group }\end{array}$ & $\begin{array}{l}\text { LTB Boundary } \\
\text { Condition }\end{array}$ & $\begin{array}{l}\text { Hangers / } \\
\text { Connection }\end{array}$ & $\begin{array}{l}\text { Buckling load } \\
\left(\mathrm{kN}^{*} \mathrm{~m}\right)\end{array}$ \\
\hline \multirow{3}{*}{ A } & \multicolumn{2}{|c|}{ Simply Supported } & 10.8 \\
\hline & Top Mounted & LBV2.56/16 & 8.1 \\
\hline & Enhanced Fixit & Connection & 13.7 \\
\hline \multirow{5}{*}{ B } & \multicolumn{2}{|c|}{ Simply Supported } & 20.9 \\
\hline & \multirow{3}{*}{ Top Mounted } & HWI424 & 15.4 \\
\hline & & HIT424 & 17.9 \\
\hline & & HB3.56/24 & 19.6 \\
\hline & \multicolumn{2}{|c|}{ Enhanced Fixity Connection } & 28.7 \\
\hline
\end{tabular}




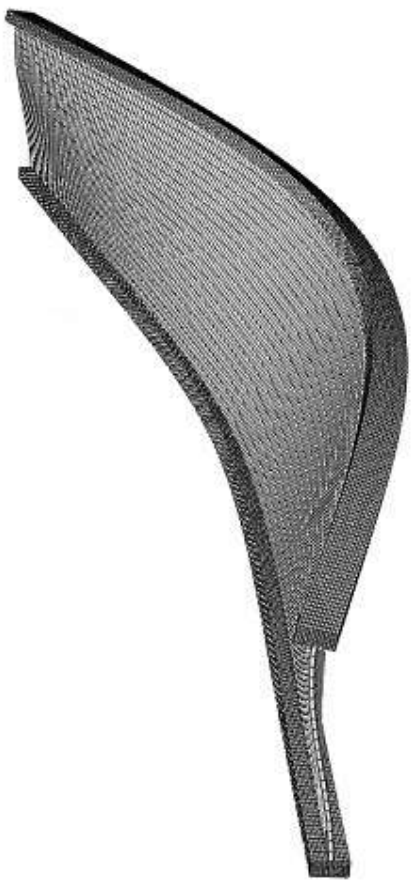

a) Simply Supported

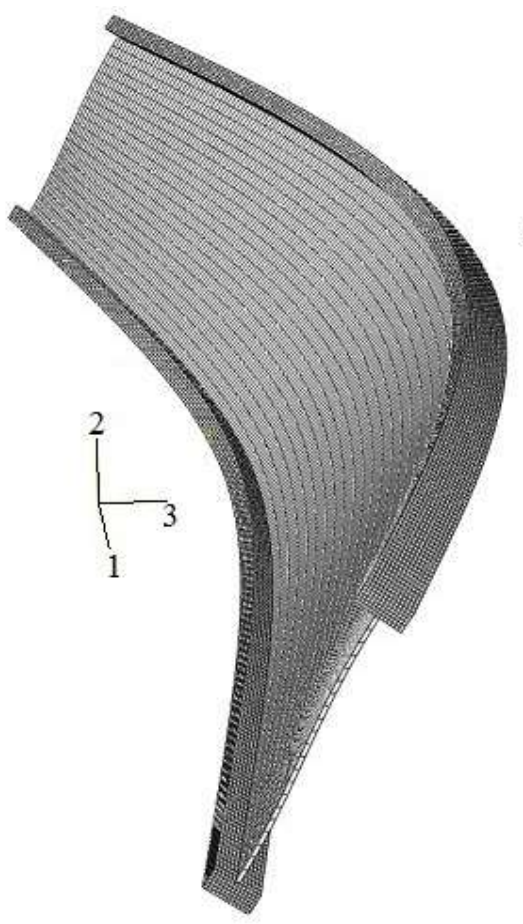

b) Spring at bottom flange

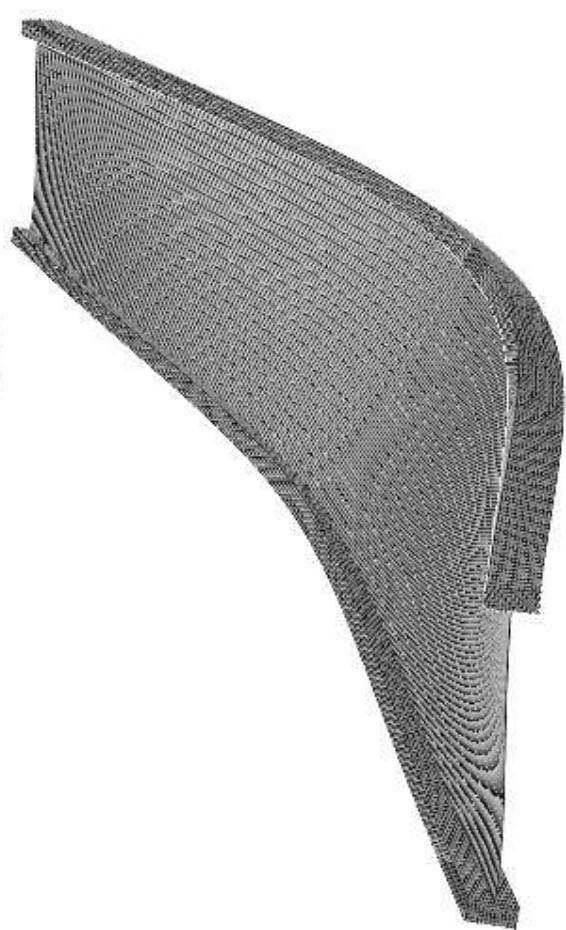

c) Enhanced rotational fixity

Figure 6-3 Main buckling mode for each boundary type 


\subsection{Geometric nonlinear analysis procedure}

The ABAQUS Software uses the modified RIKS method to conduct a nonlinear geometric analysis of the I-joists (Simulia 2014). The iterative procedure used by the software enables the user to include initial imperfections on the joists by using a preceding eigenvalue mode and scales it to match the initial out-of-straightness of the top flange of the specimen. The initial imperfections incorporated in the numerical model is illustrated in Figure 6-4. Table 6-6 presents the out-ofstraightness that was measured during the LTB experiment of some specimens tested with simply supported end conditions.

The RIKS method uses load increments to calculate the stiffness matrix of the structure. Every analysis required between 10 and 15 automatic load increments with and an average of 55 iterations to converge. Figure 6-5 illustrates an example of analysis steps and their nonlinear buckling deformation. Figure 6-6 plots an example of the lateral displacement of the top flange as a function of the internal moment and Figure 6-7 plots an example of the angular rotation of the section with respect to the internal moment. 


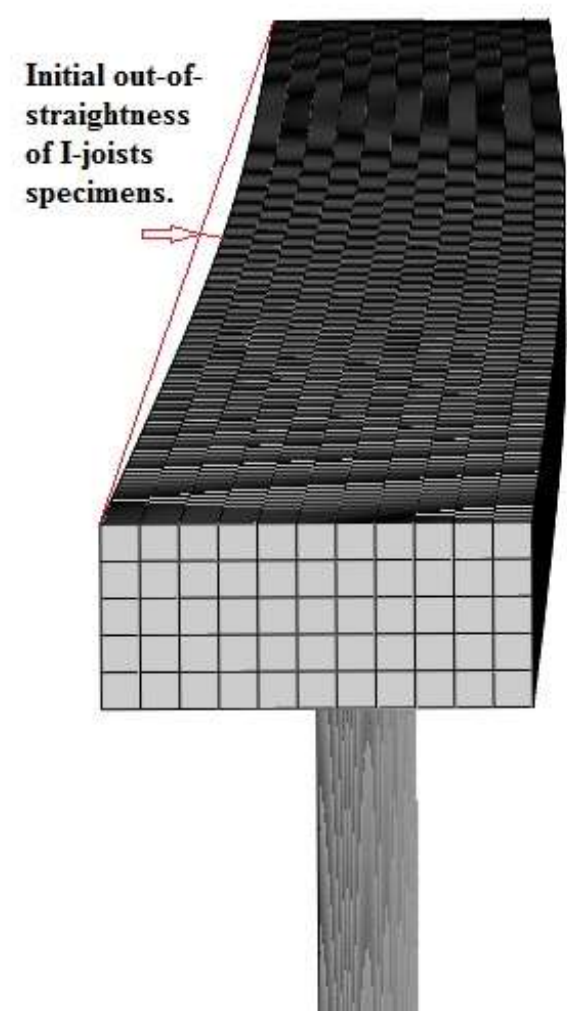

Figure 6-4 Initial imperfection of joists in FE model

Table 6-6 Initial Out-of-Straightness of selected specimens with varying flanges properties.

\begin{tabular}{|c|c|c|c|c|c|}
\hline $\begin{array}{l}\text { Group } \\
\text { Sample }\end{array}$ & $\begin{array}{c}\text { Specimen } \\
\#\end{array}$ & $\begin{array}{l}\text { Out of } \\
\text { straightness } \\
\quad(\mathrm{mm})\end{array}$ & $\begin{array}{l}\text { Group } \\
\text { Sample }\end{array}$ & $\begin{array}{c}\text { Specimen } \\
\#\end{array}$ & $\begin{array}{l}\text { Out of } \\
\text { straightness } \\
(\mathrm{mm})\end{array}$ \\
\hline \multirow{6}{*}{ A } & 1 & 1.8 & \multirow{7}{*}{ B } & 1 & 4.5 \\
\hline & 2 & 7.3 & & 2 & 5.5 \\
\hline & 3 & 4.3 & & 3 & 5.0 \\
\hline & 4 & 5.8 & & 4 & 3.0 \\
\hline & 5 & 3.0 & & 5 & 0.5 \\
\hline & 6 & 0.5 & & 6 & 5.5 \\
\hline & & & & 7 & 15.0 \\
\hline
\end{tabular}




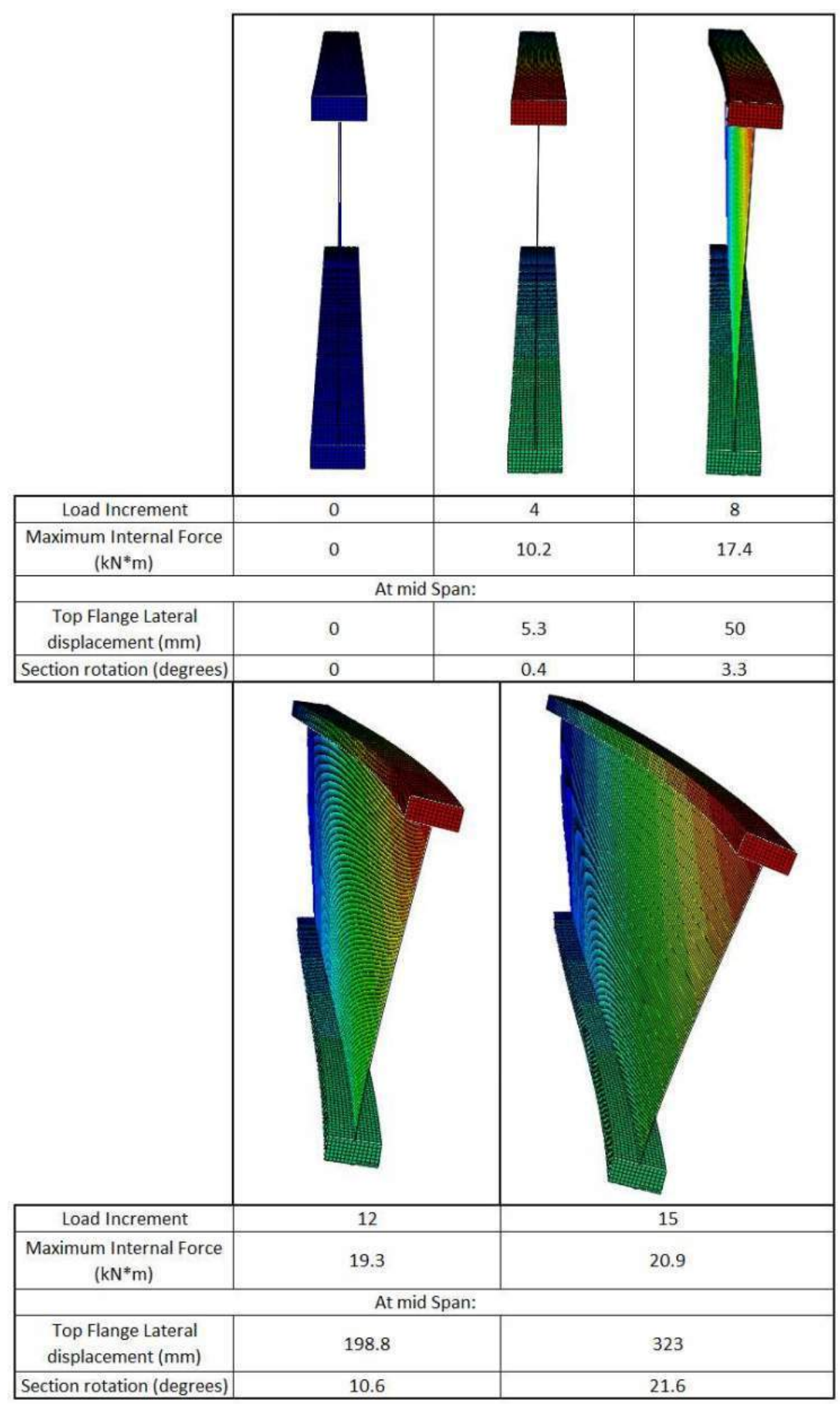

Figure 6-5 Finite Element geometric nonlinear analysis steps 


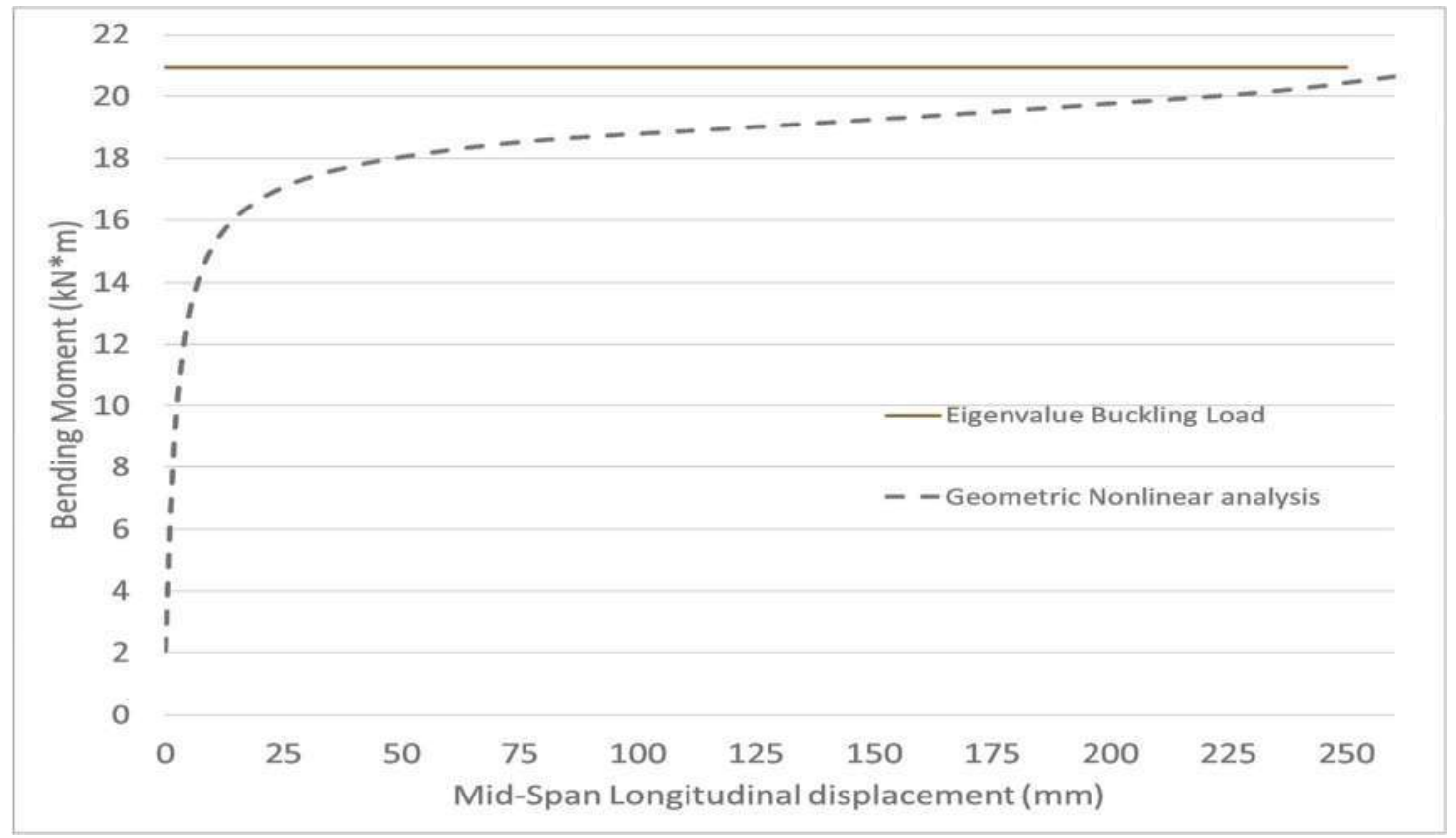

Figure 6-6 Specimen B-4 Lateral Displacement of Top Flange - Buckling load and geometric nonlinear behavior

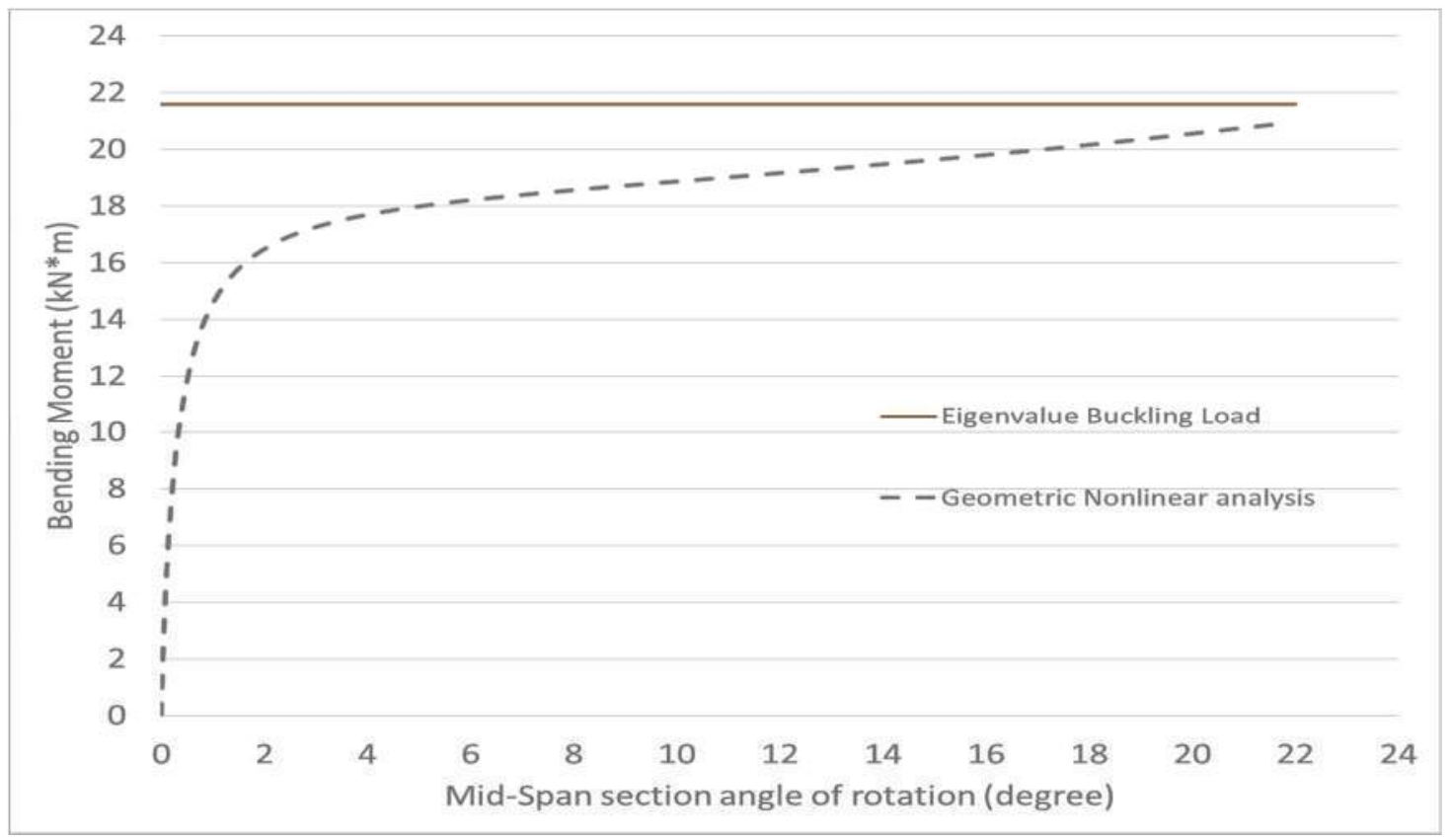

Figure 6-7 Specimen B-4 - Section rotation - Buckling load and geometric nonlinear behavior 


\section{CHAPTER 7}

\section{DISCUSSION}

This chapter discusses the results of both the experimental investigation conducted and the numerical modeling developed in order to predict the lateral-torsional buckling capacity of wood I-joists. Section 7.1 summarizes the findings of the influence of the connectors' rigidity from the experimental investigation. Section 7.2 presents the main comparison between the numerical and experimental data and section 7.3 focuses on the nonlinear analysis of the joists.

\subsection{Influence of the connector's rigidity}

\subsubsection{Analysis method}

This section discusses experimental results for "realistic" boundary conditions and compares the results to those obtained from idealized simply supported conditions. Since solely basing the comparison on average values would not be appropriate, statistical analysis was conducted by means of t-test.

A statistical two-tails t-test was conducted to compare the results. The test was done to determine if there is sufficient difference between two data sets in order to consider them as part of same or two separate groups. The confidence level for this analysis is $95 \%$.

$$
\text { if }-t_{\text {crit }} \leq t_{\text {stat }} \leq t_{\text {crit }} \text { the null hypothesis is rejected }
$$

In this study, the null hypothesis represents a significant influence by the hanger connections on the LTB load.

Sections 7.1.2 discusses comparisons for most typical joist hangers used commercially and Section 7.1.3 provides suggestions for improvements to the connection in order to enhance the LTB capacity. 


\subsubsection{Influence of commercial hangers stiffness based on experimental investigation}

Joist specimens from each group were tested with end nailing, face mounted or top mounted commercial hangers. The inclusion of such realistic boundary connections either had no effect or generally negative effect on buckling load compared with those tested with simply supported end conditions. The results of average buckling load obtained and their COV for all the hangers and the nailed connection are summarized in Table 7-1. The results are also presented graphically in Figure 7-1 and Figure 7-2 for specimen's group A and B, respectively.

Table 7-1 Commercial hangers ultimate buckling load

\begin{tabular}{|c|c|c|c|c|c|}
\hline $\begin{array}{l}\text { Sample } \\
\text { Group }\end{array}$ & $\begin{array}{l}\text { Hangers / } \\
\text { Connection }\end{array}$ & & $\begin{array}{l}\text { Buckling load } \\
\left(\mathrm{kN}^{*} \mathrm{~m}\right)\end{array}$ & $\begin{array}{l}\text { AVG SS Load } \\
\left(\mathrm{kN}^{*} \mathrm{~m}\right)\end{array}$ & $\begin{array}{c}\% \\
\text { Difference }\end{array}$ \\
\hline \multirow{8}{*}{ A } & \multirow{2}{*}{ *TM - LBV2.56/16 } & Average & 9.0 & \multirow{8}{*}{$\begin{array}{c}\text { Average : } 10.6 \\
\text { COV : } 5.4 \%\end{array}$} & \multirow{2}{*}{-15.1} \\
\hline & & COV & 5.1 & & \\
\hline & \multirow{2}{*}{ **FM - IUS2.56/16 } & Average & 9.0 & & \multirow{2}{*}{-14.5} \\
\hline & & COV & 0.3 & & \\
\hline & \multirow{2}{*}{ **FM - HU316 } & Average & 9.2 & & \multirow{2}{*}{-12.7} \\
\hline & & COV & 1.4 & & \\
\hline & \multirow{2}{*}{$\begin{array}{l}\text { Nails in End grain } \\
\text { (NLD) }\end{array}$} & Average & 10.0 & & \multirow{2}{*}{-5.0} \\
\hline & & COV & 0.63 & & \\
\hline \multirow{12}{*}{ B } & \multirow{2}{*}{ *TM - HWI424 } & Average & 18.4 & \multirow{12}{*}{$\begin{array}{c}\text { Average : } 19.8 \\
\text { COV : } 8.4 \%\end{array}$} & \multirow{2}{*}{-7.3} \\
\hline & & COV & 3.9 & & \\
\hline & \multirow{2}{*}{ *TM - HIT424 } & Average & 19.7 & & \multirow{2}{*}{-0.9} \\
\hline & & $\mathrm{COV}$ & 9.0 & & \\
\hline & \multirow{2}{*}{ *TM - HB3.56/24 } & Average & 19.9 & & 04 \\
\hline & & COV & 1.7 & & 0.4 \\
\hline & \multirow{2}{*}{ **FM - IUS3.56/16 } & Average & 16.4 & & \multirow{2}{*}{-17.3} \\
\hline & & COV & 5.1 & & \\
\hline & \multirow{2}{*}{ **FM - MIU3.56/16 } & Average & 18.2 & & \multirow{2}{*}{-8.4} \\
\hline & & COV & 2.5 & & \\
\hline & \multirow{2}{*}{$\begin{array}{l}\text { Nails in End grain } \\
\text { (NLD) }\end{array}$} & Average & 21.5 & & \multirow{2}{*}{8.2} \\
\hline & & COV & 0.9 & & \\
\hline
\end{tabular}

*TM : Top Mounted Hangers

**FM : Face Mounted Hangers 


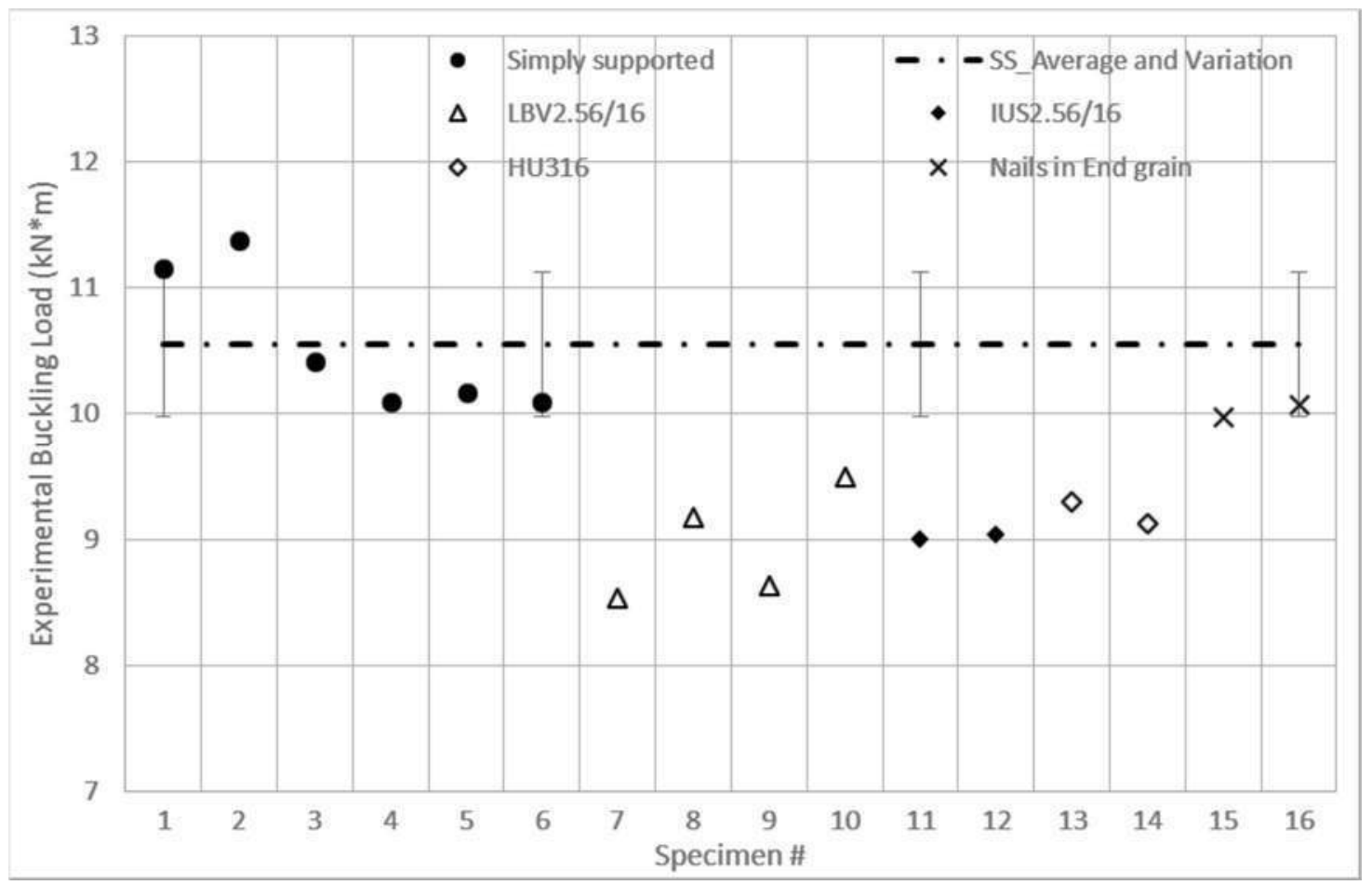

Figure 7-1 LTB load resistance of group A joist specimens

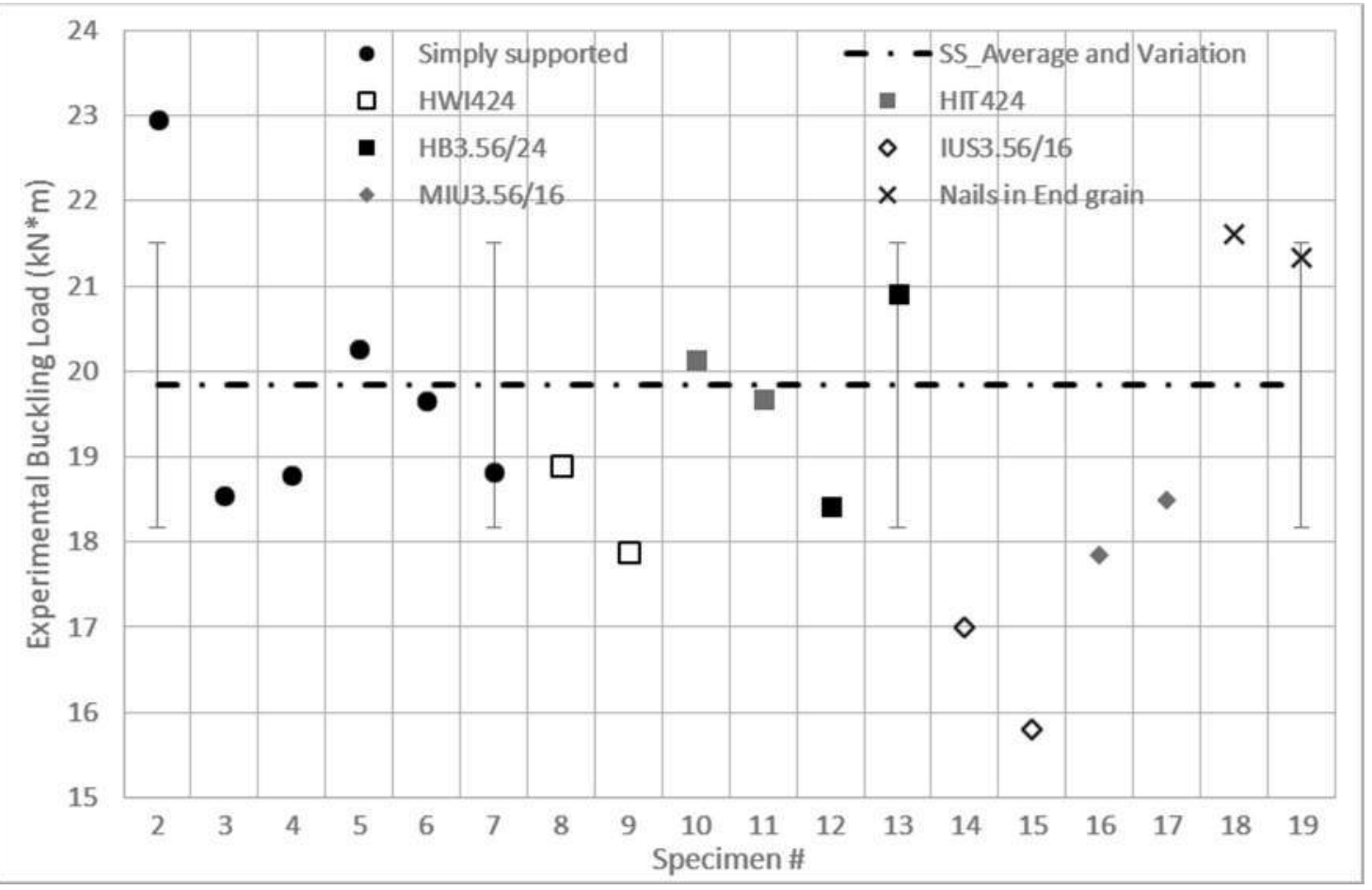

Figure 7-2 LTB load resistance of group B joist specimens 
For the top mounted hangers, group A specimens, which were tested with only LBV2.56/16 hangers resulted in LTB load with an average reduction of $15.1 \%$ compared to the simplysupported case. Group B specimens were tested with 3 different hangers, namely HIT424, HWI424 and HB3.56/24. As the results indicate, the most flexible hanger (HWI424) yielded an average reduction in buckling load of $7.3 \%$ while stiffer hangers (HIT424 and HB3.56/24) yielded an average reduction of $0.9 \%$ and a slight increase of $0.4 \%$, respectively.

A closer look at the data using the statistical analysis confirms the lower results obtained with the LBV2.56/16 hangers tested with the group A but rejects any significant difference with any of the hangers tested with group B, as seen in Table 7-2. The numbers in bold reflect the tests where the null hypothesis from the t-test cannot be rejected.

Table 7-2 Statistical t-test results with hangers connections

\begin{tabular}{|c|c|c|c|}
\hline $\begin{array}{c}\text { Specimen } \\
\text { Group }\end{array}$ & $\begin{array}{c}\text { Group } \\
\text { Comparision }\end{array}$ & tStat & $\begin{array}{c}\text { Absolute } \\
\text { tCritical }\end{array}$ \\
\hline \multirow{4}{*}{ A } & TM_LBV-SS & 4.88 & 2.31 \\
\cline { 2 - 4 } & FM_IUS -SS & 6.57 & 2.57 \\
\cline { 2 - 4 } & FM_HU - SS & 5.39 & 2.45 \\
\cline { 2 - 4 } & NLD - SS & $\mathbf{2 . 2 4}$ & $\mathbf{2 . 5 7}$ \\
\hline \multirow{6}{*}{ B } & TM_HW-SS & $\mathbf{1 . 7 2}$ & $\mathbf{2 . 5 7}$ \\
\cline { 2 - 4 } & TM_HIT-SS & $\mathbf{0 . 1 2}$ & $\mathbf{4 . 3 0}$ \\
\cline { 2 - 4 } & TM_HB-SS & $\mathbf{- 0 . 1 1}$ & $\mathbf{2 . 4 5}$ \\
\cline { 2 - 4 } & FM_IUS - SS & 3.8 & 2.78 \\
\cline { 2 - 4 } & FM_MIU - SS & $\mathbf{2 . 2 2}$ & $\mathbf{2 . 4 5}$ \\
\cline { 2 - 4 } & NLD - SS & $\mathbf{2 . 3 7}$ & $\mathbf{2 . 5 7}$ \\
\hline
\end{tabular}

The experimental observations indicated that the top flange could be considered restrained from any lateral movement. However, a lateral displacement of the joists' bottom flange was detected for some of the hangers, as shown in Figure 7-3 for the HWI424 hanger. The displacement was most significant for the LBV2.56/16 and HWI424 hangers, which corroborates the observed reduction in the buckling load for those two hangers. Consistently, little to no lateral movement was observed in the bottom flange of the HIT424 and HB3.56/24 hangers. For all cases, a maximum reduction of approximately $19 \%$ was observed. 


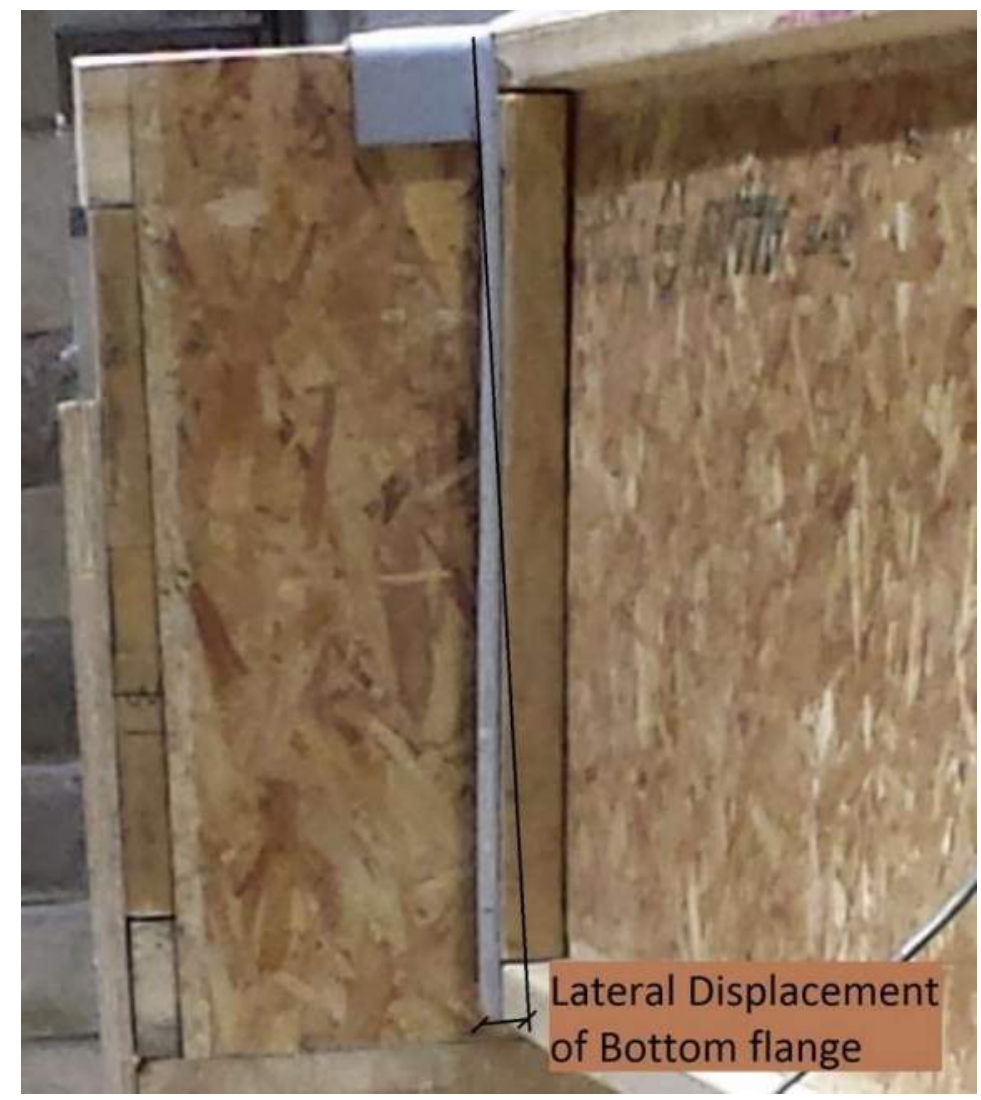

Figure 7-3 Bottom Flange lateral displacement with HWI424 hanger.

With the face mounted hangers, as seen in Table 7-1, the reduction in buckling load for the IUS2.56/16 and HU316 hangers used with specimen group A is estimated to $14.5 \%$ and $12.7 \%$, respectively. For group B specimens tested with the IUS3.56/16 hanger, the reduction is on average $17.3 \%$. As indicated by the statistical analysis no significant increase was observed for the MIU3.56/16 hangers. Although in the case of face-mounted hangers, the bottom flanges were generally held in place by the hanger side plate and the top flange was not directly supported, stiffeners were used to restrain the joist from laterally translating. Other factors could include the number of nails connecting the hanger to the support which, when inadequate, may cause some slippage.

The IUS hangers were made from thinner gauge and they also had the lowest number of fasteners connecting the hanger to the support compared to the other face mounted hangers. For hangers IUS2.56/16 tested with the specimens group A, no stiffeners were used, since the joists top flange 
was supported directly by the hanger. The IUS3.56/16 hanger tested with group B could not support the top flange so stiffeners had to be installed as per the manufacturer's specifications.

The HU316 hanger had a thicker metal frame and more fasteners linked it to the support but unlike the IUS2.56/16 hanger, it does not support the top flange of the joists directly. This configuration prevents the overall rotation of the section but does not fully restrain the lateral translation or the rotation of the top flange. Figure 7-4 shows a top view of the joists in its deformed shape. A translation of the top flange can be observed which could explain the reduction in buckling load.

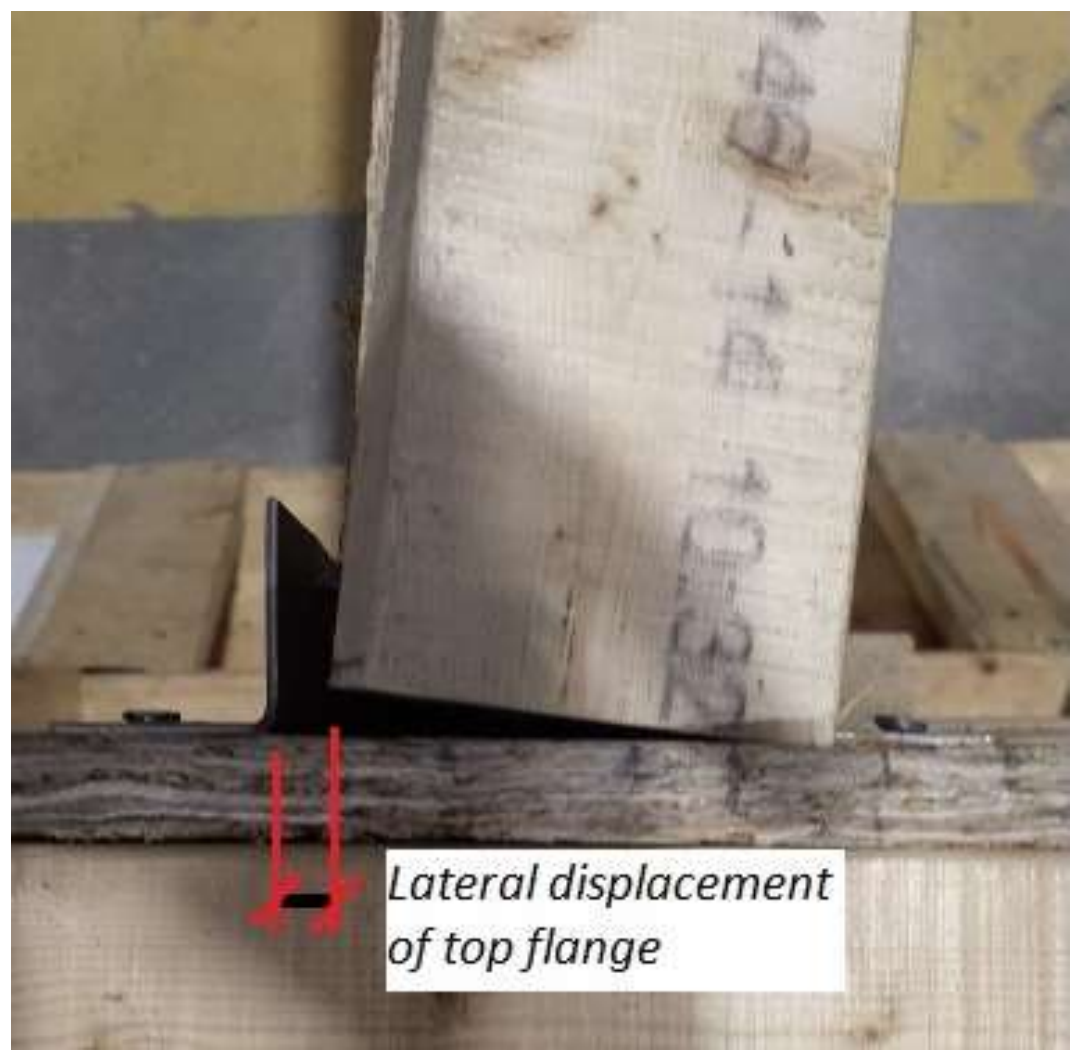

Figure 7-4 Top view of displacement of joist top flange with HU316 hanger

For specimen group A, the setup where the joists were connected to the support with nails, fastened through the end grain of the flange, showed an average load reduction of $5 \%$. With the group B, 
the same connection setup yielded average increases of the buckling load of $8.2 \%$. Although in principle having two nails would provide some level of rotational fixity, the weak withdrawal capacity and the potential for nail slippage meant that the contribution was insignificant, as shown in Figure 7-5. The statistical test also rejects any significant difference which means that such connection could be compared to the simply supported end condition.

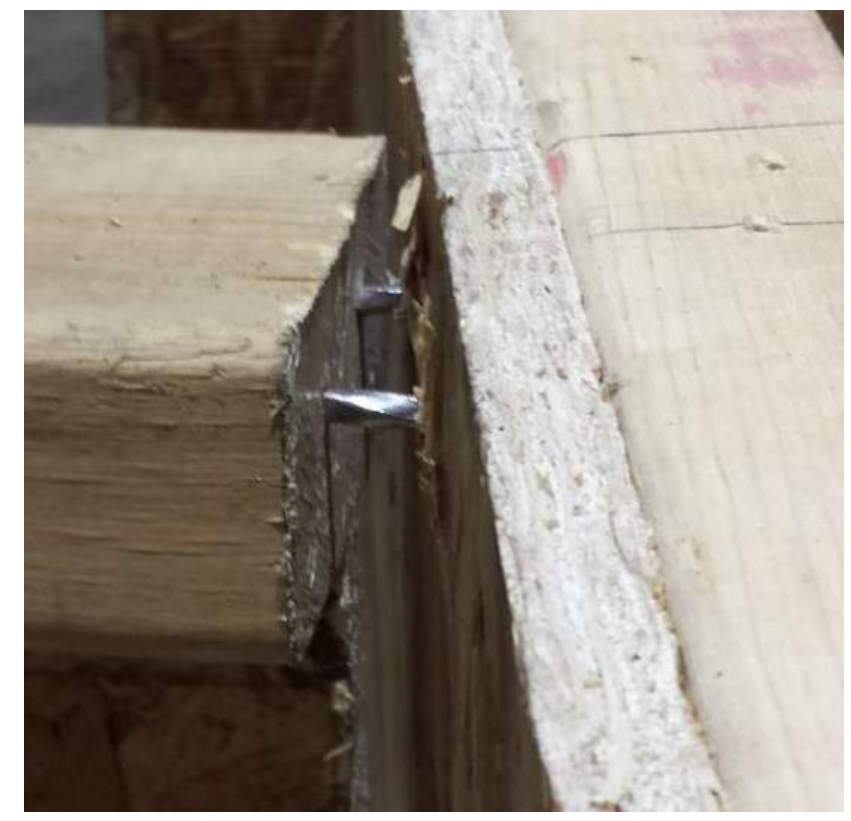

Figure 7-5 Nails withdrawal in end grain under buckling rotation

When considering the implication of the reduction on design of floor joists, it is noteworthy to mention that Hooley and Madsen (1964) had suggested that 15\% reduction would be appropriate to use for design when dealing with non-idealized conditions. It should be noted that the selected value for reduction was not based on testing "realistic" boundary conditions but rather an estimate provided by the researchers. Although this estimate seems reasonable on average, it is nonconservative in some cases. Based on the test configurations considered in the current study, it is recommended that design provisions for lateral torsional buckling be modified to include a reduction of $20 \%$ rather than $15 \%$ to account for non-idealized boundary conditions and to ensure better safety. 


\subsubsection{Proposed measures to enhance connection rigidity}

In order to enhance the rotational restraint in the weak direction, two connectors were investigated to provide additional moment restraint: a modified HWI hanger (HWR) and a connection developed using two angle brackets. Lateral displacements at the bottom of the HWI hanger was prevented by welding a steel plate on each side of the hanger. The developed bracket connection was intended to create high level of rotational restraint of the top flange. A summary of the results can be seen in Table 7-3.

Table 7-3 Ultimate buckling load of enhanced connections

\begin{tabular}{|c|c|c|c|c|c|}
\hline $\begin{array}{l}\text { Sample } \\
\text { Group }\end{array}$ & $\begin{array}{l}\text { Hangers / } \\
\text { Connection }\end{array}$ & & $\begin{array}{c}\text { Buckling } \\
\text { load }\left(k N^{*} m\right)\end{array}$ & $\begin{array}{l}\text { AVG SS Load } \\
\quad\left(\mathrm{kN}^{*} \mathrm{~m}\right)\end{array}$ & $\begin{array}{c}\% \\
\text { Increase }\end{array}$ \\
\hline \multirow{2}{*}{ A } & \multirow{2}{*}{$\begin{array}{c}\text { Angle Contained } \\
\text { Flanges (ACF) }\end{array}$} & Average & 15.0 & \multirow{2}{*}{$\begin{array}{c}\text { Average : } 10.6 \\
\text { COV : } 5.4 \%\end{array}$} & \multirow{2}{*}{42.4} \\
\hline & & COV & 0.3 & & \\
\hline \multirow{4}{*}{ B } & \multirow{2}{*}{$\begin{array}{c}\text { Side Screwed } \\
\text { (HWR) }\end{array}$} & Average & 23.0 & \multirow{4}{*}{$\begin{array}{c}\text { Average : } 19.8 \\
\text { COV : } 8.4 \%\end{array}$} & \multirow{2}{*}{15.8} \\
\hline & & COV & 2.4 & & \\
\hline & \multirow{2}{*}{$\begin{array}{c}\text { Angle Contained } \\
\text { Flanges (ACF) }\end{array}$} & Average & 24.1 & & \multirow{2}{*}{21.5} \\
\hline & & COV & 3.9 & & \\
\hline
\end{tabular}

The data from the tests are also presented graphically in Figure 7-6 and Figure 7-7 for the presentation of specimen's group A and B respectively. 


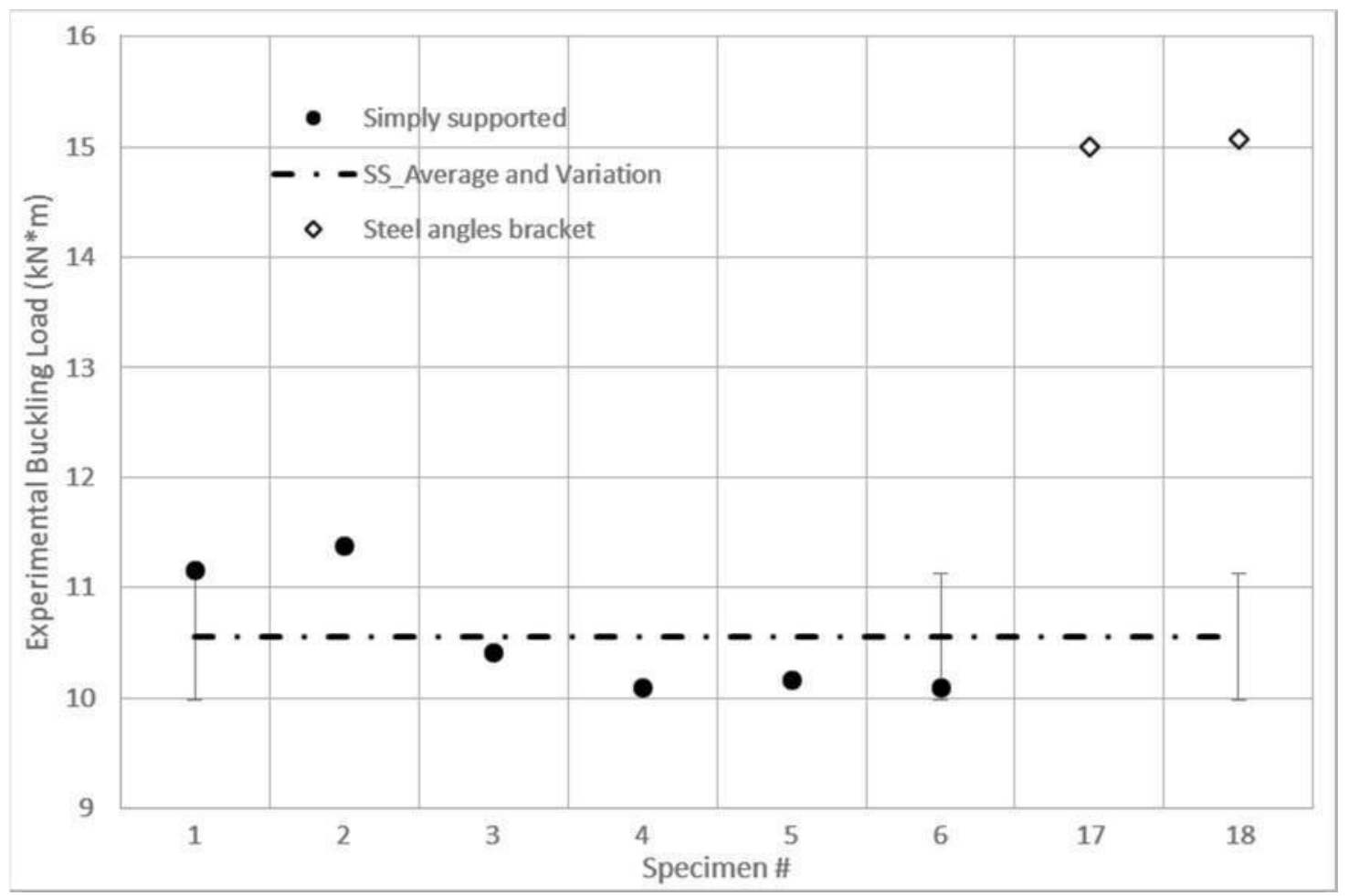

Figure 7-6 LTB load resistance of group A with enhance connection

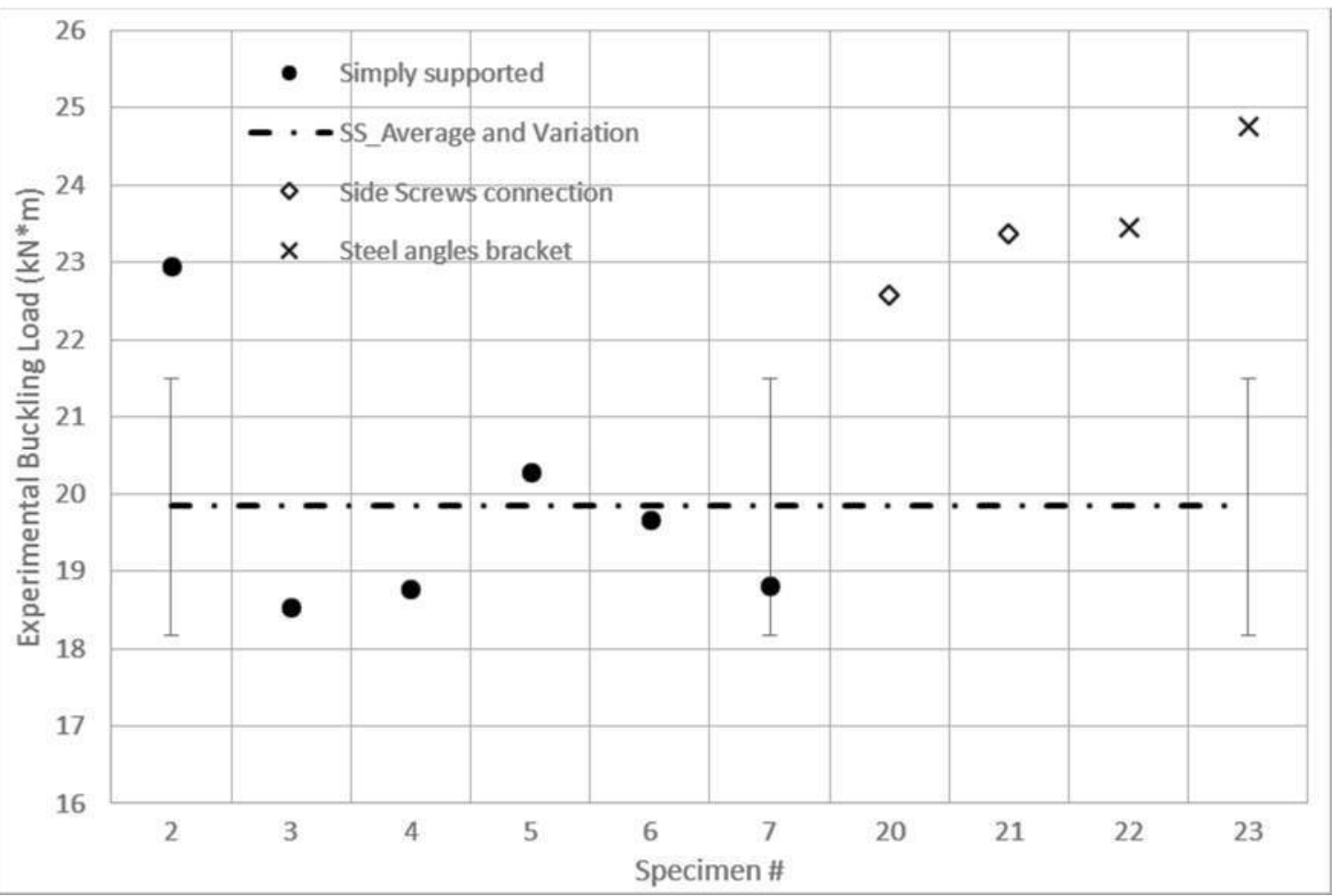

Figure 7-7 LTB load resistance of group B with enhanced connection 
A closer look at the data using the statistical analysis confirms the increase in LTB load obtained in Table 7-4.

Table 7-4 Statistical t-test results for enhanced connections

\begin{tabular}{|c|c|c|c|}
\hline $\begin{array}{c}\text { Specimen } \\
\text { Group }\end{array}$ & $\begin{array}{c}\text { Group } \\
\text { Comparison }\end{array}$ & tStat & $\begin{array}{c}\text { Absolute } \\
\text { tCritical }\end{array}$ \\
\hline A & ACF - SS & -19.02 & 2.57 \\
\hline \multirow{2}{*}{ B } & HWR - SS & 4.00 & 2.45 \\
\cline { 2 - 4 } & ACF - SS & 4.5 & 3.18 \\
\hline
\end{tabular}

The modified HWI connection performed well and enhanced the performance compared to the unmodified HWI hanger. The increase was on average $24.9 \%$ compared to the unmodified connection and approximately $15 \%$ compared to the reference case with simply supported conditions.

The connection with the angle bracket was capable of providing some rotational fixity. An increase of $42 \%$ and $21 \%$ was achieved for specimen groups A and B, respectively. Little to no rotation about the beam's weak axis was observed at each end, as seen in Figure 7-8.

The developed bracket connection was merely an attempt to show that by using simple considerations for the joist and beam connections, enhancement of the LTB capacity can be achieved rather easily. Although outside the scope of the current research project, development of connections that specifically targets maximizing the LTB capacity would be interesting to investigate. 


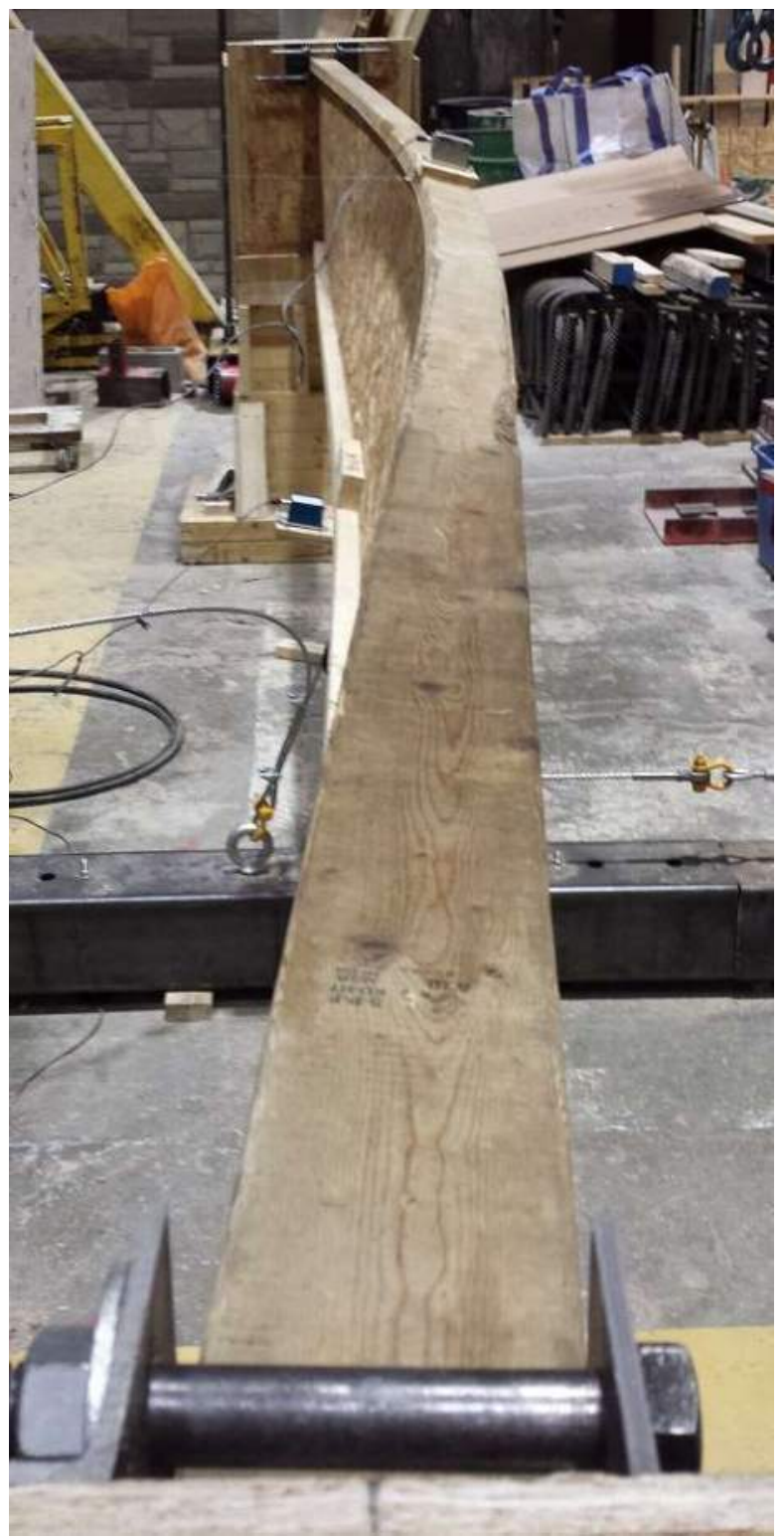

Figure 7-8 Buckling shape of joist with angle bracket connection. 


\subsection{Experimental vs numerical predictions of lateral torsional buckling loads}

\subsubsection{Simply supported end conditions}

This section compares the experimental results and the numerical eigenvalue predictions from the FE model. To validate the numerical model, the buckling load obtained from twelves specimens tested under simply supported end conditions for both specimen group A (specimen \#1 to \#6) and group B (specimen \#2 to \#7) were compared to the FE model eigenvalue predictions. Material properties obtained from the components tests were used as input. Table 7-5 summarizes the buckling loads obtained from the experimental tests and the numerical predictions. All graphs for force-displacement curve of the specimens tested experimentally and predicted buckling loads for each model predictions are presented in Appendix B .

Table 7-5 Buckling load and predictions for simply supported joists

\begin{tabular}{|c|c|c|c|c|}
\hline \multirow{3}{*}{$\begin{array}{c}\text { Sample } \\
\text { Group }\end{array}$} & $\begin{array}{c}\text { Specimen } \\
\#\end{array}$ & $\begin{array}{c}\text { Experiment } \\
\left(\mathrm{kN}{ }^{*} \mathrm{~m}\right)\end{array}$ & $\begin{array}{c}\text { FE Prediction } \\
\left(\mathrm{kN}{ }^{*} \mathrm{~m}\right)\end{array}$ & $\begin{array}{c}\text { FEA Prediction } \\
\text { Difference \% }\end{array}$ \\
\hline \multirow{4}{*}{} & 1 & 11.2 & 10.8 & -3.1 \\
\cline { 2 - 5 } & 2 & 11.4 & 11.2 & -2.0 \\
\cline { 2 - 5 } & 3 & 10.4 & 11.0 & 5.2 \\
\cline { 2 - 5 } & 4 & 10.1 & 11.5 & 13.9 \\
\cline { 2 - 5 } & 5 & 10.2 & 10.7 & 5.5 \\
\cline { 2 - 5 } & 6 & 10.1 & 10.9 & 8.2 \\
\cline { 2 - 5 } & Average & 10.6 & 11.0 & 4.6 \\
\cline { 2 - 5 } & COV \% & 5.4 & 2.5 & 6.0 \\
\hline \multirow{4}{*}{ B } & 2 & 23.0 & 21.9 & -4.4 \\
\cline { 2 - 5 } & 3 & 18.5 & 17.4 & -6.1 \\
\cline { 2 - 5 } & 4 & 18.8 & 21.4 & 14.0 \\
\cline { 2 - 5 } & 5 & 20.3 & 18.7 & -7.7 \\
\cline { 2 - 5 } & 6 & 19.7 & 19.1 & -2.7 \\
\cline { 2 - 5 } & 7 & 18.8 & 19.1 & 1.6 \\
\cline { 2 - 5 } & Average & 19.8 & 19.6 & -0.9 \\
\cline { 2 - 5 } & COV \% & 8.4 & 8.8 & 8.0 \\
\hline
\end{tabular}




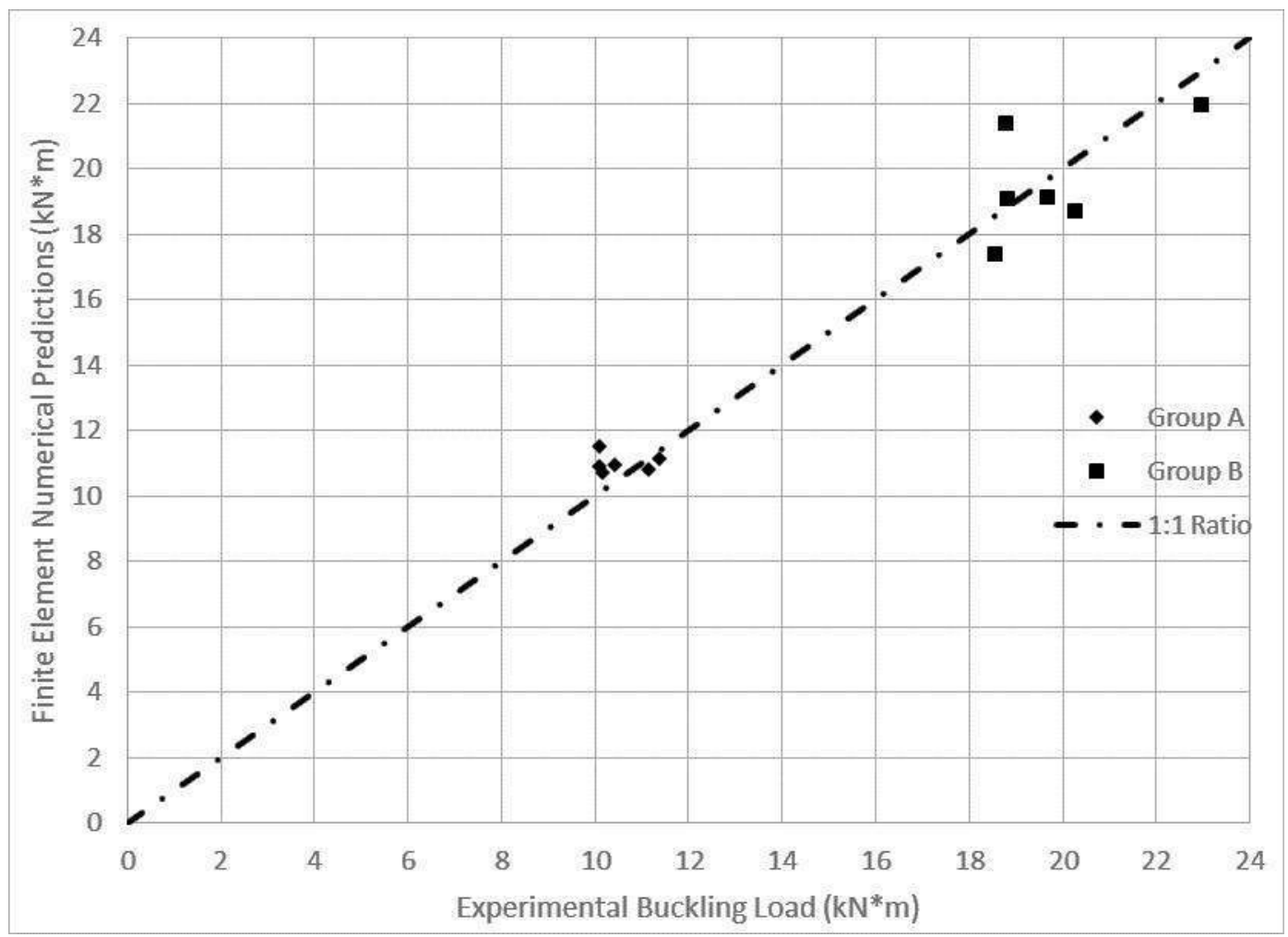

Figure 7-9 Simply supported specimens numerical predictions vs experimental observations

The FE analysis overestimated the buckling load on average by $4.6 \%$ with a COV of $6.1 \%$ for group A and slightly underestimated the buckling load by $0.9 \%$ with COV $8.0 \%$ for the group B. The variability found in the results can be attributed to the following factors:

- The properties obtained from the specimens were cut from I-joists tested for full-scale LTB and might have been affected by the loading history.

- Only a portion of the flange length is considered in the component test. However the joist flange consists of several lumber pieces finger-jointed together. This could mean that the tested piece may not be representative of the overall flange properties.

- Due to geometric nonlinearity and nature of the wood, conducting linear analysis may not be appropriate. This is discussed further in section 7.3.

As mentioned in the previous paragraph only component tests from selected joists were conducted. The model could, however, still be compared with the test results based on average input 
properties, as provided in Table 5-1 and Table 5-2. The results are shown in Table 7-6 for each specimen.

Table 7-6 Buckling load and average prediction for simply supported joists

\begin{tabular}{|c|c|c|c|c|}
\hline $\begin{array}{c}\text { Sample } \\
\text { Group }\end{array}$ & & $\begin{array}{c}\text { Experiment } \\
(\mathrm{kN} * \mathrm{~m})\end{array}$ & $\begin{array}{c}\text { FE Average } \\
(\mathrm{kN} * \mathrm{~m})\end{array}$ & $\begin{array}{c}\text { Difference } \\
\%\end{array}$ \\
\hline \multirow{2}{*}{$\mathrm{A}$} & Average & 10.6 & 10.8 & 2.8 \\
\cline { 2 - 5 } & COV \% & 5.4 & -- & 5.3 \\
\hline \multirow{2}{*}{$\mathrm{B}$} & Average & 20.8 & 20.93 & 2.3 \\
\cline { 2 - 5 } & COV \% & 13.8 & -- & 12.2 \\
\hline
\end{tabular}

In general the model seems capable of predicting the average behavior with reasonable accuracy (less than 3\%), however the variability found in group B seems significantly higher but not unexpected.

\subsubsection{Model prediction of joists with hangers and nails}

To compare the numerical predictions with the test results with hangers and nailed configurations, a finite element model where the flanges' lateral restrains were replaced by springs, as describe in Chapter 6, was developed. Initially average material properties were used as input values for the numerical model, however, to obtain better prediction available components test results were used as input for selected joist tests.

For the top mounted hangers, the bottom flange lateral restraint was replaced by a spring with stiffness obtained from experiments (see section 0) while the top flange was assumed to be fully restrained. The results of the model prediction are summarized in the Table 7-7. For group A specimens, the LBV2.56/16 hangers' predictions yielded an average buckling load value that was $9.5 \%$ lower than that obtained experimentally with a COV of 5.1\%. For group B, three hangers with various lateral stiffness were tested. The numerical models' buckling load for HWI424, HIT424 and HB3.56/24 were on average 16.3\%, 8.6\% and 1.8\% lower than the observed experimental load, respectively. 
Table 7-7 Top Mounted hangers experimental vs numerical predictions

\begin{tabular}{|c|c|c|c|c|c|}
\hline $\begin{array}{l}\text { Sample } \\
\text { Group }\end{array}$ & $\begin{array}{l}\text { Hangers / } \\
\text { Connection }\end{array}$ & & $\begin{array}{l}\text { Buckling load } \\
\qquad\left(\mathrm{kN}^{*} \mathrm{~m}\right)\end{array}$ & $\begin{array}{l}\text { FE Predictions } \\
\qquad\left(\mathrm{kN}^{*} \mathrm{~m}\right)\end{array}$ & $\begin{array}{c}\% \\
\text { Difference }\end{array}$ \\
\hline \multirow{2}{*}{$A$} & \multirow{2}{*}{ LBV2.56/16 } & Average & 9.0 & 8.1 & -9.5 \\
\hline & & COV \% & 5.1 & -- & 5.1 \\
\hline \multirow{6}{*}{ B } & \multirow{2}{*}{ HWI424 } & Average & 18.4 & 15.4 & -16.4 \\
\hline & & cov \% & 3.9 & -- & 3.9 \\
\hline & \multirow{2}{*}{ HIT424 } & Average & 19.7 & 17.9 & -8.6 \\
\hline & & COV \% & 9.0 & -- & 9.0 \\
\hline & \multirow{2}{*}{ HB3.56/24 } & Average & 19.9 & 19.6 & -1.8 \\
\hline & & COV \% & 1.7 & -- & 1.7 \\
\hline
\end{tabular}

It can be observed from Table 7-7 that the predicted buckling is consistently lower than that obtained experimentally. This skew in predicting the buckling load could be attributed to the experimental setup related to the hanger rigidity. It is proposed that future research focuses on the test setup and whether having the joist installed as part of the setup may give more precise results. Using more precise values for material properties but on limited test sample, the resulting LTB loads still yielded lower predictions as seen in Table 7-8. The results show a slight improvement in the prediction and seem to be a bit more consistent with an underestimation of the buckling load by around $10 \%$.

Table 7-8 Top Mounted hangers with respective material properties values

\begin{tabular}{|c|c|c|c|c|c|}
\hline $\begin{array}{c}\text { Sample } \\
\text { Group }\end{array}$ & $\begin{array}{c}\text { Hangers / } \\
\text { Connection }\end{array}$ & $\begin{array}{c}\text { Specimen } \\
\#\end{array}$ & $\begin{array}{c}\text { Experiment } \\
(\mathrm{kN} * \mathrm{~m})\end{array}$ & $\begin{array}{c}\text { FE Predictions } \\
(\mathrm{kN} * \mathrm{~m})\end{array}$ & \% Difference \\
\hline \multirow{4}{*}{$\mathrm{A}$} & \multirow{3}{*}{ LBV2.56/16 } & 9 & 8.6 & 7.9 & -8.8 \\
\cline { 3 - 6 } & & 10 & 9.5 & 8.2 & -13.8 \\
\cline { 3 - 6 } & & Average & 9.1 & 8.0 & -11.3 \\
\cline { 3 - 6 } & & COV \% & 6.8 & 2.8 & 4.0 \\
\hline \multirow{3}{*}{$\mathrm{B}$} & \multirow{3}{*}{$\mathrm{HWI424}$} & 8 & 18.9 & 16.7 & -11.7 \\
\cline { 3 - 6 } & & 9 & 17.9 & 16.5 & -7.6 \\
\cline { 3 - 6 } & & Average & 18.4 & 16.6 & -9.7 \\
\cline { 3 - 6 } & & COV \% & 3.9 & 0.7 & 3.2 \\
\hline
\end{tabular}


Unlike the top mounted hangers which could be tested directly, the fact that the I-joist top flange is not directly supported by the face mounted hangers makes it difficult to develop an experimental method to obtain stiffness values for the top flange. The modelling of the joists with face mounted hangers was deemed outside the scope of the current research work.

As observed in section 7.1.2, the nailed connection tested behaved in a similar manner to those obtained with the simply supported condition due to the low nail withdrawal stiffness in end grain. No specific tests were conducted for nail withdrawal stiffness, however the test results were compared with the numerical prediction of the joists with simply supported end condition and average material properties, as shown in Table 7-9.

Table 7-9 Nailed connection experimental vs numerical predictions

\begin{tabular}{|c|c|c|c|c|}
\hline $\begin{array}{c}\text { Sample } \\
\text { Group }\end{array}$ & & $\begin{array}{c}\text { Experiment } \\
(\mathrm{kN} * \mathrm{~m})\end{array}$ & $\begin{array}{c}\text { FE Predictions } \\
(\mathrm{kN} * \mathrm{~m})\end{array}$ & $\begin{array}{c}\% \\
\text { Difference }\end{array}$ \\
\hline \multirow{2}{*}{$\mathrm{A}$} & Average & 10.0 & 10.8 & 7.9 \\
\cline { 2 - 5 } & COV \% & 0.6 & -- & 0.5 \\
\hline \multirow{2}{*}{$\mathrm{B}$} & Average & 21.5 & 20.9 & -2.5 \\
\cline { 2 - 5 } & COV \% & 0.9 & -- & 0.6 \\
\hline
\end{tabular}

It can be observed from Table 7-9 that the nailed connection could be considered as simply supported end condition. Although the nail withdrawal capacity is very low, it was expected that the analysis results would yield slightly higher buckling load as observed from specimens group A. The slight reduction found in specimens group B could possibly be attributed to the use of average material properties and possible lateral slip in the nails. 


\subsubsection{Model prediction with enhanced connections}

The hanger bracket was modeled with idealized rotational fixity because little rotation at each support was observed during the experimental program (Figure 7-8). The numerical prediction obtained using average material properties were compared to the experimental results obtained for the enhanced connections. The results are shown in the Table 7-10.

Table 7-10 Enhanced rotational connections experimental vs numerical predictions

\begin{tabular}{|c|c|c|c|c|c|}
\hline $\begin{array}{l}\text { Sample } \\
\text { Group }\end{array}$ & $\begin{array}{l}\text { Hangers / } \\
\text { Connection }\end{array}$ & $\begin{array}{c}\text { Specimen } \\
\#\end{array}$ & $\begin{array}{l}\text { Experiment } \\
\left(\mathrm{kN}^{*} \mathrm{~m}\right)\end{array}$ & $\begin{array}{l}\text { FE Predictions } \\
\qquad\left(\mathrm{kN}^{*} \mathrm{~m}\right)\end{array}$ & $\begin{array}{c}\% \\
\text { Difference }\end{array}$ \\
\hline \multirow{2}{*}{$A$} & \multirow{2}{*}{$\begin{array}{c}\text { Angle Contained } \\
\text { Flanges (ACF) }\end{array}$} & Average & 15.0 & 13.7 & -8.7 \\
\hline & & COV \% & 0.3 & -- & 0.3 \\
\hline \multirow{4}{*}{ B } & \multirow{2}{*}{$\begin{array}{l}\text { Side Screwed } \\
\text { (HWR) }\end{array}$} & Average & 23.0 & 28.7 & 24.8 \\
\hline & & COV \% & 2.4 & -- & 2.4 \\
\hline & \multirow{2}{*}{$\begin{array}{c}\text { Angle Contained } \\
\text { Flanges (ACF) }\end{array}$} & Average & 24.1 & 28.7 & 19.0 \\
\hline & & COV \% & 3.9 & -- & 3.9 \\
\hline
\end{tabular}

For the screw connection, the numerical prediction overestimated the buckling load by approximately $24.8 \%$, which means that model overestimates the rotational fixity. This is expected since some lateral deformation is anticipated in the screws.

The angles brackets connections with both group A and group B showed varying results when compared to the respective numerical model with rotational fixity. The model for group A predicted a lower buckling load (around 8.7\%) and the model for group B predicted higher load (19\%) than what has been observed experimentally. Considering the great difference when comparing the results between each group, a new numerical analysis was developed where the material properties of each joists were used so one could compare each joists tested more closely with the numerical model. The results are presented in Table 7-11 
Table 7-11 Angle bracket connections comparison with respective material properties.

\begin{tabular}{|c|c|c|c|c|}
\hline $\begin{array}{c}\text { Sample } \\
\text { Group }\end{array}$ & $\begin{array}{c}\text { Specimen } \\
\#\end{array}$ & $\begin{array}{c}\text { Experiment } \\
(\mathrm{kN} * \mathrm{~m})\end{array}$ & $\begin{array}{c}\text { FE Predictions } \\
(\mathrm{kN} * \mathrm{~m})\end{array}$ & $\begin{array}{c}\% \\
\text { Difference }\end{array}$ \\
\hline \multirow{4}{*}{$\mathrm{A}$} & 17 & 15.0 & 13.8 & -7.8 \\
\cline { 2 - 5 } & 18 & 15.1 & 14.9 & -1.3 \\
\cline { 2 - 5 } & Average & 15.0 & 14.4 & -4.6 \\
\cline { 2 - 5 } & COV \% & 0.3 & 5.1 & 4.8 \\
\hline \multirow{4}{*}{ B } & 22 & 23.4 & 26.9 & 14.7 \\
\cline { 2 - 5 } & 23 & 24.8 & 25.8 & 4.4 \\
\cline { 2 - 5 } & Average & 24.1 & 26.4 & 9.5 \\
\cline { 2 - 5 } & COV \% & 3.9 & 2.8 & 6.6 \\
\hline
\end{tabular}

It can be observed that the numerical model yields results that predict the buckling load with reasonable accuracy. One possible explanation for the deviation in the obtained results could be attributed to the fact that clamping force used with the bracket connection was not measured and could have influenced the ultimate load obtained. More research should be conducted to investigate the effect of the clamping action and how to develop numerical input parameters to predict greater accuracy for the LTB load of the joists.

An attempt was made to evaluate the stiffness of top mounted joist hangers and the prediction is within $10 \%$ compared to the experimental results. More work is needed on improving these estimates for both top mounted as well as other boundary conditions. This work is considered outside the scope of the current thesis.

\subsection{Nonlinear lateral torsional buckling behavior}

\subsubsection{Geometric nonlinear analysis with Simply Supported end conditions.}

The experimental procedures presented in Table 4-2 included several repetitions of non-destructive loading tests for each specimen. A few selected specimens of each group were also tested to failure.

Although reasonable agreement between the elastic buckling load analysis and the experimental results was achieved (Table 7-6), Figure 7-10 and Figure 7-11 clearly show that the behavior of 
the joists is non-linear depending primarily on their initial out-of-straightness. Some of the joists reach their ultimate buckling capacity at a displacement range of 180 to $240 \mathrm{~mm}$. The reported displacement may be unacceptable from a serviceability point of view. It is therefore suggested that a limit of the lateral displacement be imposed on the design for lateral torsional buckling of timber joists and beams. Obviously such limits depends on several factors which are mostly related to tolerances for non-structural components. Such tolerances are well established for vertical deflection of joists and beams. For example, the timber design code (CSA 2014) requires that a serviceability check be considered on floor joists and beams where the vertical displacement is not to exceed the span over 180. Whether similar, more or less stringent requirements are needed for lateral displacement is a larger subject than can be adequately addressed in this thesis.

In an attempt to investigate the implication of various limits, the average capacity curve for both specimens group A and B is compared with the idealized linear solution. The results are presented in Table 7-12 for L/600, L360, L/240, L/120 and L/60 span ratio.

Table 7-12 Average moment compared to numerical predictions at various span ratio

\begin{tabular}{|c|c|c|c|c|c|c|}
\hline & Span Ratio & L/600 & $\mathrm{L} / 360$ & $\mathrm{~L} / 240$ & $\mathrm{~L} / 120$ & $L / 60$ \\
\hline \multirow{5}{*}{$\begin{array}{c}\text { Group } \\
\text { A }\end{array}$} & Displ. (mm) & 7.6 & 12.7 & 19.1 & 38.1 & 76.2 \\
\hline & Average $(\mathrm{kN} * \mathrm{~m})$ & 5.3 & 6.1 & 7.4 & 8.3 & 9.0 \\
\hline & COV \% & 38.6 & 31.6 & 21.4 & 14.1 & 10.4 \\
\hline & FEA_SS $(k N * m)$ & \multicolumn{5}{|c|}{10.6} \\
\hline & \% Difference & -49.4 & -41.9 & -30.4 & -21.6 & -14.3 \\
\hline \multirow{5}{*}{$\begin{array}{c}\text { Group } \\
\text { B }\end{array}$} & Displ. (mm) & 9.7 & 16.1 & 24.1 & 48.3 & 96.5 \\
\hline & Average $(\mathrm{kN} * \mathrm{~m})$ & 10.1 & 12.4 & 13.9 & 16.1 & 17.8 \\
\hline & COV \% & 25.9 & 18.8 & 14.1 & 9.2 & 8.6 \\
\hline & FEA_SS $(k N * m)$ & \multicolumn{5}{|c|}{19.8} \\
\hline & \% Difference & -49.1 & -37.6 & -29.9 & -18.8 & -10.5 \\
\hline
\end{tabular}




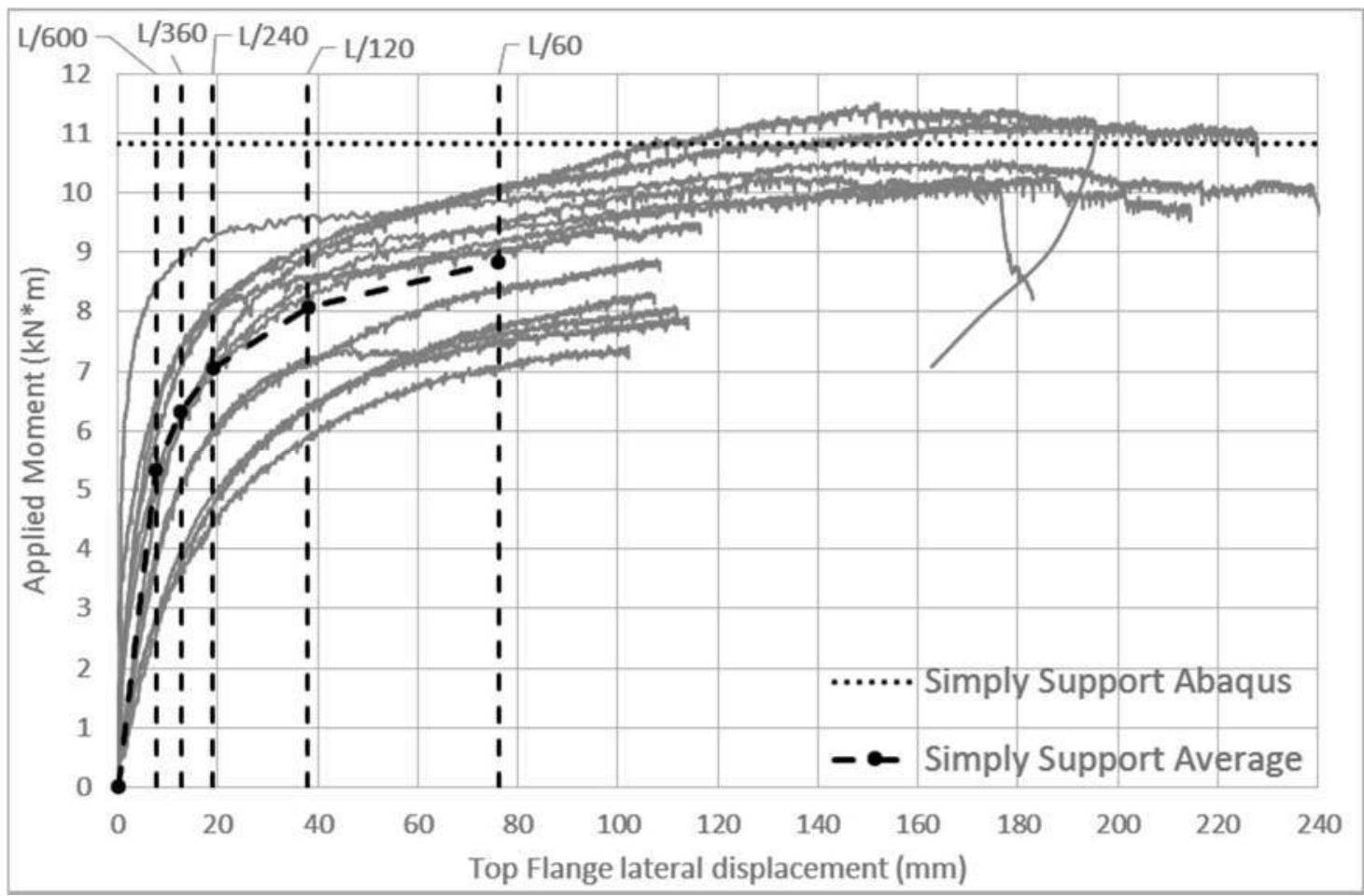

Figure 7-10 Specimen group A - Top Flange displacement with Simply Supported Condition

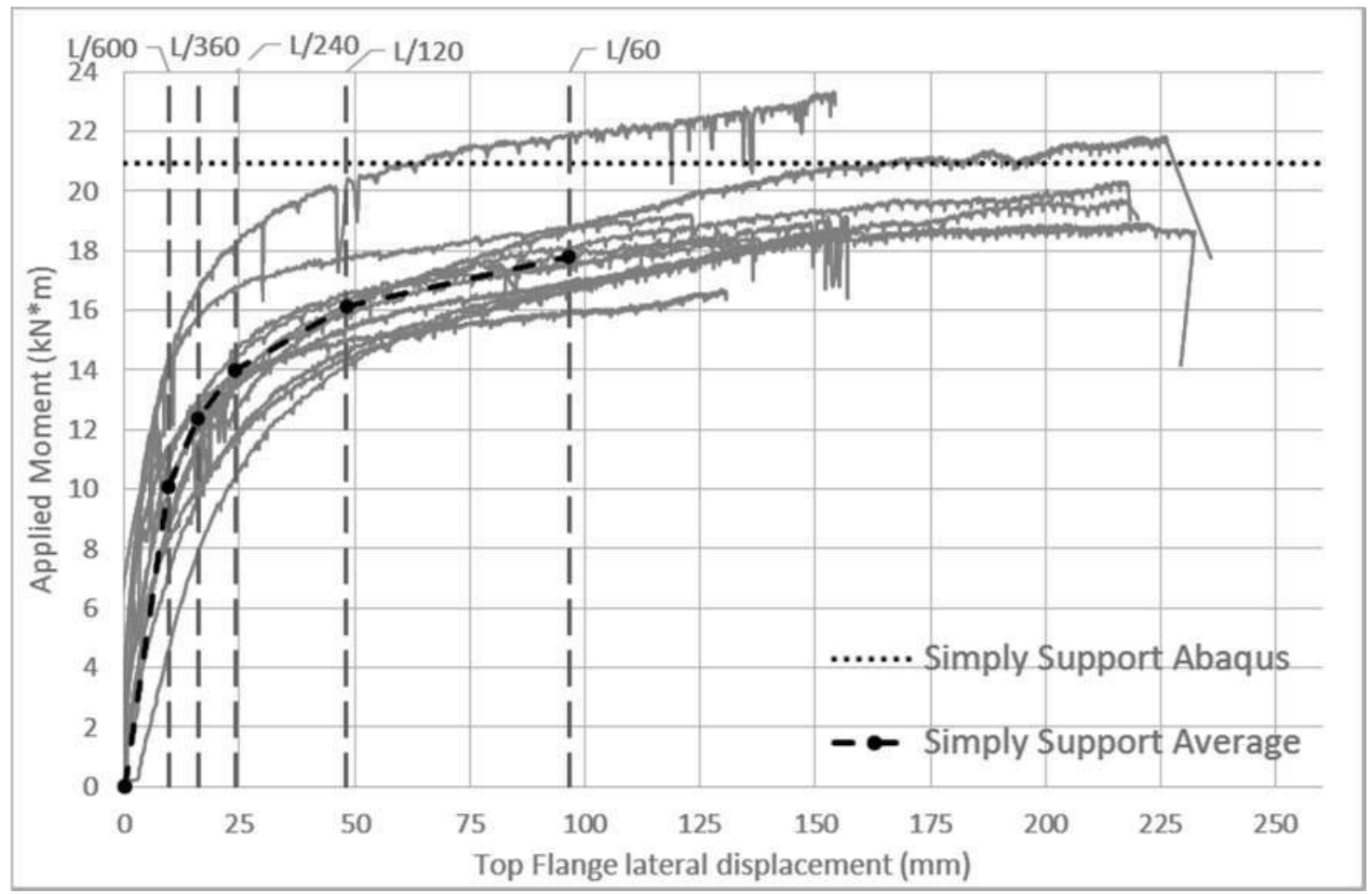

Figure 7-11 Specimen group B - Top Flange displacement with Simply Supported Condition 
It can be observed that within all the reference points, the lower displacement ratios are shown to have a higher variation in their resistance value which could be attributed to the variation in the initial out-of-straightness. As the displacement of the top flange increases, the critical load average associated with each ratio tends to increase and their standard deviation decrease. From Table 7-12 it can be clearly seen that depending on what the design displacement is, the difference in capacity relative to the ultimate elastic capacity could be significant. For example almost only half of the elastic moment capacity is obtained at a span ration of L/600. Even if the L/60 limit is adopted, the actual moment capacity is on average $10-15 \%$ less than that calculated based on elastic theory.

\subsubsection{Commercial hangers and enhanced connection influence on LTB behavior of joists.}

Section 7.1.2 showed the impact of including realistic boundary conditions on the ultimate buckling load of I-joists. In order to investigate if such change in boundary conditions have any effect on the non-linear behavior of the joists prior to ultimate failure, selected specimens were tested with the simply supported conditions and then retested with various joists hangers. Only joists where the measured out of straightness values were observed to be the same for the simply supported and joist hanger boundary conditions are considered. The comparison was undertaken relative to the span ratios discussed in the previous section. The results are presented in Table 7-13. 
Table 7-13 Resisting moment of joists tested with simply support condition and hangers at various Span ratio displacements

\begin{tabular}{|c|c|c|c|c|c|c|c|}
\hline & & & $L / 600$ & $L / 360$ & $\mathrm{~L} / 240$ & $\mathrm{~L} / 120$ & $\mathrm{~L} / 60$ \\
\hline \multirow{6}{*}{$\begin{array}{c}* \text { TM - } \\
\text { HWI424 }\end{array}$} & \multirow{3}{*}{ B8 } & $\mathrm{SS}\left(\mathrm{kN}^{*} \mathrm{~m}\right)$ & 14.1 & 15.5 & 16.3 & 17.1 & 17.7 \\
\hline & & Hangers $\left(\mathrm{kN}^{*} \mathrm{~m}\right)$ & 10.3 & 12.3 & 13.5 & 15.2 & 16.7 \\
\hline & & \%Diff & -26.9 & -21.2 & -17.4 & -10.8 & -5.9 \\
\hline & \multirow{3}{*}{ B9 } & $\mathrm{SS}(\mathrm{kN} * \mathrm{~m})$ & 10.7 & 13.0 & 14.4 & 16.6 & 18.0 \\
\hline & & Hangers $\left(\mathrm{kN}^{*} \mathrm{~m}\right)$ & 9.4 & 12.0 & 13.4 & 14.9 & 16.2 \\
\hline & & \%Diff & -12.4 & -7.9 & -6.7 & -10.0 & -10.3 \\
\hline \multirow{6}{*}{$\begin{array}{c}\text { *FM - } \\
\text { IUS3.56/16 }\end{array}$} & \multirow{3}{*}{ B14 } & $\mathrm{SS}(\mathrm{kN} * \mathrm{~m})$ & 12.3 & 13.7 & 14.6 & 15.7 & 16.2 \\
\hline & & Hangers $(\mathrm{kN} * \mathrm{~m})$ & 5.9 & 8.2 & 10.1 & 12.6 & 14.7 \\
\hline & & \%Diff & -52.1 & -40.1 & -31.1 & -19.3 & -9.5 \\
\hline & \multirow{3}{*}{ B15 } & $\mathrm{SS}(\mathrm{kN} * \mathrm{~m})$ & 8.8 & 11.0 & 12.8 & 14.6 & 15.8 \\
\hline & & Hangers $(\mathrm{kN} * \mathrm{~m})$ & 4.8 & 6.9 & 8.8 & 11.7 & 14.0 \\
\hline & & \%Diff & -45.3 & -37.5 & -31.0 & -19.9 & -11.5 \\
\hline
\end{tabular}

As observed for the case of simply support condition, as the displacement of the top flange increases, the variability of the results tends to decrease. It can be observed in Table 7-13 that the joists with realistic boundary conditions (joist hangers) have moment resistances that are consistently lower than those obtained from the simply supported boundary conditions.

The same analysis was made with the enhanced connections to verify if these connections also have higher resistance values prior to ultimate resistance. The results in Table 7-14 show that the buckling moment is consistently higher for the joists with enhanced boundary connections for all span aspect ratios. 
Table 7-14 Resisting moment of joists tested with simply support condition and Enhanced connections at various Span ratio displacements

\begin{tabular}{|c|c|c|c|c|c|c|c|}
\hline & & & $\mathrm{L} / 600$ & $L / 360$ & $\mathrm{~L} / 240$ & $\mathrm{~L} / 120$ & $\mathrm{~L} / 60$ \\
\hline \multirow{6}{*}{$\begin{array}{c}\text { Side } \\
\text { Screwed } \\
\text { (HWR) }\end{array}$} & \multirow{3}{*}{ B20 } & $\mathrm{SS}(\mathrm{kN} * \mathrm{~m})$ & 11.9 & 14.4 & 15.9 & 17.9 & 19.0 \\
\hline & & Hangers $(\mathrm{kN} * \mathrm{~m})$ & 12.3 & 14.6 & 16.3 & 19.2 & 21.3 \\
\hline & & \%Diff & 3.5 & 1.45 & 2.6 & 7.1 & 11.9 \\
\hline & \multirow{3}{*}{ B21 } & $\mathrm{SS}(\mathrm{kN} * \mathrm{~m})$ & 12.1 & 14.0 & 15.4 & 16.3 & 17.7 \\
\hline & & Hangers $(\mathrm{kN} * \mathrm{~m})$ & 15.1 & 17.2 & 18.7 & 20.4 & 21.7 \\
\hline & & \%Diff & 25.0 & 23.6 & 20.9 & 25.5 & 22.9 \\
\hline \multirow{6}{*}{$\begin{array}{l}\text { Angle } \\
\text { Contained } \\
\text { Flanges } \\
\text { (ACF) }\end{array}$} & \multirow{3}{*}{ B22 } & $\mathrm{SS}(\mathrm{kN} * \mathrm{~m})$ & 7.5 & 10.3 & 12.4 & 15.1 & 17.0 \\
\hline & & Hangers $(\mathrm{kN} * \mathrm{~m})$ & 13.3 & 16.1 & 18.0 & 20.7 & 22.4 \\
\hline & & \%Diff & 76.9 & 56.3 & 44.5 & 37.2 & 31.9 \\
\hline & \multirow{3}{*}{ B23 } & $\mathrm{SS}(\mathrm{kN} * \mathrm{~m})$ & 10.3 & 13.0 & 14.7 & 16.8 & 18.3 \\
\hline & & Hangers $(\mathrm{kN} * \mathrm{~m})$ & 19.3 & 21.2 & 22.3 & 23.5 & 24.6 \\
\hline & & \%Diff & 87.6 & 62.5 & 51.6 & 39.5 & 34.5 \\
\hline
\end{tabular}

\subsubsection{Experimental buckling displacements and nonlinear FEA comparison}

This section compares the nonlinear buckling behavior of the joists with the numerical predictions from the FE geometric nonlinear analysis. A sample of the comparison between the numerical and the experimental curve is shown in Figure 7-12. In general, the FE prediction of nonlinear behavior fits the experimental buckling displacements reasonably well.

Figure 7-13 shows a case where the FE nonlinear analysis follows the deflection of the tested specimen in the initial loading phase. At one point during the loading, the plotted slope of the force-displacement behaviour has a tendency to change as the beam undergoes higher lateral displacement. Its resistance still tends to rise to the predicted eigenvalue buckling load but at a slower rate. In some cases, as observed in the section 7.2.1, there is a difference between the computed and the experimental loads. This variation influences the resistance at which the nonlinear slope plotted will tend to change and induces an offset between the experimental observations and numerical predictions past this point. 


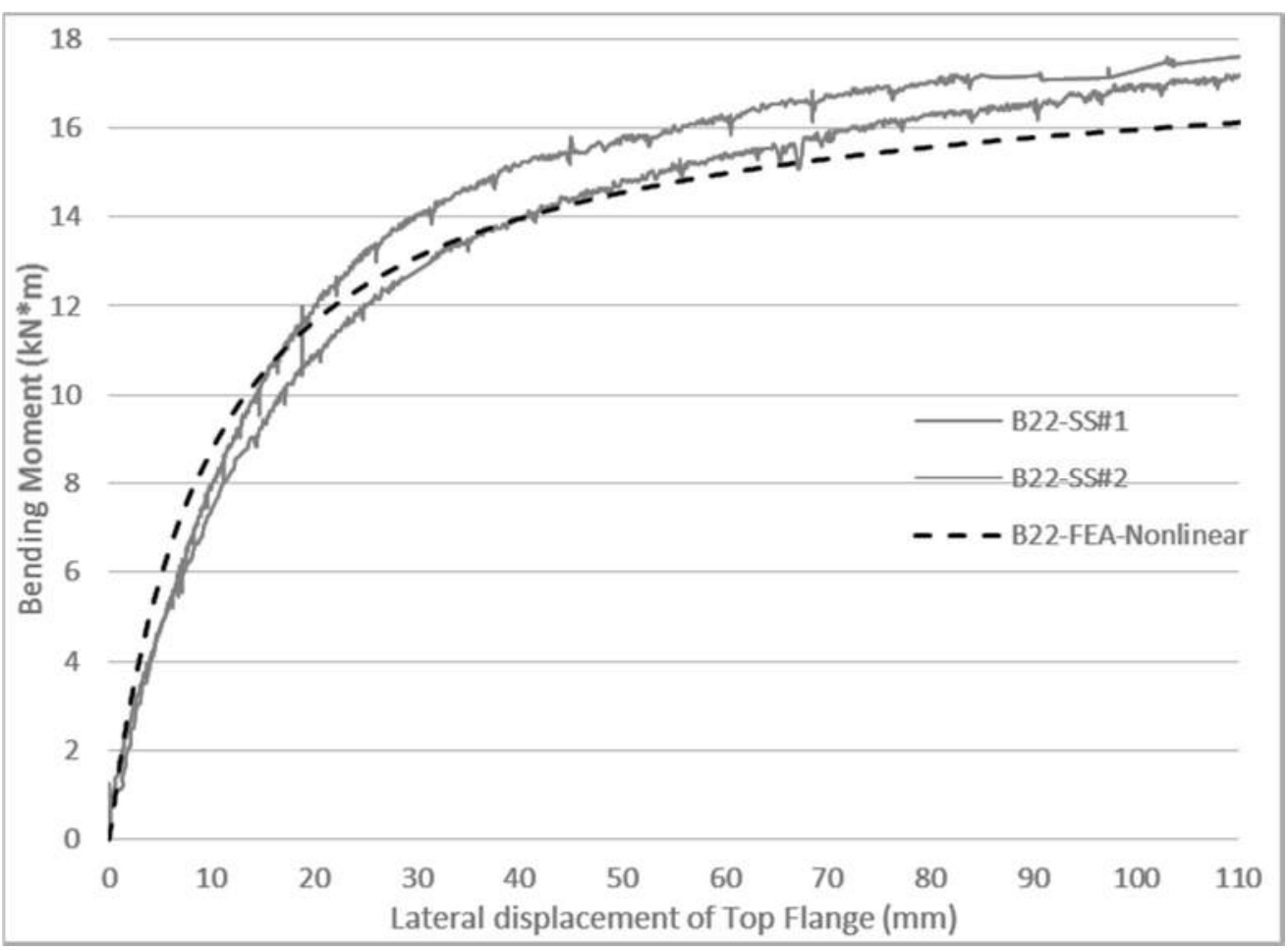

Figure 7-12 Non-linear load-displacement relationship of specimen 22, group B

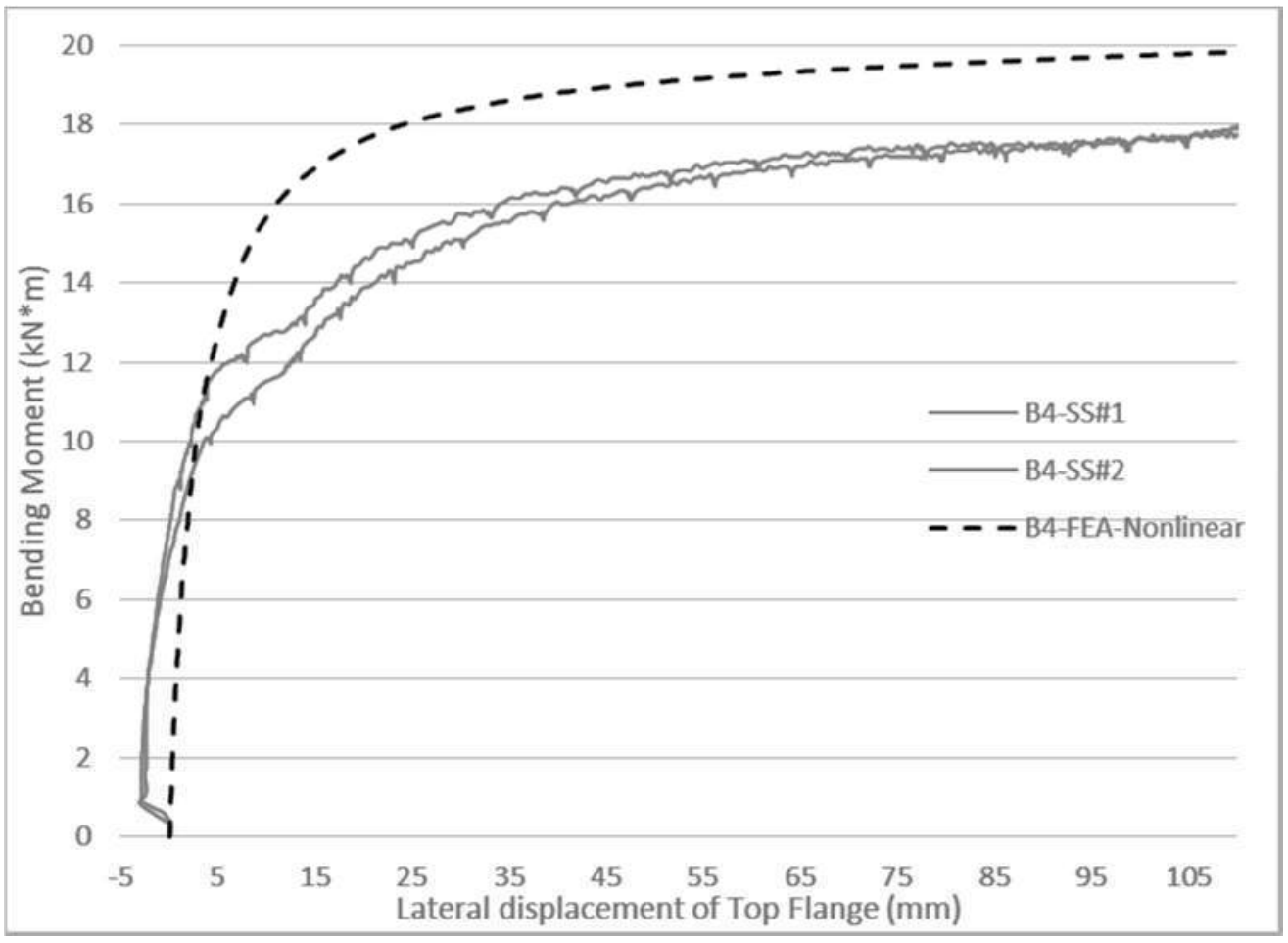

Figure 7-13 Non-linear load-displacement relationship of specimen 4, group B 
The tendency of the joists to undergo lateral displacement and rotation before reaching the buckling load is dictated by the magnitude of the initial imperfection of the joists. Figure 7-14 shows an example where the model input for initial imperfection may not be accurate. This is corroborated by the FE imperfection sensitivity (Section 3.3.3), where it was shown that the initial imperfections in the numerical model appear to affect the lower stiffness branch of the overall nonlinear behavior. Also, the measured imperfections on the test specimens did not account for the initial twist or the out-of-straightness of the bottom flange, which could also have contributed to the lack of accuracy in the model. Such imperfection could also be the cause of negative initial measurements as shown in Figure 7-13.

In general, it seems that knowing the initial out-of-straightness provides sufficient knowledge to be able to conduct non-linear buckling analysis that would describe the joist behaviour adequately.

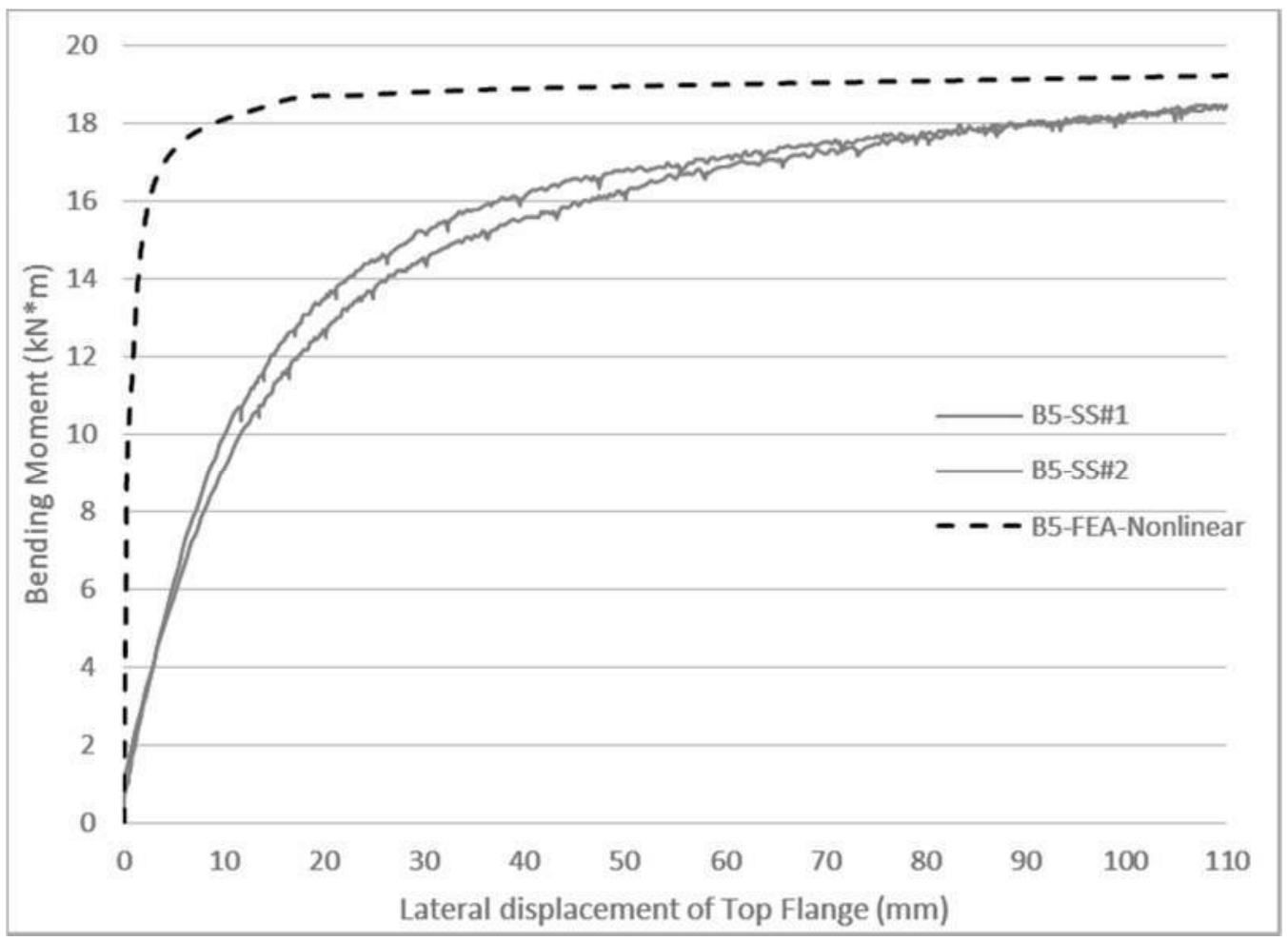

Figure 7-14 Non-linear load-displacement relationship of specimen 5, group B 


\section{CHAPTER 8}

\section{CONCLUSIONS AND RECOMMENDATIONS}

\subsection{Conclusions}

The study's main conclusions can be summarized as follows:

I. The sensitivity analysis showed that the lateral stiffness of the top flange support has the most significant influence on the lateral torsional buckling load followed by the bottom flange lateral support.

II. The experimental study showed that I-joists tested with top mounted hangers and nailed connections did not have significant decrease of the buckling load when compared to the simply supported boundary condition. However, the I-joists tested with the face mounted hangers exhibited a significantly lesser buckling load. To take into account the decrease in the buckling load with the use of realistic boundary conditions, a reduction of $20 \%$ rather than $15 \%$ is recommended. All enhanced connections tested showed a significant increase of the buckling load when compared to the simply supported end conditions.

III. Finite element analysis of the linear eigenvalue buckling load was found to be in reasonable agreement with the experimental results for the simply supported end conditions but underestimated the buckling load by approximately $10 \%$ for the joists tested with top mounted hangers. The nailed connection yielded results that could be considered comparable to the simply supported end conditions.

IV. The nonlinear behavior of the joists is influenced by the initial imperfections of the beams. Experimental results on simply supported I-joists have shown a general reduction in the load applied on the beam, varying from $49 \%$ to $15 \%$ with initial imperfection ratios ranging from $\mathrm{L} / 600$ to $\mathrm{L} / 60$, respectively. 


\subsection{Recommendations for future research}

I. Further research should develop more precise methods to compute the various support stiffness.

II. Nonlinear buckling behavior of the I-joists should be investigated including variables such as initial out-of-straightness of both flanges and initial twist of the section.

III. Further research on limitations for serviceability limits for the nonlinear buckling behavior of the joists should be undertaken to determine if additional load reduction factors are necessary for design purposes. 


\section{REFERENCES}

AFPA, American Forest \& Paper Association. 2003. "Designing for lateral torsional buckling in wood members,." In Technical Report, edited by American Wood Council, 43. American Forest \& Paper Association.

Aguilar, Jose Maria Villasenor. 2013. 'Lateral-Torsional Buckling Instability Caused by Individuals Walking on Wood Composite I-Joists', Disseration, Virginia Polytechnic Institute and State University.

Ascione, Francesco. 2014. 'Influence of initial geometric imperfections in the lateral buckling problem of thin walled pultruded GFRP I-profiles', Composite Structures, 112: 85-99.

ASTM, American society for testing materials. 2011. "D3043 - Standard Test Methods for Structural Panels in Flexure." In.

- - . 2015. "D198 - Standard Test Methods of Static Tests of Lumber in Structural Sizes." In.

AWC, American Wood Council. 2015. "National Design Specification for Wood Construction." In. Leesburg, VA.

Bell, Kolbein, and Trond Even Eggen. 2001. "Stability of timber beams and columns." In IABSE Conference, edited by International Association for Bridge and Structural Engineering, 155-62. Lahti.

Bohm, M., P. Sedivka, J. Bomba, and J. Reisner. 2011. 'Strength Characteristics of OSB in Bending Difference between Upper and Lower Panel Faces', Drvna Industrija, 62: 123-27.

Burow, Jesse R., Harvey B. Manbeck, and John J. Janowiak. 2006. "Lateral Stability of Composite Wood IJoists Under Concentrated-Load Bending." In, edited by American Society of Agricultural and Biological Engineers, 1867-80.

Cascade, Boise. 2014. "AllJoist Specifier Guide." In.

CEN. 2004. "Eurocode 5: Design of timber structures - Part 1-1: General rules and rules for buildings." In. Belgium: Comité Européen de Normalisation Brussels.

CISC. 2009. "Design of Steel Structures." In. Mississauga, Ontario: Canadian Standard Association.

CSA, Canadian Standards Association. 2014. "Engineering design in wood." In CAN/CSA-O86-14. Mississauga (Ontario) Canada: CSA.

Du, Yang. 2016. 'Lateral Torsional Buckling of Wooden Beam-Deck Systems', Articles, University of Ottawa.

Du, Yang, Magdi Mohareb, and Ghasan Doudak. 2016. 'Nonsway Model for Lateral Torsional Buckling of Wooden Beams under Wind Uplift', Journal of Engineering Mechanics. 
FPL, Forest Product Laboratory. 2010. "Wood Handbook: Wood as an Engineering Material." In FPL- GTR190, edited by Forest Products Laboratory USDA Forest Service., 509. Madison, Wisconsin.

Gjelsvik, Atle. 1981. 'The theory of thin walled bars', Journal of Applied Mechanics, 49.

Grandmont, Jean-Frédéric. 2011. 'Analyse Structurale du Système Âme-Semelles de Poutrelles en Bois à Configuration en I', Université Laval.

Hindman, Daniel, Harvey B. Manbeck, and John J Janowiak. 2003. "Torsional Rigidity and Lateral Stability of SCL and I-joist Beams." In, edited by American Society of Agricultural and Biological Engineers. Las Vegas, NV.

Hindman, Daniel P., Harvey B. Manbeck, and John J. Janowiak. 2005a. 'Measurement and prediction of lateral torsional buckling loads of composite wood materials: I-joist sections', Forest Products Journal, 55: 43-48.

- - . 2005b. 'Measurement and prediction of lateral torsional buckling loads of composite wood materials: Rectangular sections', Forest Products Journal, 55: 42-47.

Hooley, R. F., and B. Madsen. 1964. 'Lateral Buckling of Glued Laminated Beams', Journal of Structural Engineering Division, ASCE, 90: 201-303.

Hu, Ye. 2016. 'Lateral Torsional Buckling of Wooden Beams with Mid-Span Lateral Bracing', University of Ottawa.

$\mathrm{Hu}, \mathrm{Ye}$, Magdi Mohareb, and Ghasan Doudak. 2017a. 'Effect of Eccentric Lateral Bracing Stiffness on Lateral Torsional Buckling Resistance of Wooden Beams', International Journal of Structural Stability and Dynamics.

- - . 2017b. 'Lateral Torsional Buckling of Wooden Beams with Mid-span Lateral Bracing offset from Section Mid-height', Journal of Engineering Mechanics.

Ings, N. L., and N. S. Trahair. 1987. 'Beam and column buckling under directed loading', J. Struct. Engrg., 113: 1251.

Kala, Zdeněk. 2013. 'Elastic Lateral-Torsional Buckling of Simply Supported Hot-Rolled Steel I-Beams with Random Imperfections', Procedia Engineering, 57: 504-14.

Kirby, P. A., and D. A. Nethercot. 1979. Design for structural stabilityJohn Wiley \& Sons Australia, Limited: London).

NS3470-1. 1999. "Design of timber structures. Design Rules. Part 1: Common rules, 5th Edition." In.

Pi, Yong Lin, N. S. Trahair, and S. Rajasekaran. 1992. 'Energy Equation for Beam Lateral Buckling', Journal of Structural Engineering, 118: 1462-79. 
Prescott, J., and H. Carrington. 1920. 'XIX. The buckling of deep beams. (Second paper.)', Philosophical Magazine Series 6, 39: 194-223.

SBA, Structural board association. 2004. "OSB - Performance by design." In.

Simulia. 2014. "ABAQUS/CAE User's Manual (Version 6.14)." In.: Dassault Systemes.

St-Amour, Rémi. 2016. 'Lateral Torsional Buckling of Wood I-Joist', University of Ottawa.

Suryoatmono, Bambang, and Adhijoso Tjondro. 2008. "Lateral-torsional buckling of orthotropic rectangular section beams." In. Indonesia: Parahyangan Catholic University

Thomas, H. W. 2001. 'Mechanical properties of structural-Grade oriented strand board', Holz als Roh- und Werkstoff, 59: 405-10.

Timoshenko, Stephen P., and James M. Gere. 1961. Theory of Elastic Stability 2nd Edition,(McGraw-Hill: New York).

Vlasov, V. Z. 1961. Thin-walled elastic beams, 2nd Editionlsrael program for scientific transanctions: Jerusalem).

Xiao, Qiuwu. 2014. 'Lateral Torsional Buckling of Wood Beams', Monograph, University of Ottawa.

Xiao, Qiuwu, Ghasan Doudak, and Magdi Mohareb. 2014. "LATERAL TORSIONBAL BUCKLING OF WOOD BEAMS: FEA-MODELING AND SENSITIVITY ANALYSIS." In World Conference on Timber Engineering. Quebec City.

Zahn, John J. 1973. 'Lateral stability of wood beam-and-deck systems', Journal of the Structural Division, ASCE: 1391-408.

Zhu, E., Z. Guan, P. Rodd, and D. Pope. 2005. 'Buckling of Oriented Strand Board Webbed Wood I-Joists', Journal of Structural Engineering, 131: 1629-36. 


\section{APPENDIX A}

This appendix presents the drawings of various component used in the experimental manipulations. 


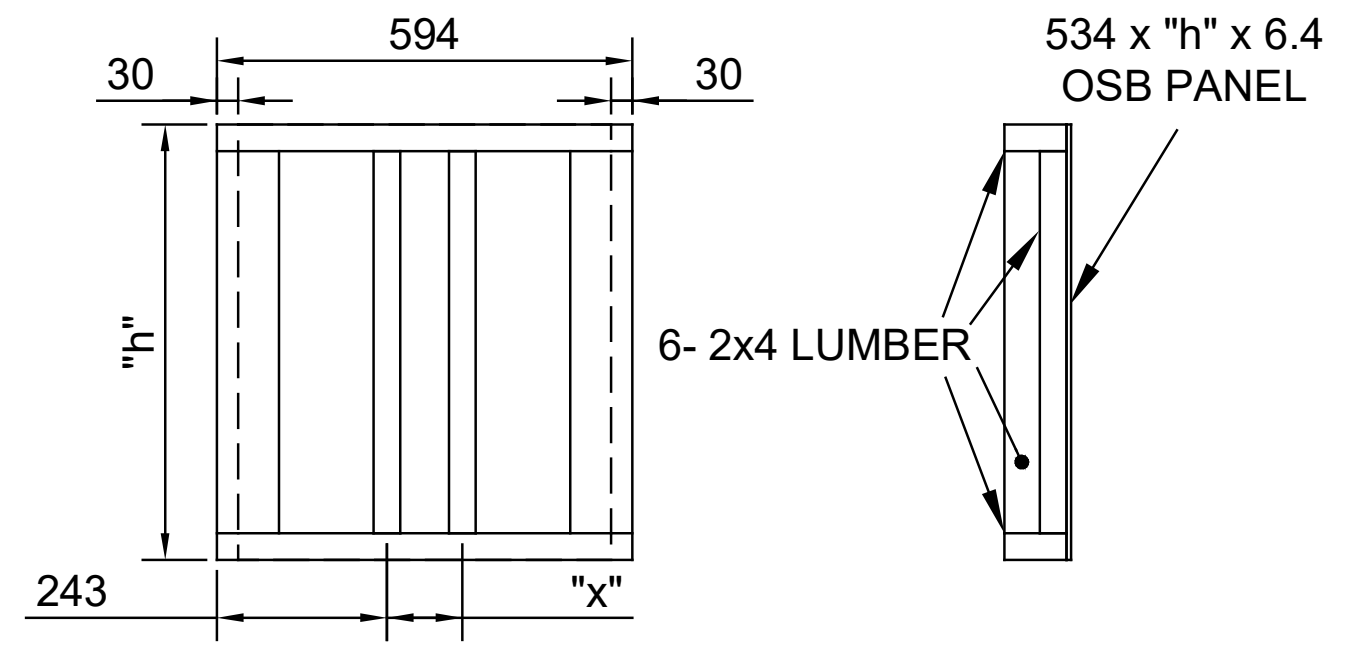

FOR FACE MOUNTED HANGERS \& CUSTOM CONNECTION

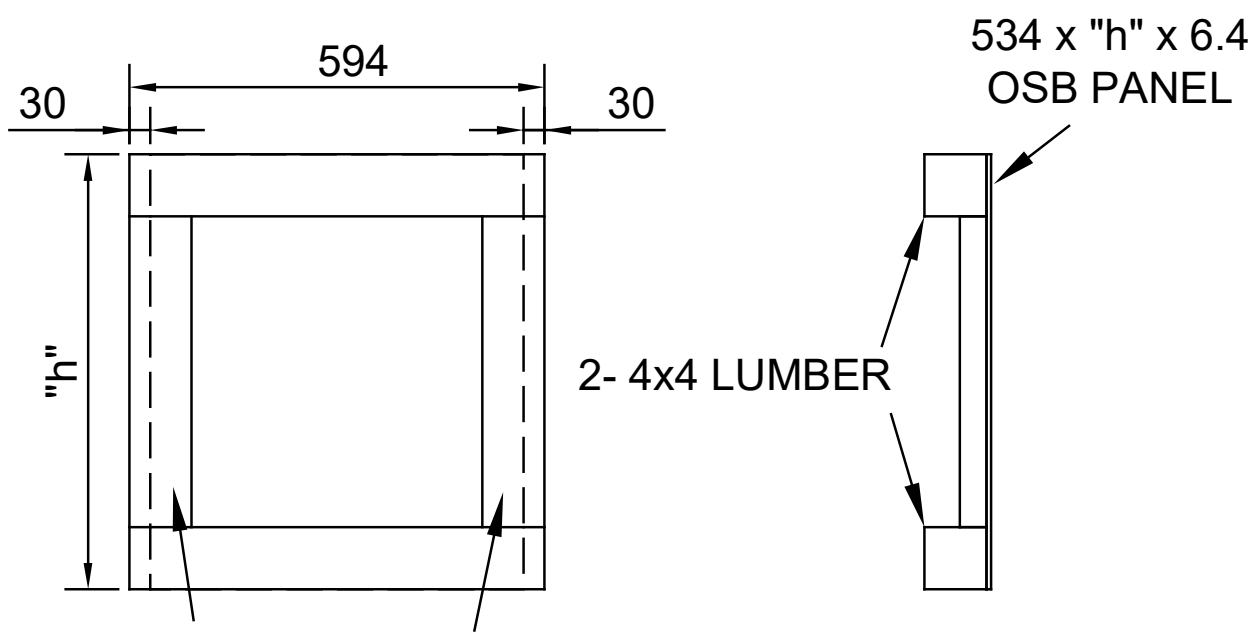

2- 2x4 LUMBER

FOR TOP MOUNTED HANGERS

\begin{tabular}{|c|c|c|}
\hline $\begin{array}{c}\text { SPECIMEN } \\
\text { GROUP }\end{array}$ & $\begin{array}{c}\text { PANEL } \\
\text { HEIGHT "h" }\end{array}$ & $\begin{array}{c}\text { SPACING } \\
\text { "x" }\end{array}$ \\
\hline A & 413 & 108 \\
\hline B & 616 & 133 \\
\hline
\end{tabular}



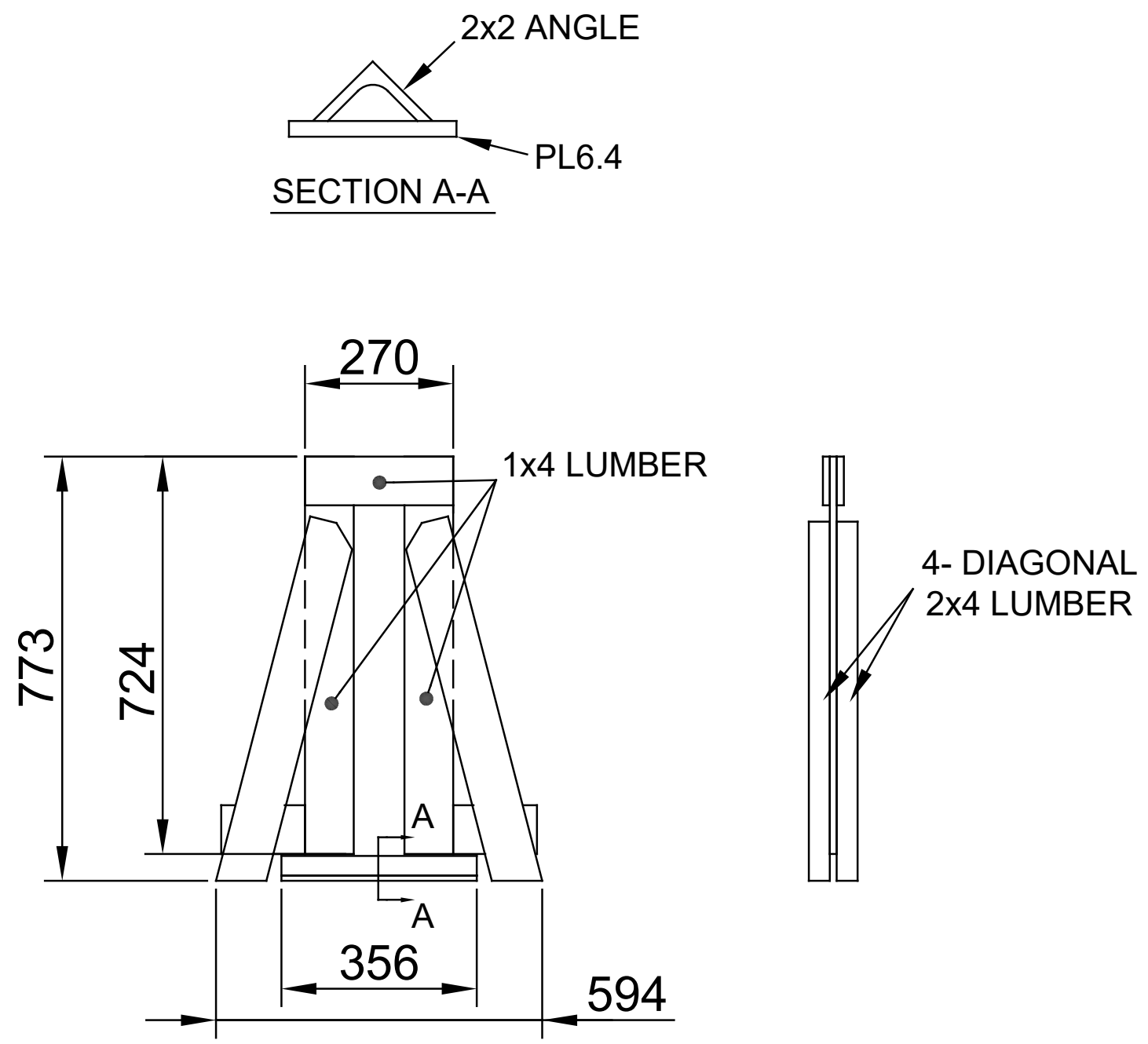

\section{WOODEN SUPPORT}

[All Dimensions are in $\mathrm{mm}$ ]

[NTS] 
$4 \times 1 / 4 \times 3 / 32 \mathrm{NDTCH}$
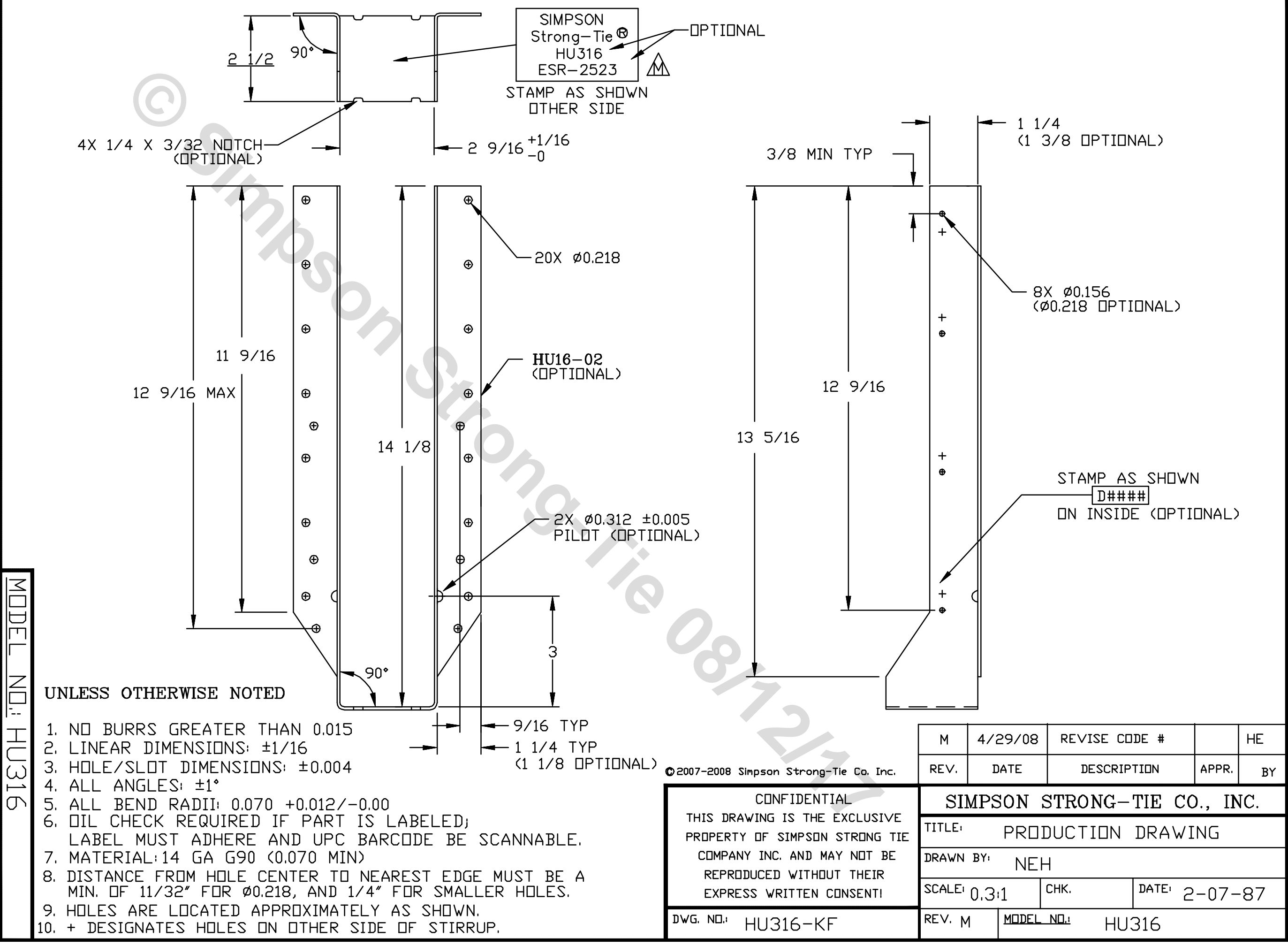

Figure A-4 Face Mounted Hangers HU316 


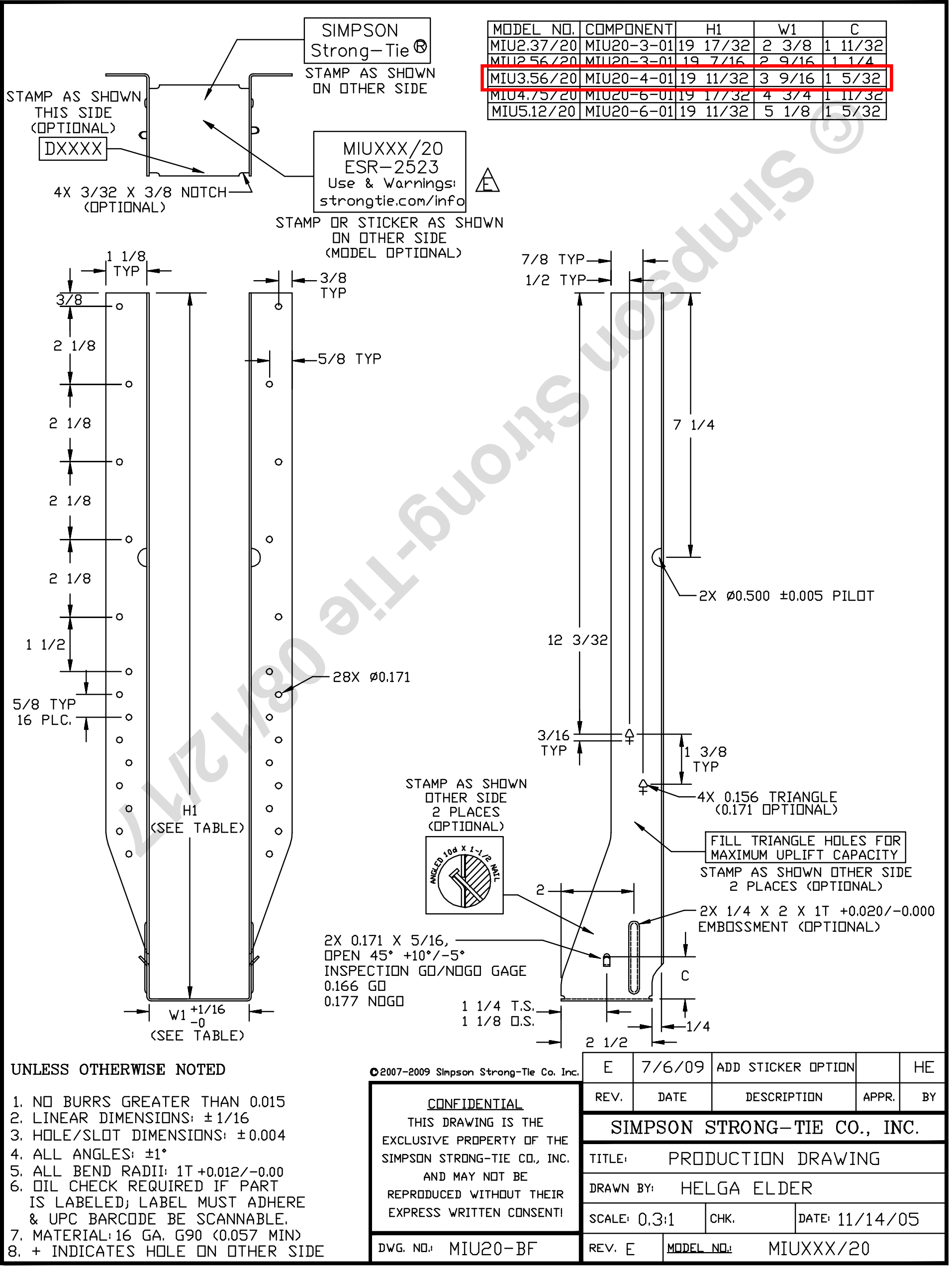




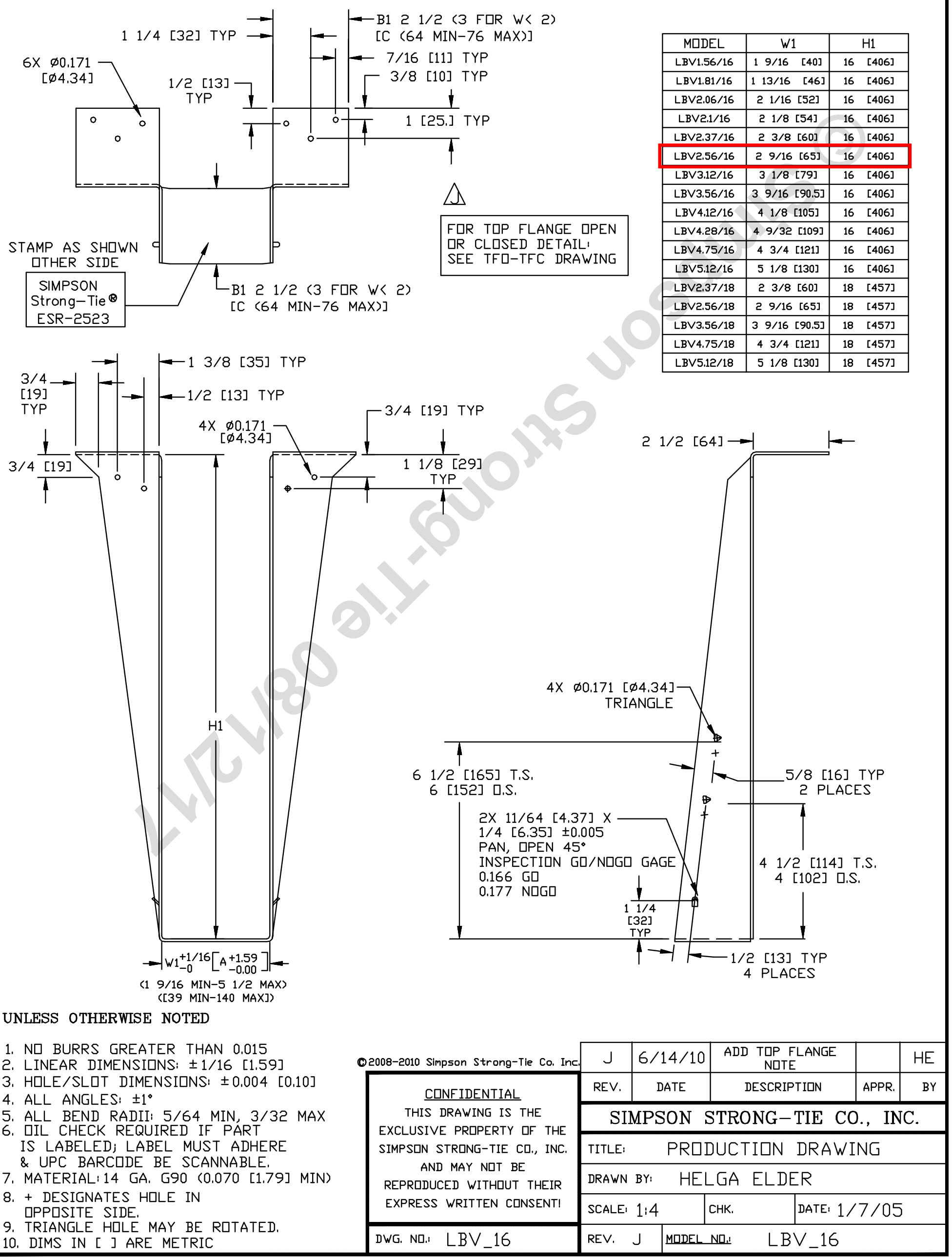




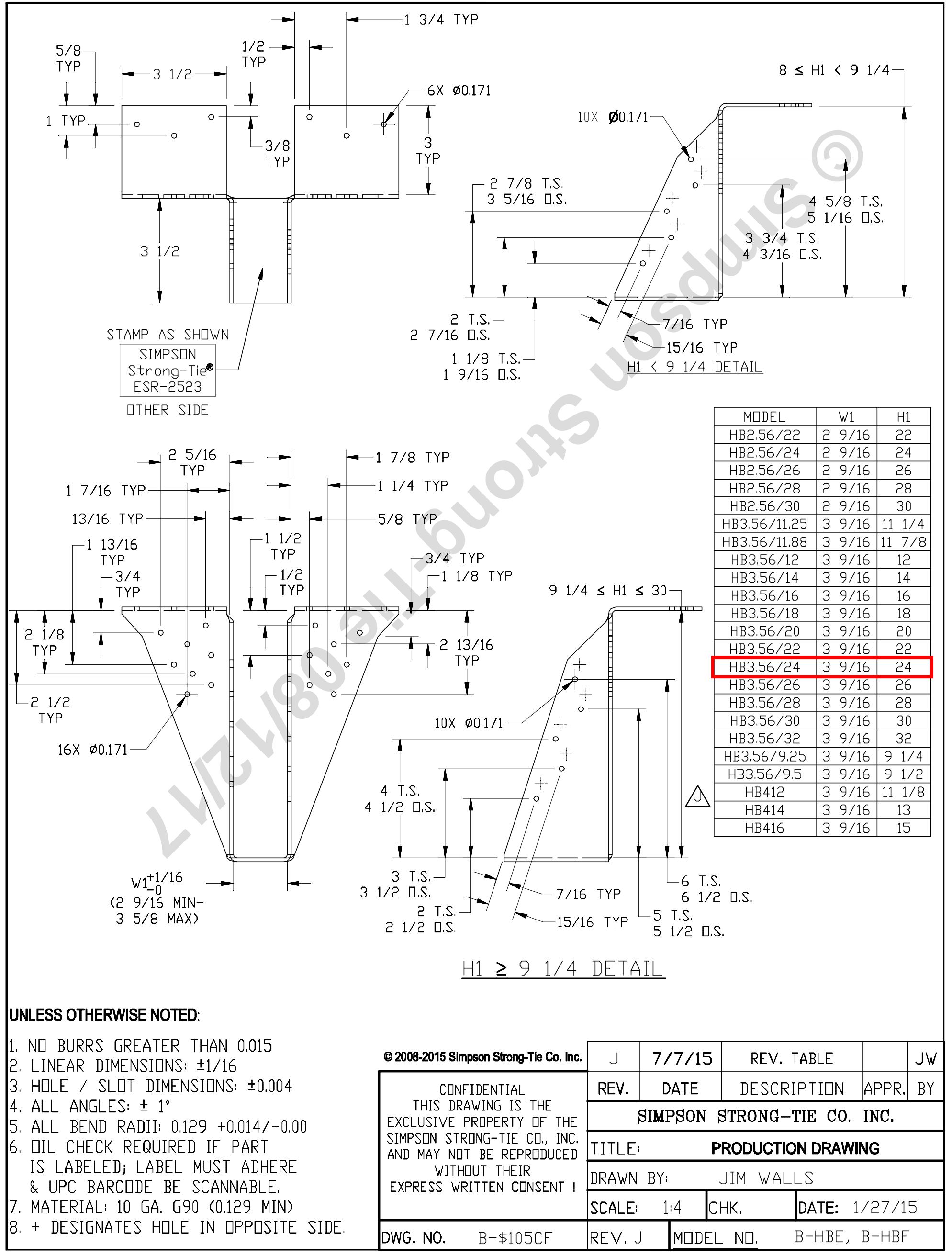




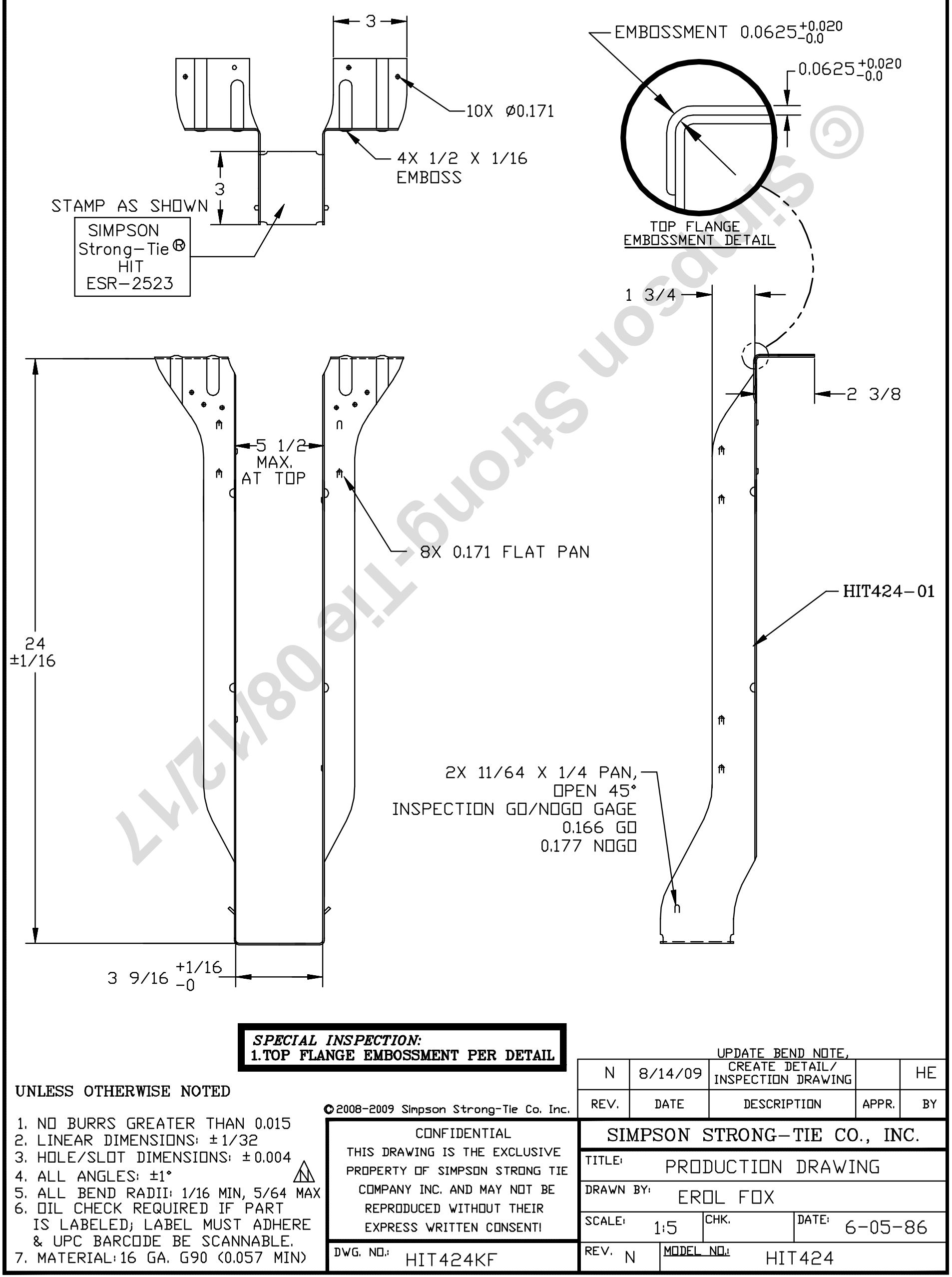

Figure A-8 Top Mounted Hangers HIT424 
A

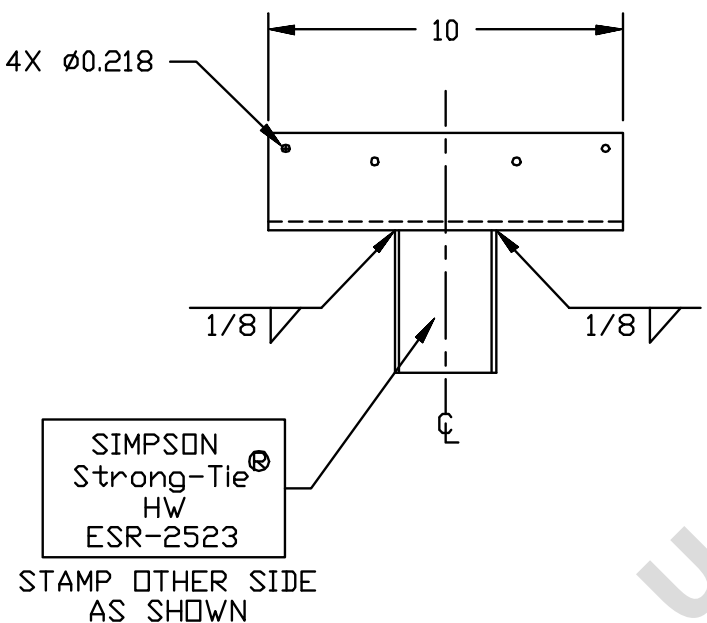

HWN20-02

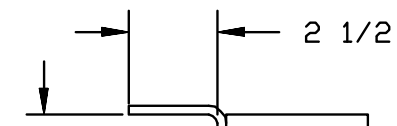

2 $1 / 2$ $\uparrow$

A $4 \times \varnothing 0.171$

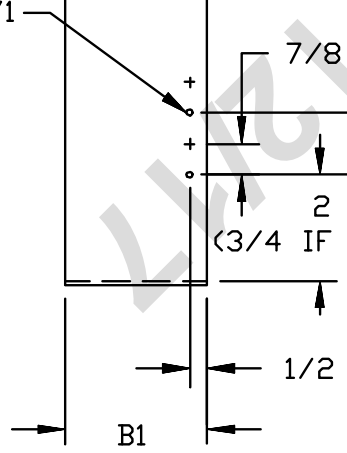

(2 $1 / 2$ MIN-4 MAX)
3 GA. $(0.229$ MIN $)$

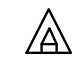
\lceil
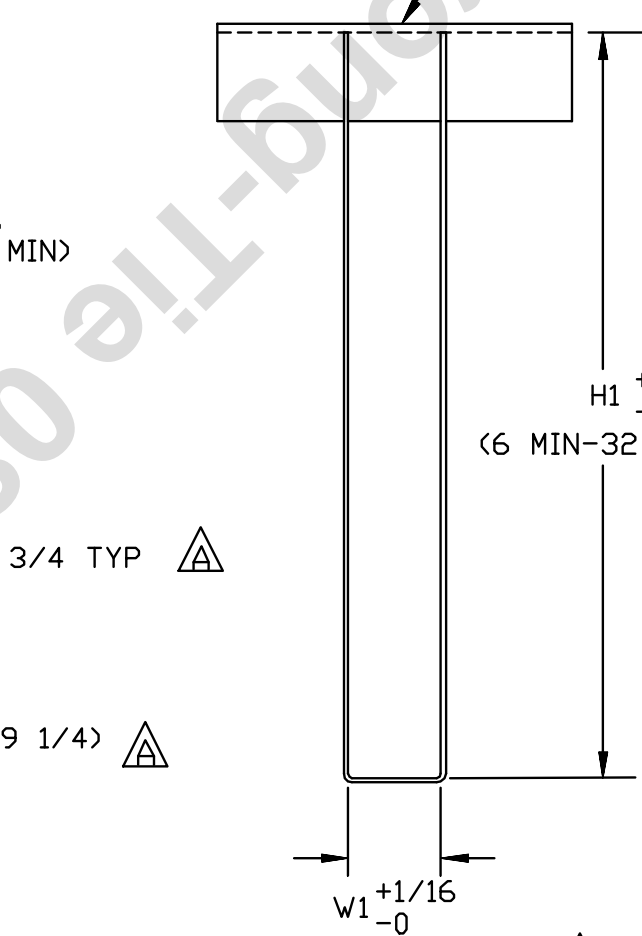

(2 $5 / 16$ MIN-7 MAX) A

\begin{tabular}{|c|c|c|c|}
\hline MDDEL & B1 & W1 & $\mathrm{H} 1$ \\
\hline HWI322 & 4 & $29 / 16$ & 22 \\
\hline HWI324 & 4 & $29 / 16$ & 24 \\
\hline HWI326 & 4 & $29 / 16$ & 26 \\
\hline HWI328 & 4 & $29 / 16$ & 28 \\
\hline HWI330 & 4 & $29 / 16$ & 30 \\
\hline $\mathrm{HW} 2.75 / 11.25$ & 4 & $23 / 4$ & $11 \quad 1 / 4$ \\
\hline$H W 2.75 / 11.88$ & 4 & $23 / 4$ & $117 / 8$ \\
\hline HW2.75/12 & 4 & $23 / 4$ & 12 \\
\hline HW2.75/14 & 4 & $23 / 4$ & 14 \\
\hline$H W 2.75 / 16$ & 4 & $23 / 4$ & 16 \\
\hline$H W 2.75 / 9.25$ & 4 & $23 / 4$ & $91 / 4$ \\
\hline HW2.75/9.5 & 4 & $23 / 4$ & $91 / 2$ \\
\hline HW211.25-2 & 4 & $31 / 8$ & $111 / 4$ \\
\hline HW211,88-2 & 4 & $31 / 8$ & $117 / 8$ \\
\hline HW29.25-2 & 4 & $31 / 8$ & $91 / 4$ \\
\hline HW29.5-2 & 4 & $31 / 8$ & $91 / 2$ \\
\hline HW3.3 & 4 & $33 / 8$ & \\
\hline HWI422 & $21 / 2$ & $39 / 16$ & 22 \\
\hline HWI424 & $21 / 2$ & $39 / 16$ & 24 \\
\hline HWI426 & $21 / 2$ & $39 / 16$ & 26 \\
\hline HWI428 & $21 / 2$ & $39 / 16$ & 28 \\
\hline HWI430 & $21 / 2$ & $39 / 16$ & 30 \\
\hline HWI432 & $21 / 2$ & $39 / 16$ & 32 \\
\hline HW3512-2 & $21 / 2$ & $43 / 4$ & 12 \\
\hline HW3514-2 & $21 / 2$ & $43 / 4$ & 14 \\
\hline HW3516-2 & $21 / 2$ & $43 / 4$ & 16 \\
\hline HW3518-2 & $21 / 2$ & $43 / 4$ & 18 \\
\hline HW3520-2 & $21 / 2$ & $43 / 4$ & 20 \\
\hline HW3522-2 & $21 / 2$ & $43 / 4$ & 22 \\
\hline HW3524-2 & $21 / 2$ & $43 / 4$ & 24 \\
\hline HW3526-2 & $21 / 2$ & $43 / 4$ & 26 \\
\hline HW3528-2 & $21 / 2$ & $43 / 4$ & 28 \\
\hline HWI322-2 & $21 / 2$ & $51 / 8$ & 22 \\
\hline HWI324-2 & $21 / 2$ & $51 / 8$ & 24 \\
\hline HWI326-2 & $21 / 2$ & $51 / 8$ & 26 \\
\hline
\end{tabular}

$\mathrm{H} 1_{-1 / 16}^{+0}$

(6 MIN-32 MAX)

\section{UNLESS OTHERWISE NOTED}

1. NO BURRS GREATER THAN 0.015

2. CDATING: GRAY PAINT

3. LINEAR DIMENSIDNS: $\pm 1 / 16$

4. HOLE/SLDT DIMENSIDNS: $\pm 0,004$

5. ALL ANGLES: $\pm 1^{\circ}$

6. ALL BEND RADII:

3 GA. 15/64 MIN, 1/4 MAX

11 GA. 1/8 MIN, 9/64 MAX

7. MATERIAL: AS NDTED

8. + DESIGNATES HULES LUCATED

IN DTHER SIDE IF STIRRUP.

9. WELDING PRDCEDURE SPECIFICATIUNS: 3 GA WPS-SST29009

11 GA WPS-SST29012

7 GA WPS-SST29018

\begin{tabular}{|c|c|c|c|c|c|c|}
\hline \multirow[b]{2}{*}{ O2008-2014 Simpson Strong-Tie Co. Inc. } & \multicolumn{6}{|c|}{ REV. DIM'S, \& } \\
\hline & E & $11 / 26 / 14$ & & $\begin{array}{l}\text { BEL, REM'D } \\
\text { B, ADD NDTE }\end{array}$ & & JW \\
\hline \multirow{5}{*}{$\begin{array}{c}\text { CDNFIDENTIAL } \\
\text { THIS DRAWING IS THE } \\
\text { EXCLUSIVE PRDPERTY DF THE } \\
\text { SIMPSDN STRDNG-TIE CD., INC. } \\
\text { AND MAY NDT BE } \\
\text { REPRDDUCED WITHDUT THEIR } \\
\text { EXPRESS WRIT TEN CDNSENT! }\end{array}$} & REV. & DATE & & ESCRIPTION & APPR. & BY \\
\hline & \multicolumn{6}{|c|}{ SIMPSON STRONG-TIE CO., INC. } \\
\hline & \multicolumn{6}{|l|}{ TITLE: } \\
\hline & \multicolumn{6}{|c|}{ DRAWN BY: GLADYS MLLINA } \\
\hline & \multicolumn{2}{|c|}{ SCALE: $1: 7$} & CHK. & \multicolumn{3}{|c|}{ DATE: $5 / 11 / 95$} \\
\hline DWG. NQ: $\quad W-H W A$ & \multicolumn{3}{|c|}{ REV. F MDDEL ND: } & \multicolumn{3}{|l|}{ W-HWA } \\
\hline
\end{tabular}




\section{APPENDIX B}

This appendix presents the experimental results and analytical predictions for the lateral torsional buckling tests. The measurements include the displacement of the top flange at mid-span and the moment resisted by the joist at mid-span. The linear and nonlinear numerical predictions using the FE model are shown when available. 


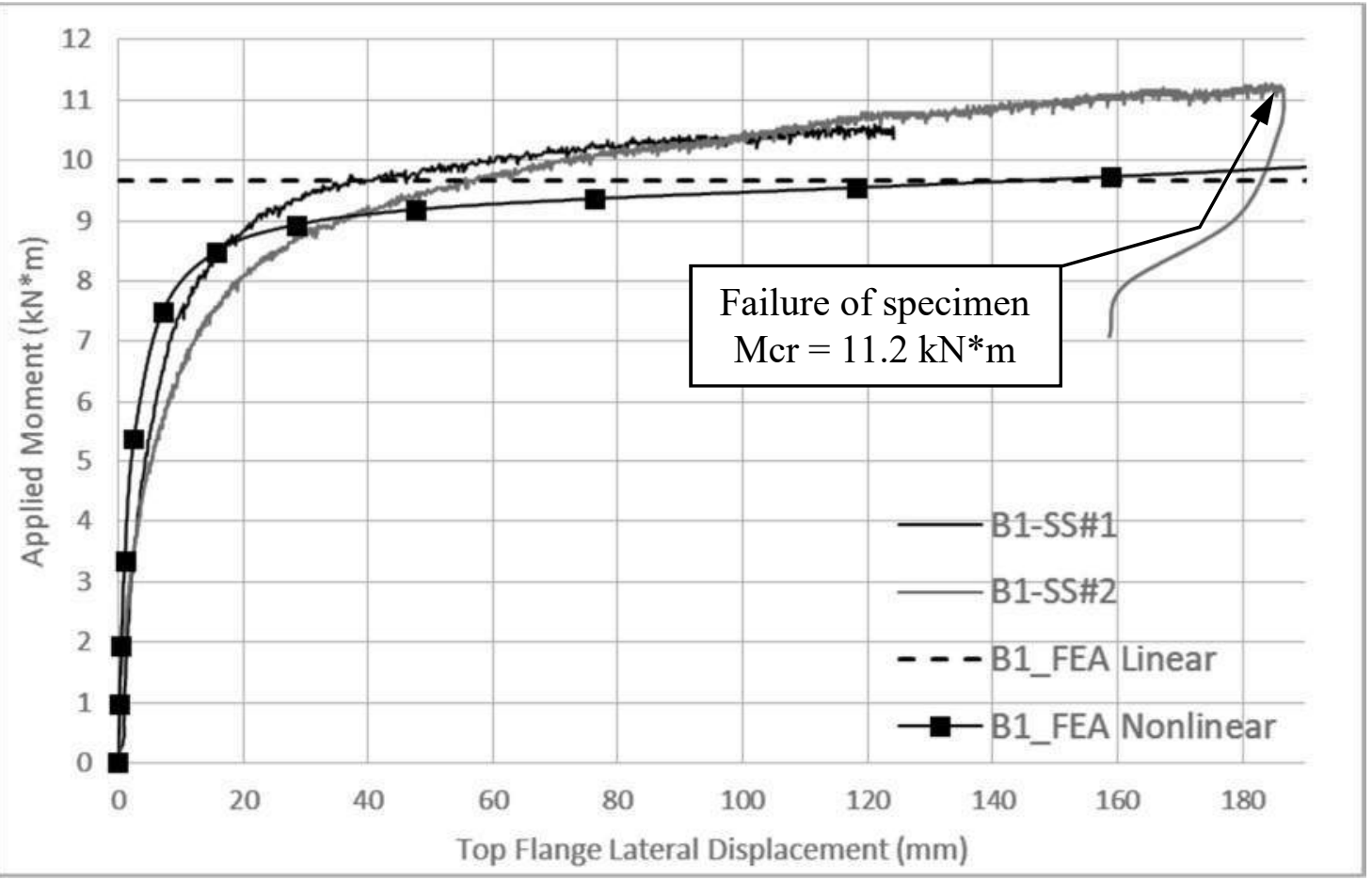

Figure B-1 Buckling displacement - Specimen A-1 - Simply Supported End conditions 
SPECIMEN 2

SAMPLE GROUP A

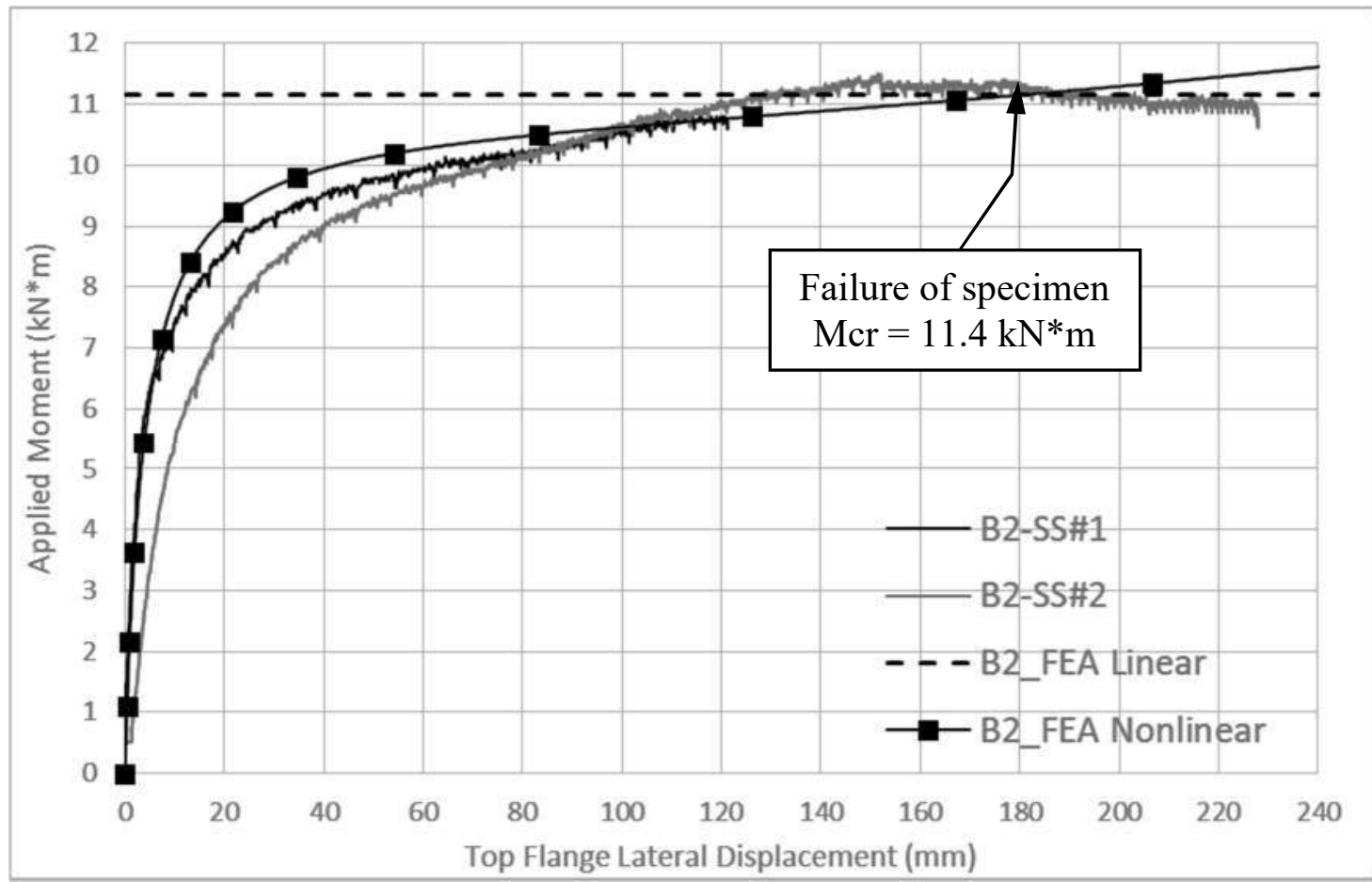

Figure B-2 Buckling displacement - Specimen A-2 - Simply Supported End conditions 
SPECIMEN 3

SAMPLE GROUP A

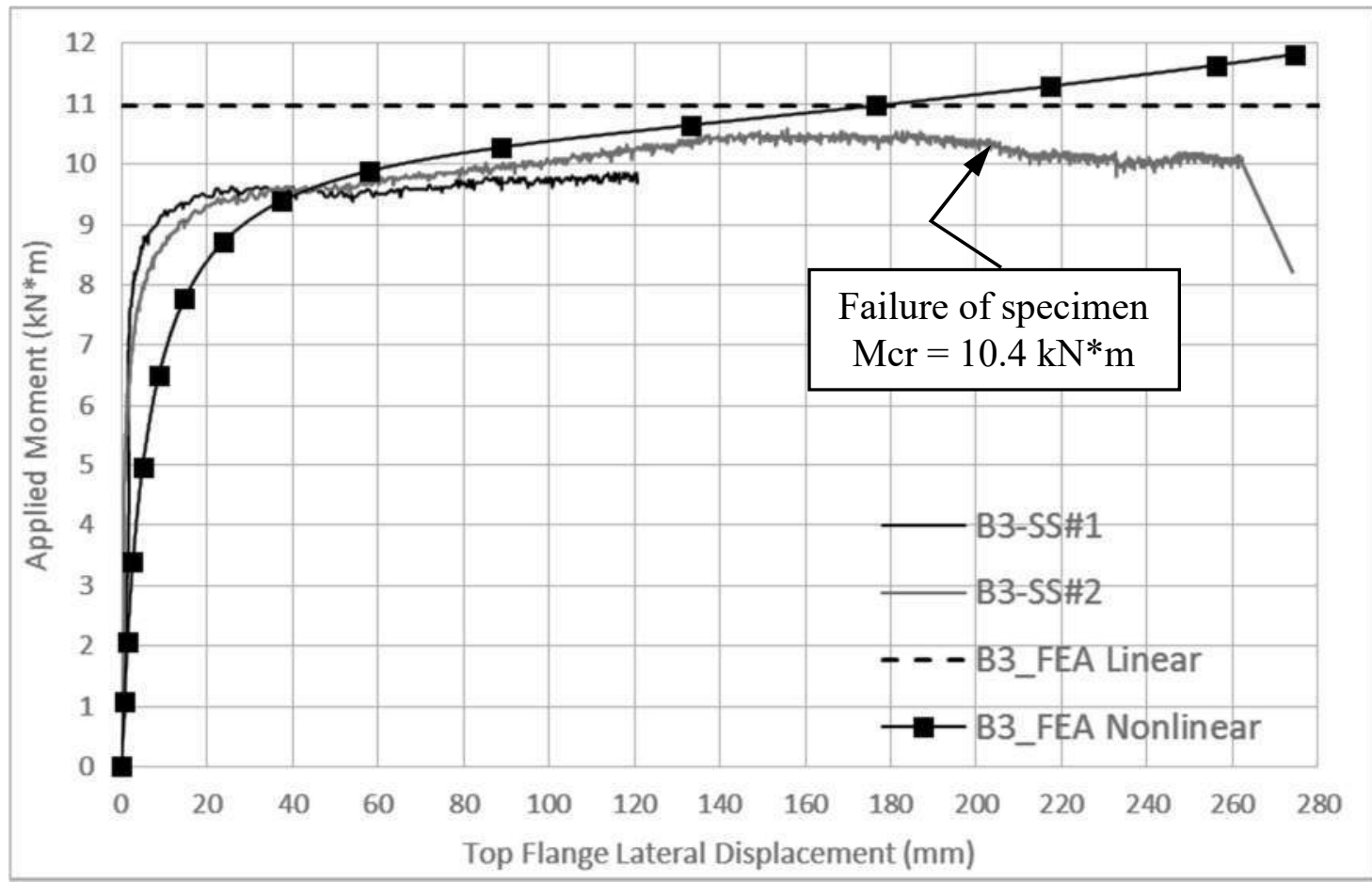

Figure B-3 Buckling displacement - Specimen A-3 - Simply Supported End conditions 


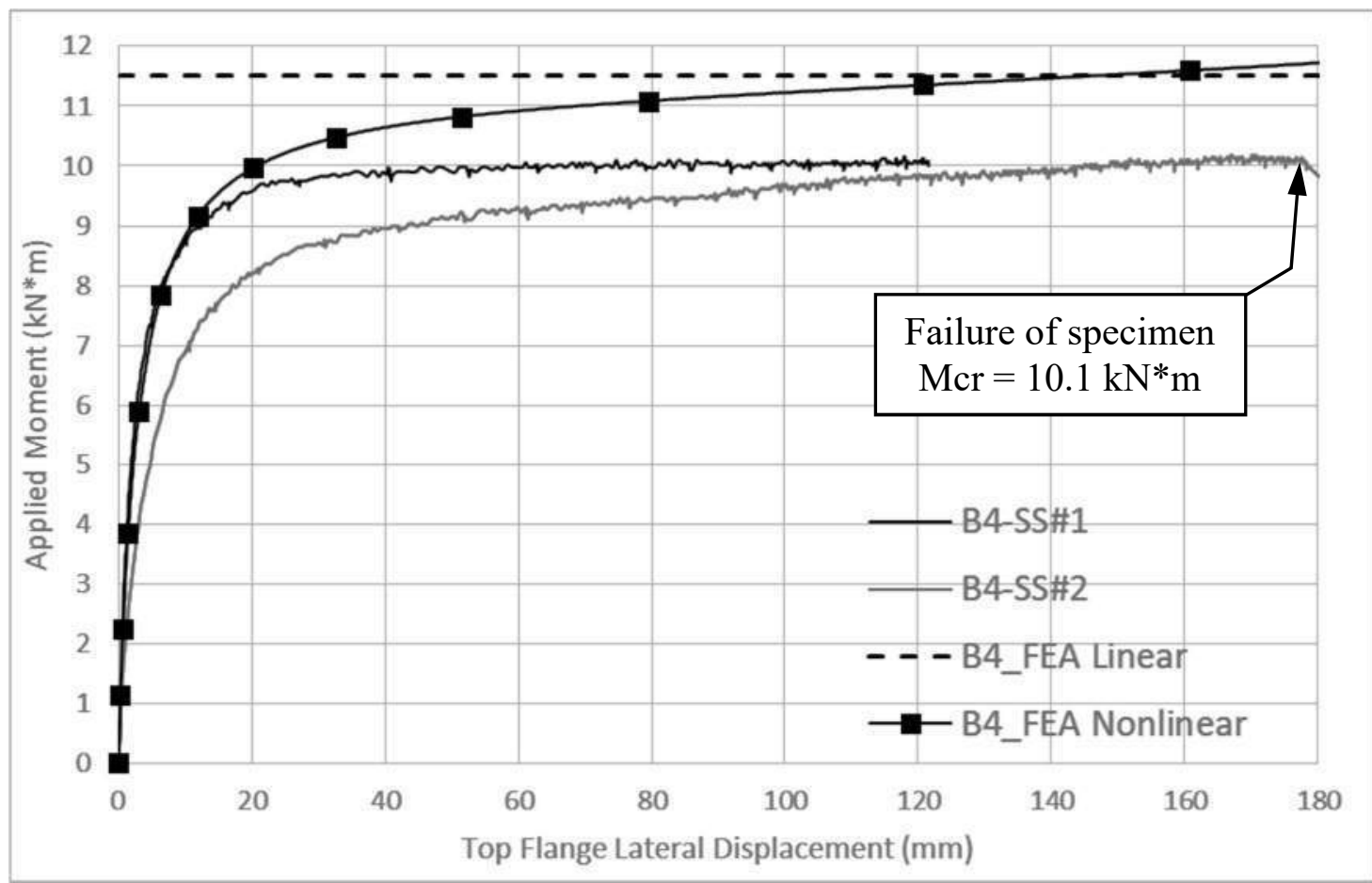

Figure B-4 Buckling displacement - Specimen A-4 - Simply Supported End conditions 


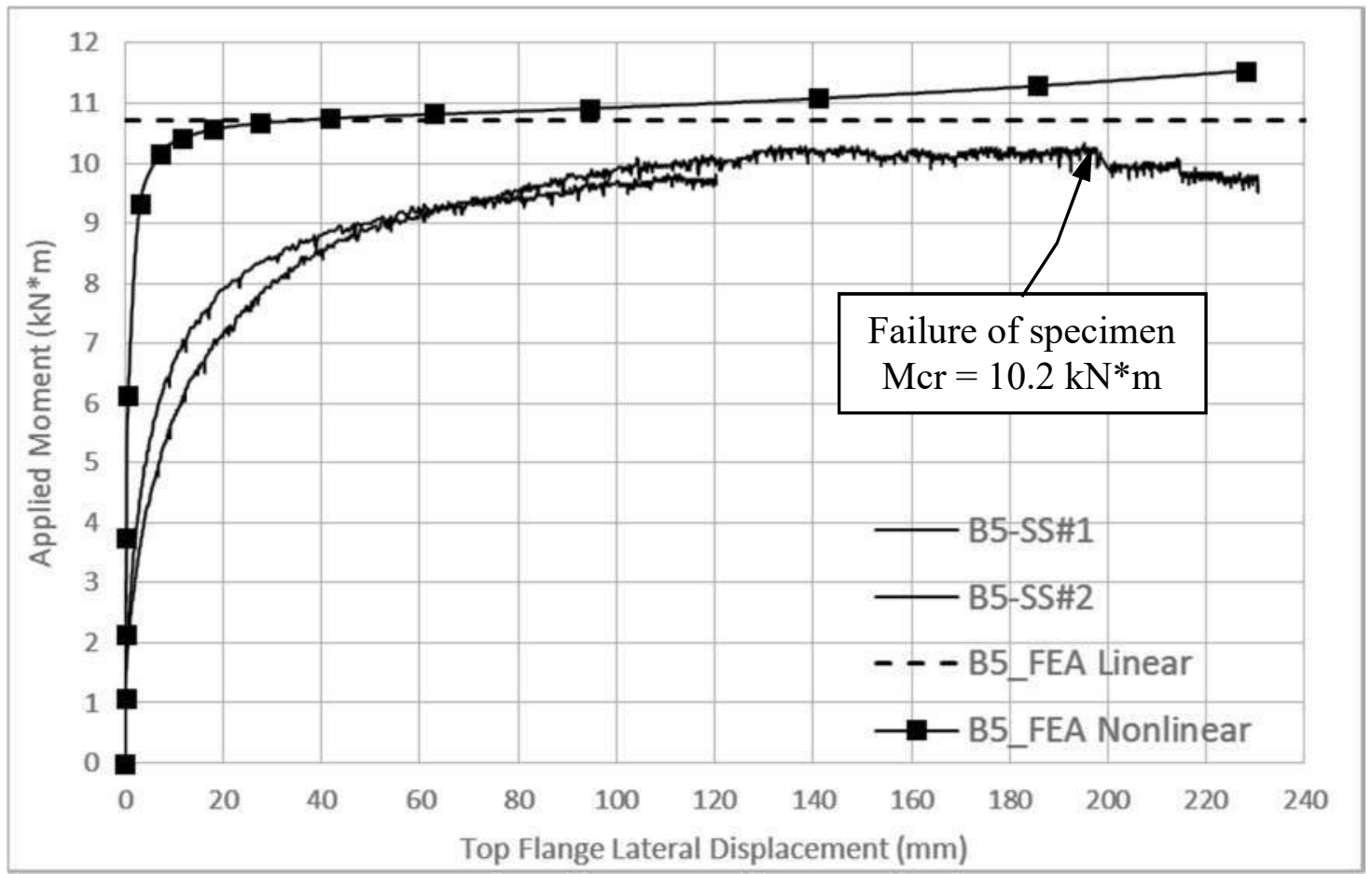

Figure B-5 Buckling displacement - Specimen A-5 - Simply Supported End conditions 


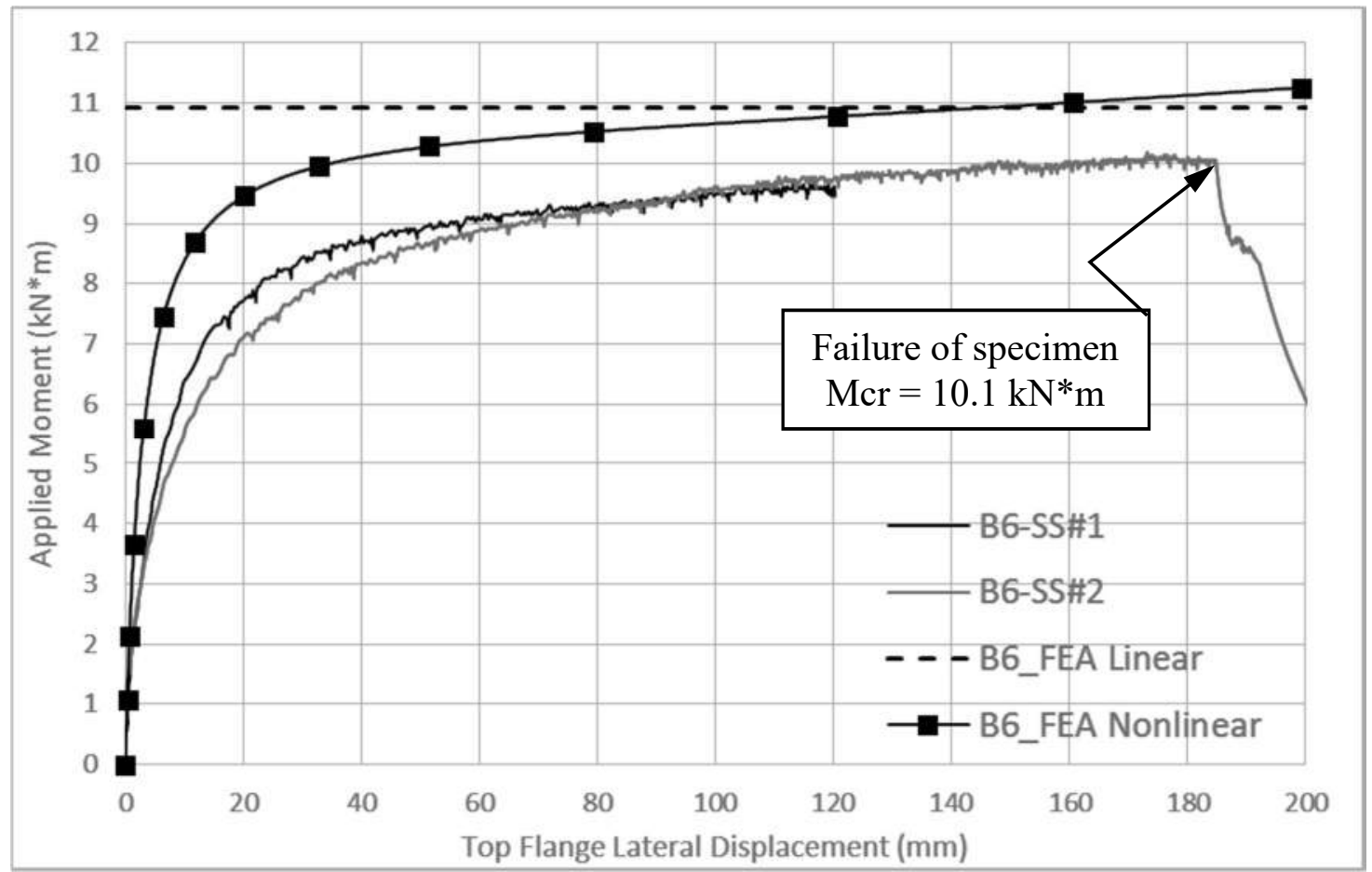

Figure B-6 Buckling displacement - Specimen A-6 - Simply Supported End conditions 


\section{SPECIMEN 7}

SAMPLE GROUP A

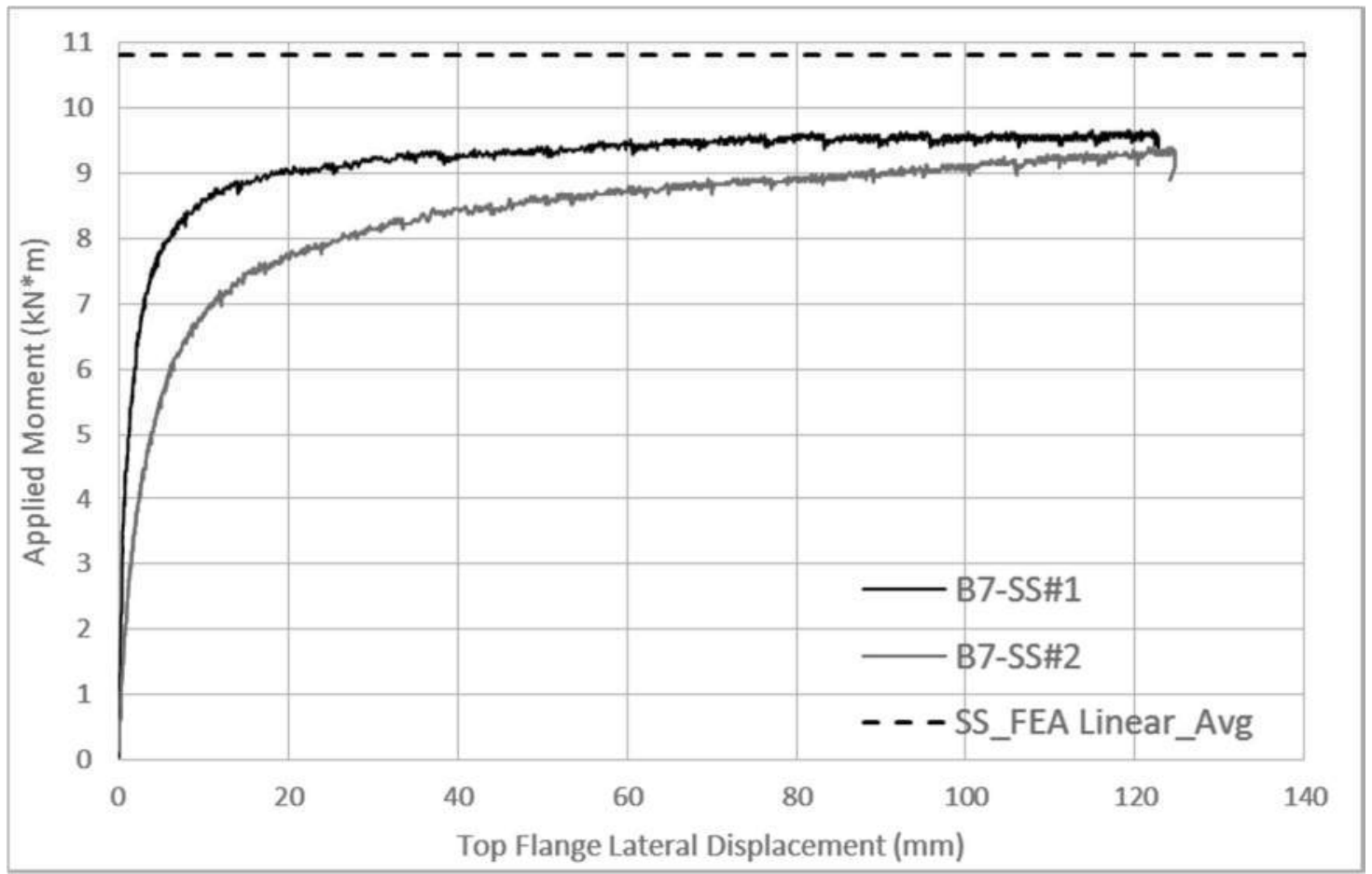

Figure B-7 Buckling displacement - Specimen A-7 - Simply Supported End conditions

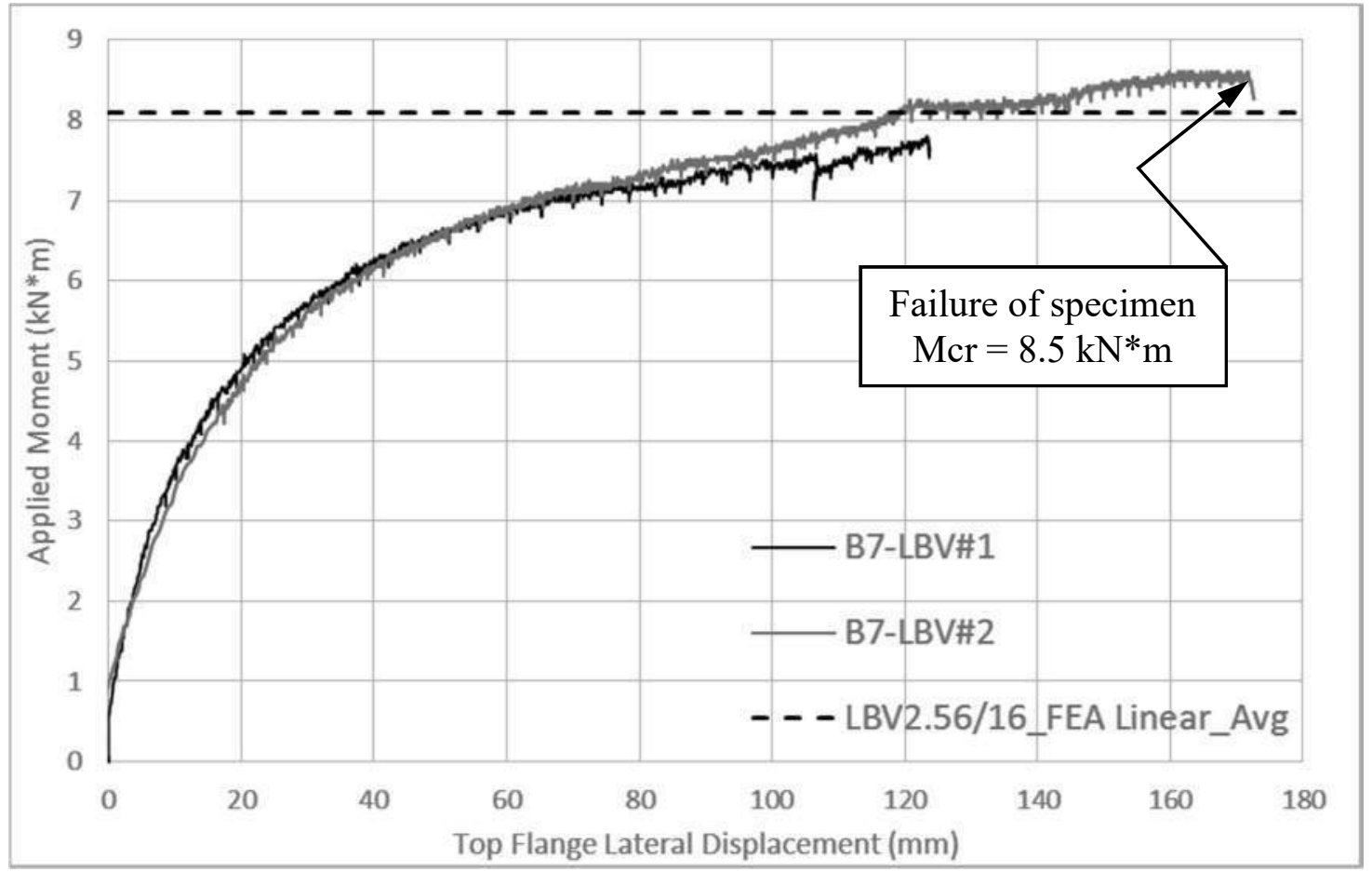

Figure B-8 Buckling displacement - Specimen A-7 - LBV2.56/16 Top Mounted Hangers 


\section{SPECIMEN 8}

SAMPLE GROUP A

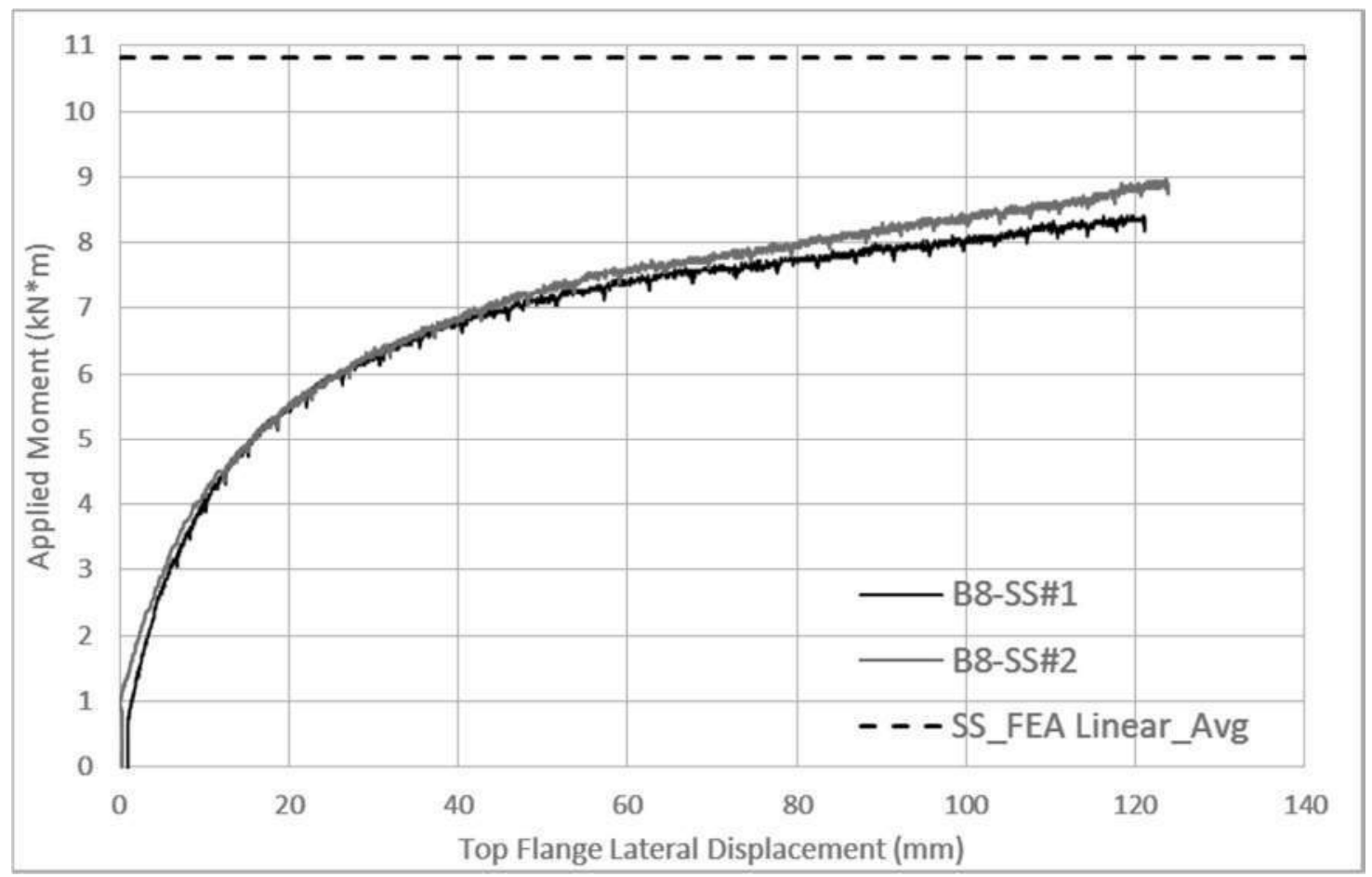

Figure B-9 Buckling displacement - Specimen A-8 - Simply Supported End conditions

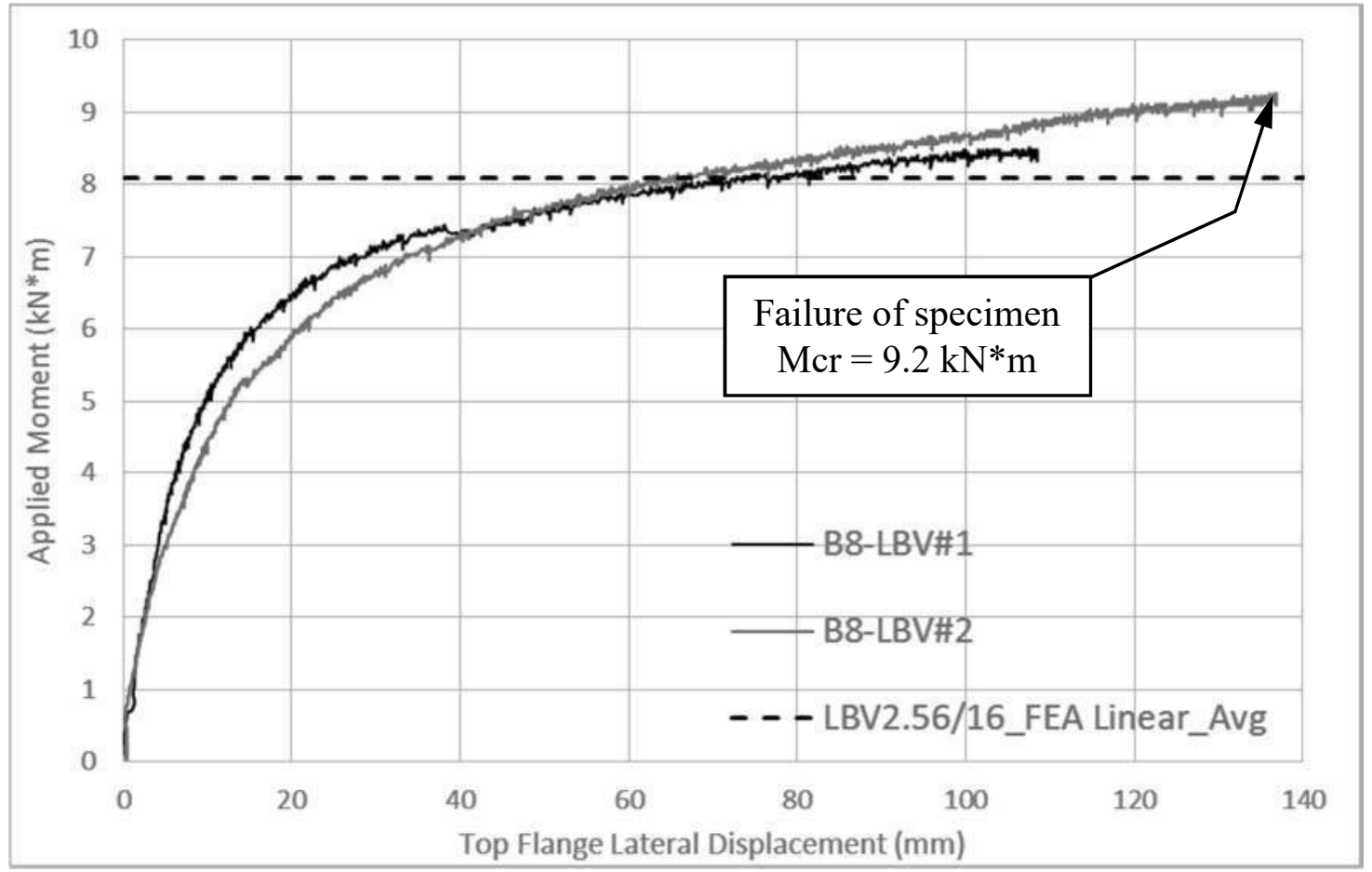

Figure B-10 Buckling displacement - Specimen A-8 - LBV2.56/16 Top Mounted Hangers 


\section{SPECIMEN 9}

SAMPLE GROUP A

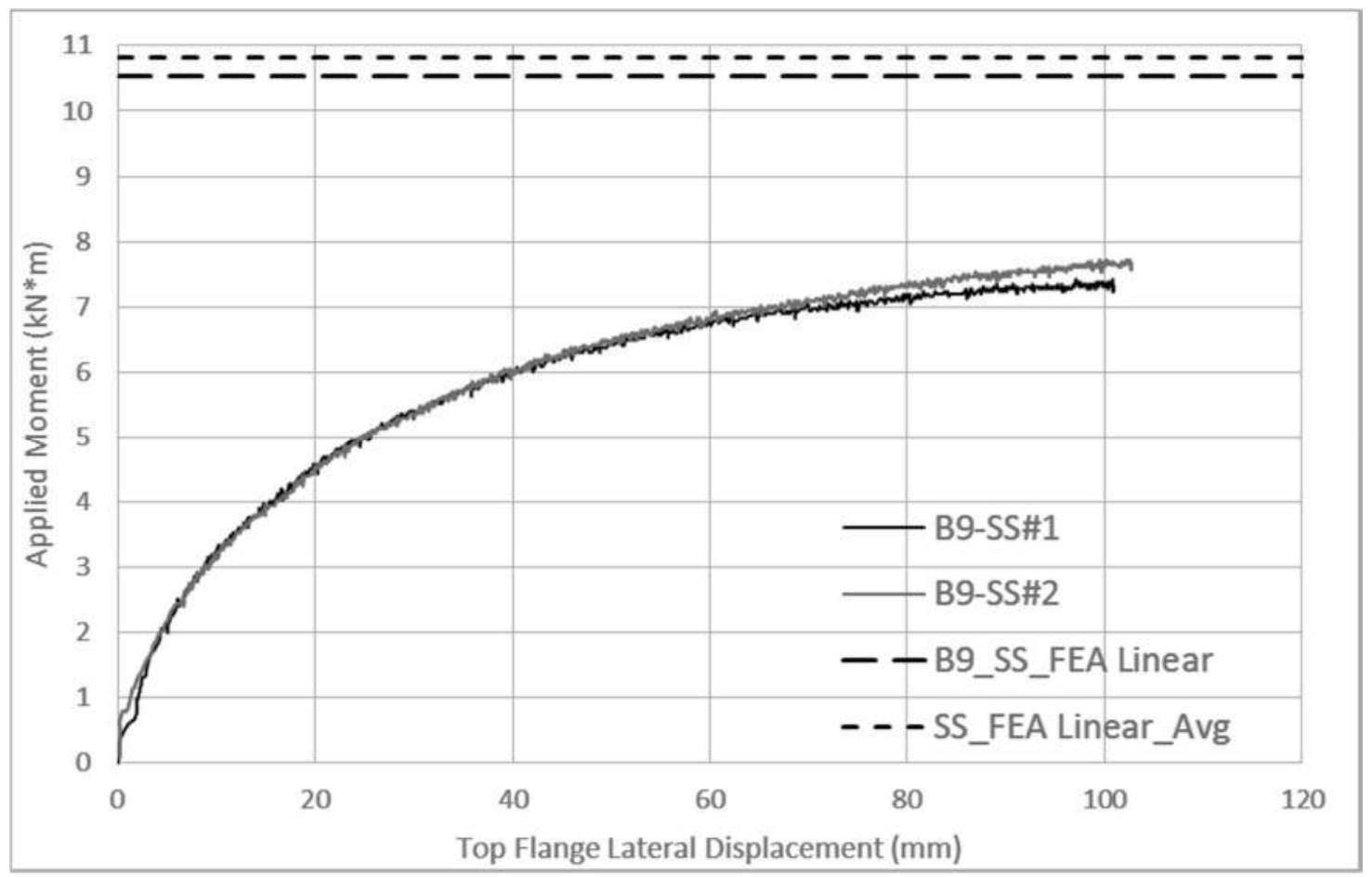

Figure B-11 Buckling displacement - Specimen A-9 - Simply Supported End conditions

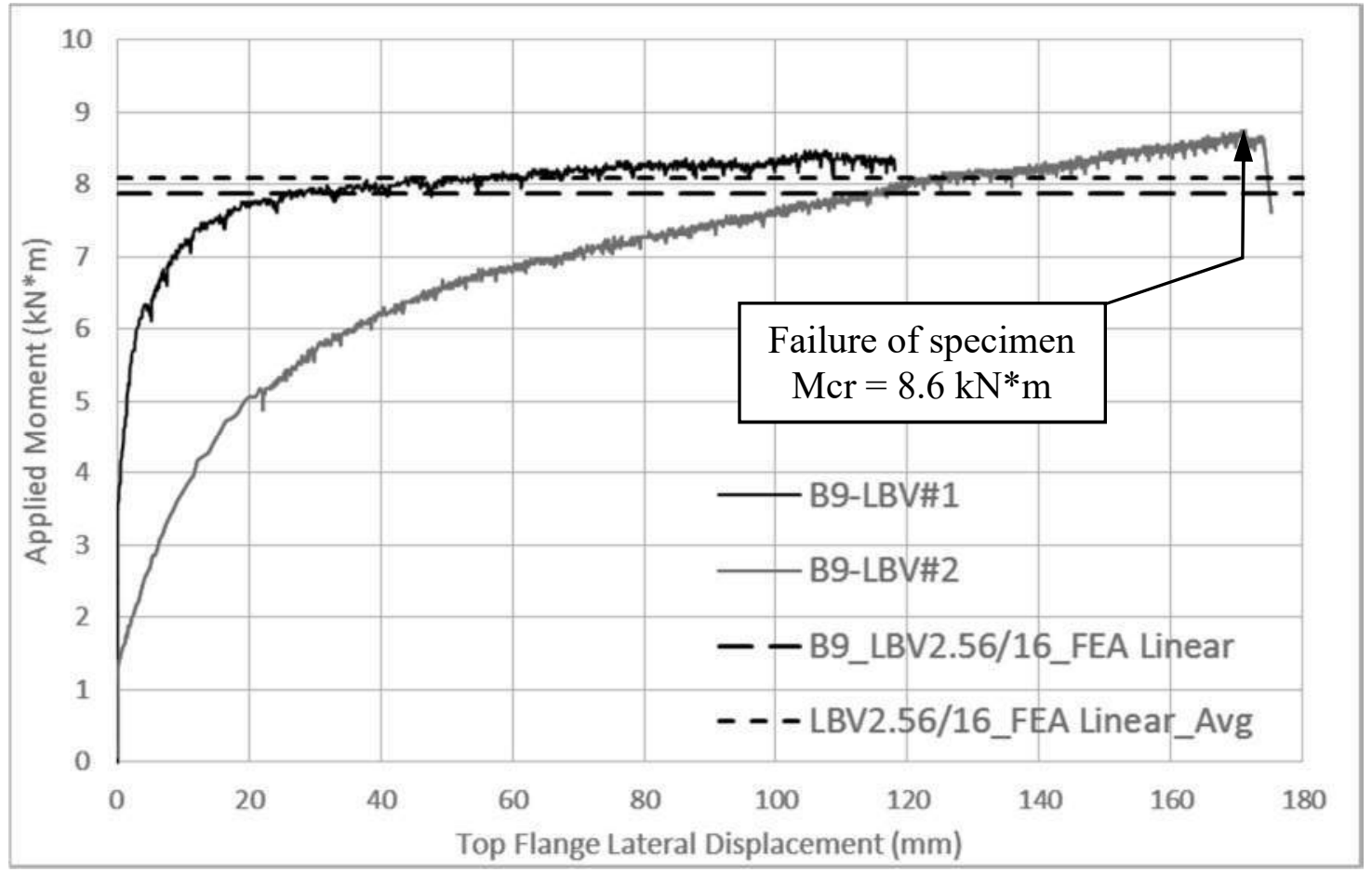

Figure B-12 Buckling displacement - Specimen A-9 - LBV2.56/16 Top Mounted Hangers 


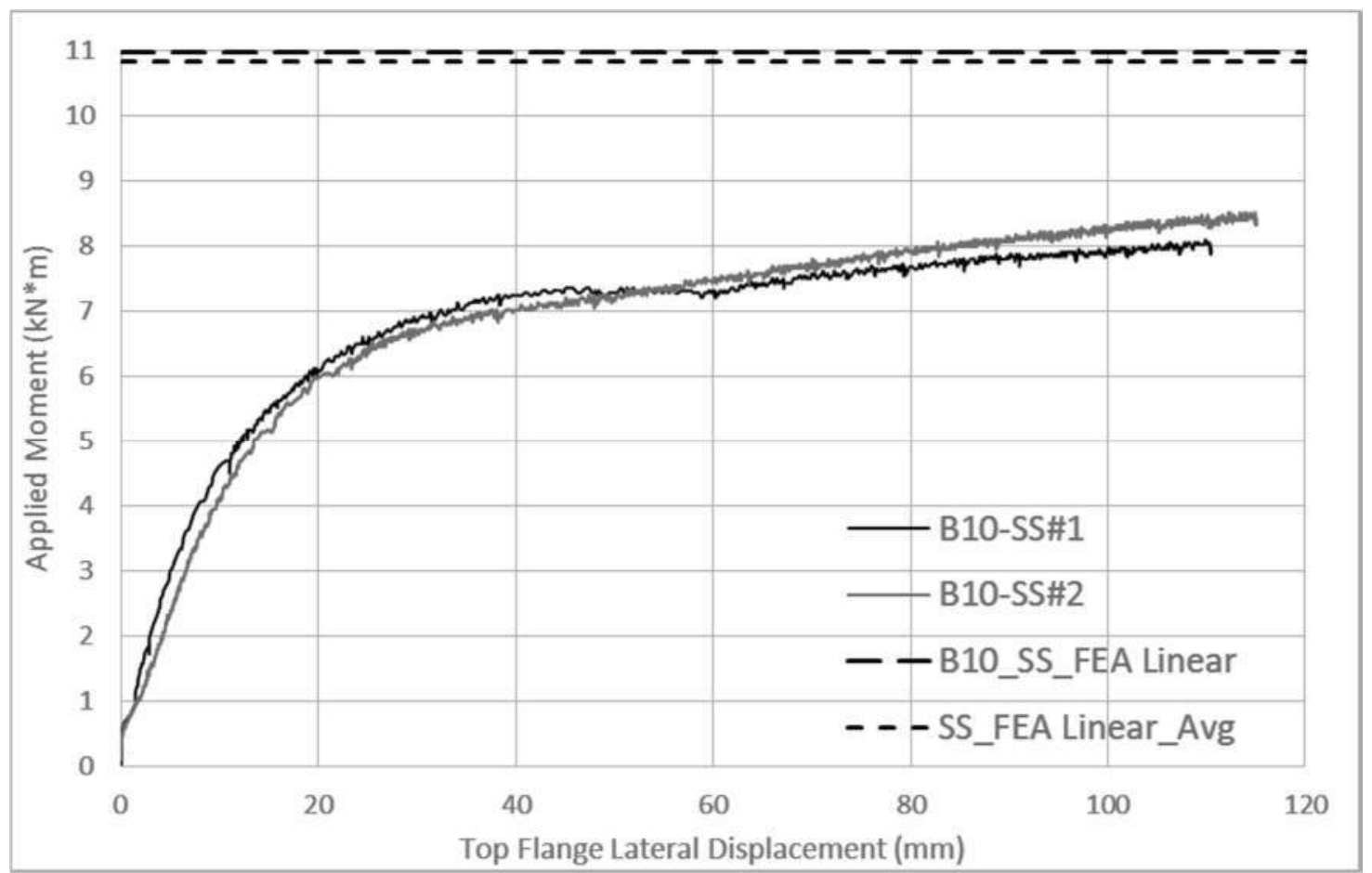

Figure B-13 Buckling displacement - Specimen A-10 - Simply Supported End conditions

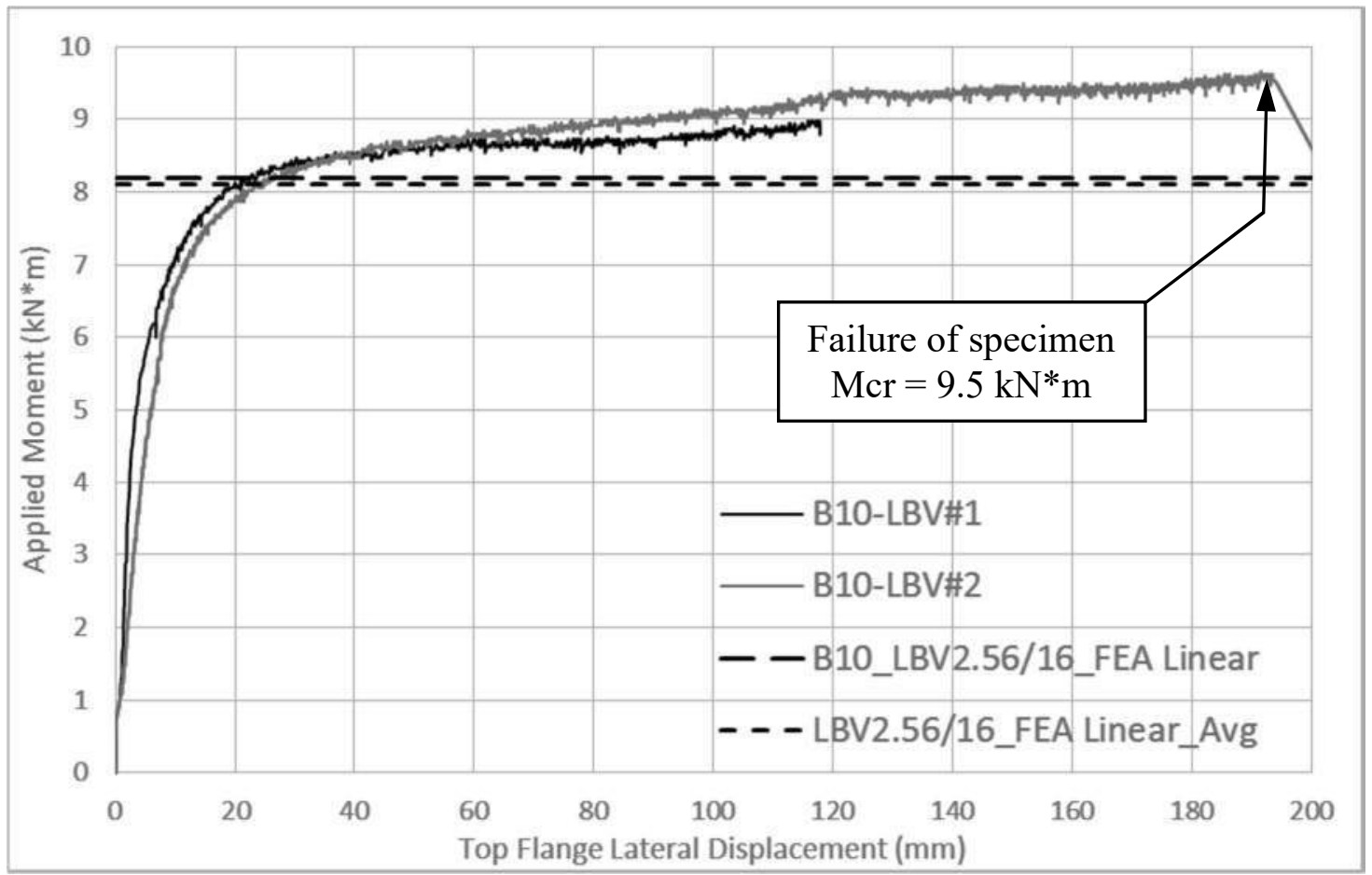

Figure B-14 Buckling displacement - Specimen A-10 - LBV2.56/16 Top Mounted Hangers 


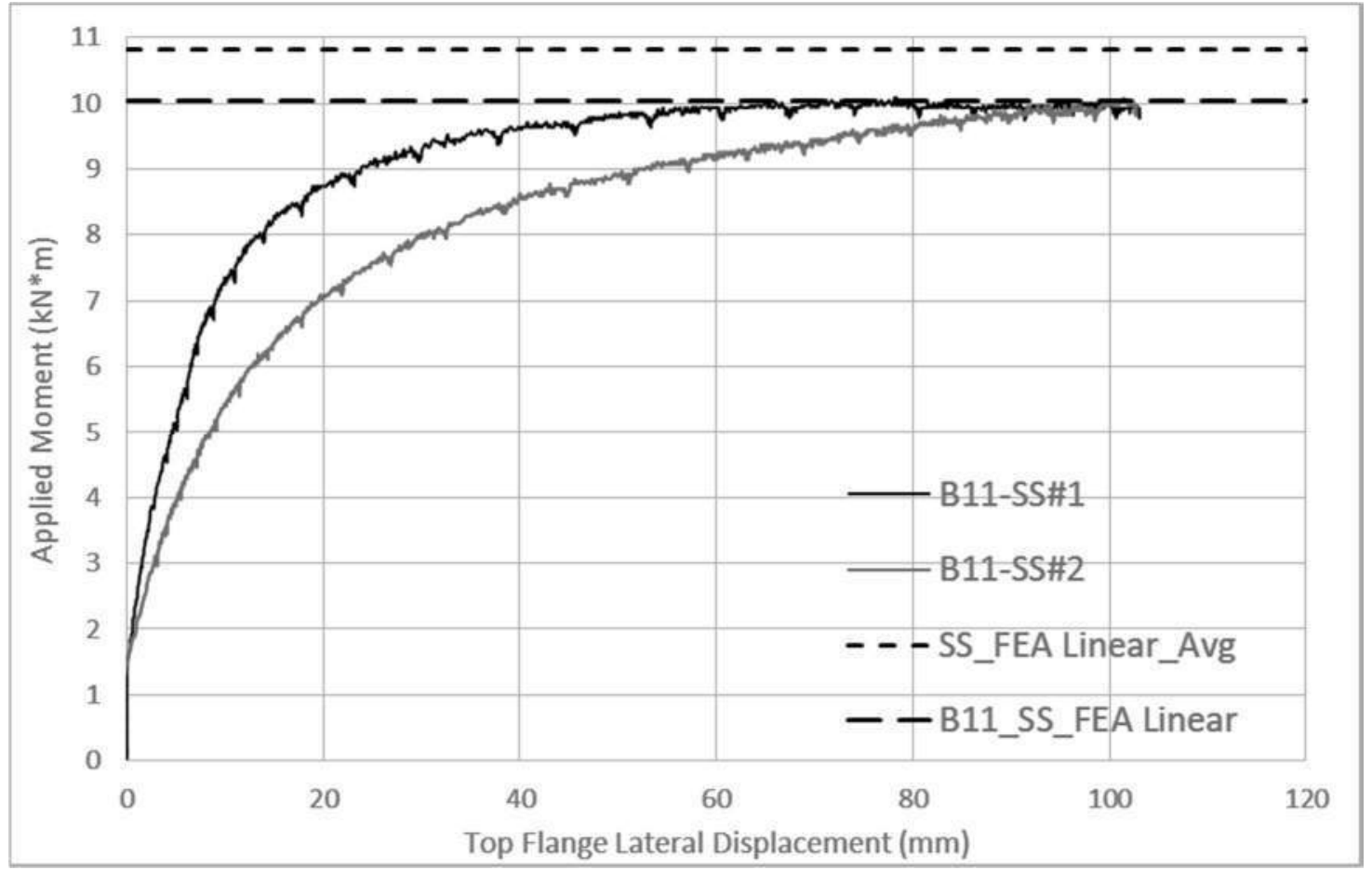

Figure B-15 Buckling displacement - Specimen A-11 - Simply Supported End conditions

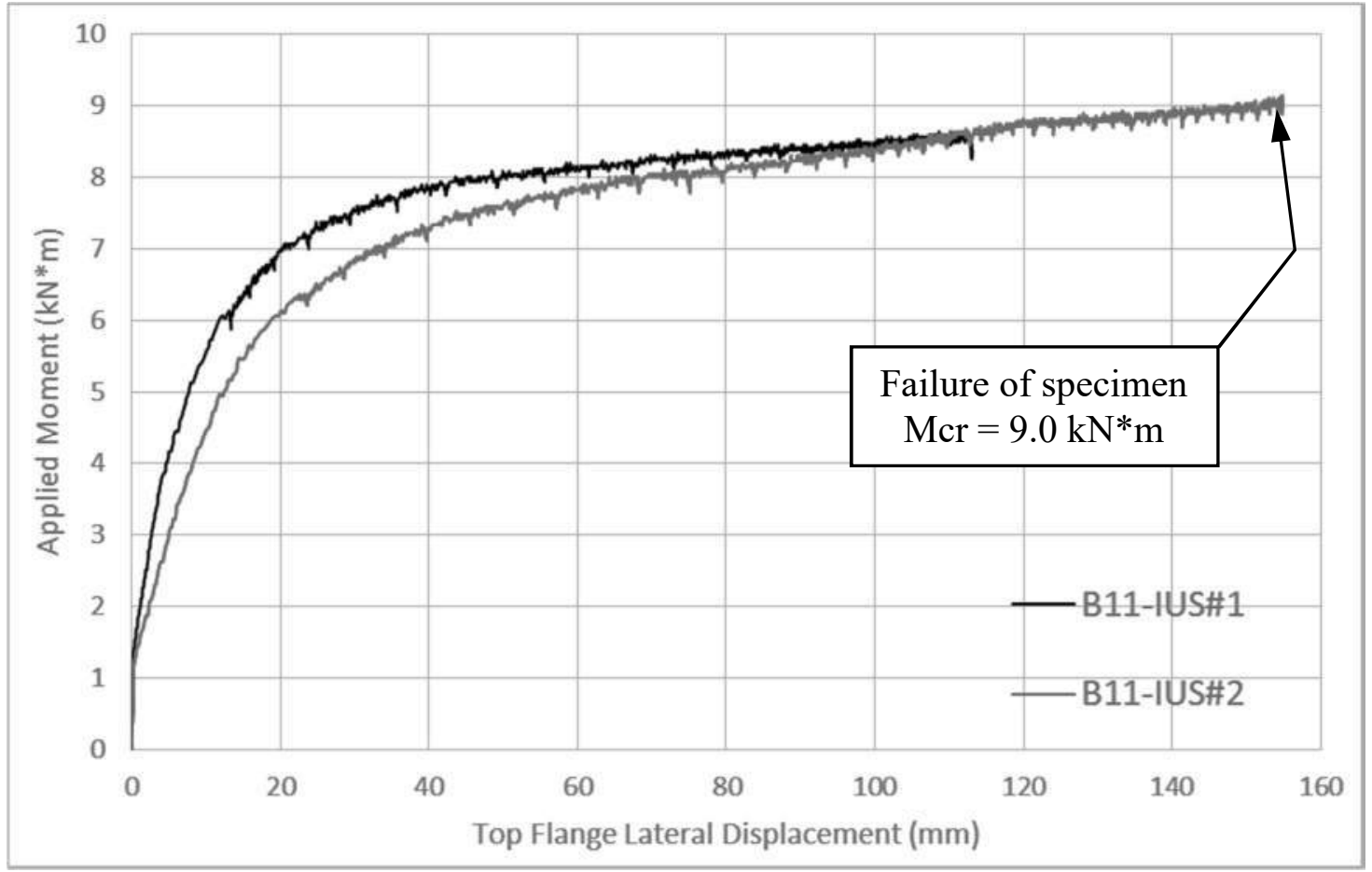

Figure B-16 Buckling displacement - Specimen A-11 - IUS2.56/16 Face Mounted Hangers 


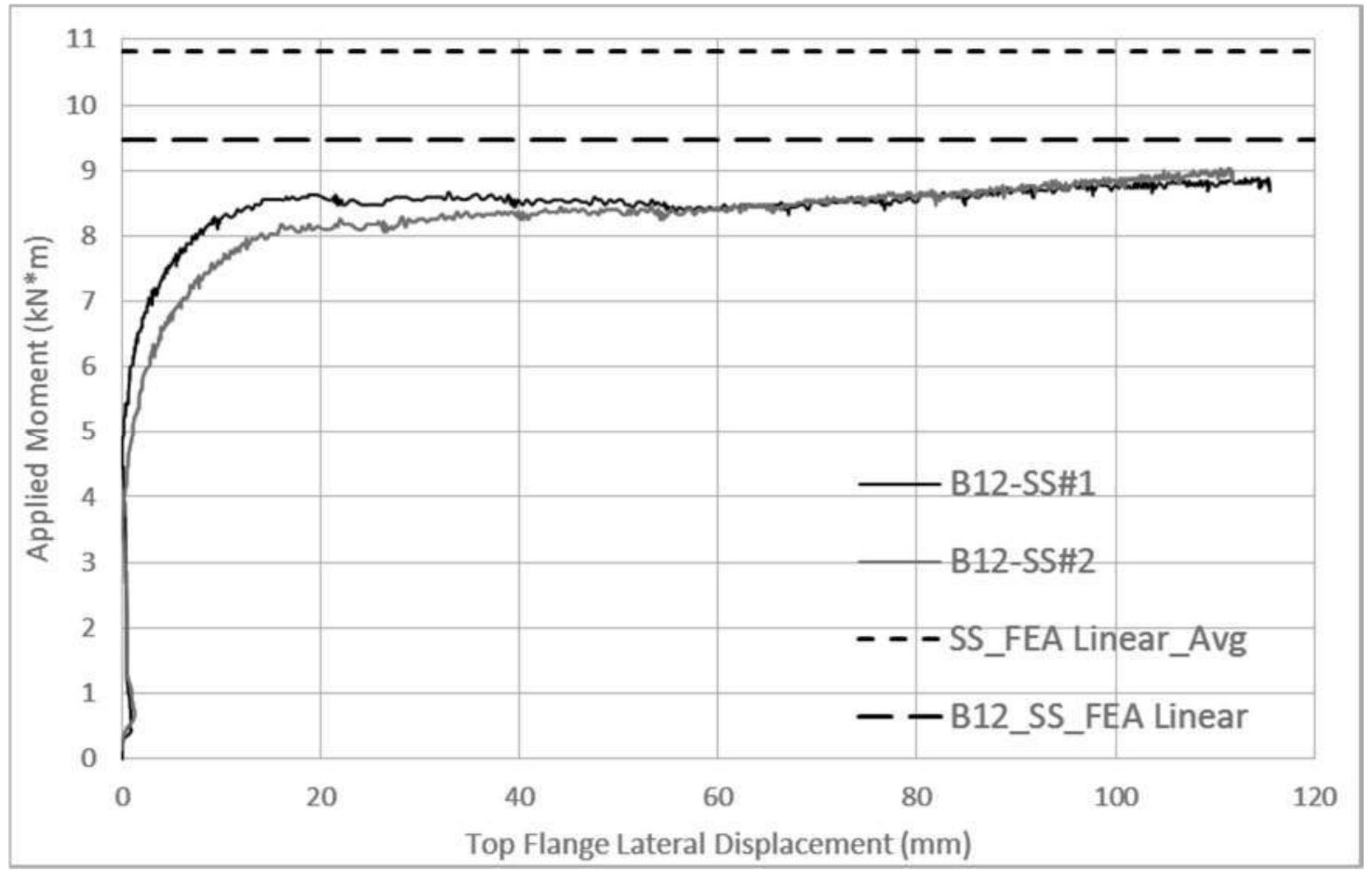

Figure B-17 Buckling displacement - Specimen A-12 - Simply Supported End conditions

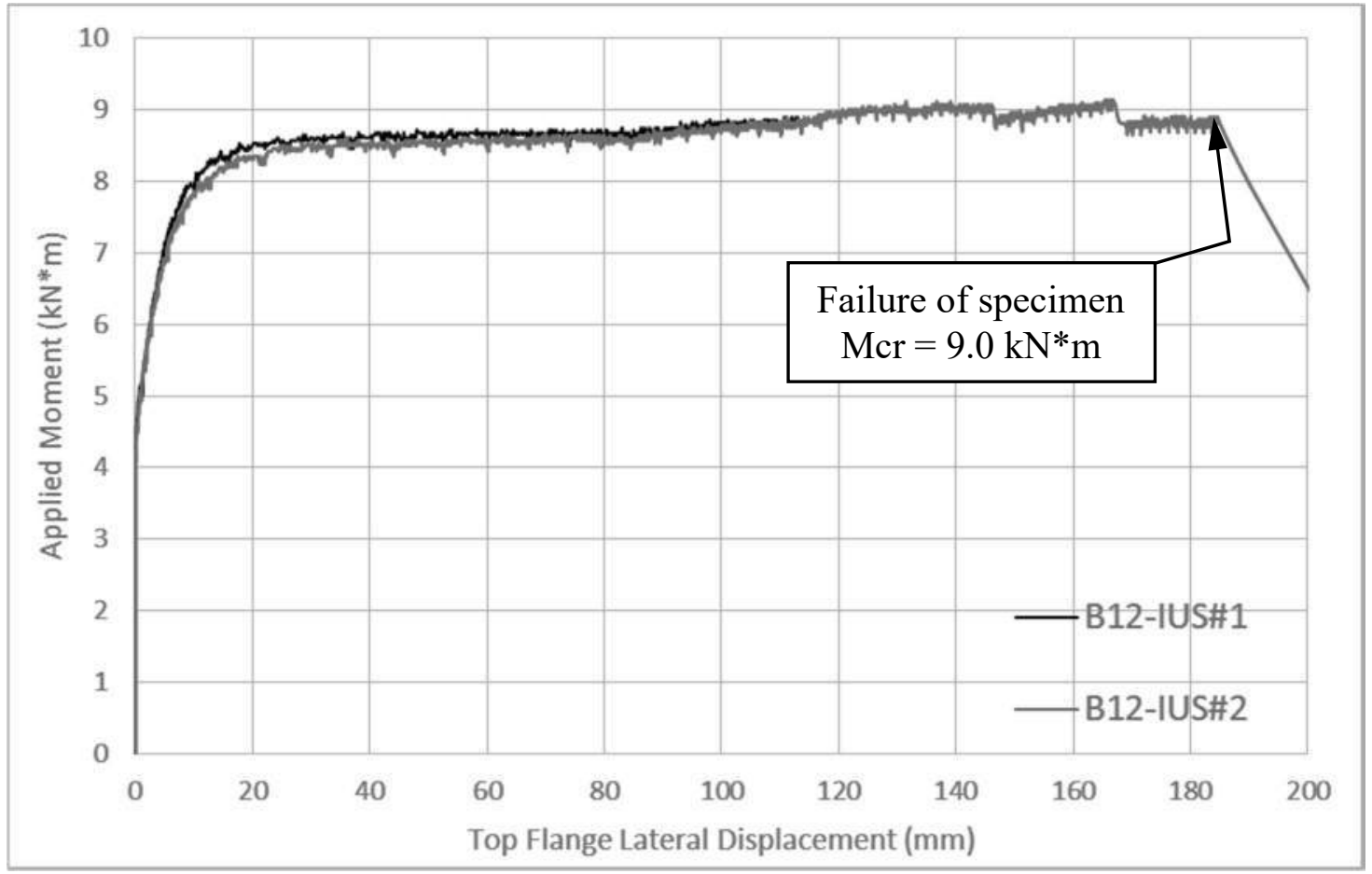

Figure B-18 Buckling displacement - Specimen A-12 - IUS2.56/16 Face Mounted Hangers 


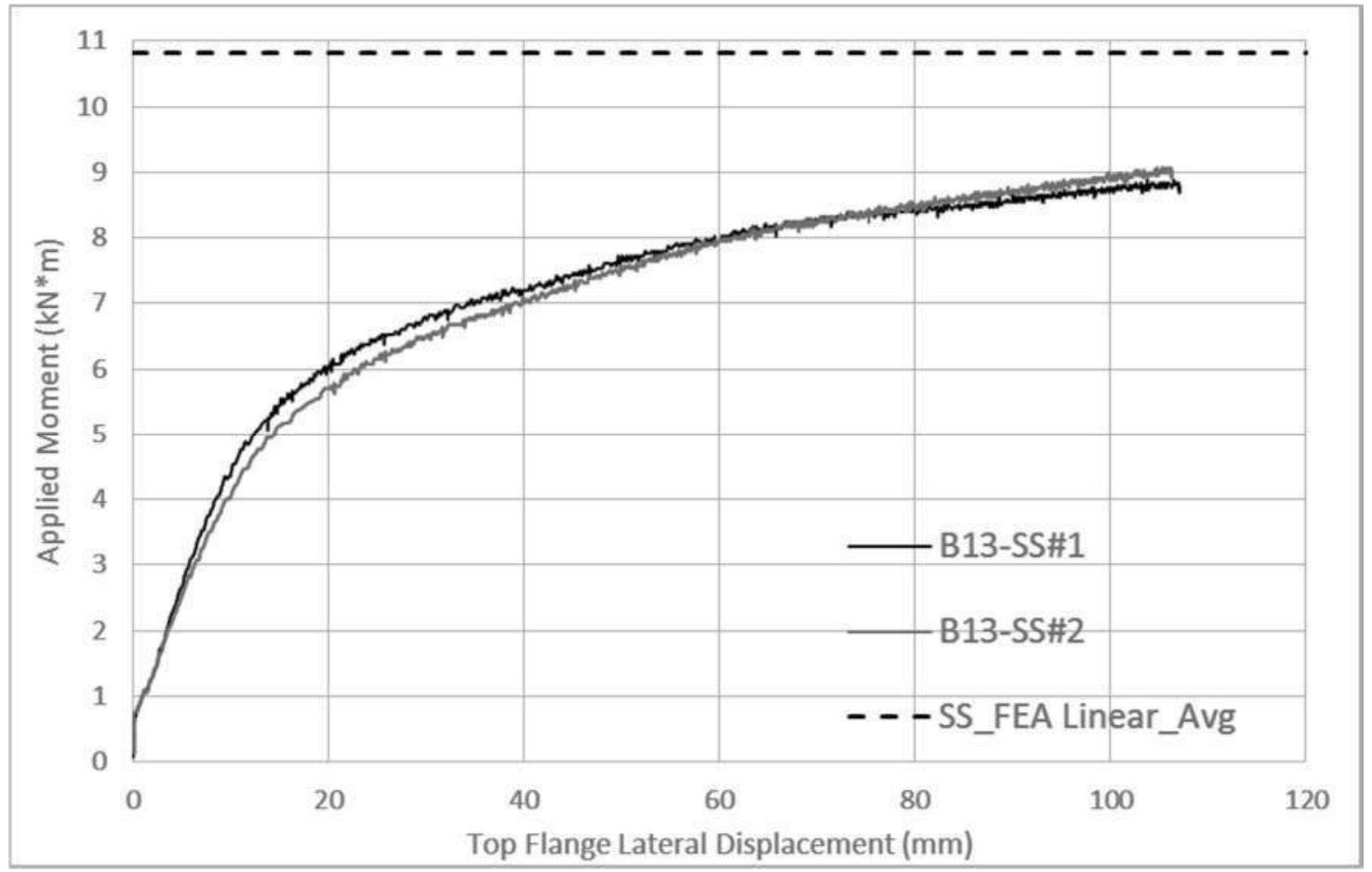

Figure B-19 Buckling displacement - Specimen A-13 - Simply Supported End conditions

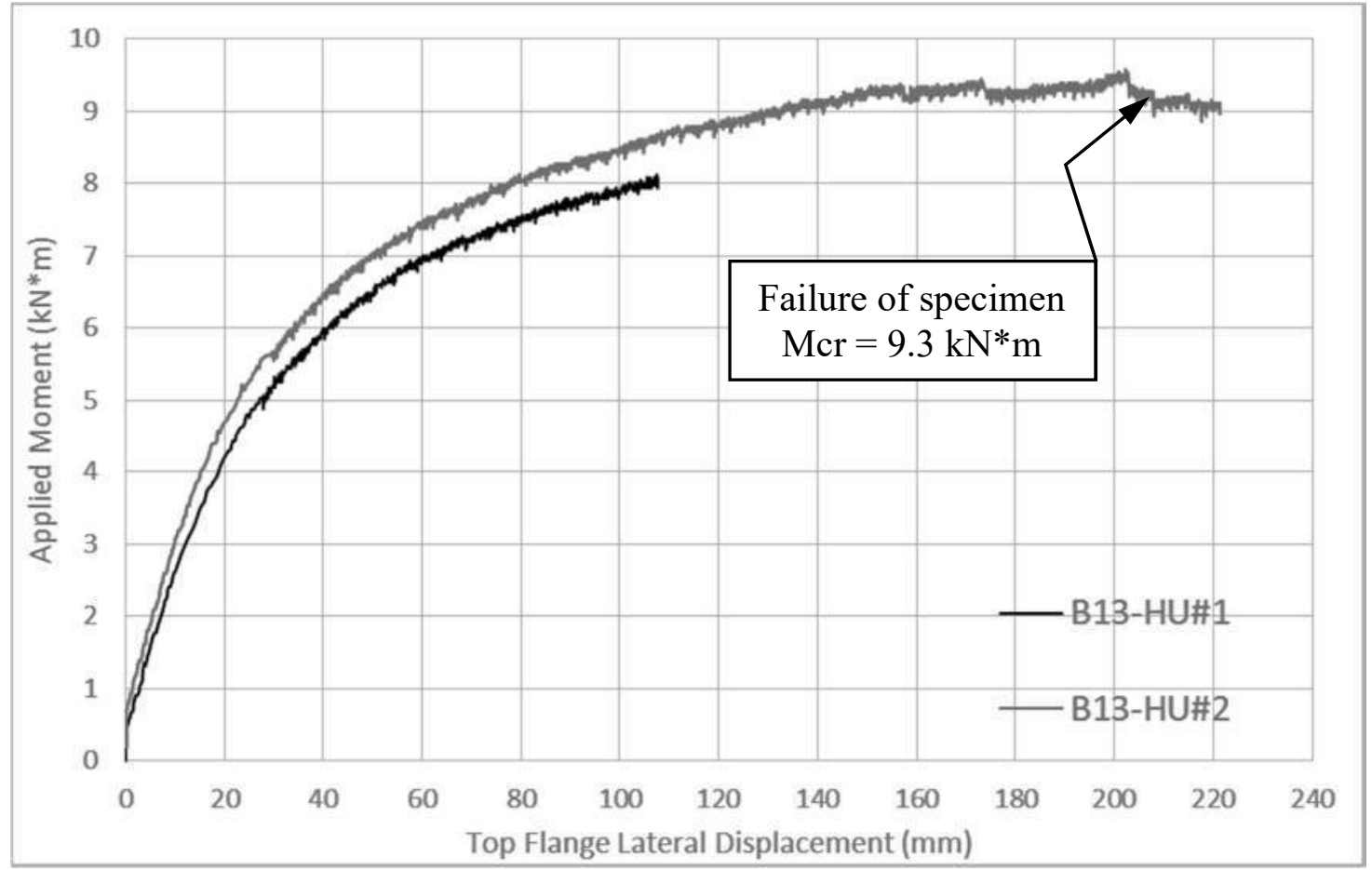

Figure B-20 Buckling displacement - Specimen A-13 - HU316 Face Mounted Hangers 


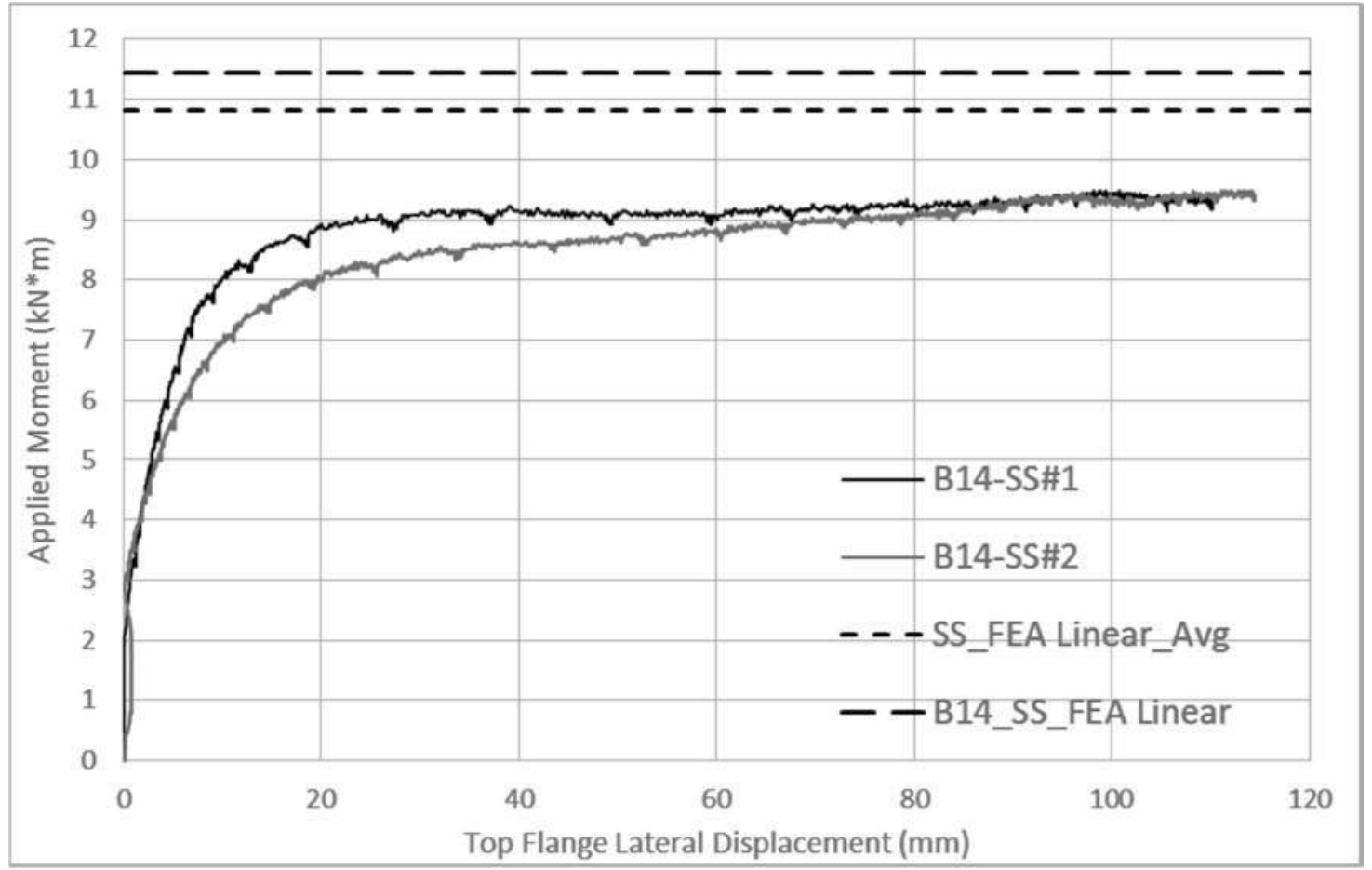

Figure B-21 Buckling displacement - Specimen A-14 - Simply Supported End conditions

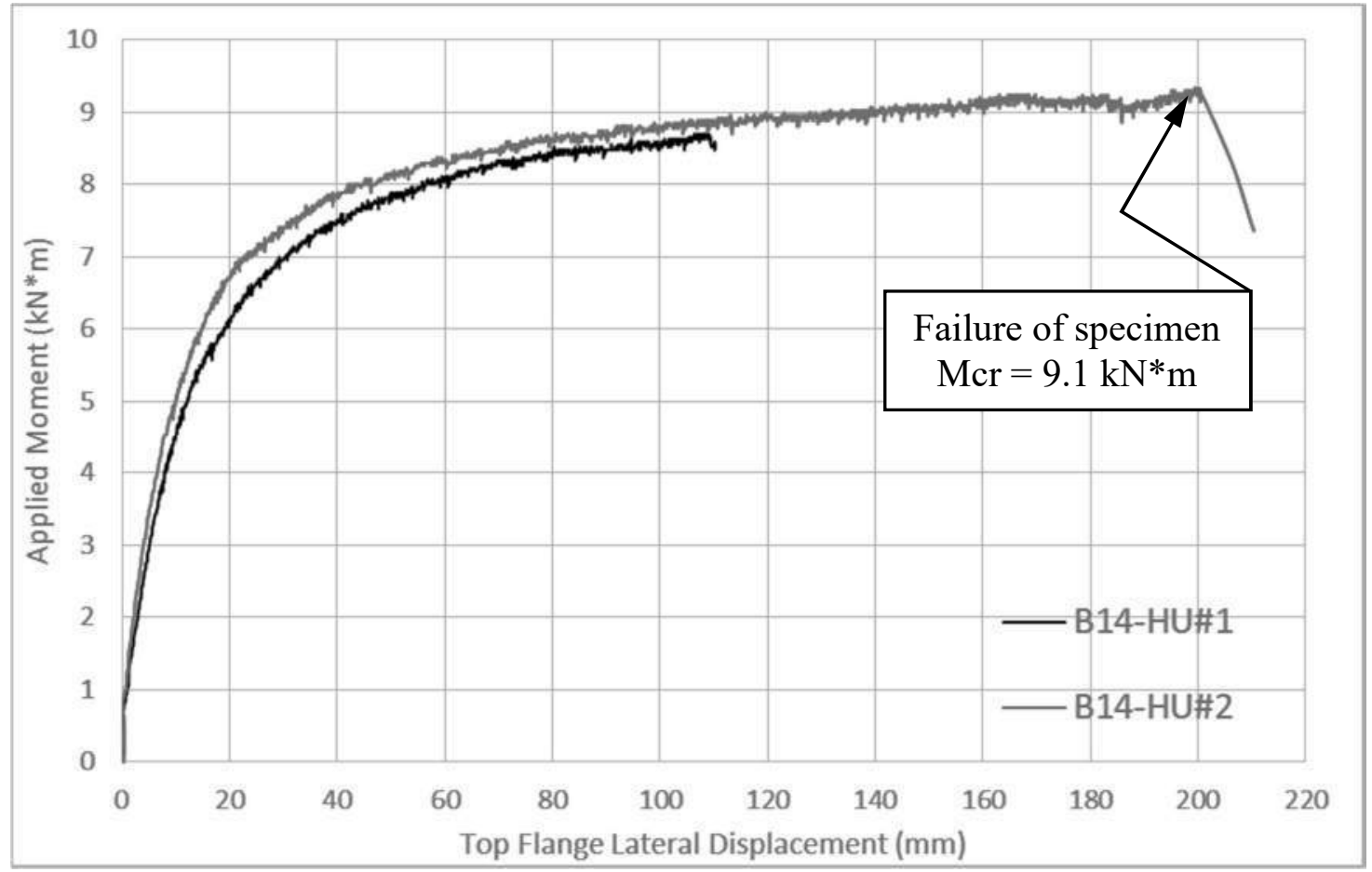

Figure B-22 Buckling displacement - Specimen A-14 - HU316 Face Mounted Hangers 


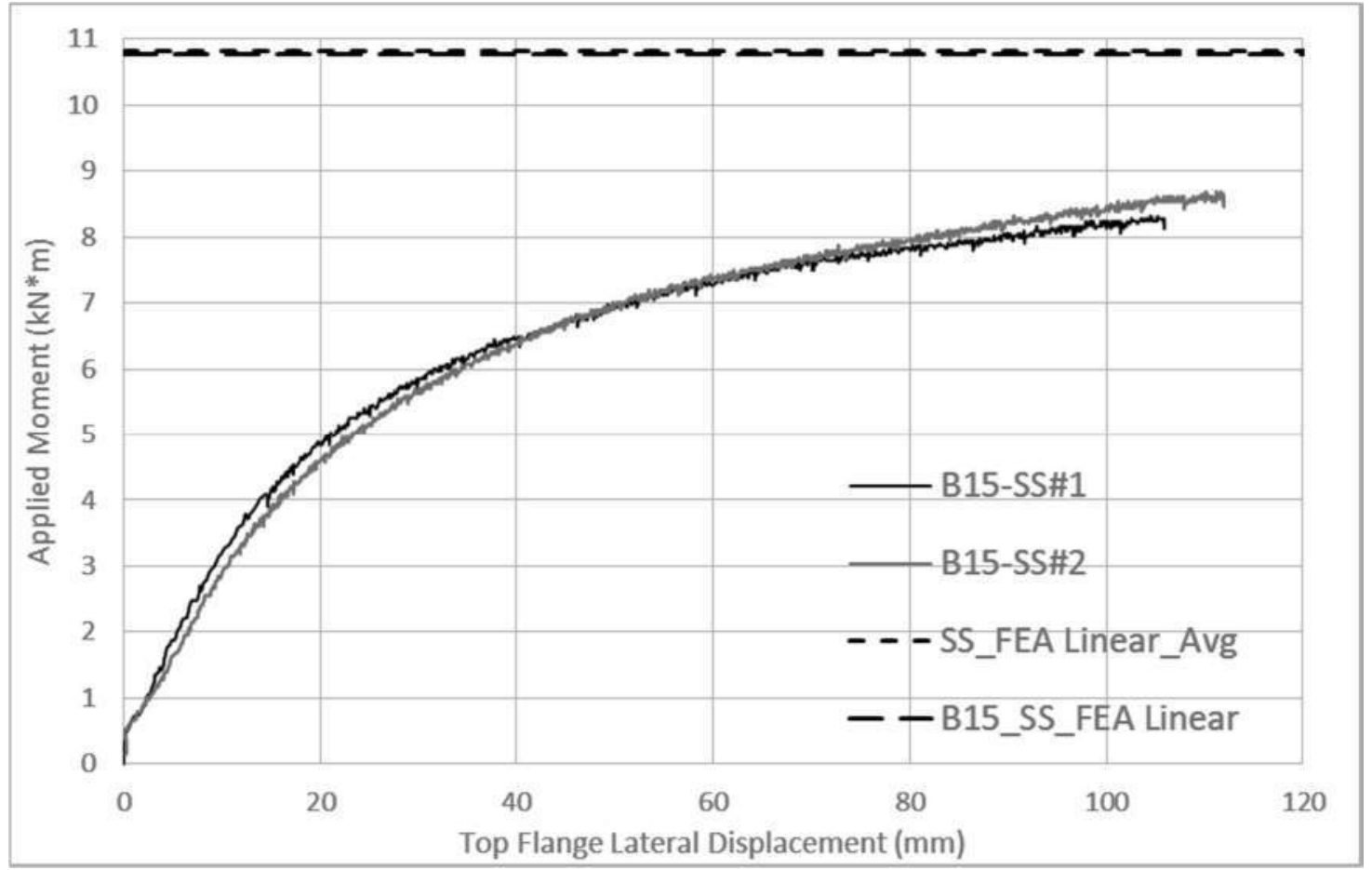

Figure B-23 Buckling displacement - Specimen A-15 - Simply Supported End conditions

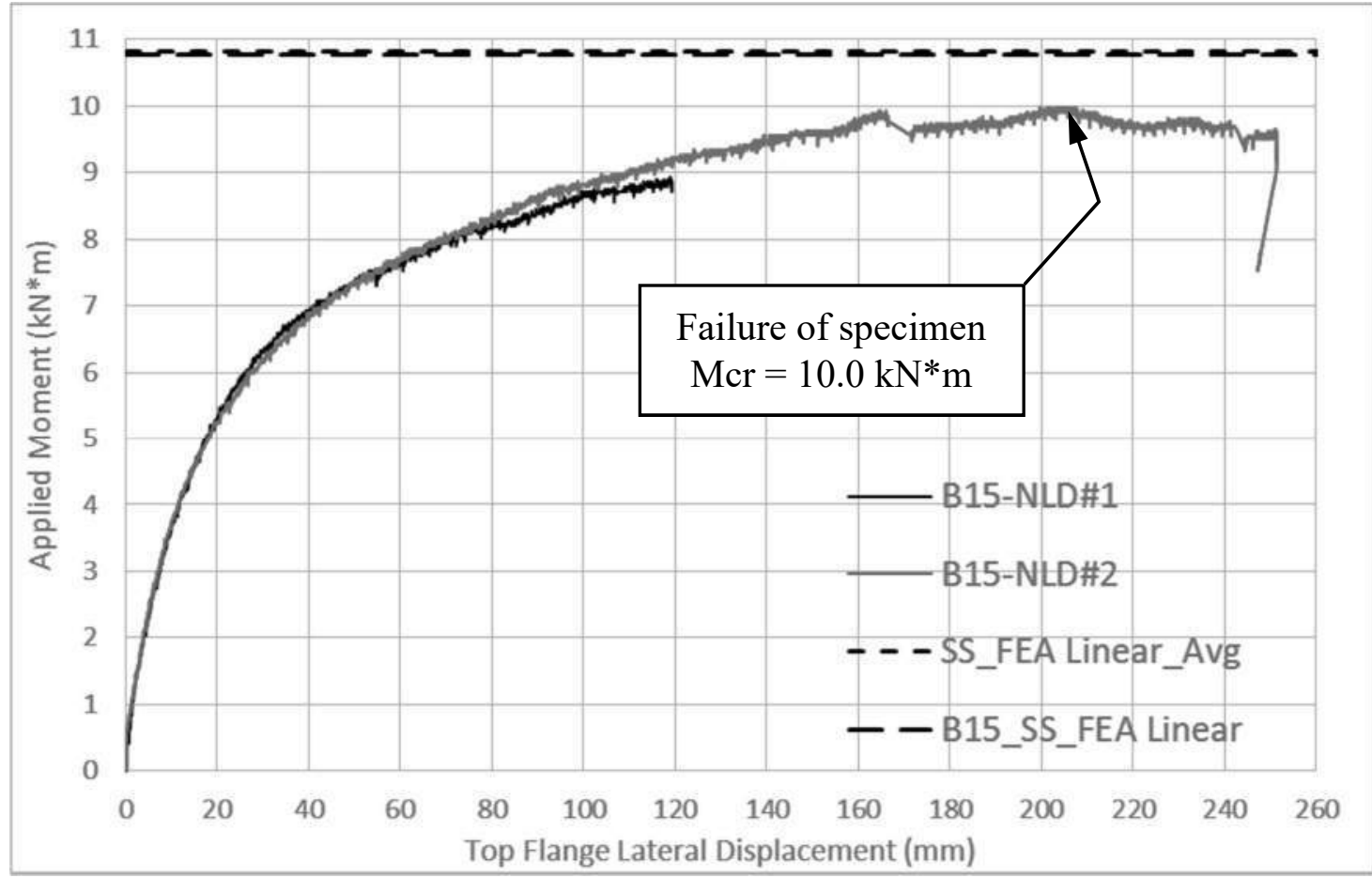

Figure B-24 Buckling displacement - Specimen A-15 - Nailed through end grain 


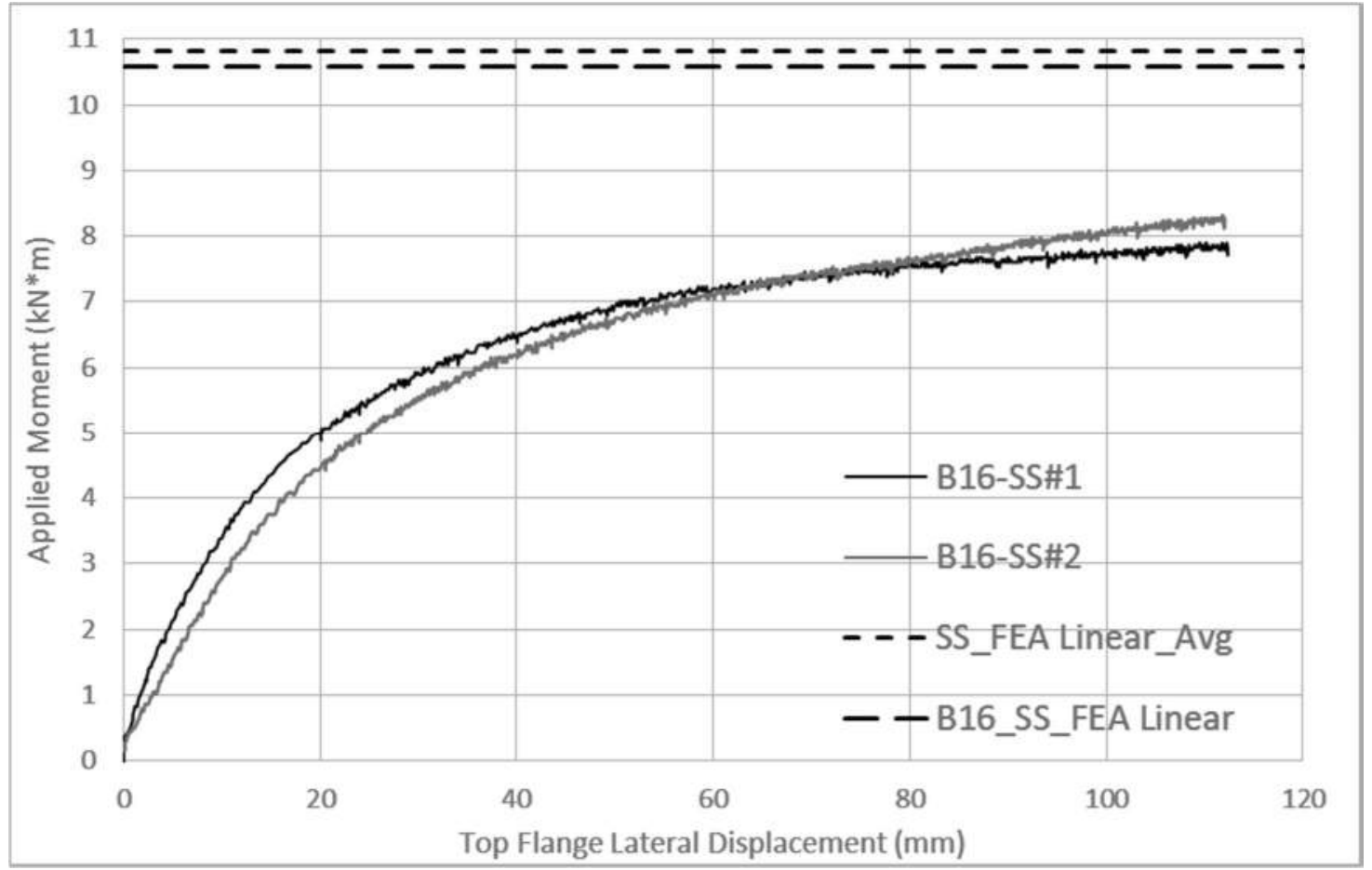

Figure B-25 Buckling displacement - Specimen A-16 - Simply Supported End conditions

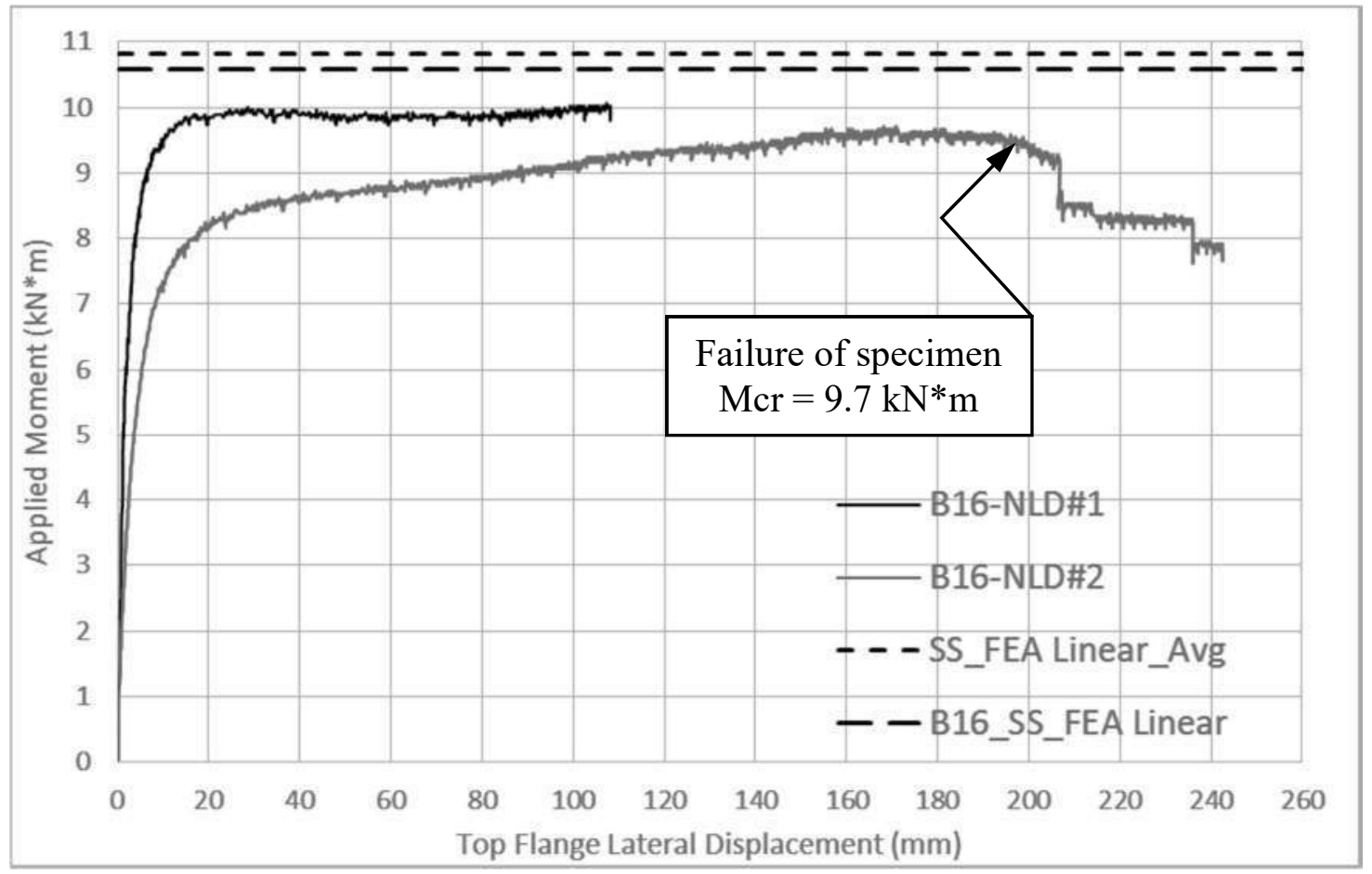

Figure B-26 Buckling displacement - Specimen A-16 - Nailed through end grain 


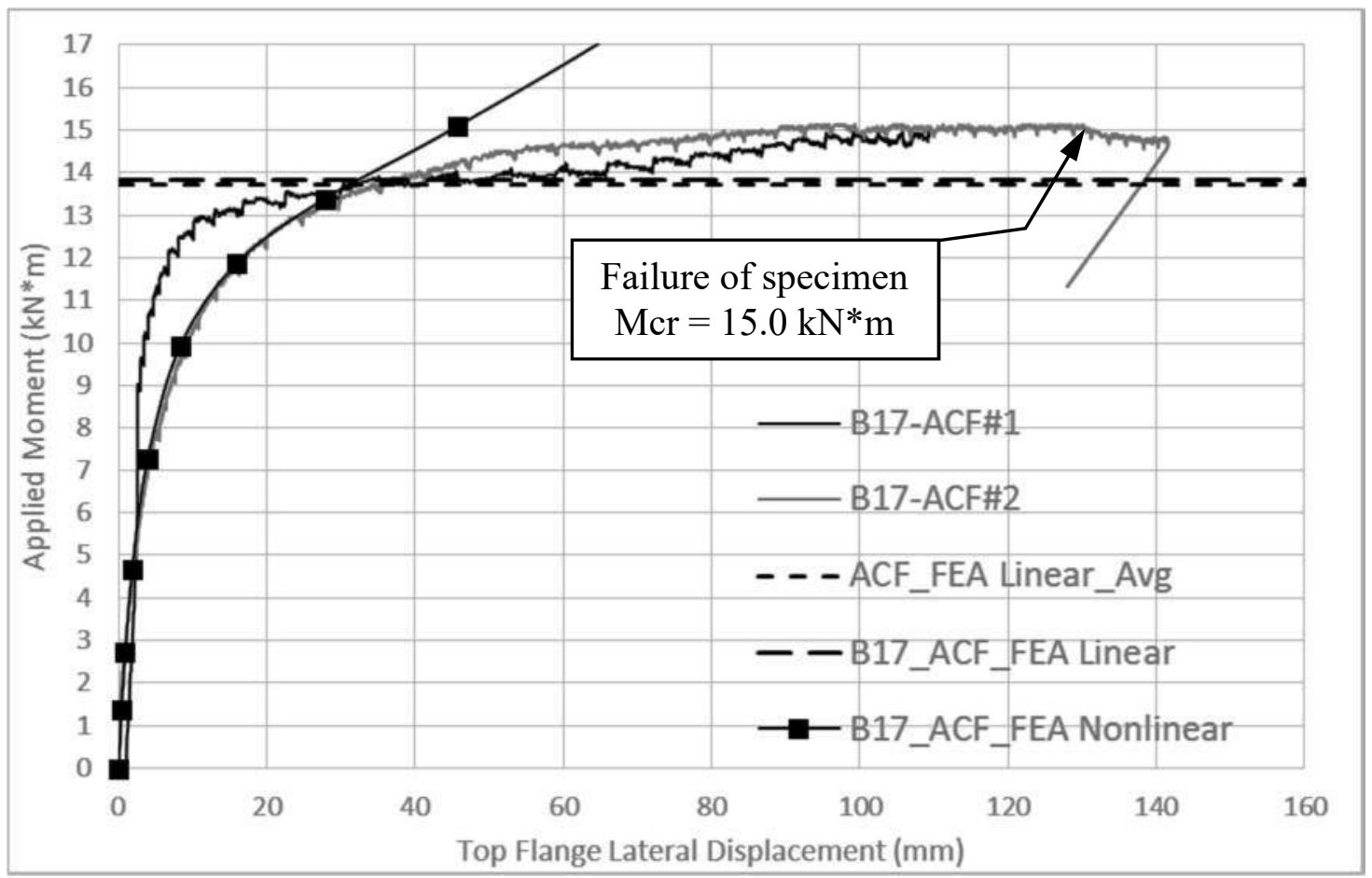

Figure B-27 Buckling displacement - Specimen A-17 - Angle bracket enhanced connection 


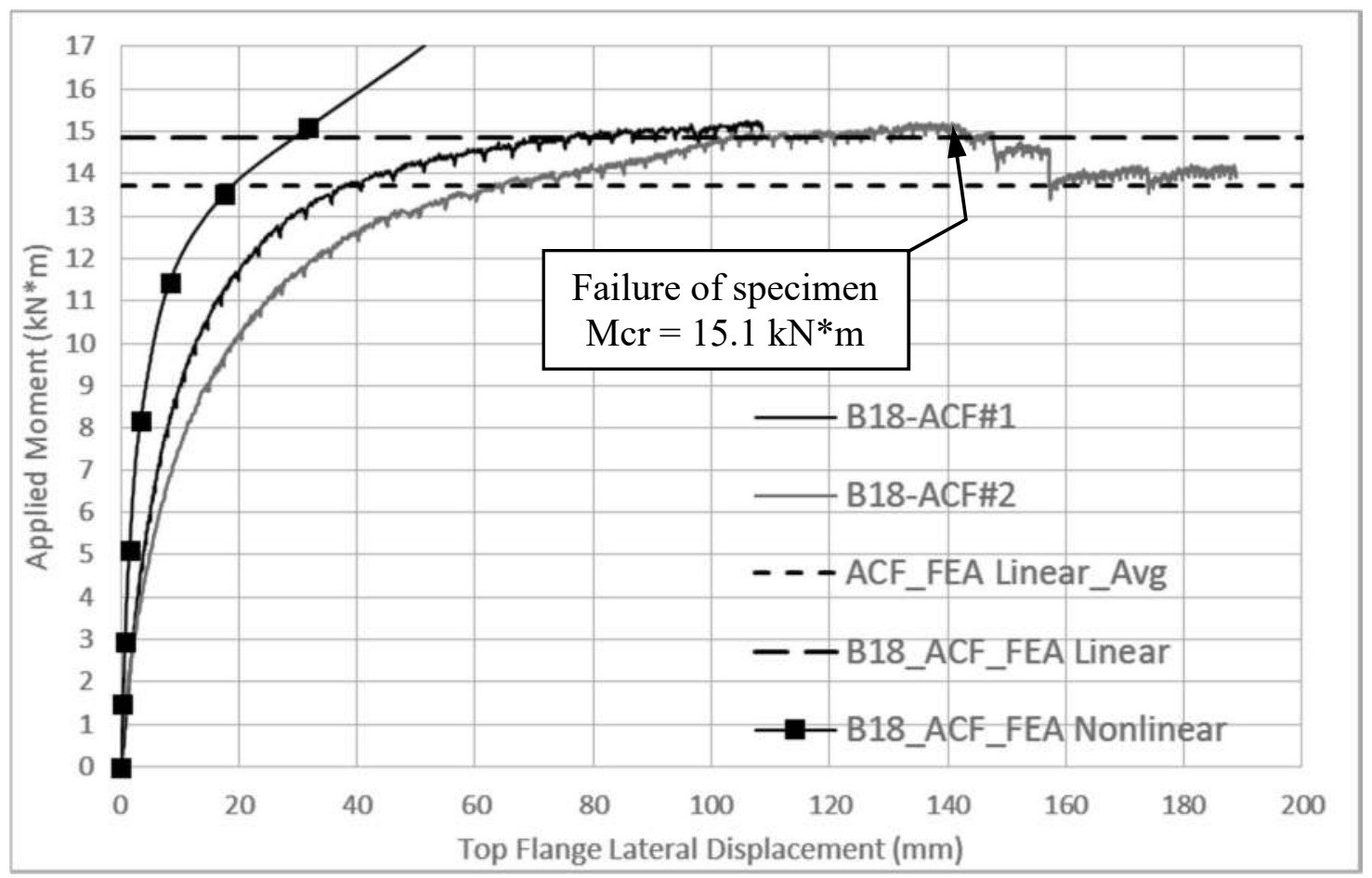

Figure B-28 Buckling displacement - Specimen A-18 - Angle bracket enhanced connection 


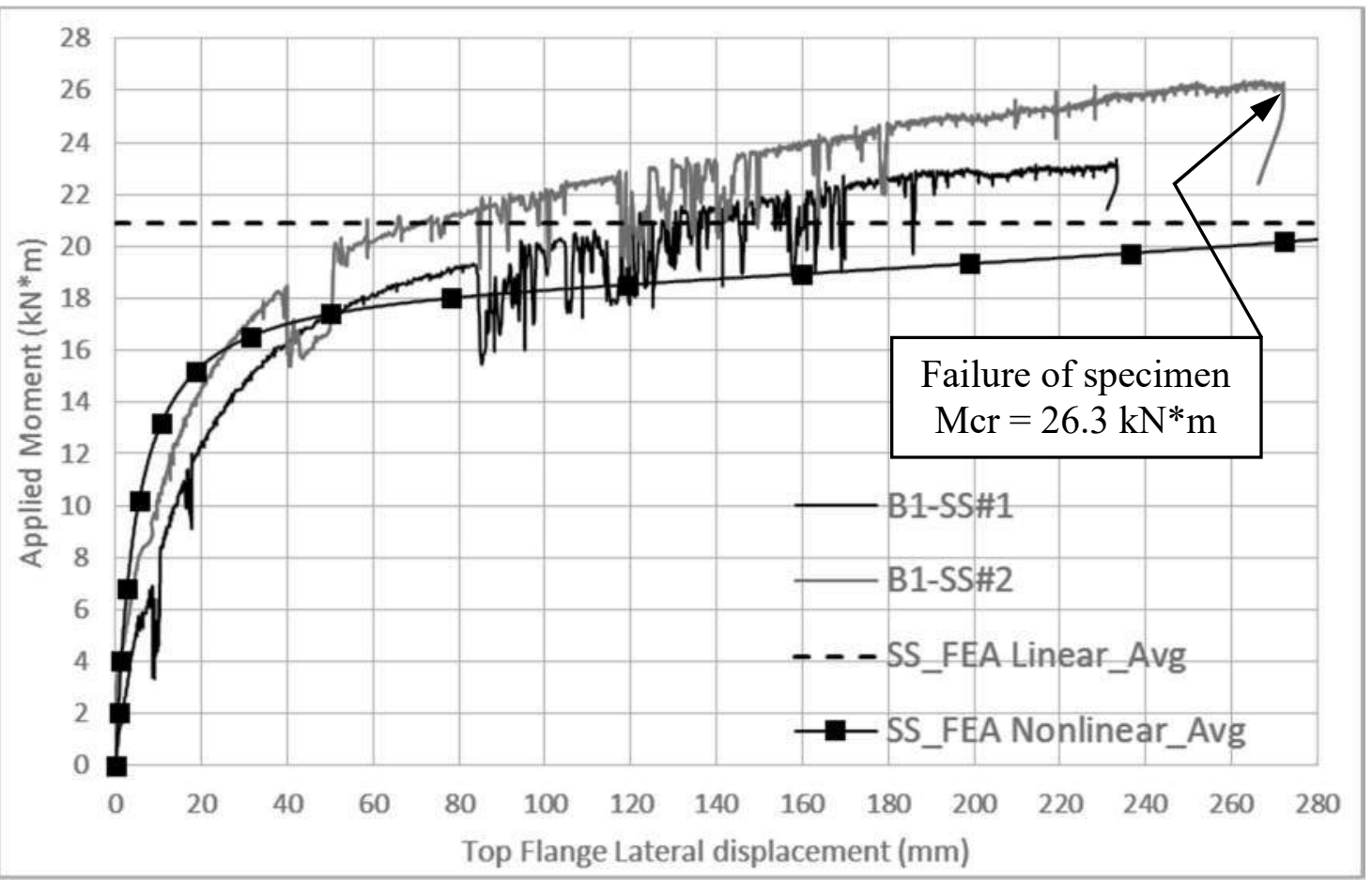

Figure B-29 Buckling displacement - Specimen B-1 - Simply Supported End conditions 


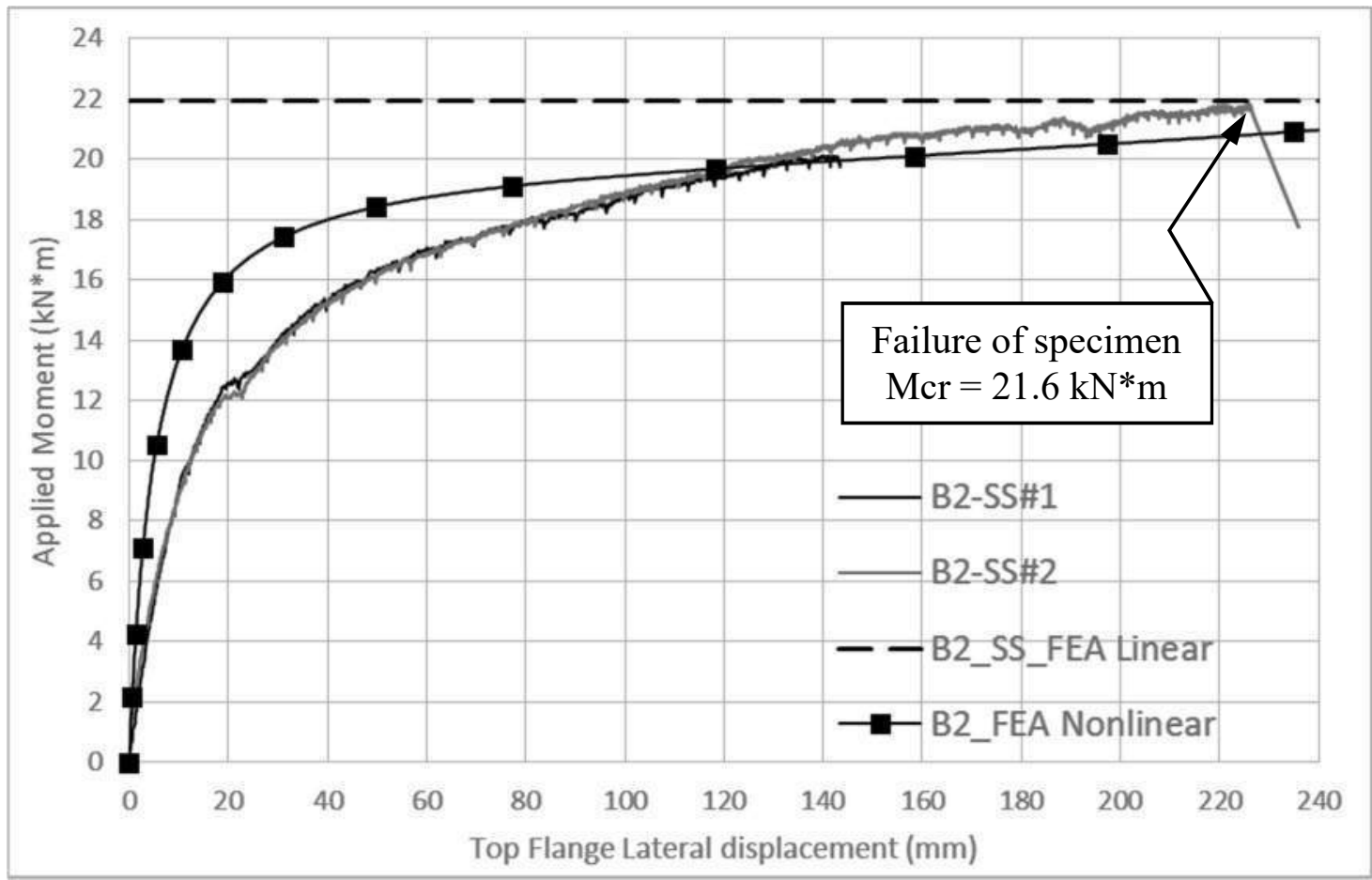

Figure B-30 Buckling displacement - Specimen B-2 - Simply Supported End conditions 


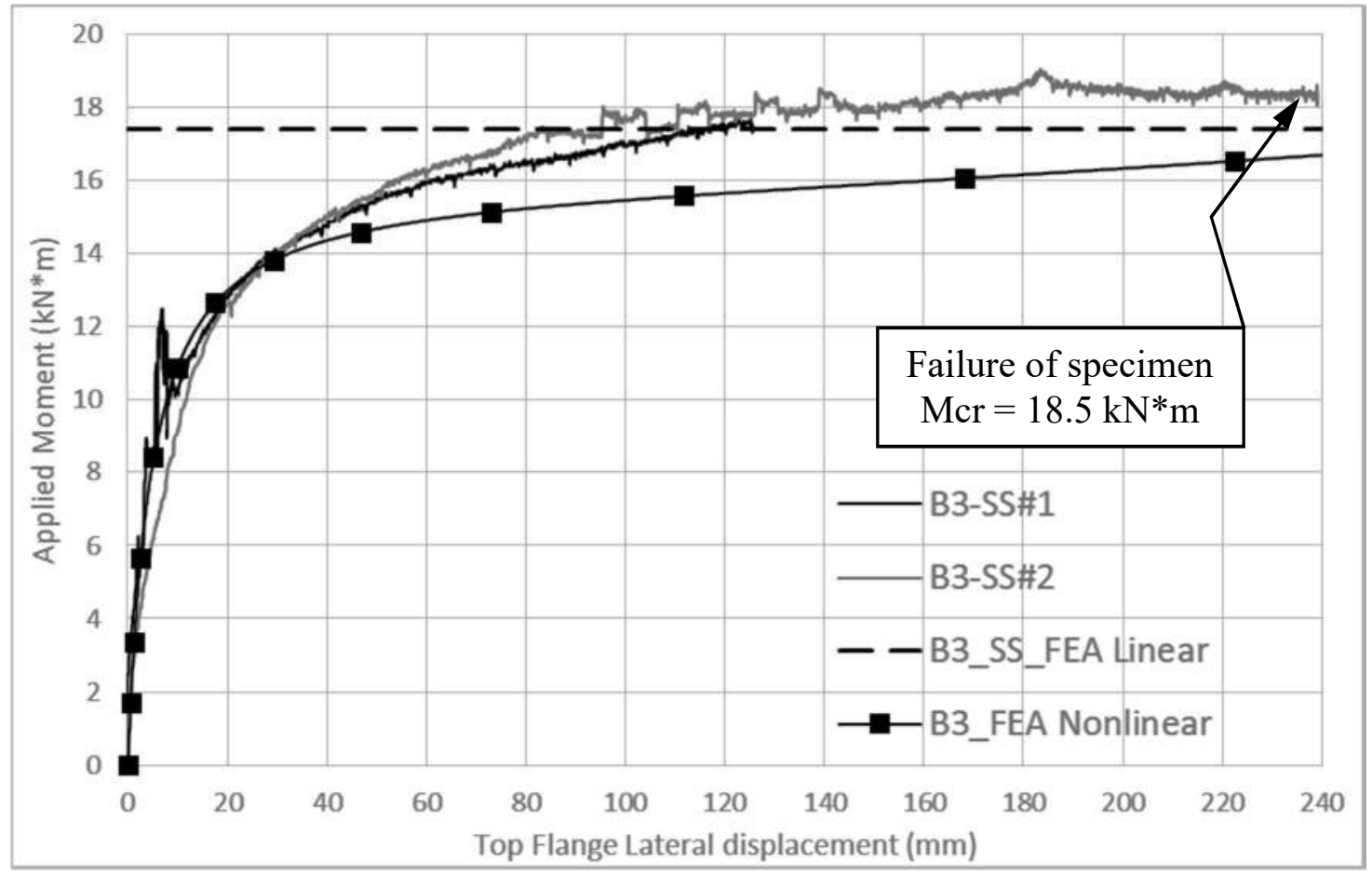

Figure B-31 Buckling displacement - Specimen B-3 - Simply Supported End conditions 
SPECIMEN 4

SAMPLE GROUP B

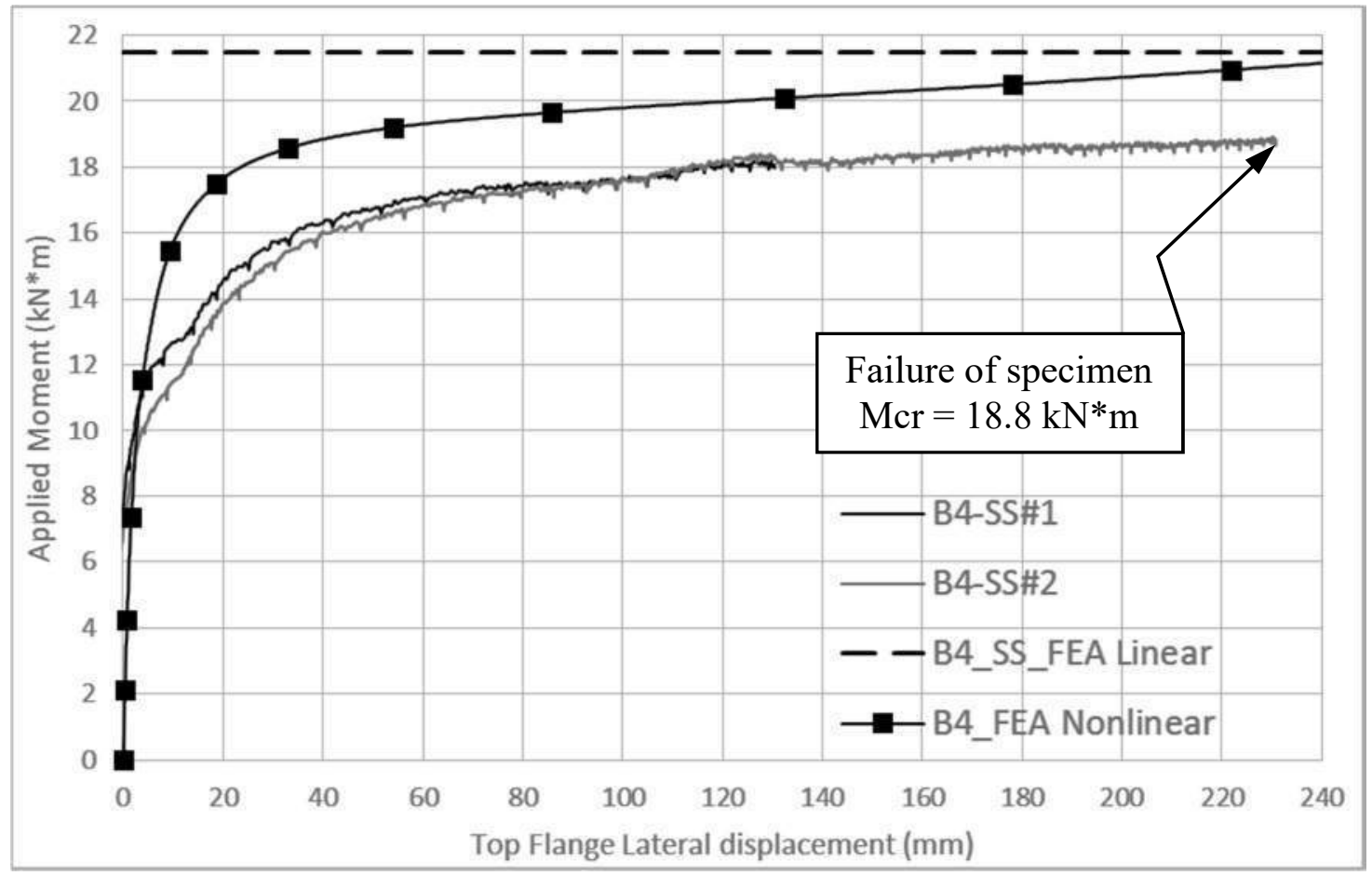

Figure B-32 Buckling displacement - Specimen B-4 - Simply Supported End conditions 
SPECIMEN 5

SAMPLE GROUP B

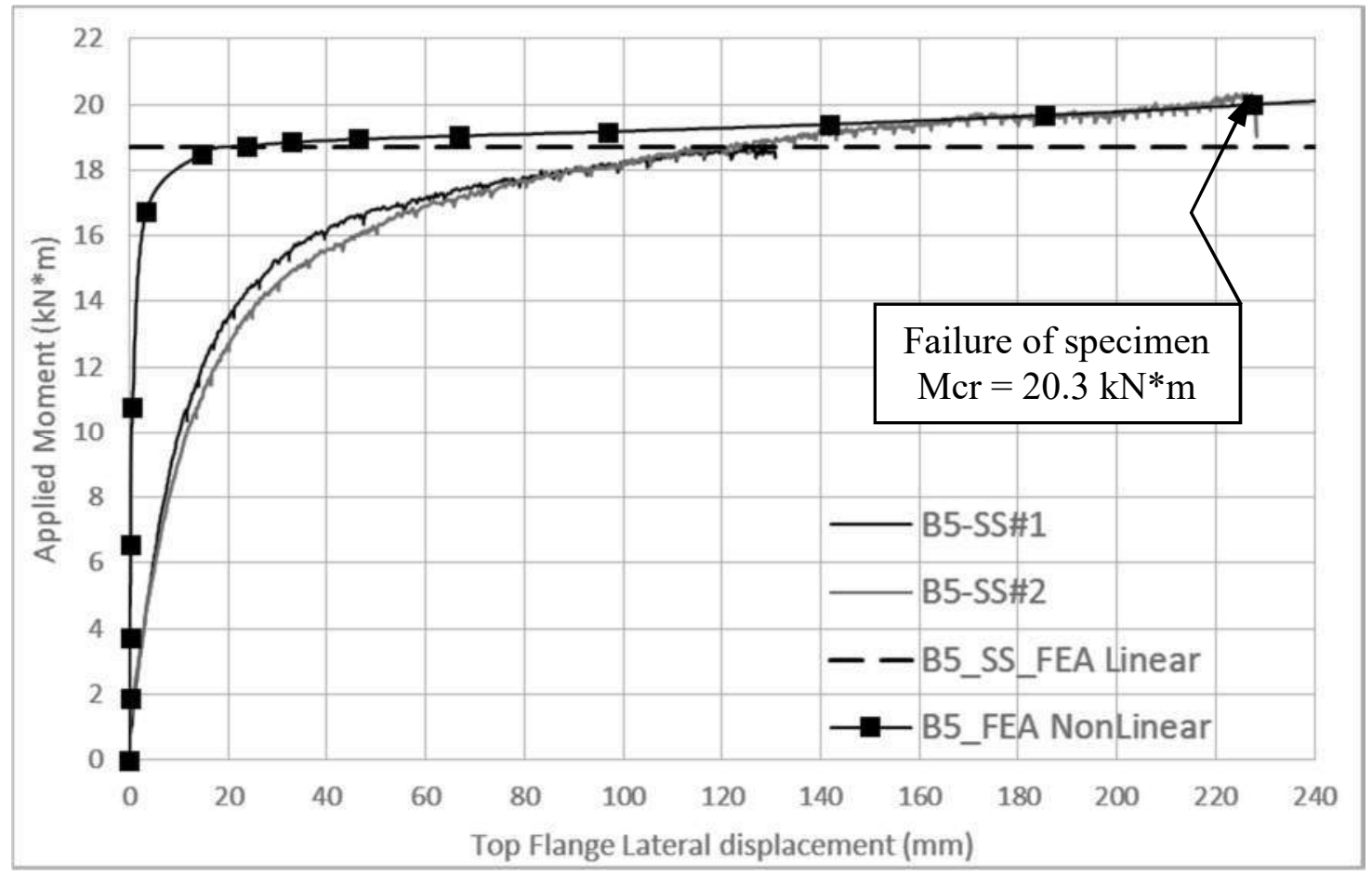

Figure B-33 Buckling displacement - Specimen B-5 - Simply Supported End conditions 


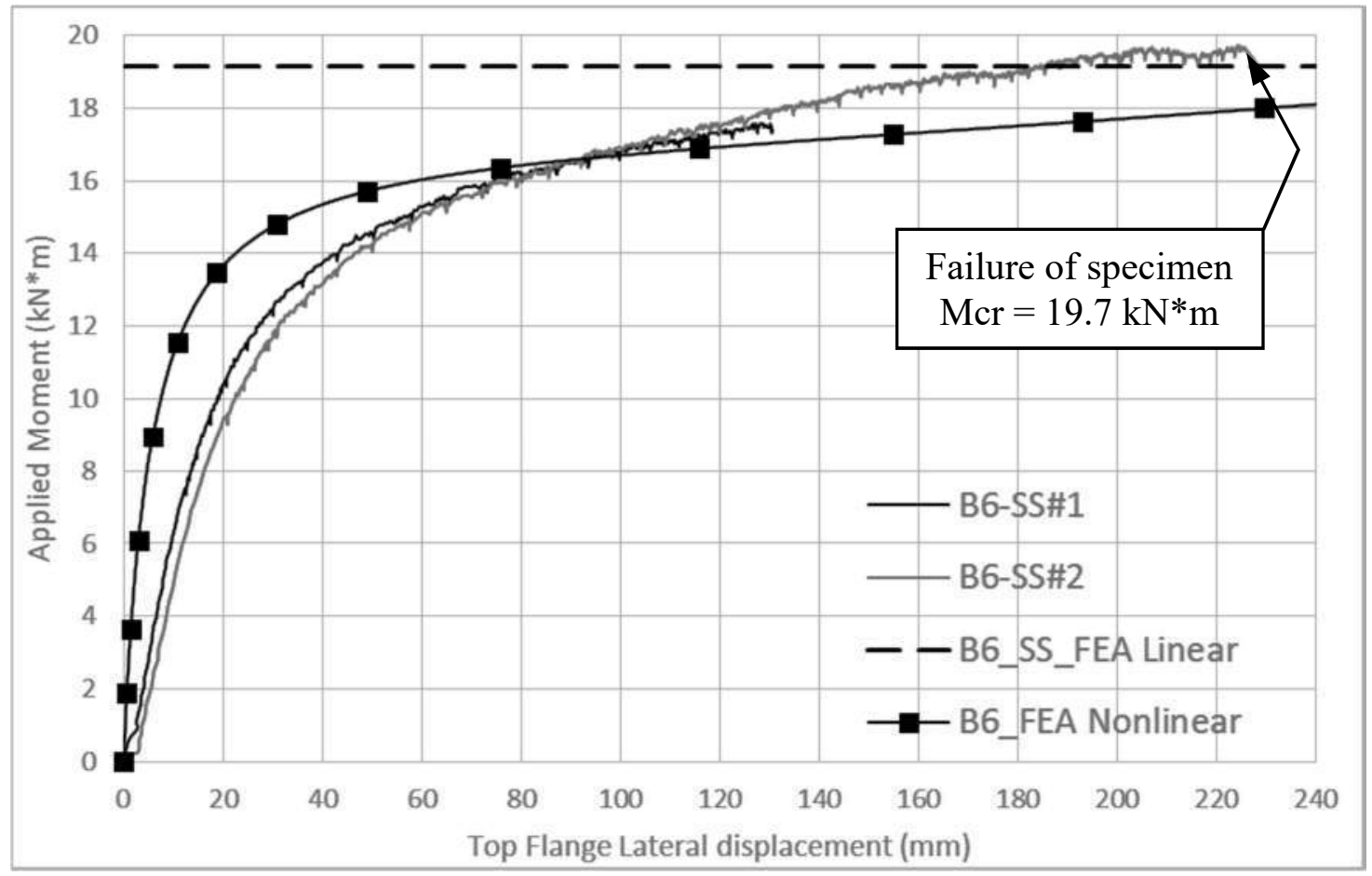

Figure B-34 Buckling displacement - Specimen B-6 - Simply Supported End conditions 


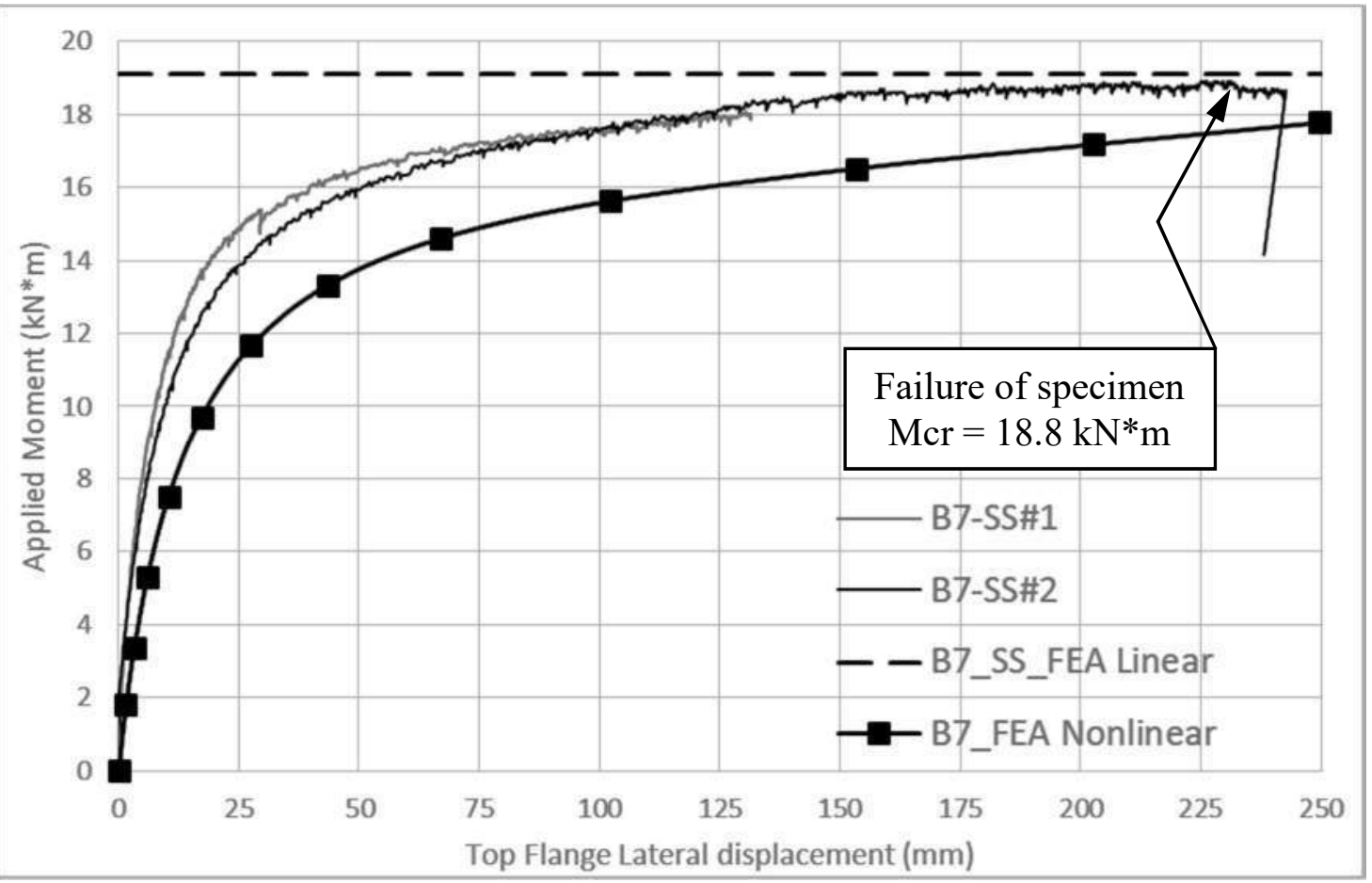

Figure B-35 Buckling displacement - Specimen B-7 - Simply Supported End conditions 


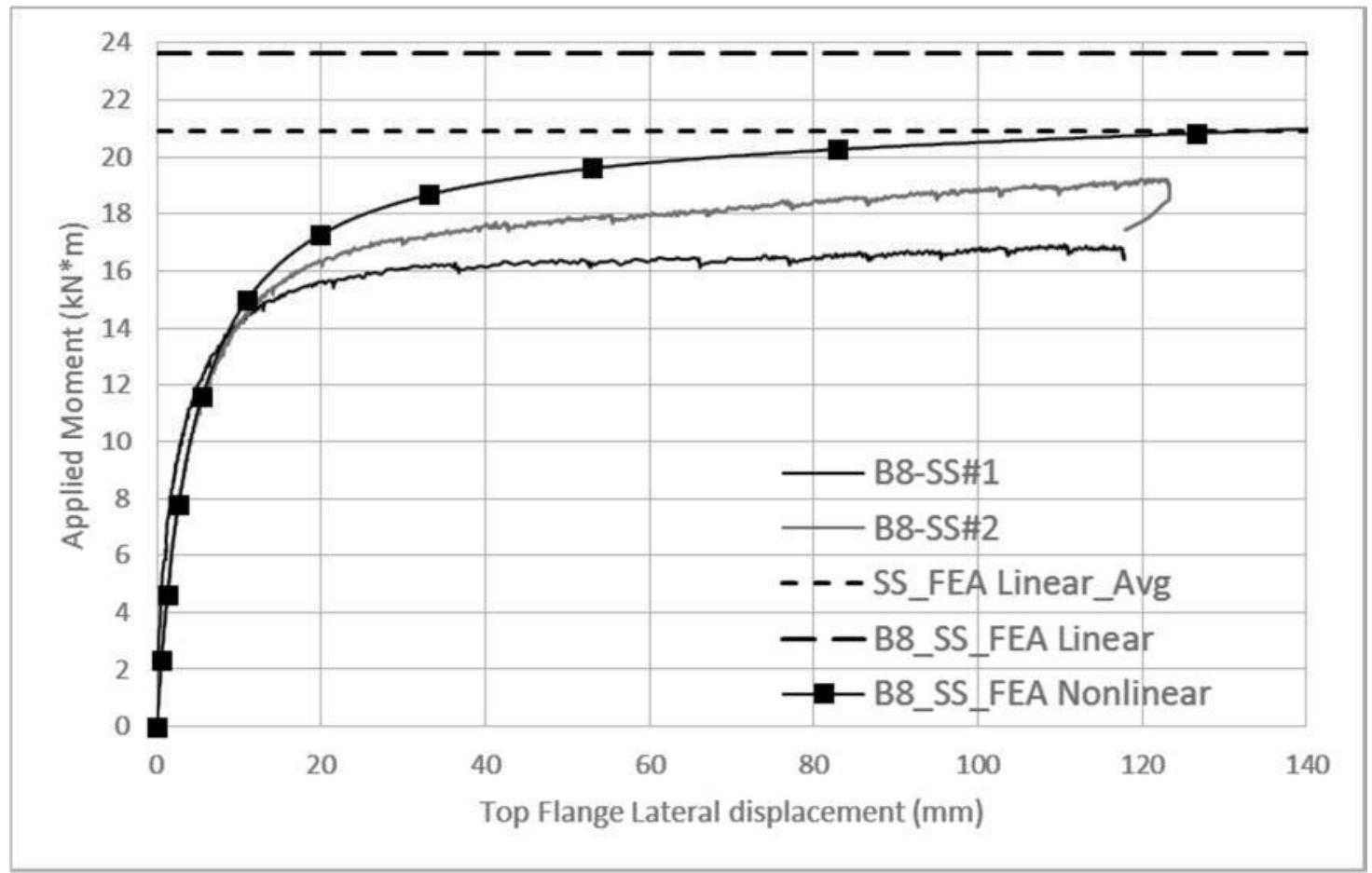

Figure B-36 Buckling displacement - Specimen B-8 - Simply Supported End conditions

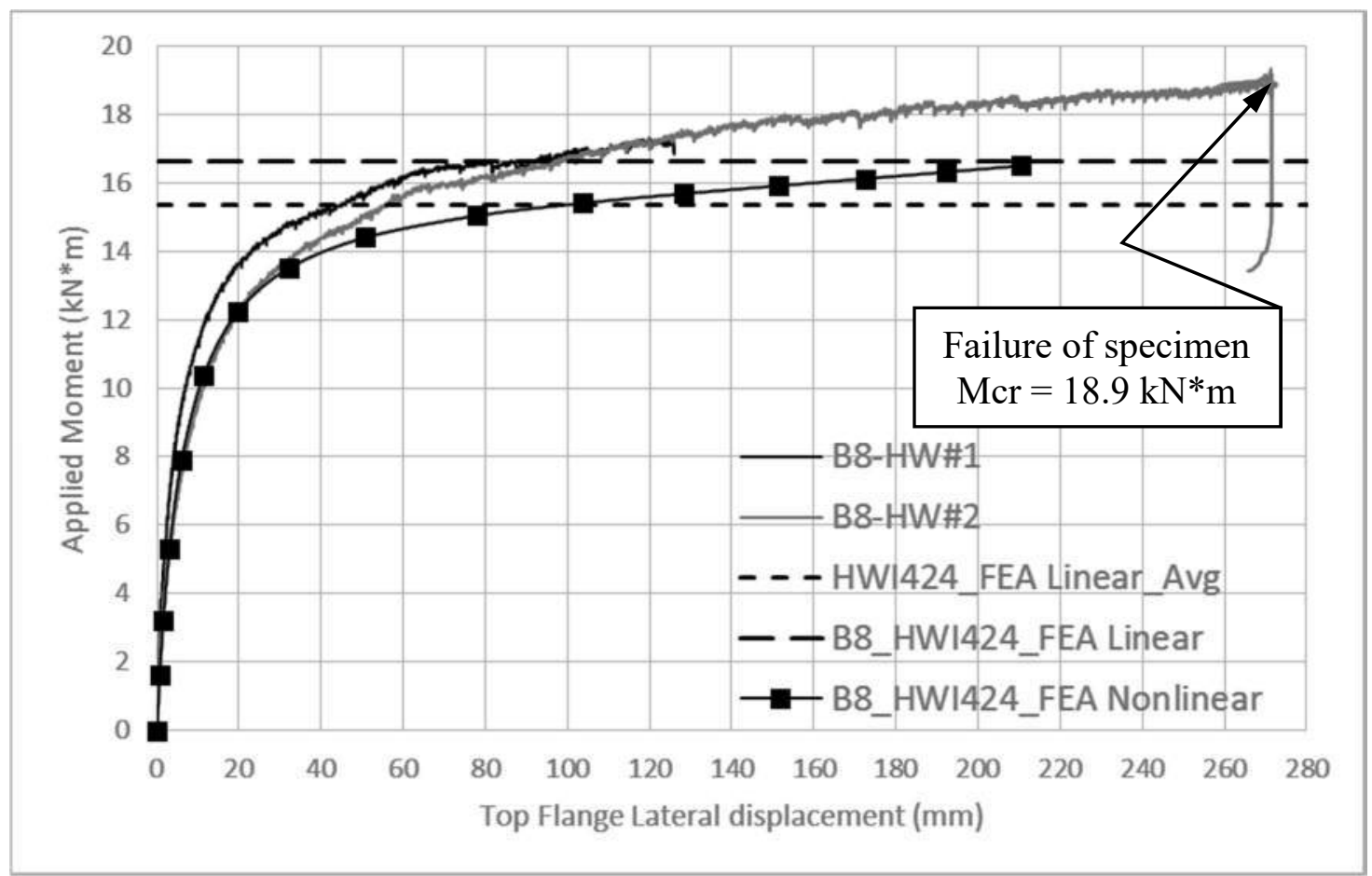

Figure B-37 Buckling displacement - Specimen B-8 - HWI424 Top Mounted Hangers 


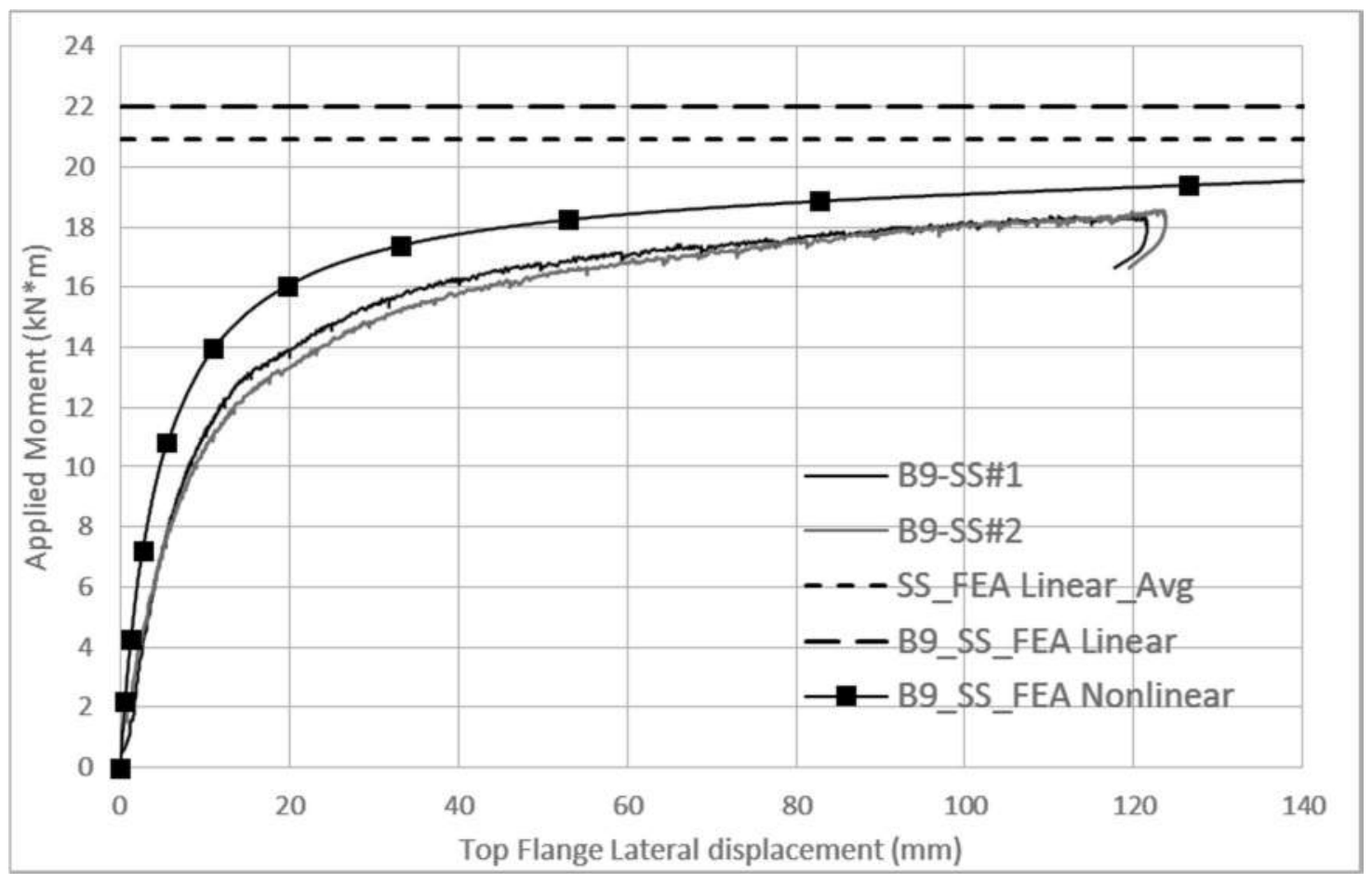

Figure B-38 Buckling displacement - Specimen B-9 - Simply Supported End conditions

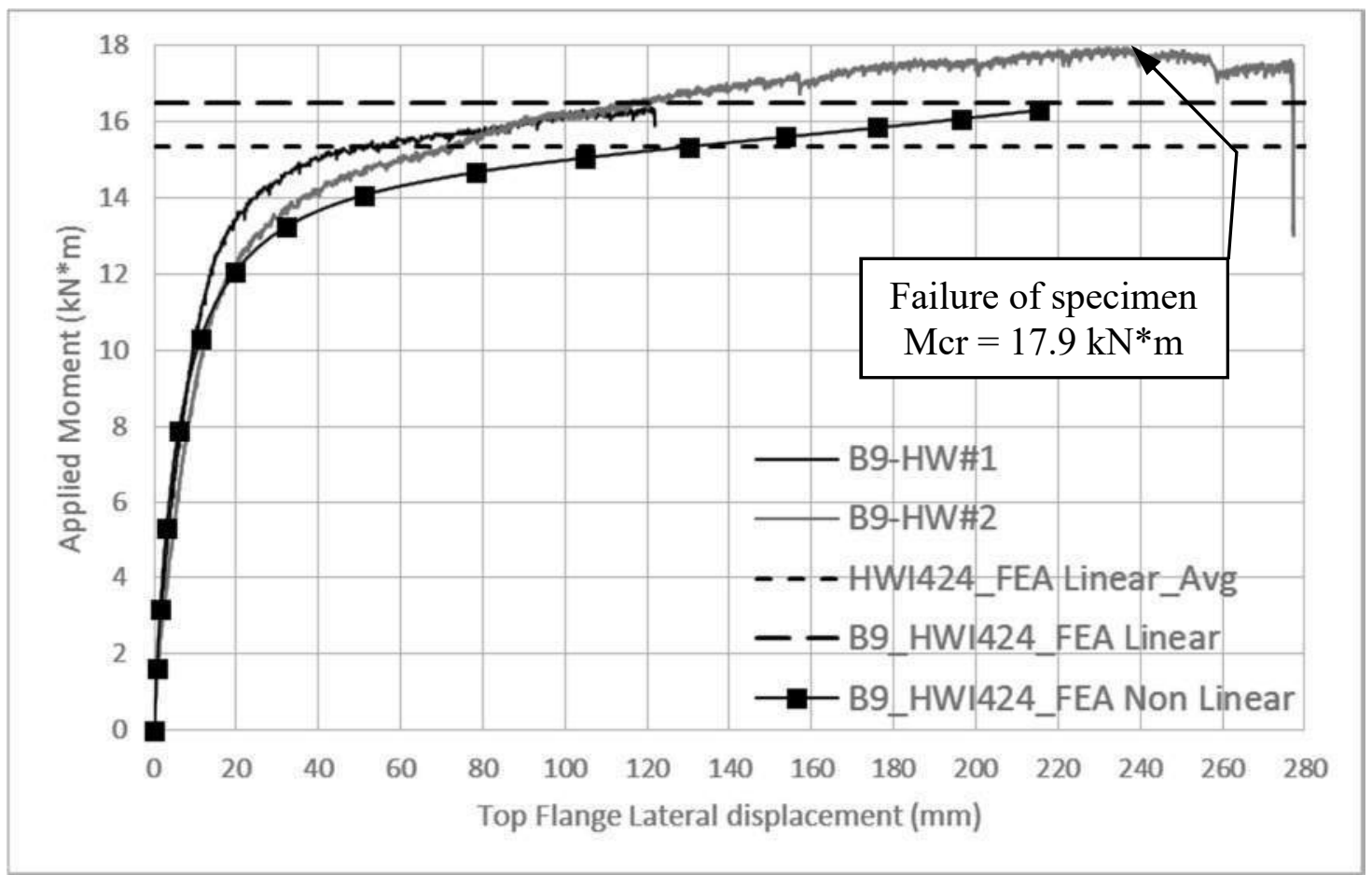

Figure B-39 Buckling displacement - Specimen B-9 - HWI424 Top Mounted Hangers 


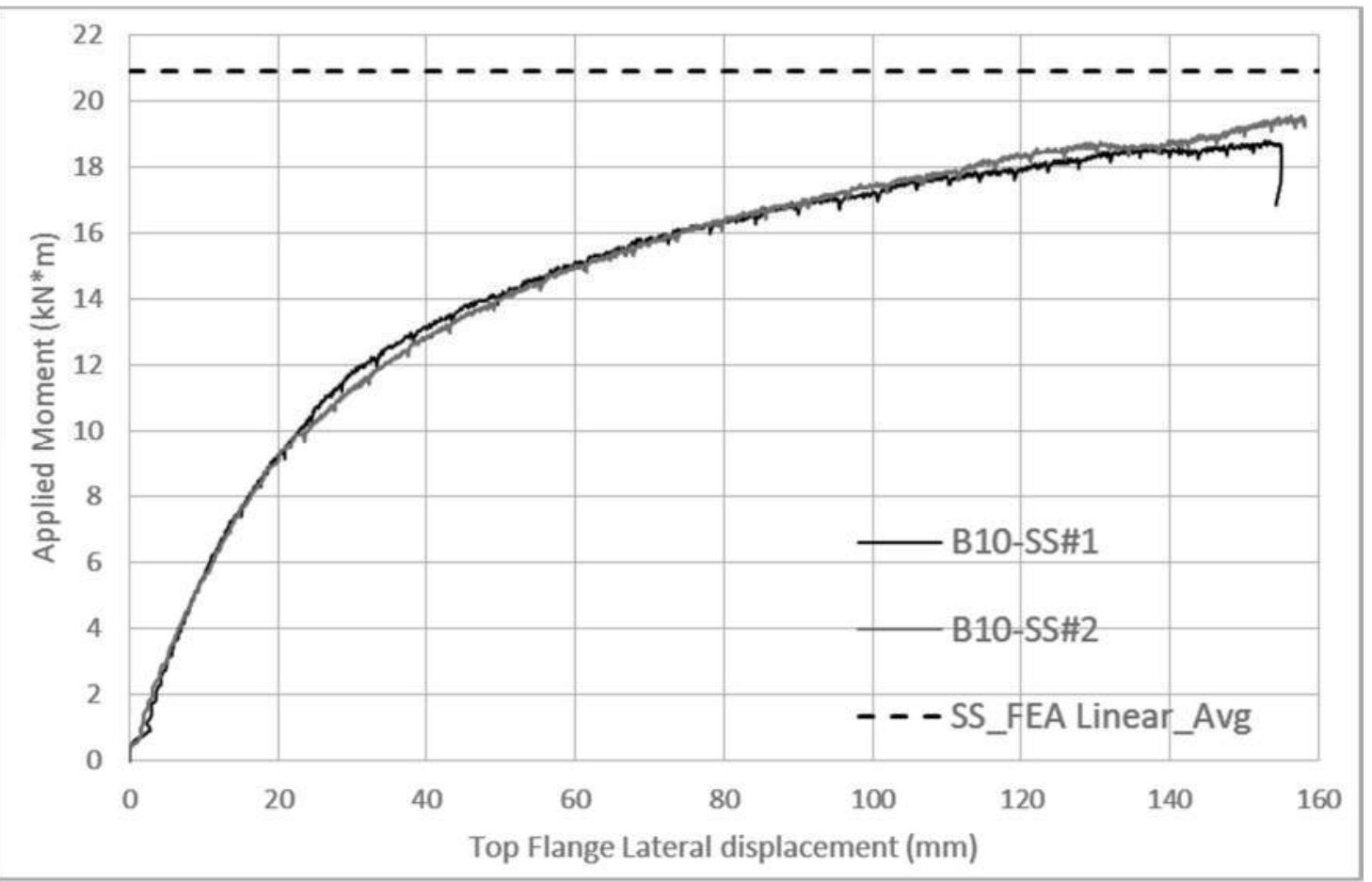

Figure B-40 Buckling displacement - Specimen B-10 - Simply Supported End conditions

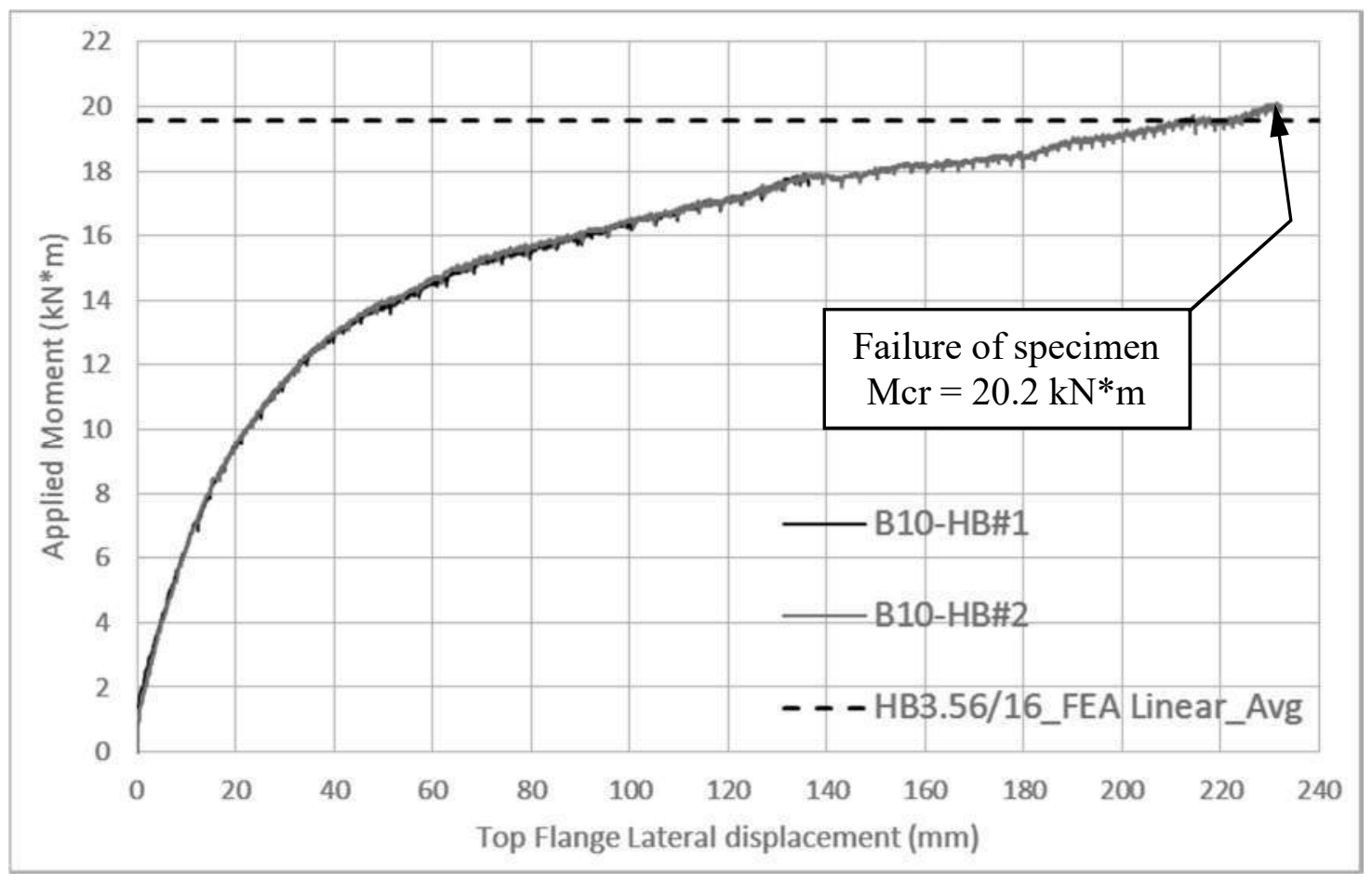

Figure B-41 Buckling displacement - Specimen B-10 - HB3.56/24 Top mounted hangers 


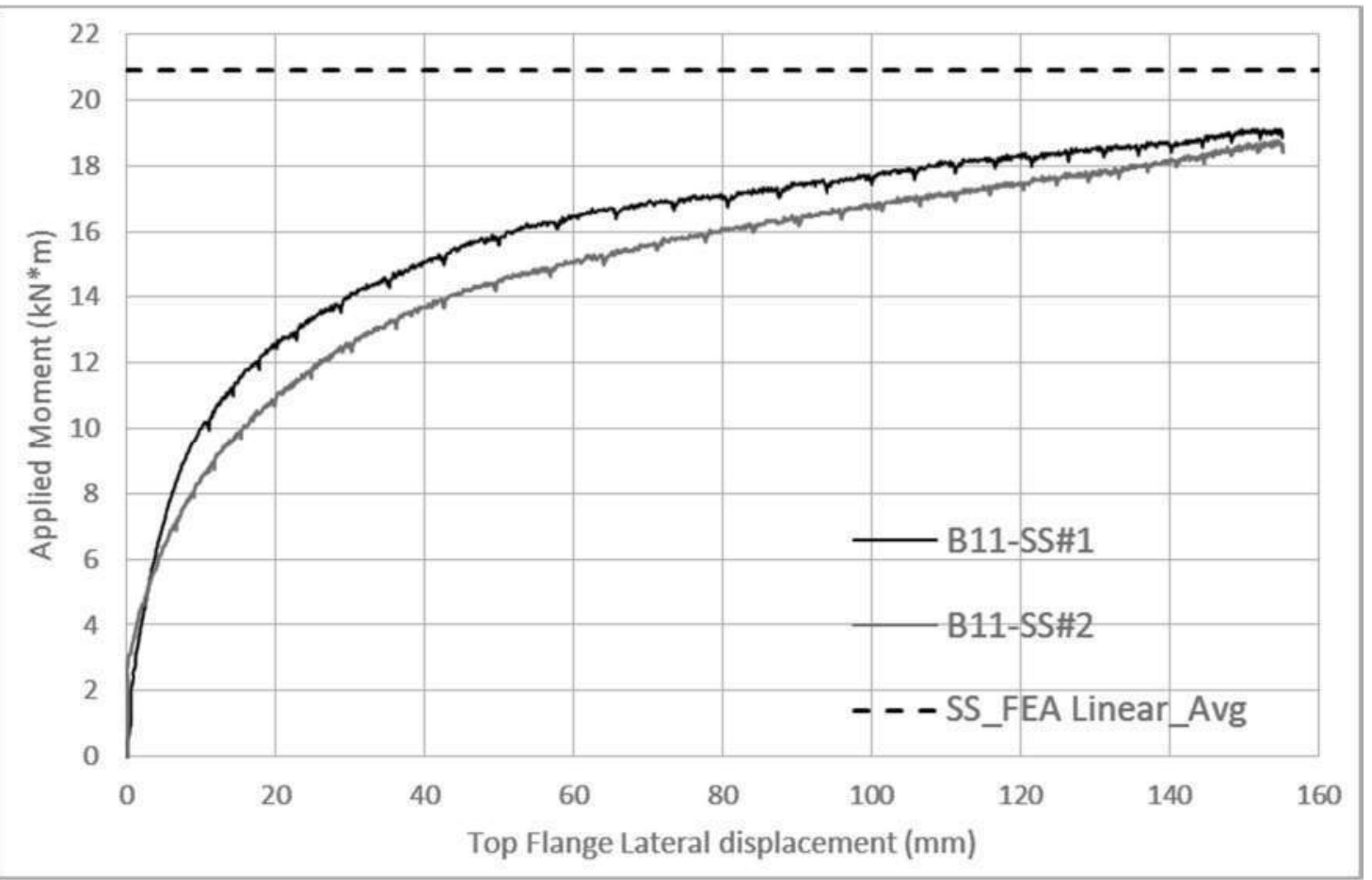

Figure B-42 Buckling displacement - Specimen B-11 - Simply Supported End conditions

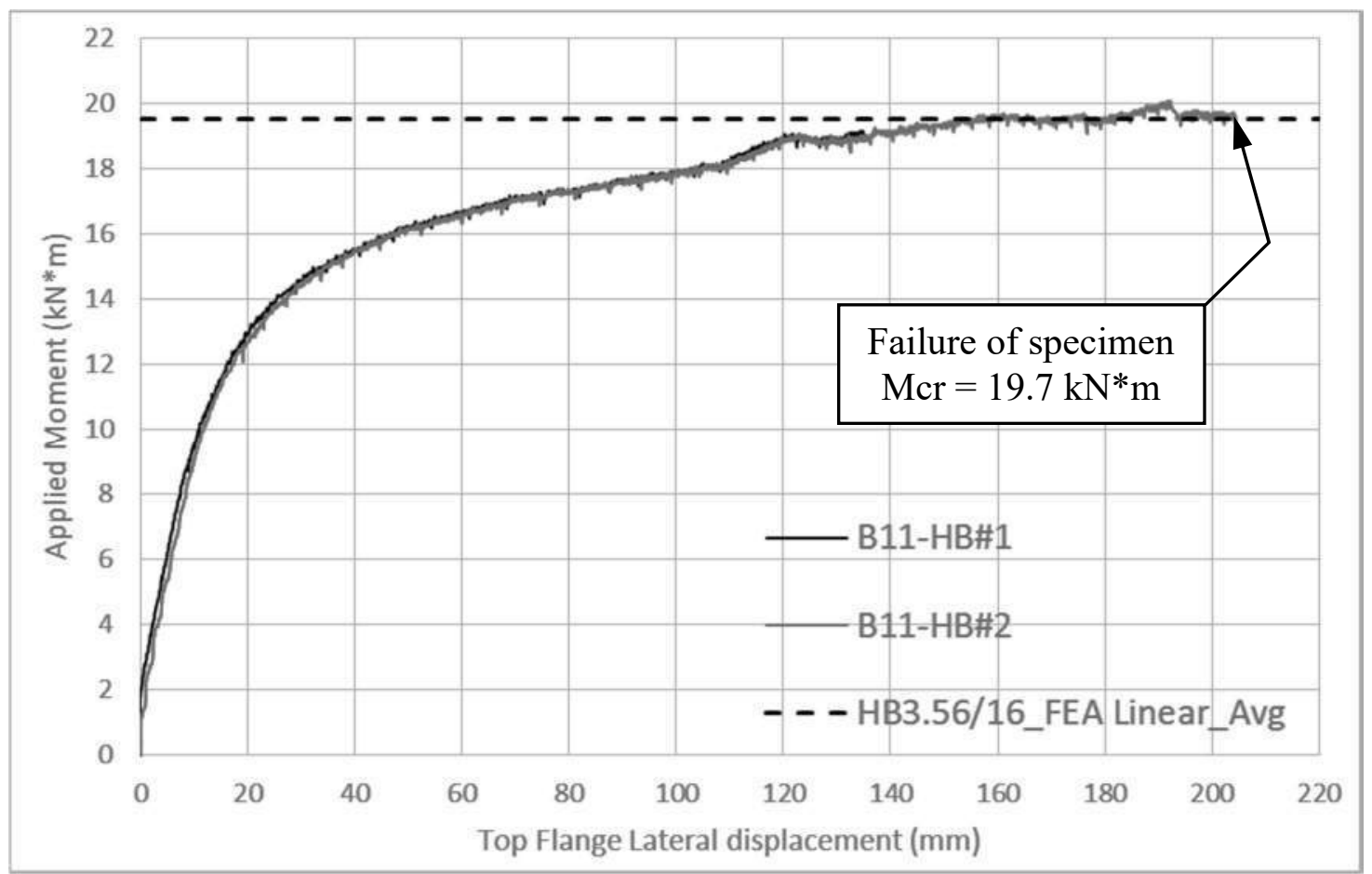

Figure B-43 Buckling displacement - Specimen B-11 - HB3.56/24 Top mounted hangers 


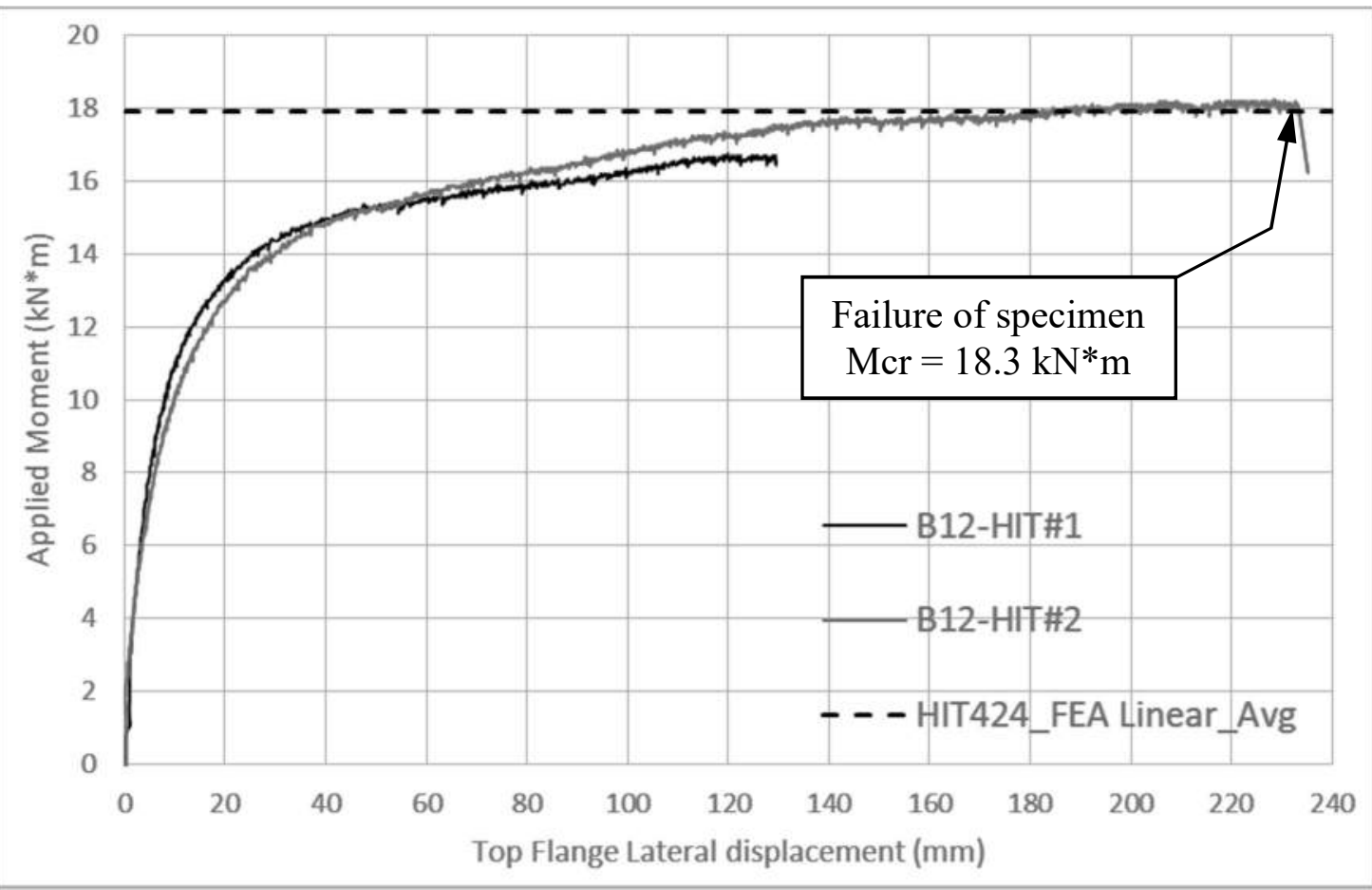

Figure B-44 Buckling displacement - Specimen B-12 - HIT424 Top mounted hangers 


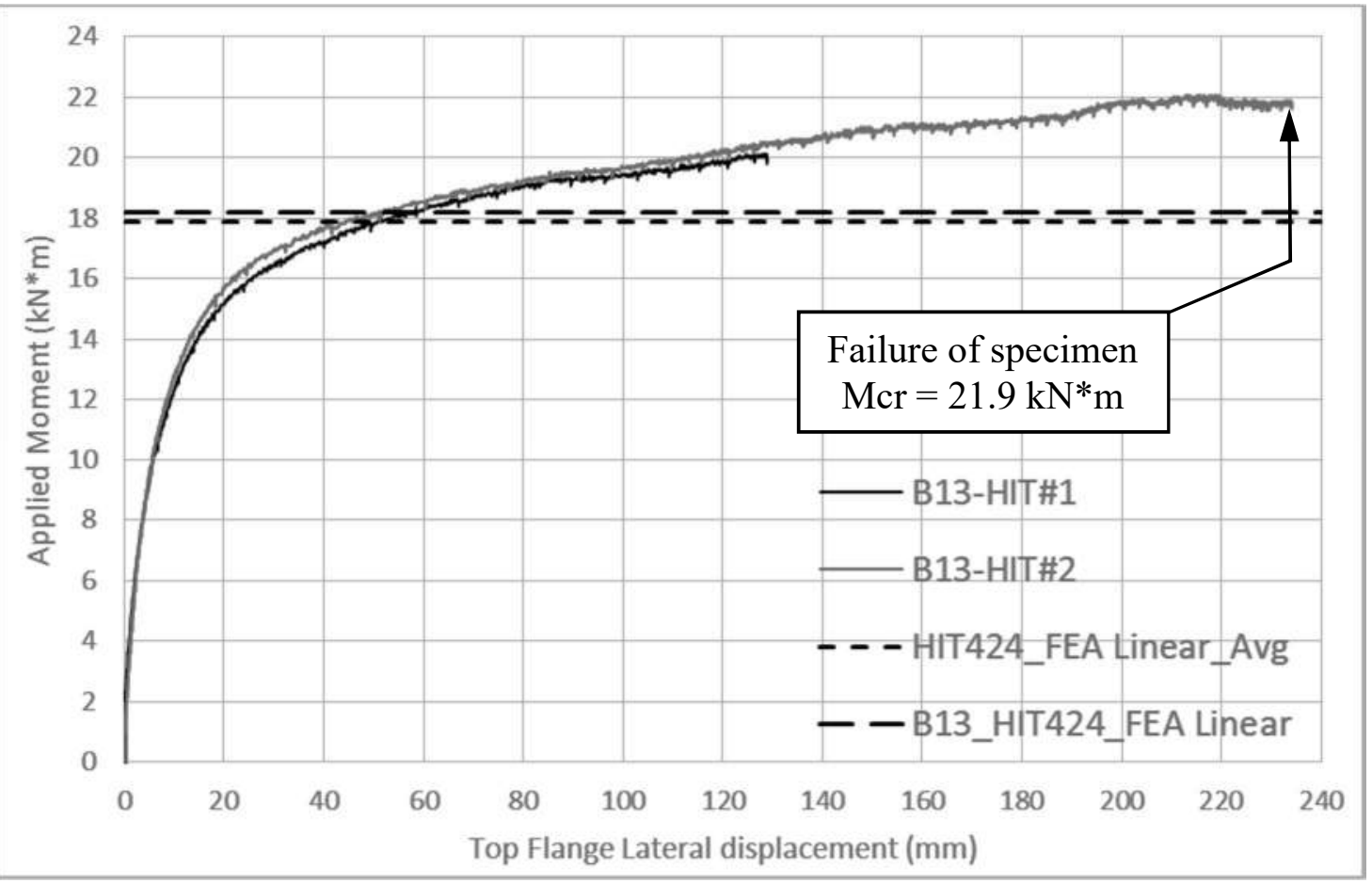

Figure B-45 Buckling displacement - Specimen B-13 - HIT424 Top mounted hangers 


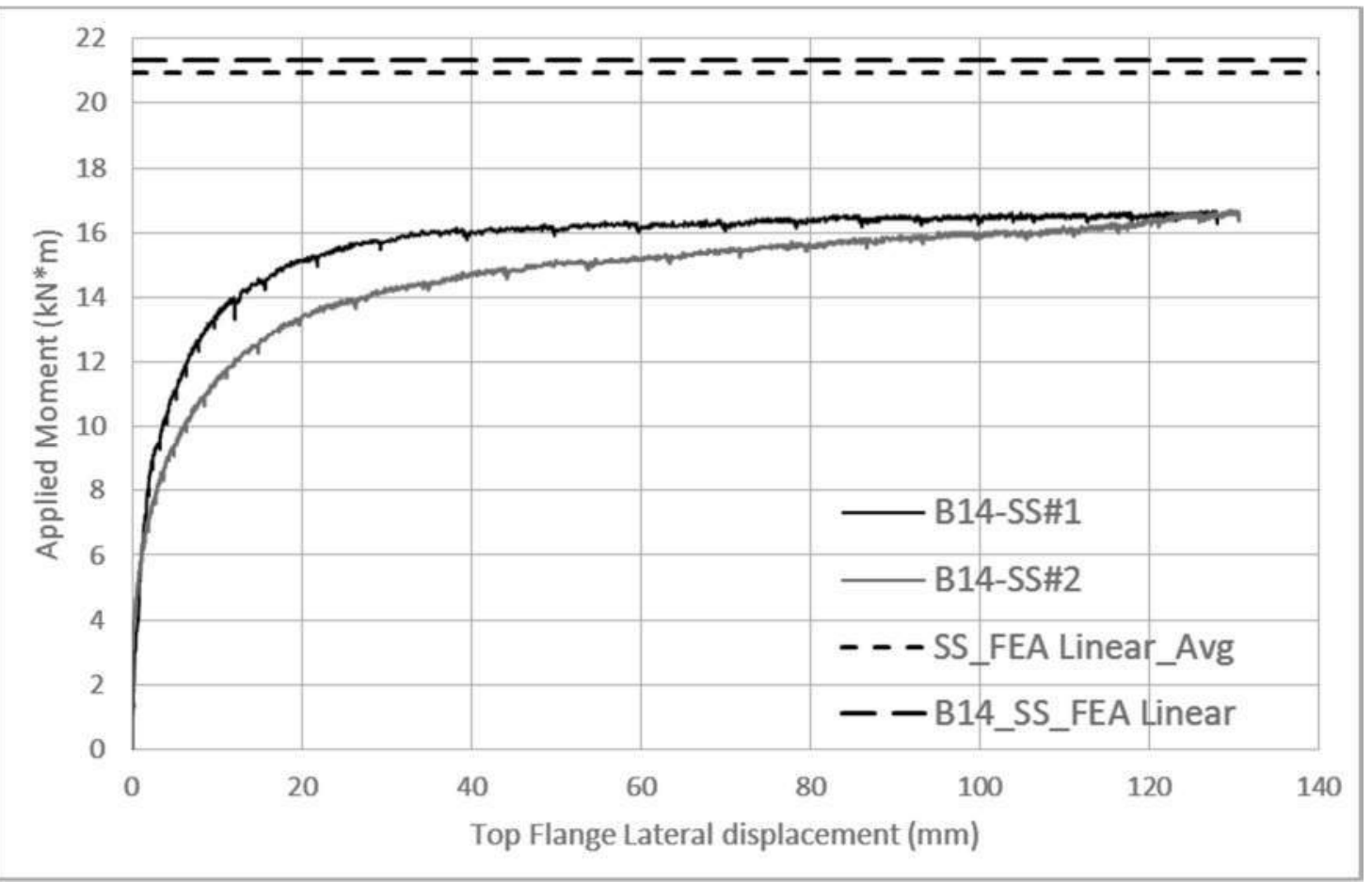

Figure B-46 Buckling displacement - Specimen B-14 - Simply Supported End conditions

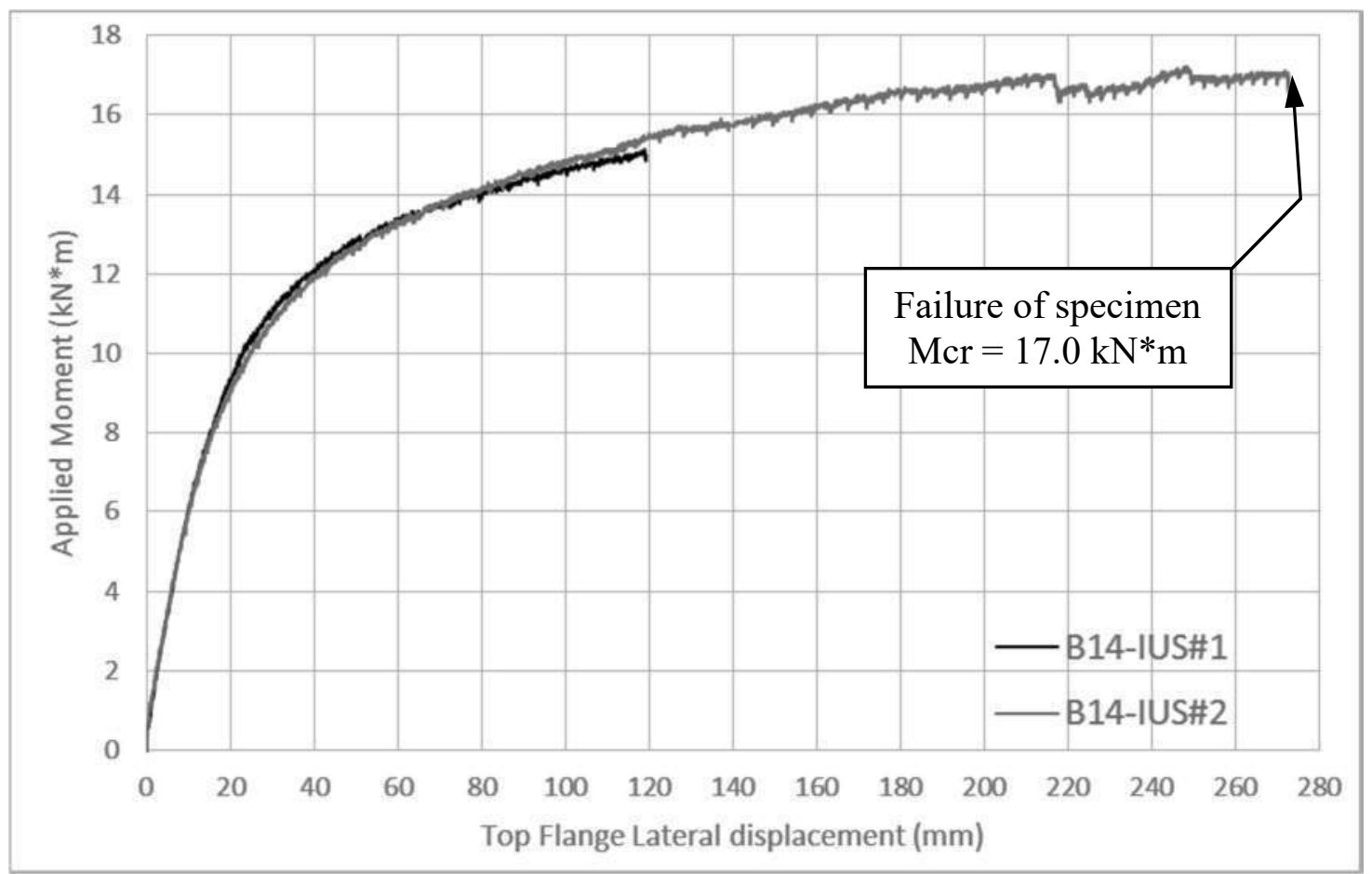

Figure B-47 Buckling displacement - Specimen B-14 - IUS3.56/16 Face mounted hangers 


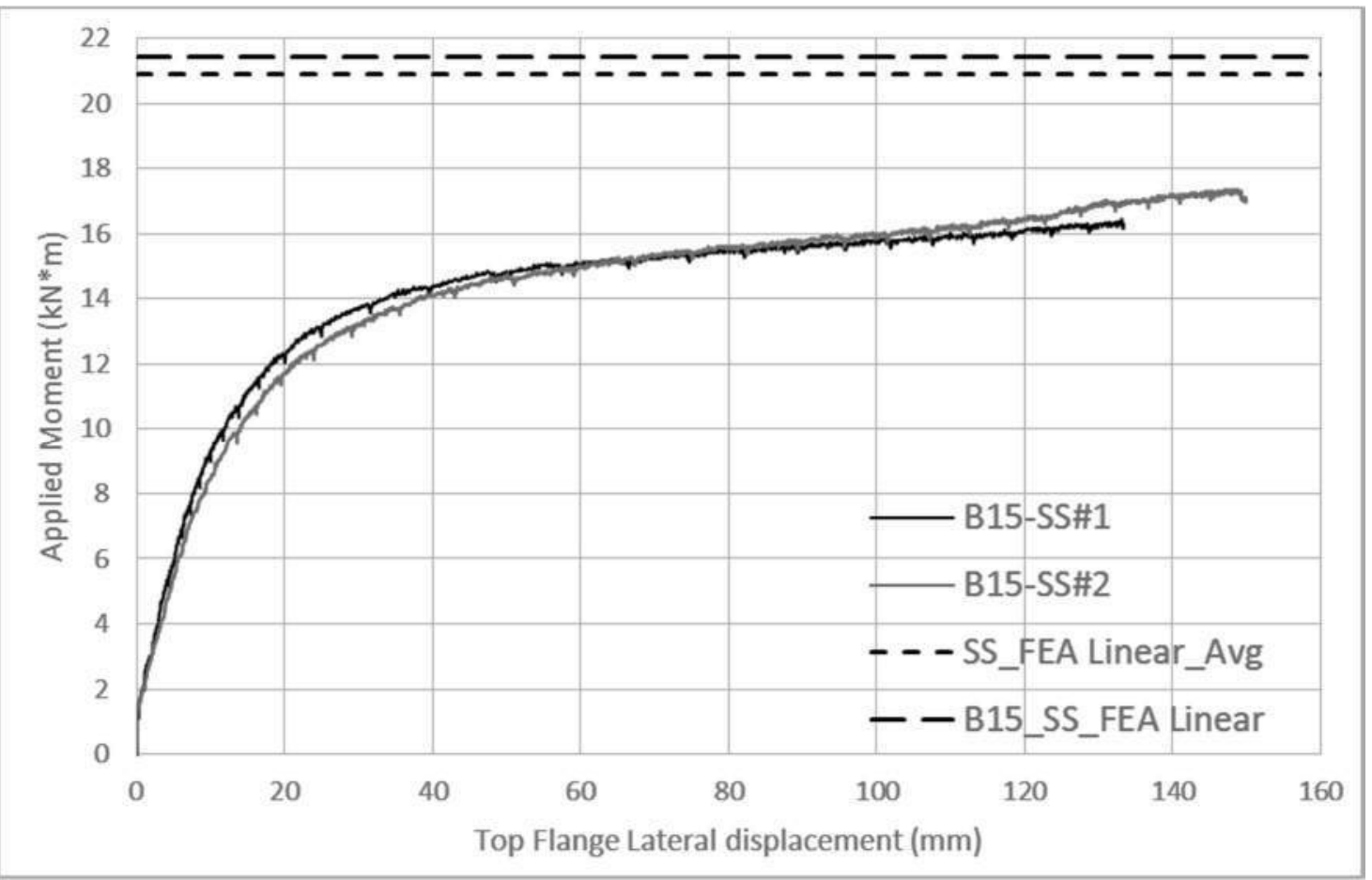

Figure B-48 Buckling displacement - Specimen B-15 - Simply Supported End conditions

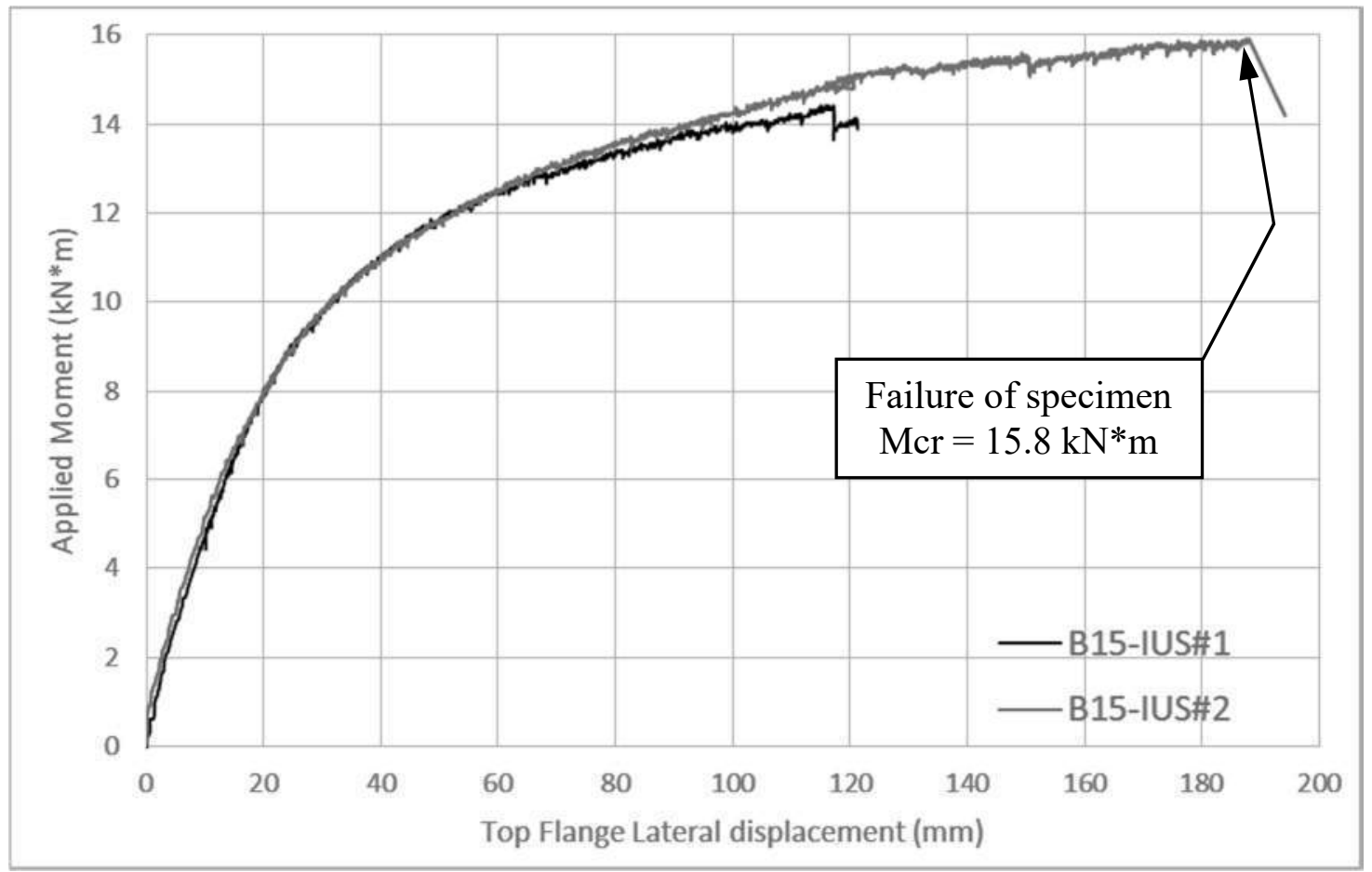

Figure B-49 Buckling displacement - Specimen B-15 - IUS3.56/16 Face mounted hangers 


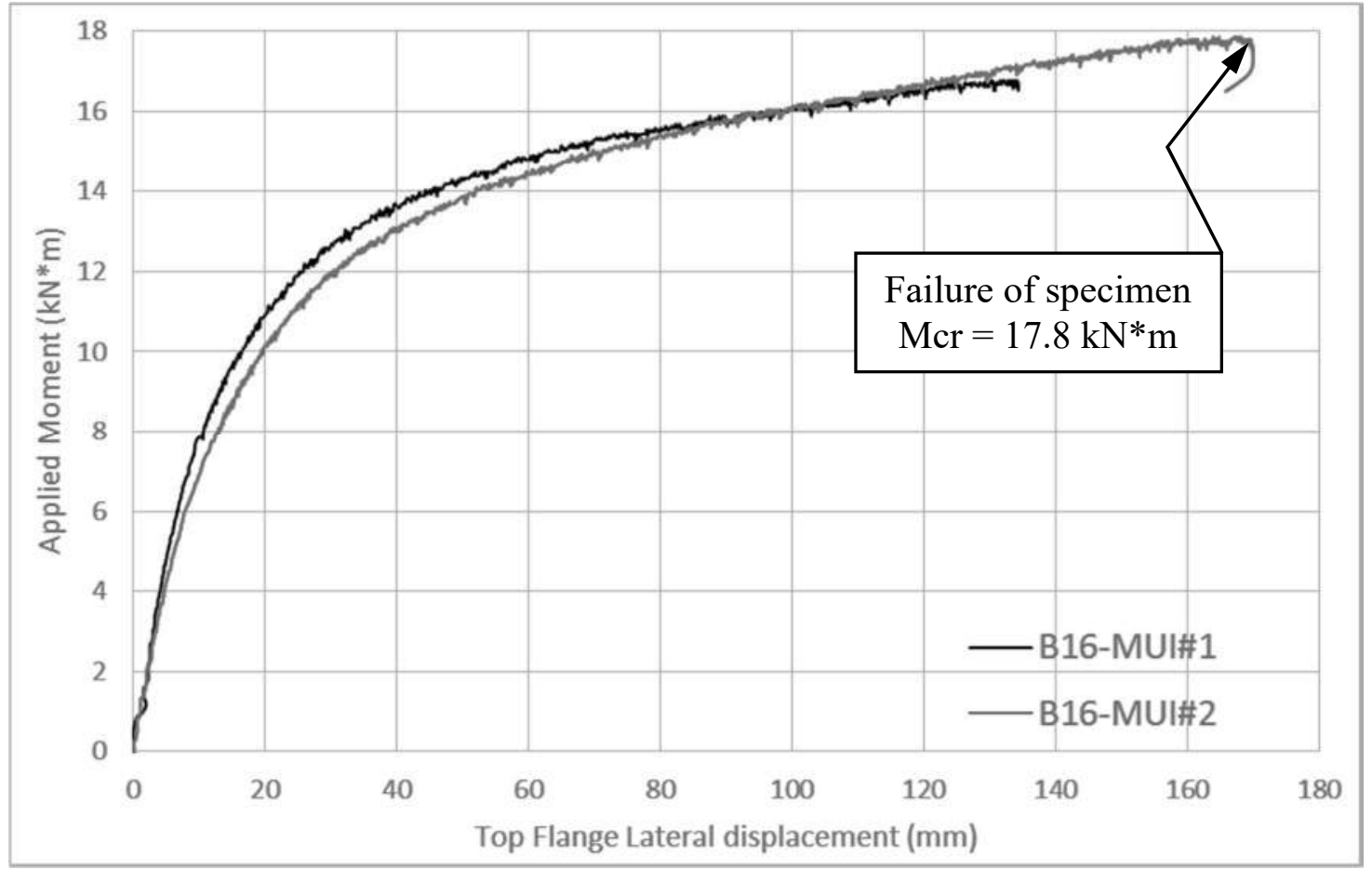

Figure B-50 Buckling displacement - Specimen B-16 - MUI3.56/16 Face mounted hangers 


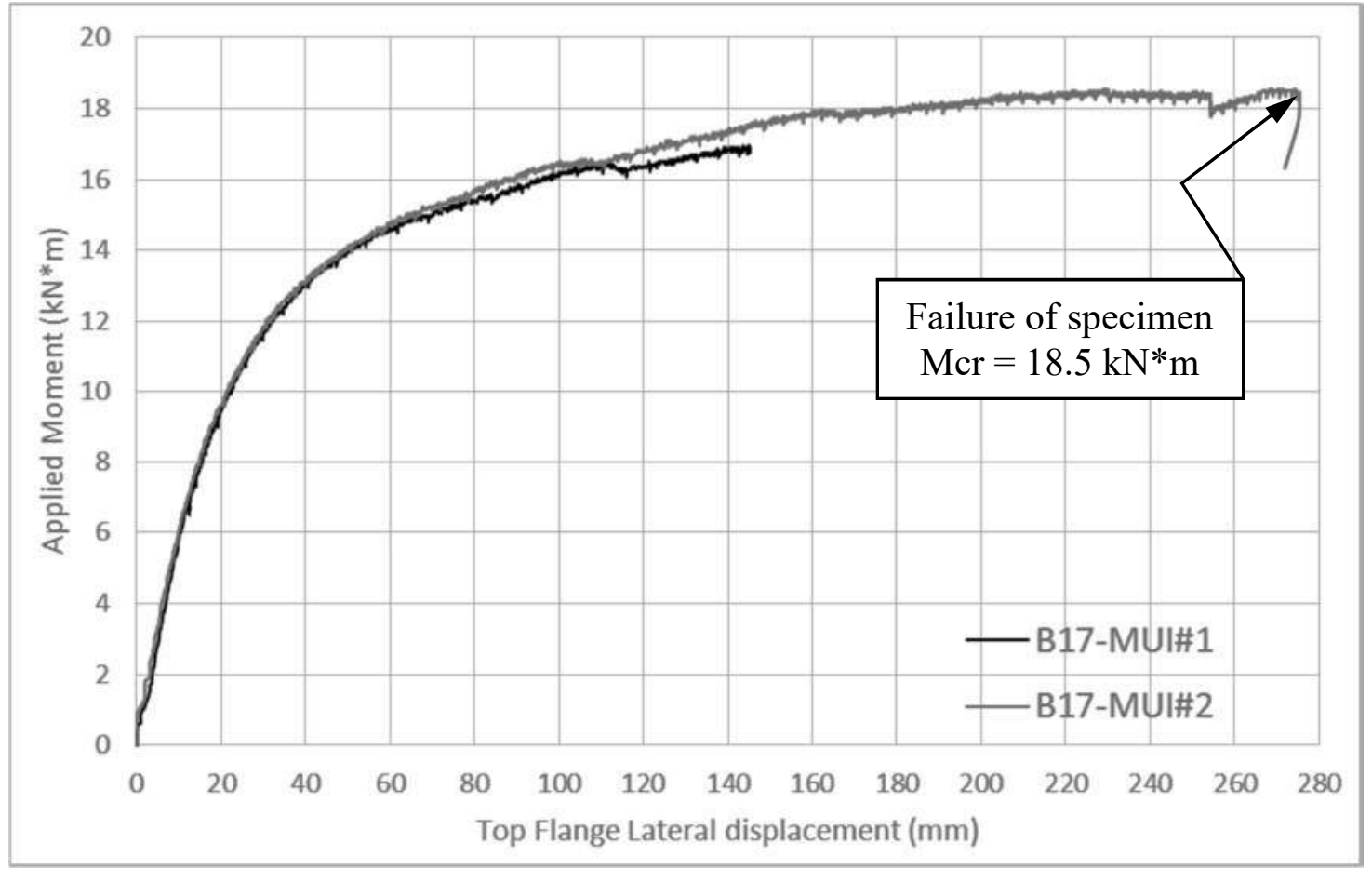

Figure B-51 Buckling displacement - Specimen B-17 - MUI3.56/16 Face mounted hangers 


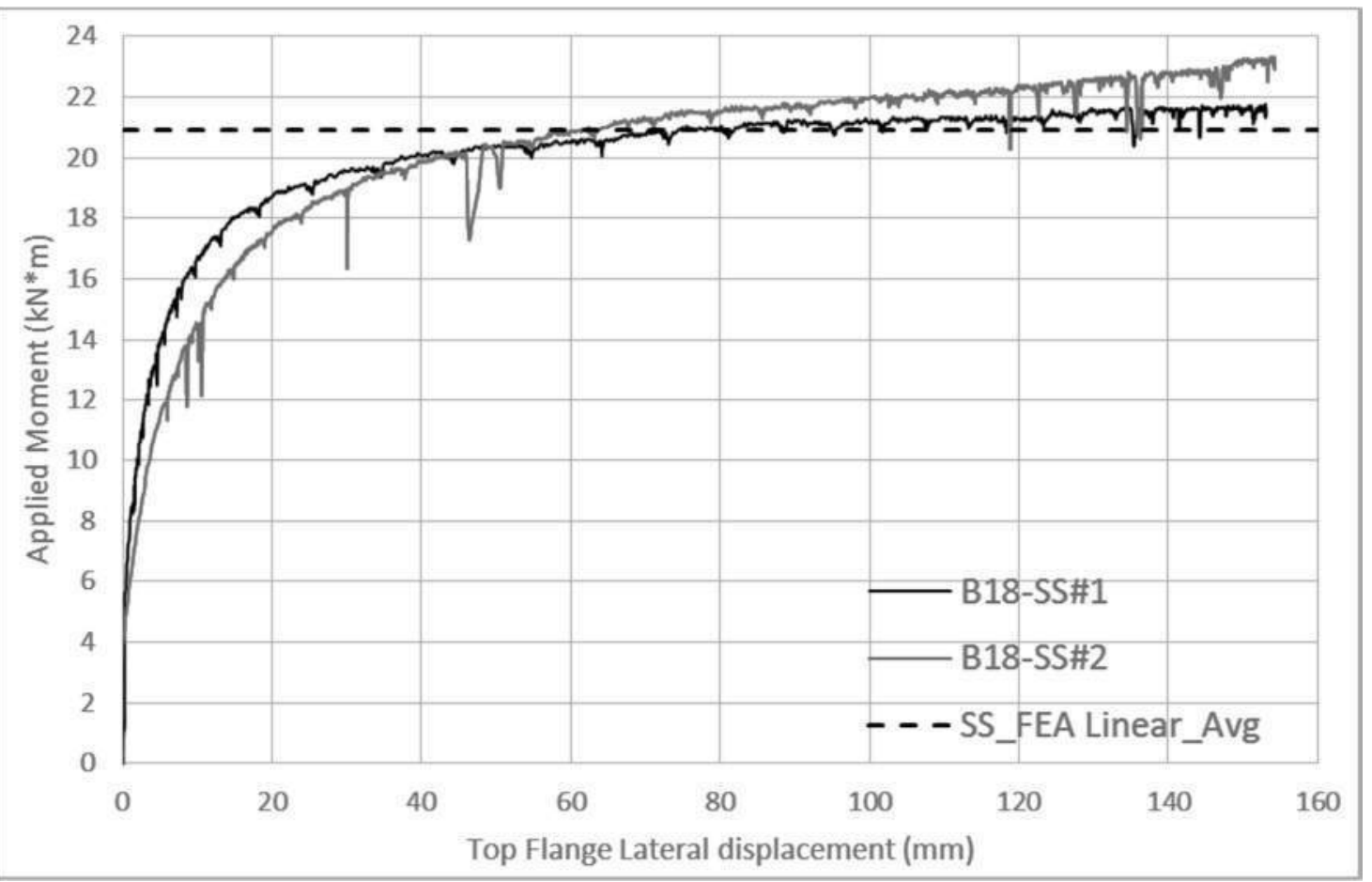

Figure B-52 Buckling displacement - Specimen B-18 - Simply Supported End conditions

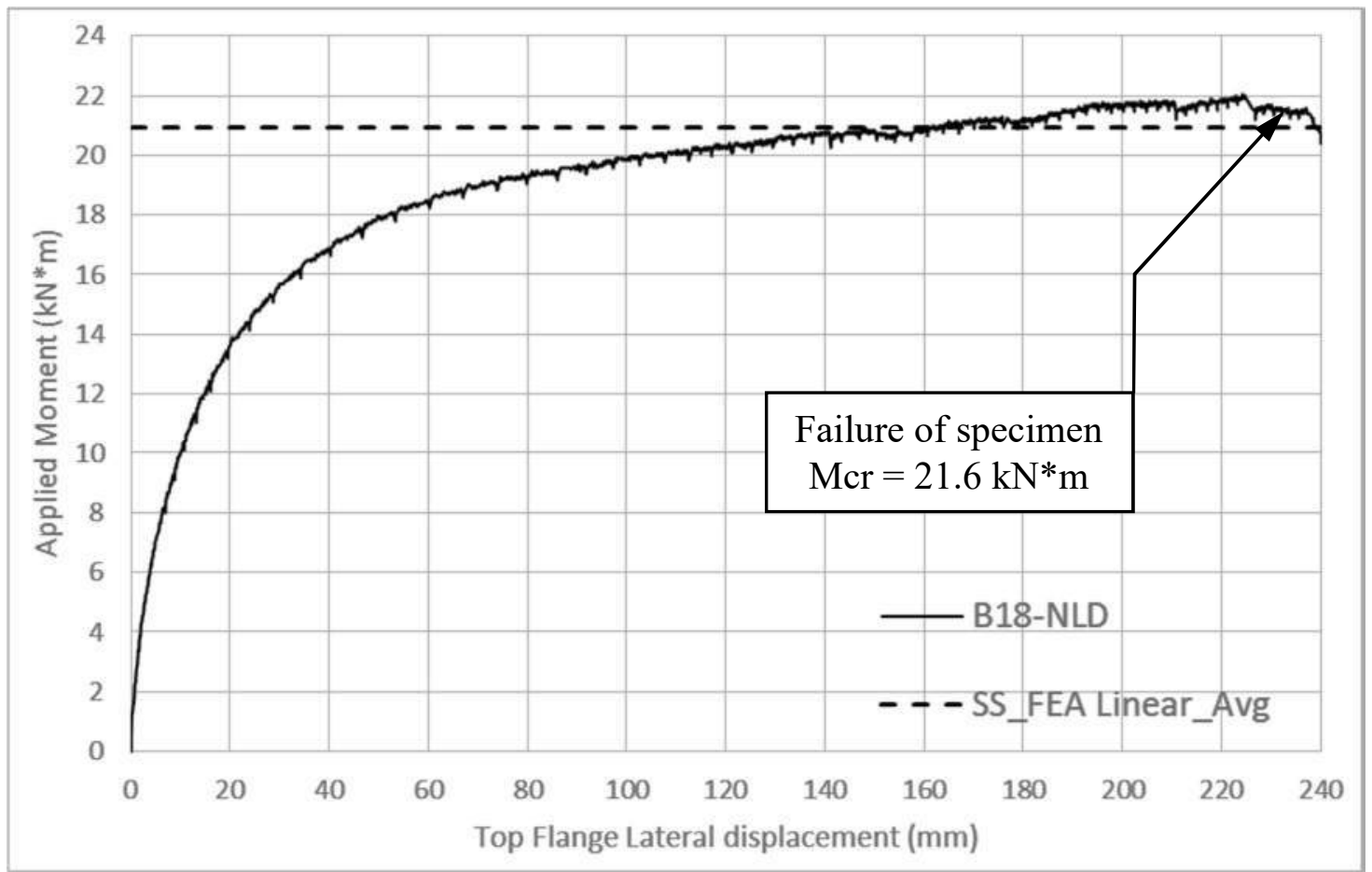

Figure B-53 Buckling displacement - Specimen B-18 - Nailed in end grain connection 


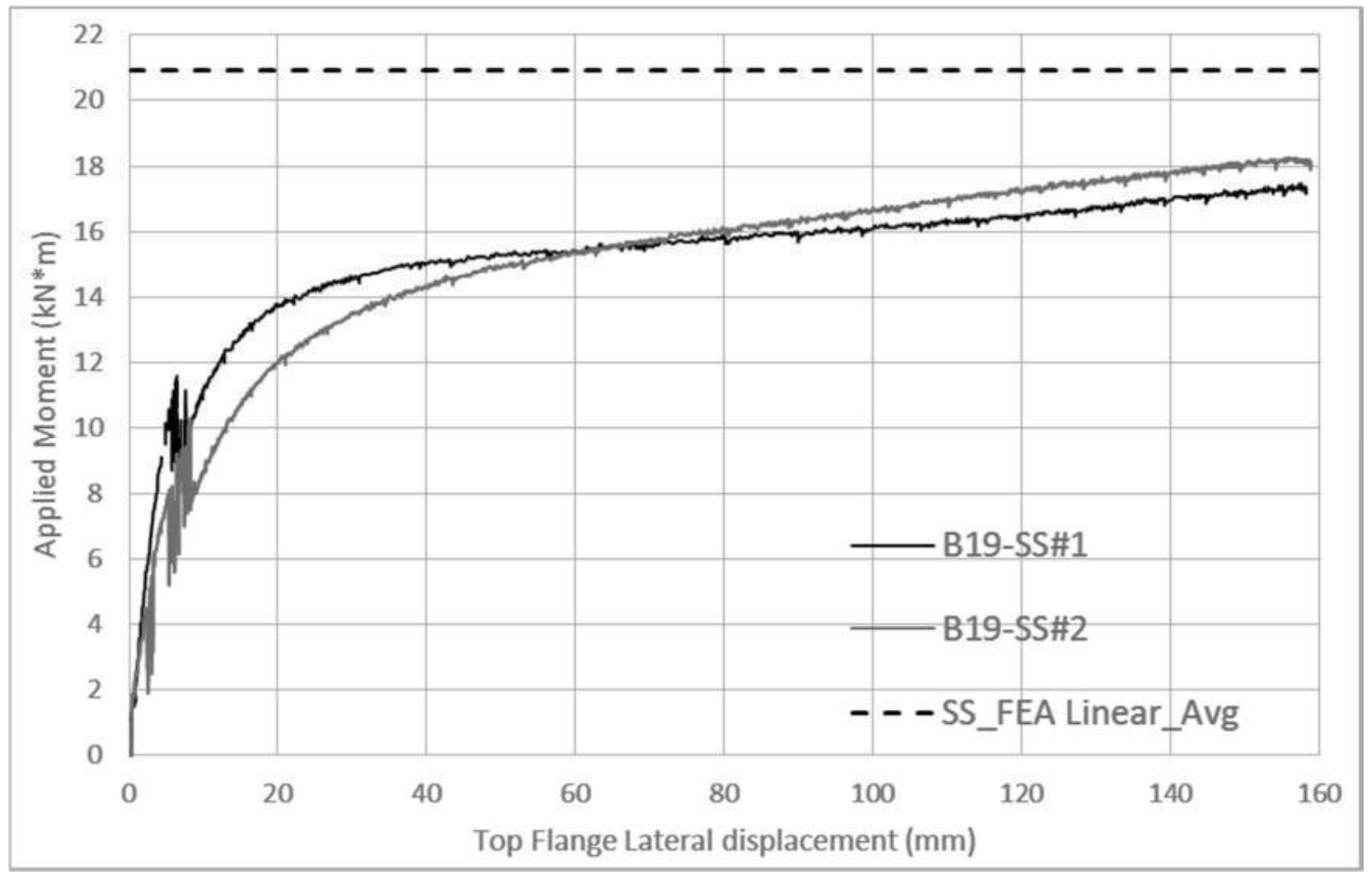

Figure B-54 Buckling displacement - Specimen B-19 - Simply Supported End conditions

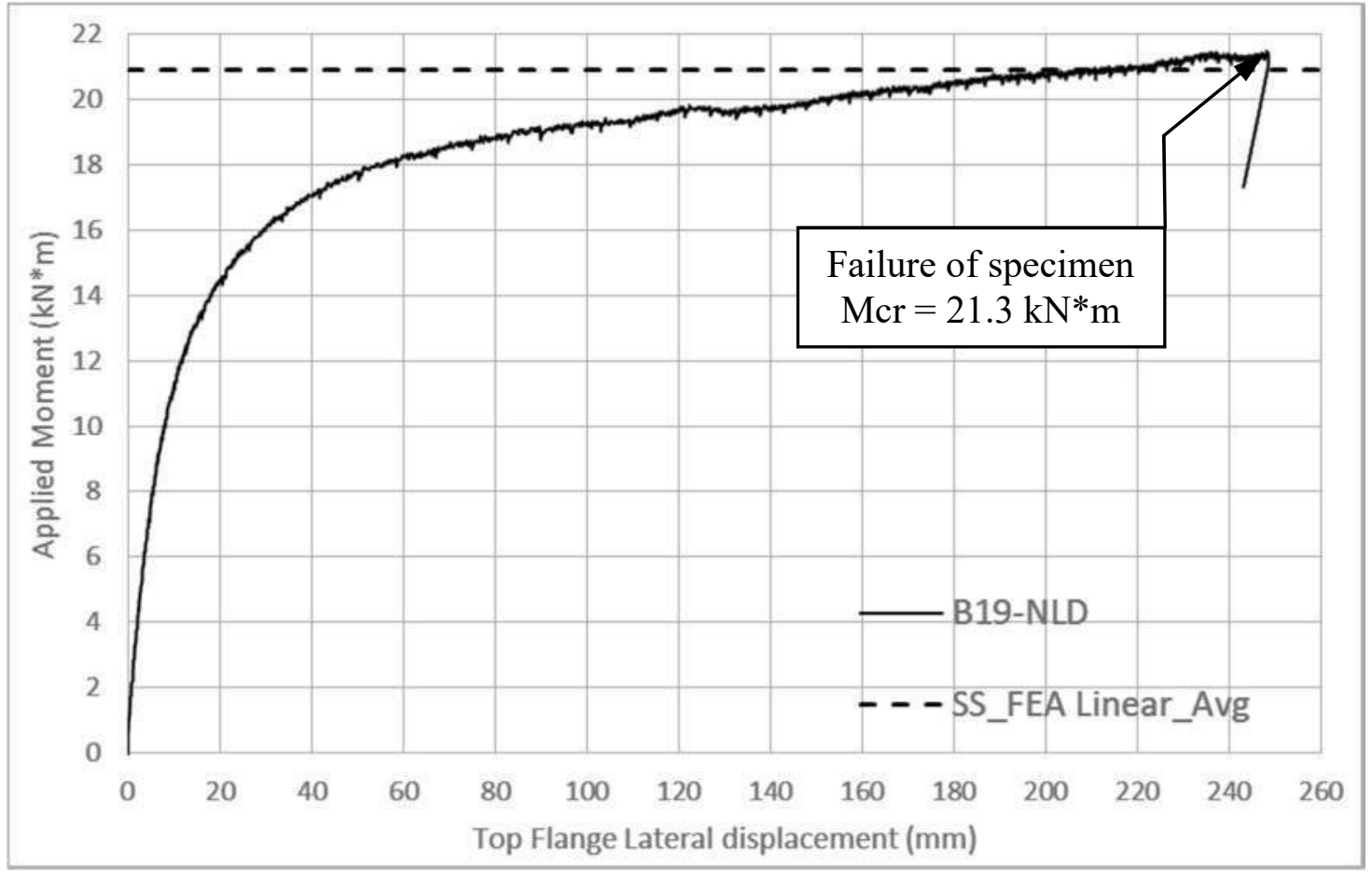

Figure B-55 Buckling displacement - Specimen B-19 - Nailed in end grain connection 


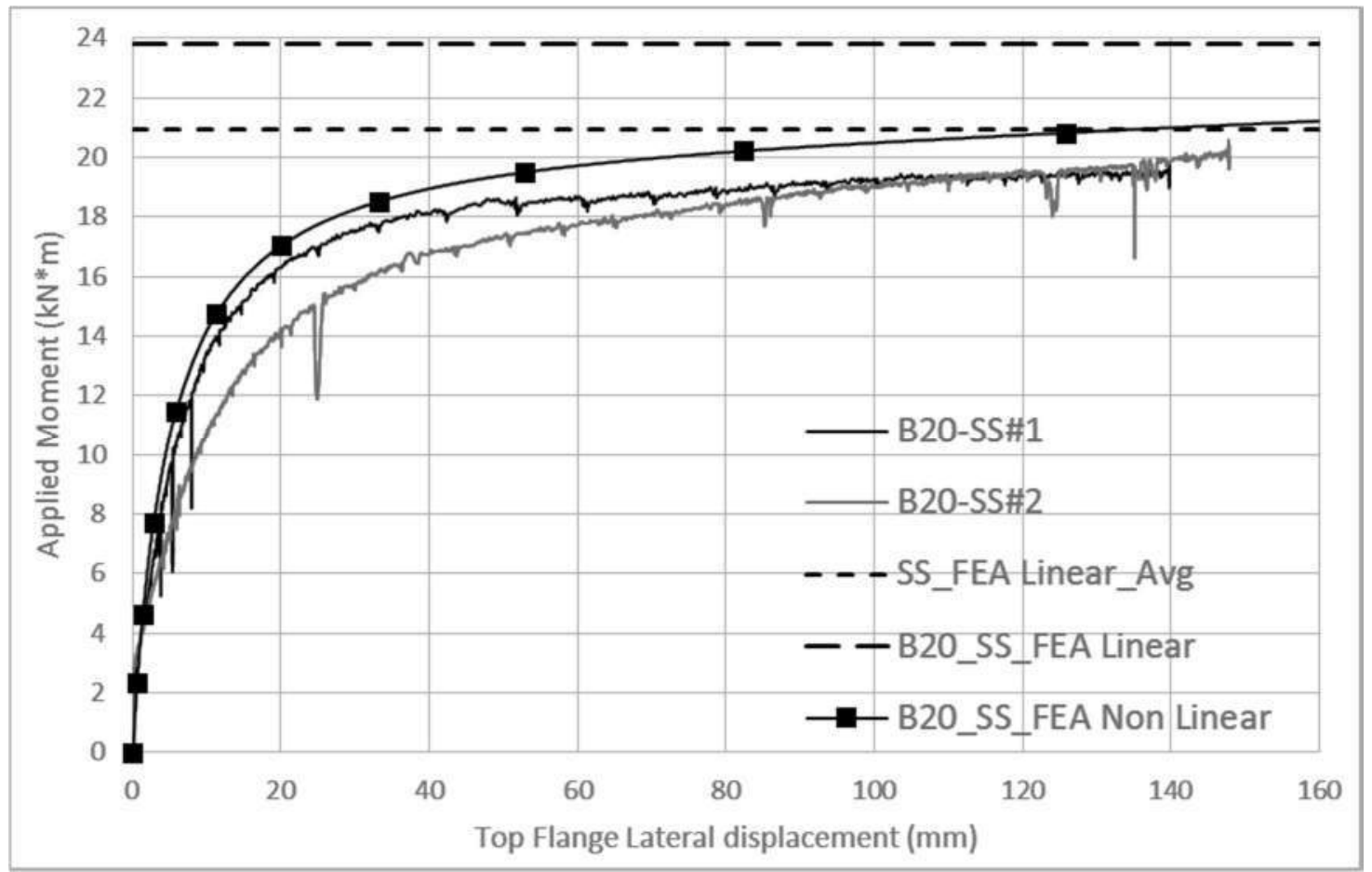

Figure B-56 Buckling displacement - Specimen B-20 - Simply Supported End conditions

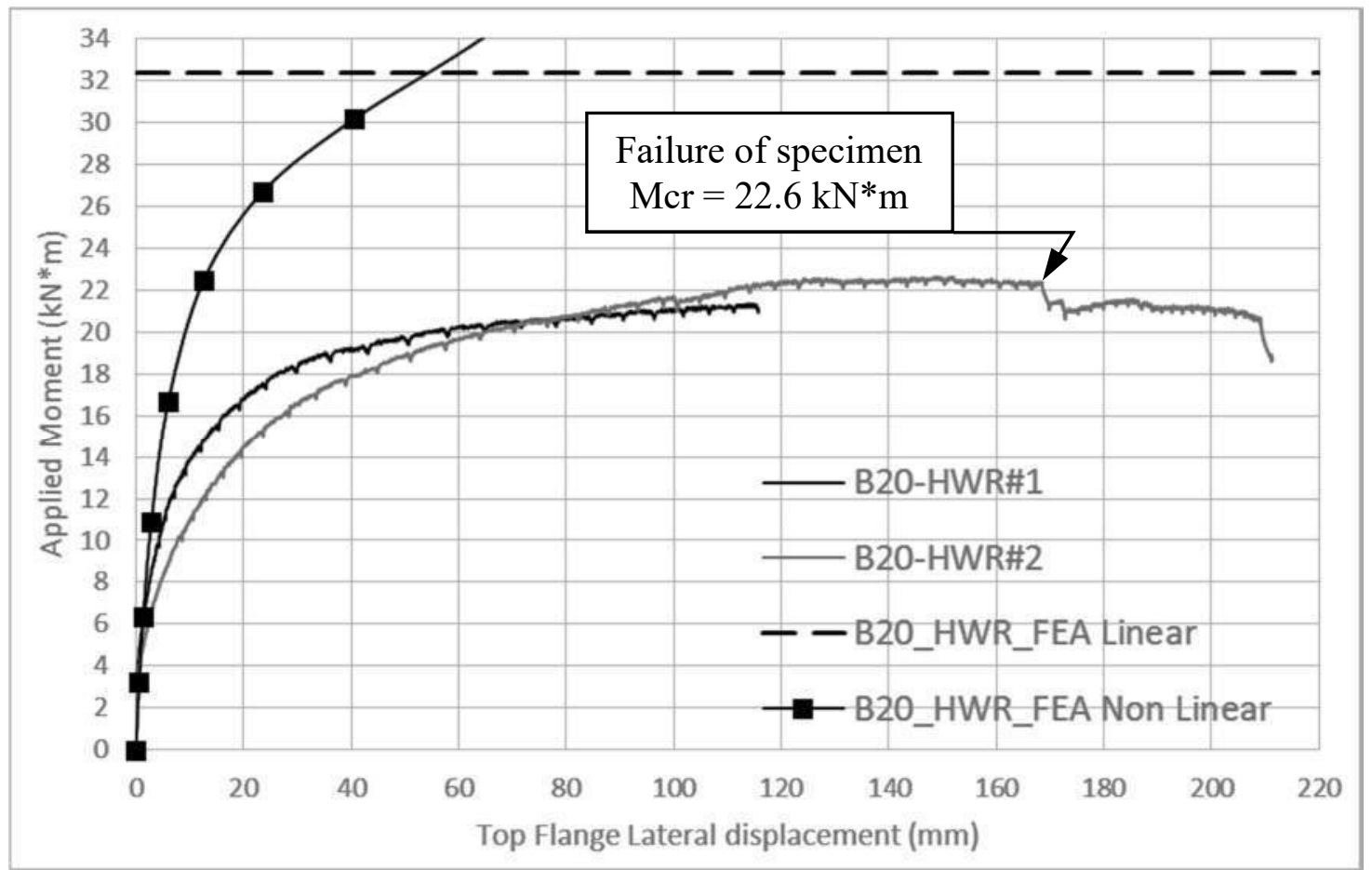

Figure B-57 Buckling displacement - Specimen B-20 - Side screwed flanges connection 


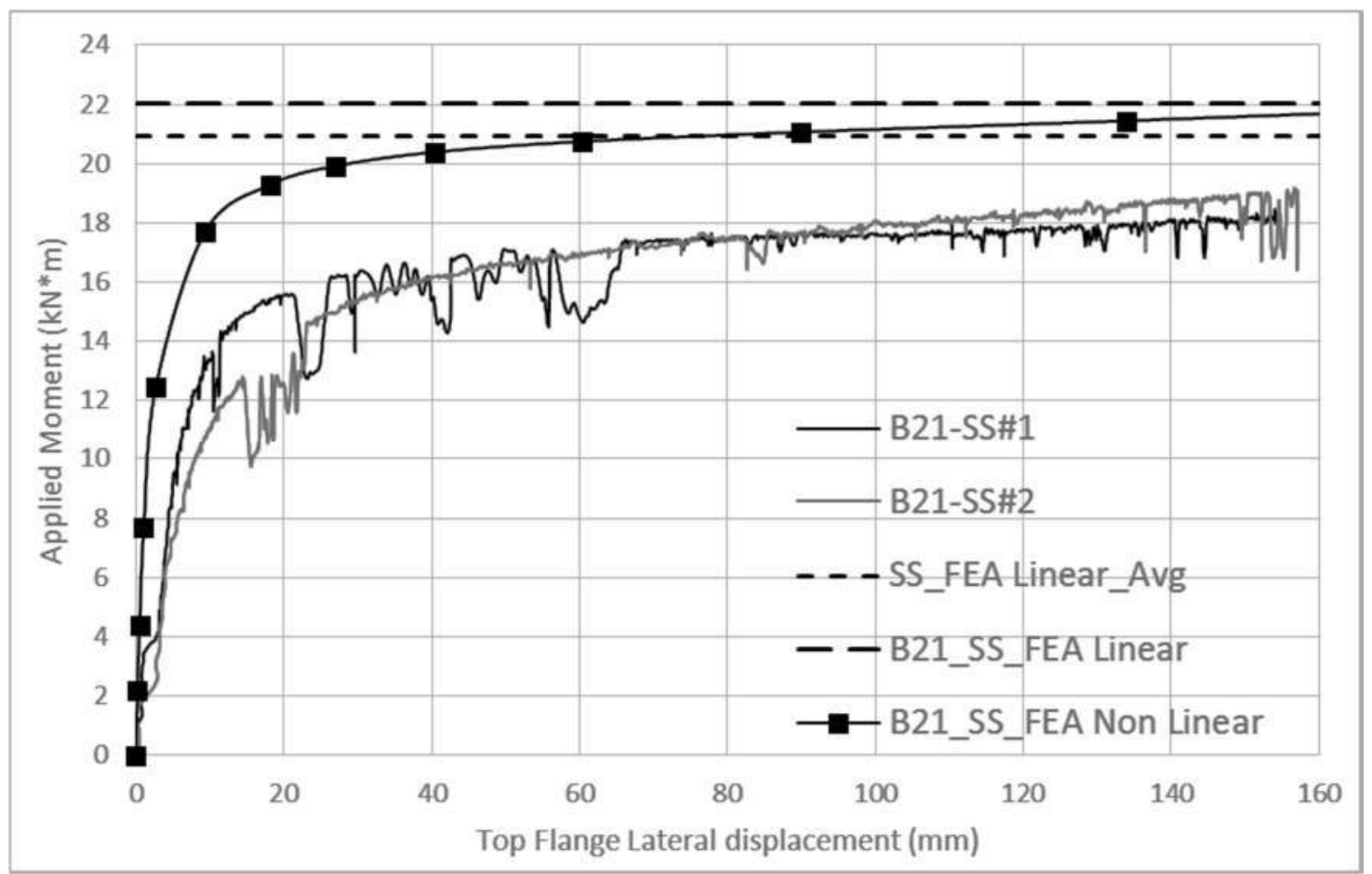

Figure B-58 Buckling displacement - Specimen B-21 - Simply Supported End conditions

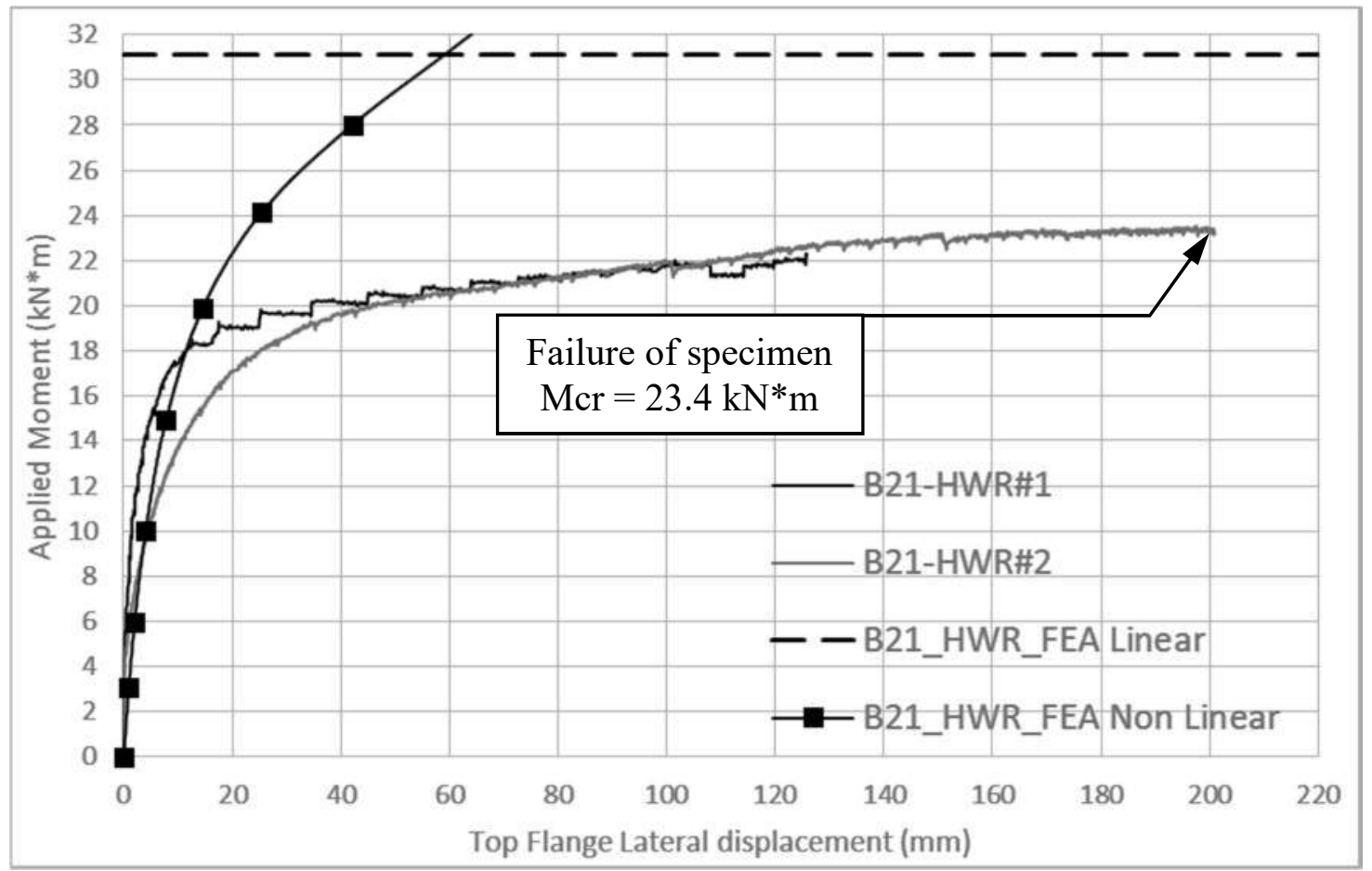

Figure B-59 Buckling displacement - Specimen B-21 - Side screwed flanges connection 


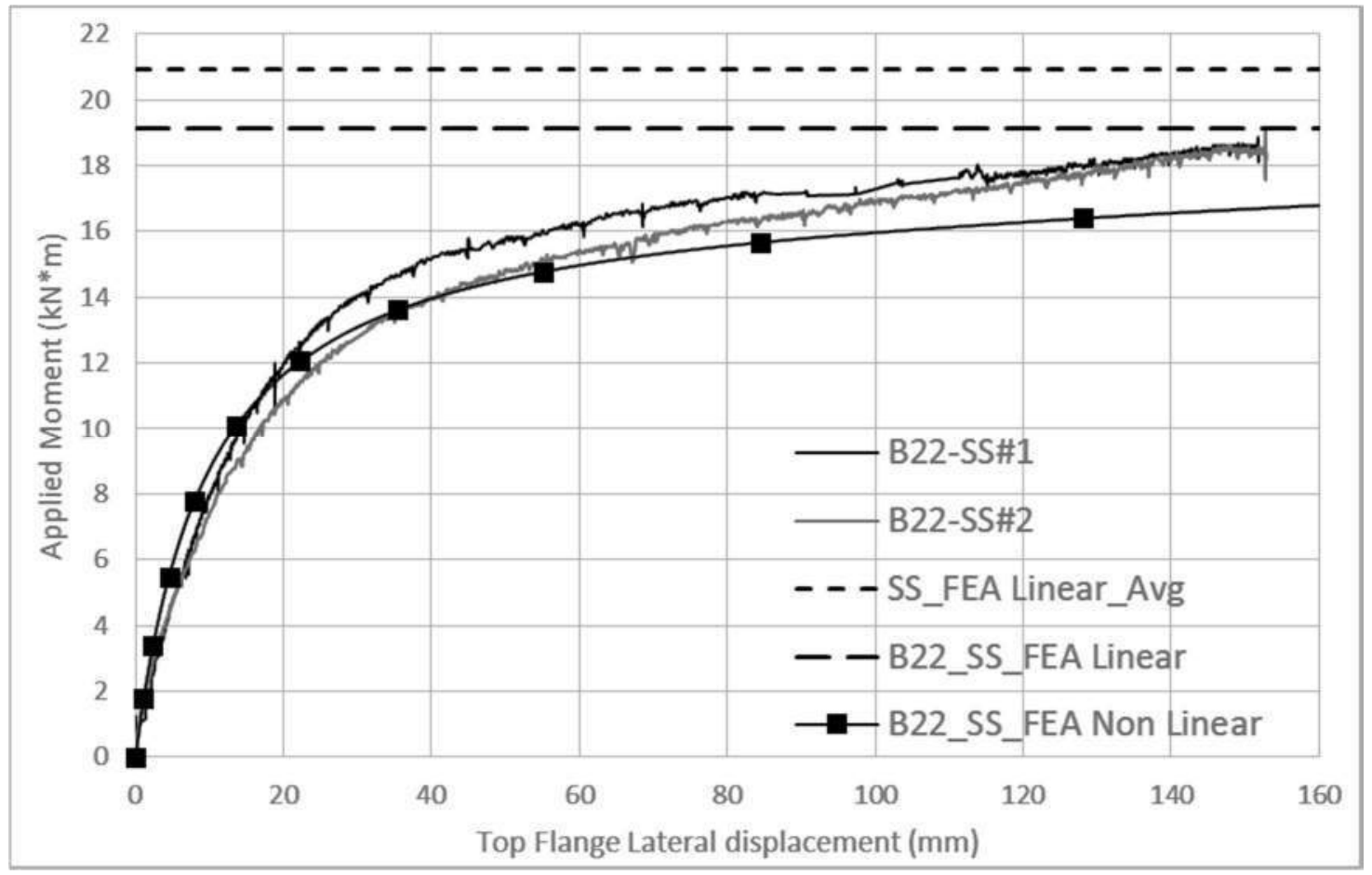

Figure B-60 Buckling displacement - Specimen B-22 - Simply Supported End conditions

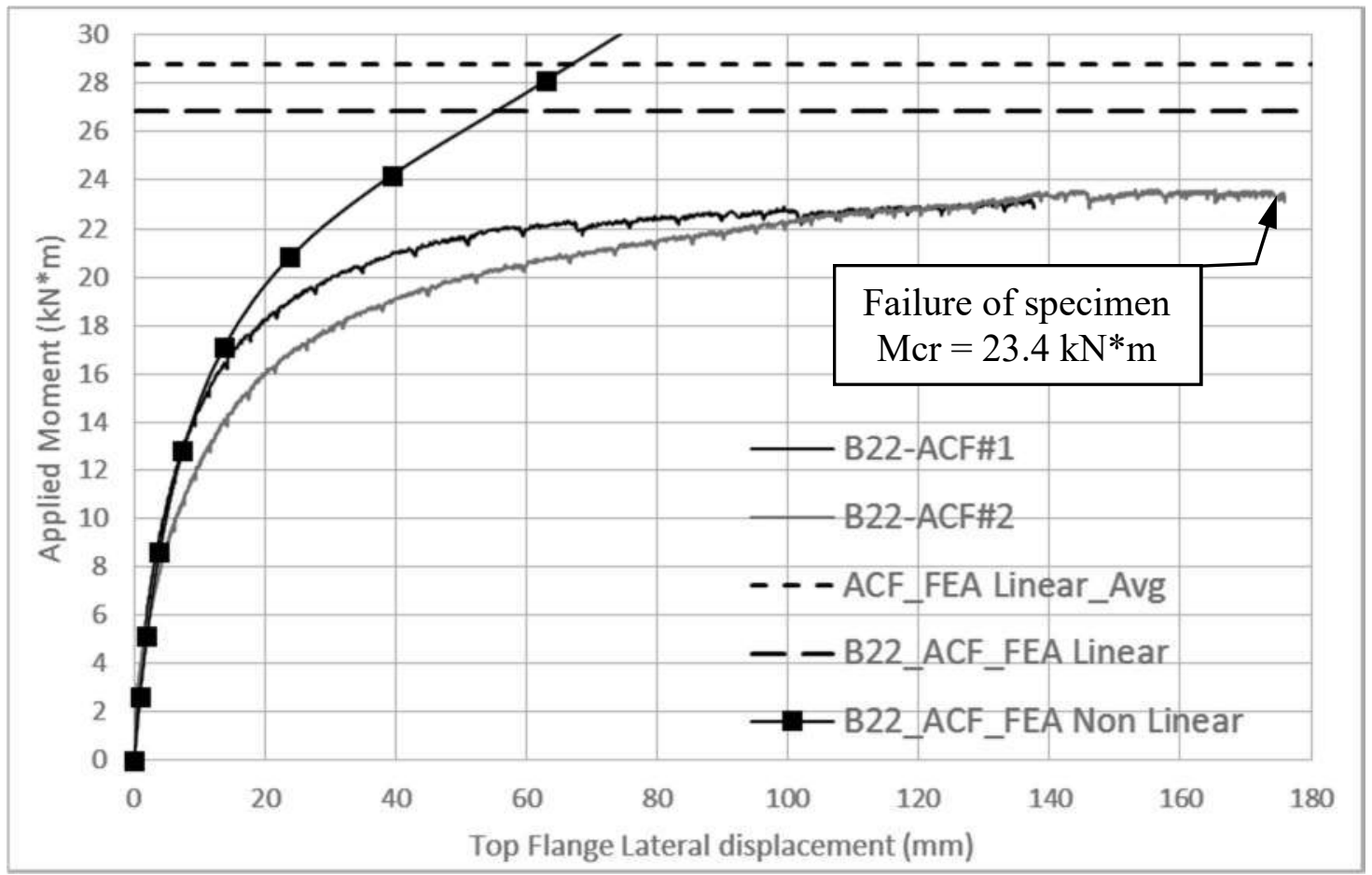

Figure B-61 Buckling displacement - Specimen B-22 - Angle bracket enhanced connection 


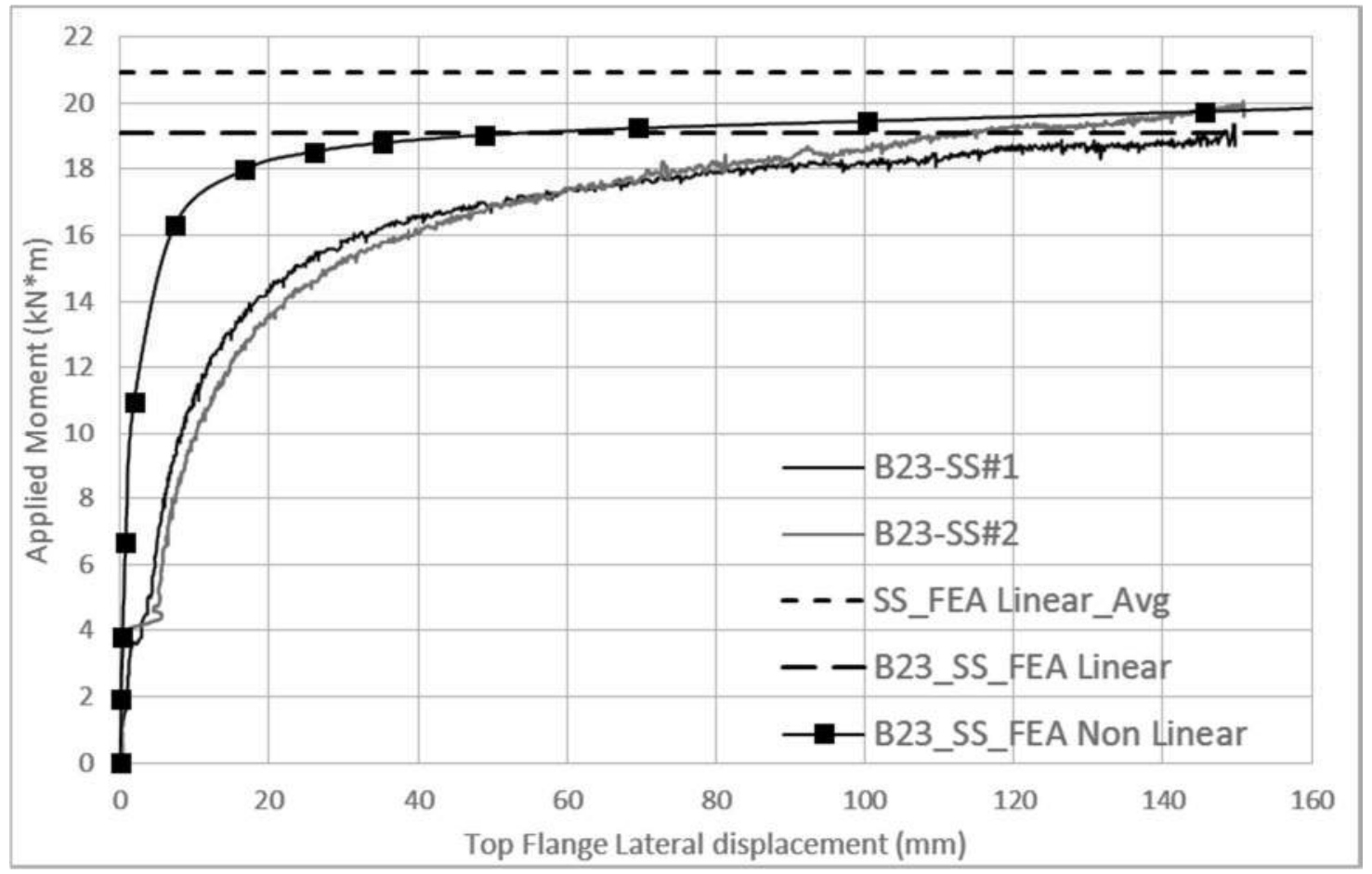

Figure B-62 Buckling displacement - Specimen B-23 - Simply Supported End conditions

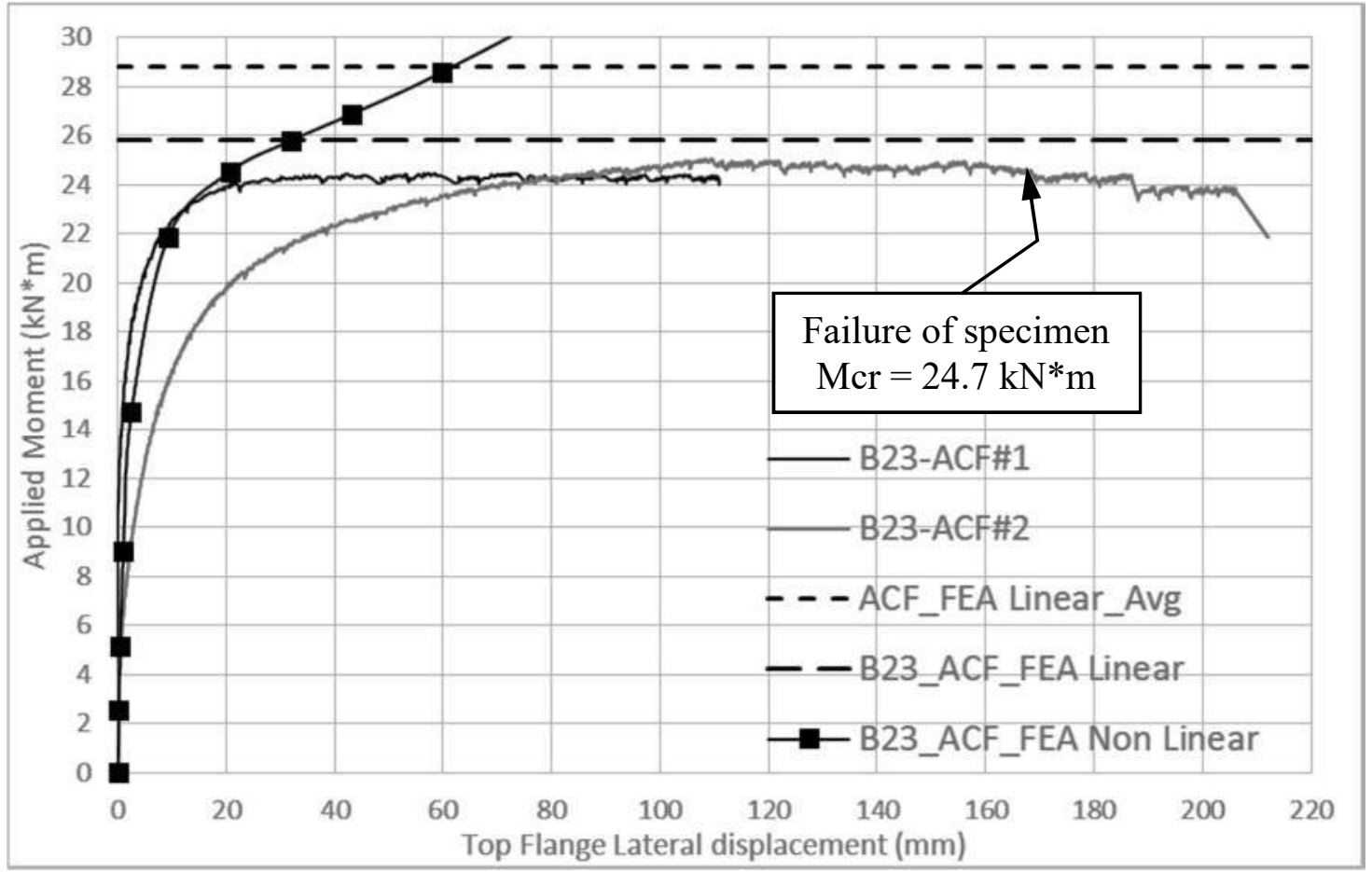

Figure B-63 Buckling displacement - Specimen B-23 - Angle bracket enhanced connection 